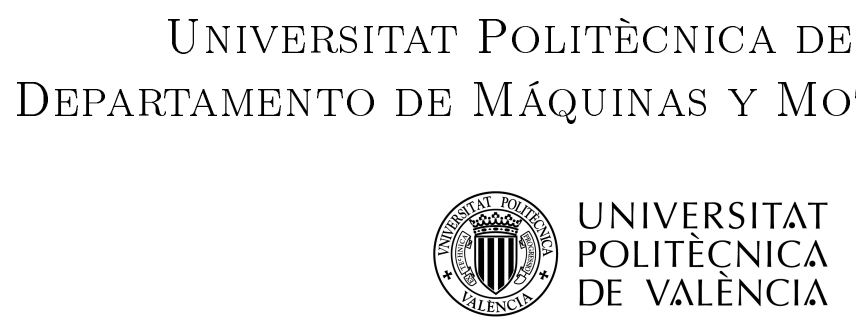

\title{
MODELLING, CONTROL AND DIAGNOSIS OF AFTERTREATMENT SYSTEMS BASED ON THREE-WAY CATALYST IN SPARK-IGNITED ENGINES
}

\author{
PhD Dissertation \\ Presented by \\ Mr. Marcelo Real Minuesa \\ Advised by \\ Associate Prof. Dr. Benjamin Pla
}

Valencia, November 2019 



\section{PhD Dissertation}

\section{Modelling, control and diagnosis of aftertreatment systems based on three-way catalyst in spark-ignited engines}

Presented by: Mr. Marcelo Real Minuesa Advised by: Associate Prof. Dr. Benjamin Pla

\section{COMMITTEE MEMBERS:}

Professor Dr. José Galindo

Associate Prof. Dr. Luis Sanchez

Associate Prof. Dr. Ivan Arsie

Valencia, 10th January 2020 

If you love something, you can never let it go. Not even for a second.

Or it's gone forever. (Josh Radnor, as Ted Mosby)

To Cecilia, Raquel and Marcelo 



\section{Acknowledgments}

Five years ago a new stage of my life began, and it is ending right now as I write these lines (... by the way, an opportune moment to apologize in advance for my non-native English skills ...).

In September 2014 I joined CMT - Motores Térmicos to carry out the master's thesis. By then, the idea of doing a $\mathrm{PhD}$ seemed far away and unlikely. I have always loved everything related with vehicles and engines, since my childhood. That is why after finishing high school I decided to leave the village, Motilla del Palancar, to study mechanical engineering in Valencia. However my cravings for knowledge were greater than the extension of the career program, and fortunately there they were, Benjamin Pla and Carlos Guardiola to help me filling that gap during the course I spent developing the master's thesis.

The problem when you start doing something you really like is that, once you have looked through the crack, you want more and more. And that is how I started the PhD program in September 2015 with mixed feelings, huge enthusiasm and certain fears, although everything is easier under the supervision of Benja. Looking back there has been a lot of nice and funny moments both with the office colleagues (Alberto, Pau, Javi, Alvin, Varun, Alfonso, Thibaout, Marco, Diego, ...) and with the bench colleagues (Vicente, Toni, Juanan, ...). All of you have contributed to make this period more fun. 
I would also like to thank Christopher Onder for allowing me to join the IDSC team during the three months of my stay at ETH, as well as to the colleagues and the administrative staff (Raffi, Hansi, Stijn, Dimitri, Richard, Philipp, Pol, Annina, ...) for being such wonderful hosts making me feel like at home, it was an amazing and nice experience.

Being honest, these four years have been hard and challenging most of the time, it's then when you really appreciate the infinite and unconditional support of those who you love, the family. Thank you Darling, Mom and Dad for being so encouraging and supportive.

Now this stage is ending, but a new one emerges (maybe from abroad), so I only hope to continue writing this happy story in the (for now equally uncertain and inspiring) future ... that's life! 


\section{Abstract}

\section{English}

In spite of the current tendency towards the electrification of the road transport, internal combustion engines have been essential in this sector and it is expected to continue being a technology with a noticeable presence during next decades. Current passenger cars based on internal combustion engines are greener than those used years ago, although it is still a developing process.

Aftertreatment systems are aimed to minimize as much a possible the impact of internal combustion engines in terms of pollutant emissions. In case of spark-ignited engines, three-way catalytic converters represent the most widespread technology during last decades, due to their compactness and cost-performance. These converters are capable to oxidise hydrocarbons and carbon monoxide while simultaneously reducing nitrogen oxide. Nonetheless, to achieve their best efficiency, the air-to-fuel ratio must be accurately controlled close to stoichiometric conditions.

In this sense, electronic engine management systems are essential to take advantage of the features of these converters. In particular, control and diagnosis strategies play a key role to achieve an effective emissions reduction under the wide range of operating conditions that arise in real 
driving conditions. The further development of this strategies is fundamental, especially taking into account the low emissions level allowed by current regulatory procedures and the trend towards zero emissions. The purpose of this dissertation is to analyse the behaviour of the aftertreatment system under very specific but at the same time very common conditions, and developing strategies that provide a further emissions reduction for systems based on three-way catalyst.

With the popularization of small turbocharged spark-ignited engines, the use of scavenging strategies to solve the typical low-end torque issues has increased. This dissertation analyses the impact of the short-circuit pulses on both three-way catalyst and $\lambda$ sensors. The short-circuit process has an important effect on the in-cycle dynamics of the exhaust gas composition. In particular, the carbon monoxide and hydrogen pulses followed by fresh air pulses cause a sensor bias. Thus a new method to on-line estimate the short-circuit rate has been proposed. This method allows to correct the sensor bias and, therefore, help to reduce the emissions penalty.

To improve the TWC efficiency under transient conditions, not only an accurate air-to-fuel ratio control upstream of the converter is required, but also to consider the dynamic behaviour of the converter itself. For example, the oxygen storage is the main responsible for the converter dynamics, and thus, a good indicator of the catalyst state, but it cannot be directly measured. Hence the development of models is key in current control strategies, to on-line track different parameters related with the state of the converter. Several models have been derived in this dissertation in order to fulfil different requirements, from the prediction of water condensation effects on the temperature evolution inside the converter just after cold-start, to the quantification of the ageing level, through the optimal catalyst purge control, or the air-to-fuel ratio disturbances rejection. 


\section{Castellano}

A pesar de la tendencia actual hacia la electrificación del transporte por carretera, los motores de combustión interna alternativos han sido esenciales en este sector y se espera que sigan siendo una tecnología con notable presencia durante las próximas décadas. Los vehículos de pasajeros actuales basados en motores de combustión interna son más ecológicos que los utilizados hace años, aunque todavía queda trabajo por hacer.

Los sistemas de postratamiento están enfocados a minimizar tanto como sea posible el impacto de los motores de combustión interna en términos de emisiones contaminantes. En el caso de los motores de encendido provocado, los catalizadores de tres vías representan la tecnología más extendida en las últimas décadas, debido a su compacidad y buena relación precio-prestaciones. Estos convertidores son capaces de oxidar hidrocarburos y monóxido de carbono al mismo tiempo que reducen los óxidos de nitrógeno. No obstante, para lograr su mejor eficiencia, el dosado debe controlarse con precisión en torno a condiciones estequiométricas.

En este sentido, los sistemas electrónicos de gestión del motor son esenciales para aprovechar las características de estos convertidores. En particular, las estrategias de control y diagnóstico desempeñan un papel clave para lograr una reducción efectiva de las emisiones en el amplio rango de condiciones de operación que se dan en condiciones de funcionamiento reales. El desarrollo de estas estrategias es fundamental, especialmente teniendo en cuenta el bajo nivel de emisiones permitido por las normativas de emisiones actuales y la tendencia hacia cero emisiones. El propósito de esta tesis doctoral es analizar el comportamiento del sistema de postratamiento en condiciones específicas pero a la vez muy comunes en conducción real, y desarrollar estrategias que proporcionen una reducción adicional de las emisiones en sistemas basados en catalizador de tres vías.

Con la popularización de pequeños motores turboalimentados de encendido provocado, ha aumentado el uso de estrategias de barrido de la cámara de combustión para mitigar los típicos problemas de falta de par a bajo régimen. Esta tesis analiza el impacto de los pulsos de cortocir- 
cuito en el catalizador y en las sondas $\lambda$. El proceso de cortocircuito de aire fresco al escape tiene un impacto importante en la dinámica intraciclo de la composición de los gases de escape. En particular, los pulsos de monóxido de carbono e hidrógeno seguidos por los pulsos de aire fresco perturban el normal funcionamiento del sensor de oxígeno. Por lo tanto, se ha propuesto un nuevo método para estimar la tasa de cortocircuito abordo. Este método permite corregir la desviación sufrida por el sensor $\mathrm{y}$, por lo tanto, ayuda a reducir la penalización en emisiones de este tipo de estrategias.

Para mejorar la eficiencia del catalizador en condiciones transitorias, no solo se requiere un control preciso del dosado aguas arriba del catalizador, sino que también resulta imprescindible considerar el comportamiento dinámico del convertidor en sí mismo. Por ejemplo, el almacenamiento de oxígeno es un buen indicador del estado del catalizador, pero no se puede medir directamente mediante sensores. Por lo tanto, el desarrollo de modelos es clave en las estrategias de control actuales, para poder estimar abordo diferentes parámetros relacionados con el estado del catalizador. Varios modelos de catalizador se han desarrollado en esta tesis doctoral para lidiar con diferentes cuestiones, desde la predicción de los efectos de la condensación de agua en la evolución de la temperatura del catalizador justo después del arranque en frío, a la cuantificación del nivel de envejecimiento, pasando por el control óptimo de purga del catalizador. 


\section{Valencià}

Malgrat la tendència actual cap a l'electrificació del transport per carretera, els motors de combustió interna alternatius han sigut essencials en aquest sector i s'espera que continuen sent una tecnologia amb notable presència durant les pròximes dècades. Els vehicles de passatgers actuals basats en motors de combustió interna són més ecològics que els utilitzats fa anys, encara que hi ha treball per fer.

Els sistemes de post-tractament estan enfocats a minimitzar tant com siga possible l'impacte dels motors de combustió interna en termes d' emissions contaminants. En el cas dels motors d'encés provocat, els catalitzadors de tres vies representen la tecnologia més estesa en les últimes dècades, pel fet que són compactes i posseeixen bona relació preuprestacions. Aquests convertidors són capaços d'oxidar hidrocarburs i monòxid de carboni al mateix temps que redueixen els òxids de nitrogen. No obstant això, per a aconseguir la seua millor eficiència, el dosatge ha de controlar-se amb precisió entorn de condicions estequiomètriques.

En aquest sentit, els sistemes electrònics de gestió del motor són essencials per a aprofitar les característiques d'aquests convertidors. En particular, les estratègies de control i diagnòstic exerceixen un paper clau per aconseguir una reducció efectiva de les emissions en l'ampli rang de condicions d'operació que es donen en condicions de funcionament reals. El desenvolupament d'aquestes estratègies és fonamental, especialment tenint en compte el baix nivell d'emissions permès per les normatives actuals i la tendència cap a zero emissions. El propòsit d'aquesta tesi doctoral és analitzar el comportament del sistema de post-tractament en condicions específiques però alhora molt comunes en conducció real, i desenvolupar estratègies que proporcionen una reducció addicional de les emissions en sistemes basats en catalitzador de tres vies.

Amb la popularització de xicotets motors amb sobrealimentació d'encés provocat, ha augmentat l'ús d'estratègies de curtcircuit per a mitigar els típics problemes de falta de parell a baix règim. Aquesta tesi analitza l'impacte dels polsos de curtcircuit en el catalitzador i en les sondes $\lambda$. El procés de curtcircuit d'aire fresc té un impacte important en la dinàmica intra-cicle de la composició dels gasos. En particular, els polsos 
de monòxid de carboni i hidrogen seguits pels polsos d'aire fresc pertorben el normal funcionament del sensor d'oxigen. Per tant, s'ha proposat un nou mètode per a estimar la taxa de curtcircuit del motor. Aquest mètode permet corregir la desviació patida pel sensor i, per tant, ajuda a reduir la penalització en emissions d'aquest tipus d'estratègies.

Per a millorar l'eficiència del catalitzador en condicions transitòries, no solament es requereix un control precís del dosatge aigües amunt del catalitzador, sinó que també resulta imprescindible considerar el comportament dinàmic del convertidor en si mateix. Per exemple, l' emmagatzematge d'oxigen és un bon indicador de l'estat del catalitzador, però no es pot mesurar directament mitjançant sensors. Per tant, el desenvolupament de models és clau en les estratègies de control actuals, per poder estimar els diferents paràmetres relacionats amb l'estat del catalitzador. Diversos models de catalitzador s'han desenvolupat en aquesta tesi doctoral per a tractar diferents qüestions, des de la predicció dels efectes de la condensació d'aigua en l'evolució de la temperatura del catalitzador just després de l'arrencada en fred, a la quantificació del nivell d'envelliment, passant pel control òptim de porga del catalitzador. 


\section{Nomenclature}

$a_{\text {cat }}$ relative catalytically active surface per catalyst volume

$\mathrm{a}_{\mathrm{v}}$ relative cross-sectional surface

A channel cross-section surface

$\mathrm{A}_{\mathrm{r}} \quad$ pre-exponential factor of Arrhenius law

c specific heat

C maximum capacity of adsorbed species

$d_{b} \quad$ channel side length

$\mathrm{d}_{\mathrm{w}} \quad$ washcoat thickness

Ea activation energy

$\mathrm{k}$ forward reaction-rate constant

K WGSR equilibrium constant

L catalyst brick length

$\dot{\mathrm{m}}_{\text {exh }}$ exhaust gas mass flow

M molecular mass

$\mathrm{r}$ reaction rate

$\mathrm{R}$ universal gas constant

s sticking probability

S state-space vector

$\mathrm{t}$ time

$\mathrm{v} \quad$ stoichiometric factor

$\mathrm{x}$ axial dimension 
$\mathrm{X}$ mass fraction in gas phase

$\mathrm{Y}$ mass fraction in solid phase

\section{Subscripts and superscripts}

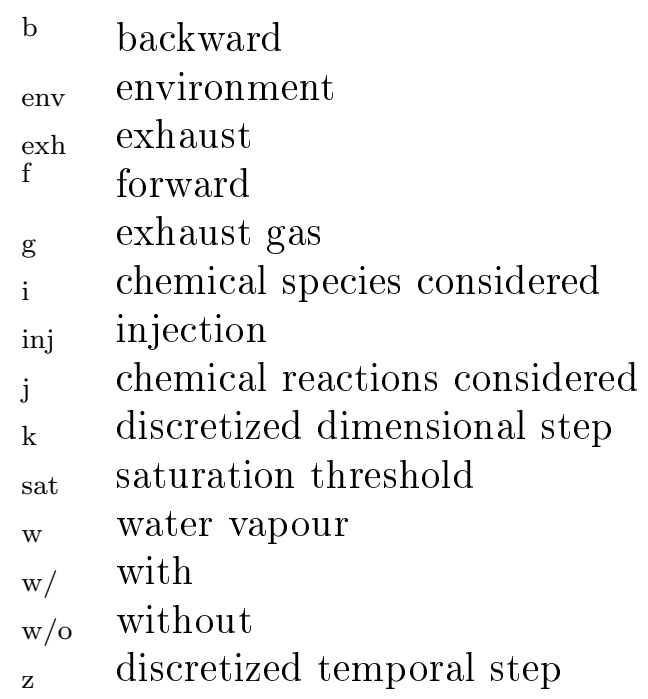

Greek symbols

$\begin{array}{ll}\alpha & \text { convection heat transfer coefficient } \\ \beta & \text { mass transfer coefficient } \\ \gamma & \text { conduction heat transfer coefficient } \\ \delta & \text { step function to enable water vapour condensation } \\ \Delta \mathrm{H}_{\text {evap }} & \text { specific heat of vaporization } \\ \Delta \mathrm{H}_{\mathrm{r}} & \text { reaction enthalpy } \\ \varepsilon & \text { volume fraction of the catalyst filled with gas } \\ \varepsilon_{\text {washcoat }} & \text { washcoat porosity } \\ \vartheta & \text { temperature } \\ \Theta & \text { fraction of sites in the noble metal coating } \\ \kappa & \text { equivalence parameters } \\ \mu & \text { adsorption rate } \\ \rho & \text { density } \\ \phi & \text { fuel-to-air equivalence ratio }\end{array}$


Acronyms

AFR air-to-fuel ratio

CAN controller area network

$\mathrm{CF}$ cost function

CLD chemiluminescence detector

CNG compressed natural gas

ECU electronic control unit

EEMS electronic engine management systems

EGR exhaust gas recirculation

EU European union

FDM finite-difference methods

HFID heated flame ionization detector

CCP can calibration protocol

DFT discrete Fourier transform

FFT fast Fourier transform

GDI gasoline direct injection

GPF gasoline particulate filter

HIL hardware-in-the-loop

LNG liquefied natural gas

LNT lean $\mathrm{NO}_{\mathrm{x}}$ trap

LQG linear quadratic Gaussian

MPC model predictive control

NDIR non-dispersive infrared detector

NMC non-methane cutter

OBD on board diagnostics

ODE ordinary differential equation

OSC oxygen storing capacity

OSL oxygen storing level

PDE partial differential equation

PID proportional-integral-derivative

RNN recurrent neural network

RTA real-time application

SC short-circuit

SI spark-ignited

SIL software in the loop 
SMC sliding mode control

SRR steam reforming reaction

TWC three-way catalyst

UEGO universal exhaust gas oxygen

VVT variable valve timming

WGSR water-gas shift reaction 


\section{Contents}

Acknowledgments

vii

Abstract

ix

Nomenclature

$\mathrm{XV}$

Contents

xix

1 Introduction 1

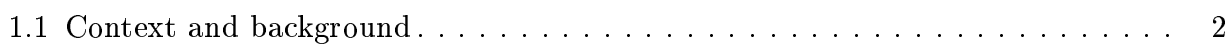

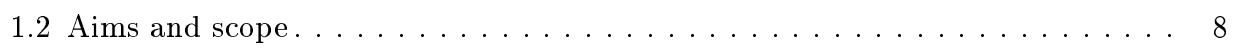

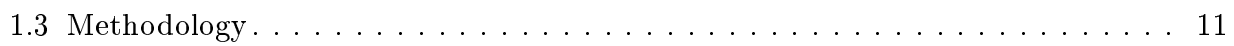

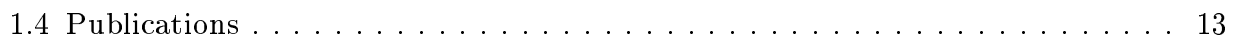

2 State of the art in TWC-based aftertreatment systems $\quad 15$

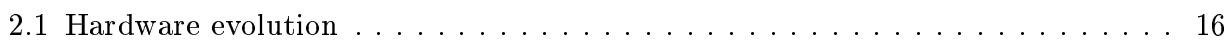

2.2 Electronic Engine Management Systems (EEMS) . . . . . . . . . . . 18

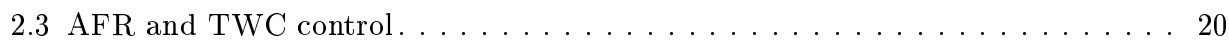


3 Experimental facility 29

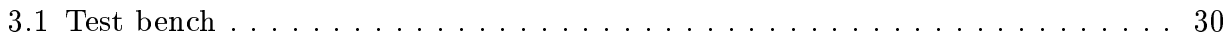

3.2 Internal combustion engine and aftertreatment components . . . . . . . . 31

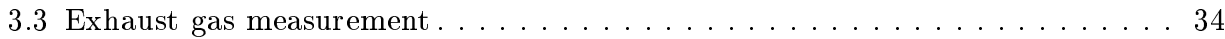

4 Modelling 41

4.1 One-Dimensional physics-based three-way catalyst modelling . . . . . . . 42

4.2 Zero-Dimensional control-oriented modelling of three-way catalyst . . . . . . 62

5 Understanding of three-way catalyst behaviour 95

5.1 Oxygen storage in three-way catalyst $\ldots \ldots \ldots \ldots \ldots \ldots$

5.2 Effects of fresh air short-circuit on the aftertreatment system . . . . . . . . 104

5.3 Three-way catalyst behaviour during cold-start phase . . . . . . . . . . . 122

6 Three-way catalyst control 141

6.1 Three-way catalyst stimulation through AFR control. . . . . . . . . . . . . . 142

6.2 Model-based control at transient conditions . . . . . . . . . . . . . . 156

6.3 AFR control under short-circuit conditions . . . . . . . . . . . . . . 169

7 Three-way catalyst ageing diagnosis 183

7.1 Model-based approach for three-way catalyst ageing quantification . . . . . . . 184

7.2 Three-way catalyst ageing diagnosis through sensor-based strategy . . . . . . . 200

8 Findings and conclusions 211

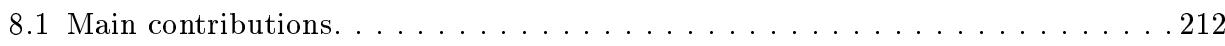

Bibliography 
Chapter 1

\section{Introduction}

Contents

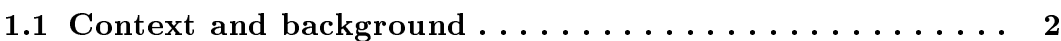

$1.1 .1 \mathrm{CO}_{2}$ emissions .................. 3

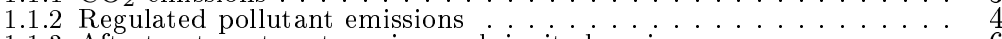

1.1.3 Aftertreatment systems in spark-ignited engines . . . . . . . . 6

1.2 Aims and scope .................. 8

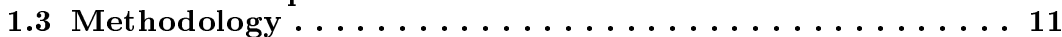

1.4 Publications. . . . . . . . . . . . . . . . 13 


\subsection{Context and background}

One of the main challenges of current societies is to get a sustainable technological progress, in order to achieve high standard of life with low environmental impact. An agile and flexible transport of both people and goods is indispensable to fulfil the logistic requirements of our society. Despite the current trend towards the electrification of the transport, reciprocating internal combustion engines have play a key role in this sector and it is expected to continue being a technology with a remarkable presence during next decades. This technological change is very complex and controversial, hence, a detailed treatment is out of the scope of the present work, but it is important to clarify some basic aspects to put in context the purpose of this dissertation.

The fundamental advantage of internal combustion powertrains is the energy density of the fuels used, which provide high flexibility to cover long distances, and also allowing refuelling in few minutes. This feature is crucial for the heavy-duty vehicle sector, but even for light-duty passenger cars, electric powertrains still have serious difficulties to be competitive, due to the reduced energy density of current batteries. In case of urban displacements the situation is different, electric vehicles are competitive from the standpoint of autonomy and also present advantages in terms of direct $\mathrm{CO}_{2}$ and pollutant emissions reduction, as it is discussed below. Despite this, the environmental burden of the batteries as well as the materials required for their manufacturing (lithium, cobalt, nickel, cooper, aluminium, etc.) generate significant doubts about considering electric vehicles as a real sustainable alternative [1], particularly if they are proposed as a massive transport for individual displacements [2]. In this sense, a deep change of the urban transport model is a more reasonable approach [3], increasing public transport, bicycle paths, pedestrian areas and avoiding traffic jams. 


\subsection{1 $\mathrm{CO}_{2}$ emissions}

From the point of view of $\mathrm{CO}_{2}$, which is not harmful for human health but contributes to the greenhouse effect, the transport sector is responsible for the $30 \%$ of the total $\mathrm{CO}_{2}$ emitted in the EU in 2016 according to the European Environment Agency, including the maritime and aviation transport. Focusing on road transport, the generation of this gas by internal combustion engines is proportional to their fuel consumption, since even a perfect combustion reaction gives $\mathrm{CO}_{2}$ and $\mathrm{H}_{2} \mathrm{O}$ as products. Thus, the direct generation of $\mathrm{CO}_{2}$ is a natural consequence of using this technology, and its reduction depends on the improvement of the engine efficiency (in practical terms around 30\% but strongly dependent on the operating conditions), which is limited by the maximum ideal efficiency of the thermodynamic cycle, either Otto, Miller, Atkinson, Diesel, etc. Electric powertrains do not generate $\mathrm{CO}_{2}$ in a direct way and their efficiency is higher even taking into account the battery charge and discharge, but the ratio of $\mathrm{CO}_{2}$ emitted per kilowatt of electric energy consumed depends on the energy mix of each country. In particular, the average proportion of electricity produced from renewable energy sources for the $28 \mathrm{EU}$ members in 2016 was only $29.5 \%$ according to Eurostats (Figure 1.1).

Another relevant aspect is the $\mathrm{CO}_{2}$ emitted during the manufacturing of the vehicle, due to the recent development of the batteries, their manufacturing costs in terms of $\mathrm{CO}_{2}$ emitted is nowadays higher than the equivalent combustion-based powertrain (Figure 1.2), although this ratio is expected to be reduced with the improvement of the manufacturing processes [2, 4]. All these facts imply that the benefits of the electric powertrain in terms of global $\mathrm{CO}_{2}$ reduction in the short and mid-term are not so evident, depending strongly on the context of each country [5]. If a drastic worldwide reduction of $\mathrm{CO}_{2}$ is required, the promotion of energy generation from renewable sources, and the change of the transport model in big cities are indispensable [6]. Encouraging the public transport to reduce the average $\mathrm{CO}_{2}$ per passenger and facilitating the use of means of transportation free of greenhouse gases when possible. Of course, all these actions require a considerable amount of time and resources, that is why electric and conventional powertrains with differ- 


\begin{tabular}{|c|c|c|c|c|c|c|c|c|c|c|c|c|c|}
\hline & 2004 & 2005 & 2006 & 2007 & 2008 & 2009 & 2010 & 2011 & 2012 & 2013 & 2014 & 2015 & 2016 \\
\hline EU-28 & 14.3 & 14.8 & 15.4 & 16.1 & 17.0 & 19.0 & 19.7 & 21.7 & 23.5 & 25.4 & 27.4 & 28.8 & 29.6 \\
\hline Belgium & 1.7 & 2.4 & 3.1 & 3.6 & 4.6 & 6.2 & 7.1 & 9.1 & 11.3 & 12.5 & 13.4 & 15.5 & 15.8 \\
\hline Bulgaria & 9.1 & 9.3 & 9.3 & 9.4 & 10.0 & 11.3 & 12.7 & 12.9 & 16.1 & 18.9 & 18.9 & 19.1 & 19.2 \\
\hline Czech Republic & 3.6 & 3.7 & 4.0 & 4.6 & 5.2 & 6.4 & 7.5 & 10.6 & 11.7 & 12.8 & 13.9 & 14.1 & 13.6 \\
\hline Denmark & 23.8 & 24.6 & 24.0 & 25.0 & 25.9 & 28.3 & 32.7 & 35.9 & 38.7 & 43.1 & 48.5 & 51.3 & 53.7 \\
\hline Germany & 9.4 & 10.5 & 11.8 & 13.6 & 15.0 & 17.3 & 18.2 & 20.9 & 23.6 & 25.3 & 28.1 & 30.8 & 32.2 \\
\hline Estonia & 0.6 & 1.1 & 1.5 & 1.5 & 2.1 & 6.1 & 10.4 & 12.3 & 15.8 & 13.0 & 14.1 & 15.1 & 15.5 \\
\hline Ireland & 6.0 & 7.2 & 8.7 & 10.4 & 11.2 & 13.4 & 14.6 & 17.4 & 19.7 & 21.0 & 22.9 & 25.2 & 27.2 \\
\hline Greece & 7.8 & 8.2 & 8.9 & 9.3 & 9.6 & 11.0 & 12.3 & 13.8 & 16.4 & 21.2 & 21.9 & 22.1 & 23.8 \\
\hline Spain & 19.0 & 19.1 & 20.0 & 21.7 & 23.7 & 27.8 & 29.8 & 31.6 & 33.5 & 36.7 & 37.8 & 37.0 & 36.6 \\
\hline France & 13.8 & 13.7 & 14.1 & 14.3 & 14.4 & 15.1 & 14.8 & 16.2 & 16.4 & 16.8 & 18.3 & 18.7 & 19.2 \\
\hline Croatia & 35.5 & 35.6 & 35.0 & 34.0 & 33.9 & 35.9 & 37.6 & 37.6 & 38.8 & 42.1 & 45.3 & 45.4 & 46.7 \\
\hline Italy & 16.1 & 16.3 & 15.9 & 16.0 & 16.6 & 18.8 & 20.1 & 23.5 & 27.4 & 31.3 & 33.4 & 33.5 & 34.0 \\
\hline Cyprus & 0.0 & 0.0 & 0.0 & 0.1 & 0.3 & 0.6 & 1.4 & 3.4 & 4.9 & 6.6 & 7.4 & 8.4 & 8.6 \\
\hline Latvia & 46.0 & 43.0 & 40.4 & 38.6 & 38.7 & 41.9 & 42.1 & 44.7 & 44.9 & 48.8 & 51.1 & 52.2 & 51.3 \\
\hline Lithuania & 3.6 & 3.8 & 4.0 & 4.7 & 4.9 & 5.9 & 7.4 & 9.0 & 10.9 & 13.1 & 13.7 & 15.5 & 16.8 \\
\hline Luxembourg & 2.8 & 3.2 & 3.2 & $\begin{array}{l}3.1 \\
3.3\end{array}$ & 3.6 & 4.1 & 3.8 & 4.1 & 4.6 & 5.3 & 5.9 & 6.2 & 6.7 \\
\hline Hungary & 2.2 & 4.4 & 3.5 & 4.2 & 5.3 & 7.0 & 7.1 & 6.4 & 6.1 & 6.6 & 7.3 & 7.3 & 7.2 \\
\hline Malta & 0.0 & 0.0 & 0.0 & 0.0 & 0.0 & 0.0 & 0.0 & 0.5 & 1.1 & 1.6 & 3.3 & 4.2 & 5.6 \\
\hline Netherlands & 4.4 & 6.3 & 6.5 & 6.0 & 7.5 & 9.1 & 9.6 & 9.8 & 10.4 & 10.0 & 10.0 & 11.1 & 12.5 \\
\hline Austria & $\begin{array}{l}4.4 \\
61.6\end{array}$ & 61.9 & 62.0 & 64.0 & $\begin{array}{r}65.1 \\
65.1\end{array}$ & 67.8 & 65.7 & 66.0 & 66.5 & 68.0 & 70.1 & 70.3 & 72.6 \\
\hline Poland & 2.2 & 2.7 & 3.0 & 3.5 & 4.4 & 5.8 & 6.6 & 8.2 & 10.7 & 10.7 & 12.4 & 13.4 & 13.4 \\
\hline Portugal & 27.5 & 27.7 & 29.3 & 32.3 & 34.1 & 37.6 & 40.7 & 45.9 & 47.6 & 49.1 & 52.1 & 52.6 & 54.1 \\
\hline Romania & 25.0 & 26.9 & 28.1 & 28.1 & 28.1 & 30.9 & 30.4 & 31.1 & 33.6 & 37.5 & 41.7 & 43.2 & 42.7 \\
\hline Slovenia & 29.3 & 28.7 & 28.2 & 27.7 & 30.0 & 33.8 & 32.2 & 31.0 & 31.6 & 33.1 & 33.9 & 32.7 & 32.1 \\
\hline Slovakia & 15.4 & 15.7 & 16.6 & 16.5 & 17.0 & 17.8 & 17.8 & 19.3 & 20.1 & 20.8 & 22.9 & 22.7 & 22.5 \\
\hline Finland & 26.7 & 26.9 & 26.4 & 25.5 & 27.3 & 27.3 & 27.7 & 29.4 & 29.5 & 30.9 & 31.4 & 32.5 & 32.9 \\
\hline Sweden & 51.2 & 50.9 & 51.8 & 53.2 & 53.6 & 58.3 & 56.0 & 59.9 & 60.0 & 61.8 & 63.2 & 65.8 & 64.9 \\
\hline United Kingdom & 3.5 & 4.1 & 4.5 & 4.8 & 5.5 & 6.7 & 7.5 & 8.9 & 10.8 & 13.8 & 17.8 & 22.3 & 24.6 \\
\hline $\begin{array}{l} \\
\text { Norway }\end{array}$ & 97.3 & 96.8 & 100.2 & 98.5 & 99.6 & 104.7 & 97.6 & 105.2 & $\begin{array}{r}103.9 \\
\end{array}$ & $\begin{array}{r}106.3 \\
\end{array}$ & 109.5 & 106.0 & 104.7 \\
\hline Iceland & 93.1 & 94.9 & 93.5 & 113.7 & 90.8 & 92.9 & 92.4 & 93.9 & 95.4 & 96.7 & 97.1 & 93.1 & 95.3 \\
\hline Albania & 63.0 & 72.1 & 74.2 & 79.6 & 73.3 & 70.7 & 74.6 & 66.1 & 72.4 & 62.7 & 71.0 & 79.2 & 86.0 \\
\hline Montenegro & & 39.1 & 37.7 & 37.6 & 38.3 & 46.6 & 45.7 & 41.6 & 42.8 & 49.1 & 51.4 & 49.6 & 51.0 \\
\hline $\begin{array}{l}\text { Former Yugoslav Republic of } \\
\text { Macedonia }\end{array}$ & 14.5 & 14.0 & 14.0 & 13.7 & 13.9 & 15.5 & 15.8 & 14.8 & 16.7 & 18.2 & 19.3 & 21.7 & 24.1 \\
\hline Serbia & 18.7 & 22.4 & 23.6 & 24.8 & 26.3 & 28.7 & 28.5 & 27.7 & 28.6 & 28.5 & 29.9 & 287 & 29.2 \\
\hline
\end{tabular}

Figure 1.1: Proportion of electricity produced from renewable energy sources against the gross consumption of electricity, EU-28, 2004-2016. Source: Eurostat

ent levels of hybridization are expected to share the market during next decades.

\subsubsection{Regulated pollutant emissions}

A different view arises when focusing on the role of the regulated pollutant emissions, that is, hydrocarbons $(\mathrm{HC})$, nitrogen oxides $\left(\mathrm{NO}_{\mathrm{x}}\right)$, carbon monoxide $(\mathrm{CO})$, particulate mass $\left(\mathrm{PM}_{10}\right.$ and $\left.\mathrm{PM}_{2.5}\right)$ and particulate number $(\mathrm{PN})$. Nowadays pollutant emissions are an important issue, in fact, some European cities have begun to implement traffic restrictions in an attempt to improve air quality. Electric vehicles do not emit $\mathrm{CO}, \mathrm{HC}$ or $\mathrm{NO}_{\mathrm{x}}$ as a consequence of their direct use, again their indirect emissions depends on the energy mix followed by each country to produce the required electricity. Thus, in some cases electric vehicles only contribute to relocate the pollution [7], which does not avoid its global consequences, like acid rain. Furthermore, the $80 \%$ of PM emitted by vehicles do not come from the combustion engine [8], but from the abrasion of brake paths, the abrasion between tyres and the road, even from 


\section{TRANSPORT CO2 EMISSIONS IN THE EU}

\section{Range of life-cycle $\mathrm{CO} 2$ emissions for different vehicle and fuel types (2014)}

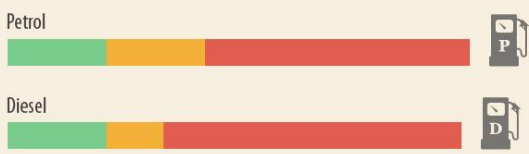

Renewable electricity 㬂

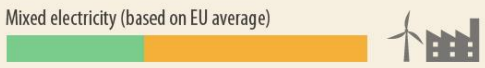

$100 \%$ coal electricity (indicative)

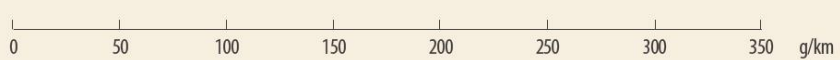

Vehicle production and disposal ___ Fuel production
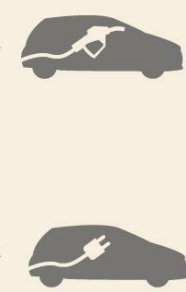

CO2 exhaust emission

Figure 1.2: Car CO2 emissions per fuel type and for electric cars. Source: European Environment Agency; TNO 
resuspension of the existing road dust as the vehicle travels. The amount of PM emitted by these sources is proportional to the weight of the car, and electric powertrains are heavier than those based on combustion.

\begin{tabular}{cccccccc}
\hline \multicolumn{2}{c}{ Emissions limits } & Euro 1 & Euro 2 & Euro 3 & Euro 4 & Euro 5a & Euro 6d \\
\hline \hline $\mathrm{THC}$ & {$[\mathrm{mg} / \mathrm{km}]$} & - & - & 200 & 100 & 100 & 100 \\
$\mathrm{NMHC}$ & {$[\mathrm{mg} / \mathrm{km}]$} & - & - & - & - & 68 & 68 \\
$\mathrm{NO}_{\mathrm{x}}$ & {$[\mathrm{mg} / \mathrm{km}]$} & - & - & 150 & 80 & 60 & 60 \\
$\mathrm{NO}_{\mathrm{x}}+\mathrm{THC}$ & {$[\mathrm{mg} / \mathrm{km}]$} & 970 & 500 & - & - & - & - \\
$\mathrm{CO}$ & {$[\mathrm{mg} / \mathrm{km}]$} & 2720 & 2200 & 2300 & 1000 & 1000 & 1000 \\
$\mathrm{PM}$ & {$[\mathrm{mg} / \mathrm{km}]$} & - & - & - & - & 5 & 4.5 \\
$\mathrm{PN}$ & {$[\mathrm{Nb} / \mathrm{km}]$} & - & - & - & - & - & $6 \cdot 10^{11}$ \\
\hline
\end{tabular}

Table 1.1: European emissions standards evolution for passenger cars (Class $M$ ) powered by SI engines. Source: Directives 91/441/EEC, 94/12/EC, 70/220/EC, 2003/76/EC,715/2007/EC and 692/2008/EC

Concerning the last ones, they have suffer a strong evolution during last decades. The pollutant emissions abatement is one of the main challenges of the automotive industry, together with the aforementioned fuel consumption reduction, even taking into account that they both present some incompatibilities. Complex aftertreatment systems have been developed to achieve the limitations imposed by the regulatory test procedures, from catalysts to particulate filters, through a wide range of sensors. Thanks to these systems, new passenger cars are much more environmentally respectful than those manufactured years ago, table 1.1 shows a summary of the evolution followed by the progressive emissions standards imposed by the EU. But it is still an ongoing task, since the combustion-based powertrains used during next decades must have a environmental burden as low as possible to minimize their impact, at least, while they continue being more competitive in terms of flexibility, autonomy and economy than other developing technologies.

\subsubsection{Aftertreatment systems in spark-ignited engines}

The best trade-off between compactness and cost-performance in sparkignited (SI) engines is provided by aftertreatment systems based on threeway catalytic converter (TWC). This converter allows to oxidise HC and $\mathrm{CO}$ while simultaneously reducing $\mathrm{NO}_{\mathrm{x}}$. However, to achieve a high con- 
version efficiency for all these species, the air-to-fuel ratio (AFR) must be accurately controlled close to stoichiometric. That is why $\lambda$ sensors are fundamental components of the aftertreatment system, usually located upstream and downstream of the converter. In order to achieve an effective emissions reduction, the software is as important as the hardware, that is, the control strategies implemented in the Electronic Control Unit (ECU) play a key role to adapt the operation of the aftertreatment system to the strongly dynamic operating conditions of the engine. Is in this field where state-of-the-art strategies are allowing to improve the overall performance of engines while reducing emissions and calibration effort. However, taking into account the low emission levels allowed by the current legislation and the trend towards zero emissions, the further development of the control and diagnosis strategies is fundamental. 


\subsection{Aims and scope}

Despite the widespread use of aftertreatment systems based on TWC for SI engines during last decades, more stringent requirements arise as regulatory test procedures reduce the emission limits allowed. Since time is always a limited resource, and TWCs are the most extended device in current SI engines, from gasoline to gas (CNG or LNG) fuelled engines, through electric hybrids, the study of other aftertreatment components like Gasoline Particulate Filter (GPF) or Lean $\mathrm{NO}_{\mathrm{x}}$ Trap (LNT), in spite of being also very interesting, is out of the scope of this work. The present dissertation pretends to cover different key aspects of the control and diagnosis of TWC-based systems. The development of a theoretic and generic AFR control strategy is not addressed here, since it is a widely covered topic by academia and robust solutions are currently applied by the industry. Instead, this dissertation studies particular operating cases where standard AFR strategies fail or show poor performance. The target is to analyse and improve the TWC control and diagnosis strategies under specific operating conditions, providing feasible and reliable strategies to settle some of the concerns of the current automotive industry regarding pollutant emissions abatement. Attending to its temporal evolution, the particular topics studied here can be classified as events with different characteristic frequency. In this sense, from high to low frequencies, the following topics have been addressed:

\section{AFR control under short-circuit conditions}

The short-circuit (SC) of fresh air from the intake manifold to the exhaust without taking part in the combustion process is an in-cycle event, thus, its characteristic frequencies depends on engine speed, in any case they are usually above $10 \mathrm{~Hz}$. The use of scavenging strategies to increase torque at low engine speed are becoming usual with the popularization of small turbocharged SI engines. The SC of fresh air affects the aftertreatment system in different ways, if the engine is operated at stoichiometric in-cylinder AFR under SC conditions an oxygen excess is expected, reducing $\mathrm{NO}_{\mathrm{x}}$ conversion efficiency. When stoichiometric AFR at catalyst inlet is imposed, a rich in-cylinder AFR is required, then increasing $\mathrm{CO}$ 
and $\mathrm{HC}$ emissions. Moreover the $\lambda$ sensor reading can be affected by the SC pulses, thus an estimation of the SC level is needed to properly control the AFR under SC conditions. Therefore, the purpose of this study is to analyse the SC effect on both the $\lambda$ sensor and the TWC.

\section{TWC stimulation through AFR control}

The characteristic frequencies of useful TWC stimulation profiles range from 10 to $0.1 \mathrm{~Hz}$. TWC stimulation consists in imposing a periodic AFR waveform at catalyst inlet, in order to improve conversion efficiency taking advantage of the simultaneous availability of reducing and oxidizing species, along with the oxygen storage capability of current TWCs. The purpose of this study is to assess the actual suitability of AFR stimulation to decrease tailpipe emissions.

The role of the TWC dynamics to cope with AFR control under transient conditions

In this section typical driving events as throttle tip out or AFR excursions with characteristic times that range from 1 to 100 seconds (that is 1 to $0.01 \mathrm{~Hz}$ ) are considered. The main parameter that drives the transient behaviour in current TWCs is their capability to store and release reducing and oxidising species. The role of the oxygen storing is particularly relevant, but it cannot be directly measured by means of onboard sensors. Hence, a proper estimation of this parameter through modelling is proposed, in order to understand the effect of transient phases on catalyst behaviour as well as to develop and implement effective control strategies.

\section{Thermal behaviour of the converter after cold-start}

After a cold-start, the heating up phase of the TWC takes several minutes, although state-of-the-art strategies are reducing this process strongly. In this respect, it can be classified as an event with characteristic times that range between 30 and 300 seconds. Since TWC efficiency is strongly linked to the temperature of the brick, a proper strategy to heat up the 
converter as fast as possible is imperative to achieve further pollutant emissions reduction. The effect of water vapour condensation and evaporation is particularly relevant during this thermal transient, thereby, the aim is to develop a TWC model capable to cope with this issue.

\section{Diagnosis of TWC ageing}

Catalyst ageing can be considered as an event with the highest characteristic times, that range from hundreds to thousands of operating hours depending on both the TWC formulation and the operating conditions. Catalyst deterioration arises as a consequence of different factors like poisoning or thermal ageing. TWC formulations are continuously improving to deal with these issues, but converters still suffer ageing at different levels throughout their lifespan. That is why the study of its main consequences in terms of TWC control and OBD is essential to keep low emissions during the life of the vehicle. 


\subsection{Methodology}

To achieve such objectives, both the theoretical and the experimental approach have been used in parallel during the development of this dissertation, since they are tightly related and converge during the validation and evaluation of the research works developed. On the one hand, the theoretical work is indispensable to create the tools that allow to face and solve the required tasks, like:

- models of hardware components

- strategies for control and diagnosis

On the other hand, the experimental work is essential to:

- understand and characterize the required phenomena

- analyse the control issues that arise under specific circumstances during the engine operation

- obtain reliable and realistic data to identify parameters and validate the models

- assess the proposed control and diagnosis strategies

First of all, a review of the current state of the art regarding engine controls and TWC-based systems can be found in Chapter 2.

The experimental work has been carried out in an engine test bench, located in the facilities of CMT Motores Térmicos, at the Universitat Politècnica de Valencia. The description of the facilities concerning test bench, engine, exhaust analysers, etc., and the specific methods used to face some particular experiments, like tracer gas method, are shown in Chapter 3.

The body of this dissertation consists of four blocks:

Modelling (Chapter 4), where two different TWC models have been specifically developed with the purpose of aiding in the development of control strategies. The first model follows a one-dimensional physic-based approach, and it is used for different off-line tasks along this dissertation, 
from the understanding of the storing capabilities of the TWC, to the comprehension of the catalyst heating up process, as well as the quantification of the converter ageing. While the second model, derived from the previous one, is a zero-dimensional control-oriented model used for on-line tasks that provides non-measurable information related to the state of the TWC in real time, and thus, supporting and complementing the AFR control strategy during transient conditions.

Understanding of TWC behavior (Chapter 5) addresses three key issues: oxygen storing during transient phases, the effect of fresh air short-circuit on the aftertreatment system and the thermal behaviour of the TWC after cold-start. This section focuses on the aforementioned topics in order to gain useful insights that help to develop control and diagnosis strategies.

Three-way catalyst control (Chapter 6) proposes particular control strategies to deal with TWC stimualtion, transient phases like AFR excursions or throttle tip out, and AFR control under short-circuit conditions.

In TWC ageing diagnosis (Chapter 7) a model-based approach to quantify the TWC ageing is developed, and then a sensor-based strategy is proposed to online estimate the ageing level of the converter.

Finally, the main conclusions and contributions of this dissertation are explained in Chapter 8. 


\subsection{Publications}

Most of the studies carried out during the development of the present dissertation have been published in indexed journals and conferences, the reader can find them listed next:

\section{Journal papers}

- Guardiola, C., Pla, B., Real, M., Travaillard, C., and Dambricourt, F. "Short-circuit effects on spark ignition engine after-treatment and air-to-fuel ratio control," International Journal of Engine Research, 2018, https://doi.org/10.1177/1468087418796705

- Guardiola, C., Pla, B., Real, M., Travaillard, C., and Dambricourt, F. "Fuel-to-air ratio control under short-circuit conditions through UEGO sensor signal analysis," International Journal of Engine Research, 2019, https://doi.org/10.1177/1468087418820747

- Guardiola, C., Climent, H., Pla, B., and Real, M. "Control-oriented modelling of three-way catalytic converter for fuel-to-air ratio regulation in spark ignited engines," Proceedings of the Institution of Mechanical Engineers, Part D: Journal of Automobile Engineering, 2019, https://doi.org/10.1177/0954407019833822

- Real, M., Hedinger, R., Pla, B., and Onder, C. "Modelling three-way catalytic converter oriented to engine cold-start conditions," International Journal of Engine Research., 2019, https://doi.org/10. $1177 / 1468087419853145$

\section{Conference papers}

- Desantes, J. M., Guardiola, C., Pla, B., and Real, M. "Oxygen catalyst depletion strategy based on TWC control-oriented modelling," 2018, IFAC-PapersOnLine, 51(31), 355-361, https : //doi .org/10. $1016 / j$. ifacol.2018.10.073

- Pla, B., Garcia-Cuevas, L., Guardiola, C., and Real, M., "Fuel-toAir Ratio Stimulation Suitability for Pollutant Emissions Reduction 
under Transient Driving Conditions," SAE Technical Paper 201901-1291, 2019, https://doi.org/10.4271/2019-01-1291 
Chapter 2

\section{State of the art in control of TWC-based aftertreatment systems}

Contents

2.1 Hardware evolution . . . . . . . . . . . . . . 16

2.2 Electronic Engine Management Systems (EEMS) . . . . . 18

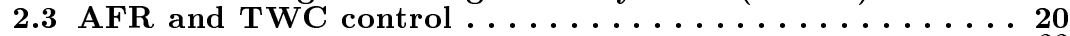

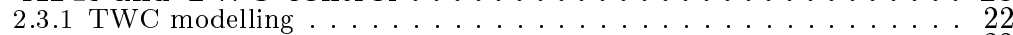

2.3 .2 Oxygen storage $\ldots \ldots \ldots \ldots \ldots \ldots \ldots \ldots \ldots \ldots \ldots$

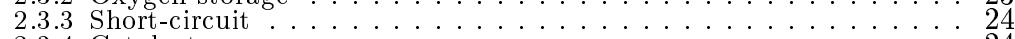

2.3 .4 Catalyst warm-up . . . . . . . . . . . . . . . 24

2.3 .5 TWC stimulation $\ldots \ldots \ldots \ldots \ldots \ldots \ldots \ldots \ldots \ldots \ldots$ 


\subsection{Hardware evolution}

Until 1970 there was not an specific law to regulate the maximum tailpipe emissions allowed [9]. By then, vehicles begin to incorporate aftertreatment systems that consist of an oxydation catalyst [10] to decrease CO and $\mathrm{HC}$ emissions, thanks to the oxygen provided by a secondary air injection at the inlet of the converter. It was a consequence of the operation at rich conditions imposed by the carburettor, since electronic controls had not been implemented yet on engines. One of the main concerns about those aftertreatment systems was their durability and ageing. Lead was an usual component of gasoline added to improve knock resistance, but lead have a poisoning effect on converters, similar to sulphur, inhibiting the catalytic activity of the noble metals added to the washcoat [11-13]. It led to the development and use of lead-free gasoline. The introduction of reduction catalysts was later. They were incorporated to the aftertreatment systems upstream of both the oxidation catalyst and the air injection, in order to take advantage of the rich exhaust gas conditions to reduce $\mathrm{NO}_{\mathrm{x}}$.

In parallel to the incorporation of the first ECUs, used to improve the control and management of first injection systems, TWCs began to be popular in the late 1980s [14]. To achieve high surface area, good thermal stability and resistance to sintering, the cordierite ceramic monolith of TWCs is usually covered with a washcoat which incoporates a doped alumina-based material $\left(\mathrm{Al}_{2} \mathrm{O}_{3}\right)$ [15], in addition to platinum (Pt) or palladium $(\mathrm{Pd})$ as oxidative catalysts, and rhodium $(\mathrm{Rh})$ for the reduction of $\mathrm{NO}_{\mathrm{x}}$. The inclusion of ECUs led to the use of electronic sensors and actuators, as the first switch-type $\lambda$ sensors. As a consequence of these advances, the proper AFR control around stoichiometric conditions was feasible, thus TWCs started to be a more competitive component, in terms of compactness and cost-performance, than the use of independent reduction and oxidation converters. Thanks to those first TWCs, once above the light-off temperature (the temperature at which at least $50 \%$ of the $\mathrm{HC}$ are converted) the emissions at steady conditions were markedly reduced in comparison with previous vehicles. However the development of the aftertreatment systems is still open [16-19], the evolution of the formulations to reduce light-off temperature [20-23], to improve the 
overall conversion efficiency [24] and to deal with transient conditions $[25,26]$ are ongoing tasks. Regarding the last one, the addition of ceriazirconia $\left(\mathrm{CeO}_{2}-\mathrm{ZrO}_{2}\right)$ is one of the last great advances [27], allowing the TWC to improve thermal stability and store oxygen, thereby, keeping low emissions even during AFR excursions different from stoichiometric conditions.

Oxygen sensors have also suffered a remarkable evolution. The first switch-type $\lambda$ sensors [28] had not its own heating system, hence they needed the heat of the exhaust gas to operate, what restricted their use in some operating conditions, for example just after the start of the engine. The heater was incorporated later, but these sensor still presented some drawbacks, as their strongly non-linear response. These sensors mostly distinguish two states, rich or lean, which also limits the control strategies that can be implemented. Heated wideband $\lambda$ sensors were introduced during the 1990s [29], providing a linear response for a wide range of air-to-fuel ratios, thus allowing a more accurate AFR control. 


\subsection{Electronic Engine Management Systems (EEMS)}

In the past, the engine control was carried out by means of mechanical systems, but their lack of flexibility and the increasing complexity of the systems implemented on engines motivated the development of EEMS [30-34], and the corresponding software platforms for automotive engine-control systems [35-41]. Regarding SI engines for example, the carburettor was used to achieve the proper air and fuel mixture thanks to the Venturi effect, without the aid of any additional electronic device. In fact, carburettors are very ingenuous and complex devices that allowed to manage the mixture of air and fuel in a very simple way. The throttle pedal was physically linked to the throttle valve (a butterfly valve) located downstream of the carburettor. Thus, the geometry of the Venturi imposes a fixed mixture law depending on the air mass flow. The amount of mixture entering the engine depends on both, the engine speed and the position of the butterfly valve (imposed by the driver). An additional valve, the choke valve located upstream of the carburettor, was used at idling conditions and after cold-start. This valve allowed to modify the mixture law by imposing a pressure drop and thereby, getting richer mixtures. However, in normal operation the mixture law was fixed, which prevented the adaptation of the air-to-fuel ratio to the changing operating conditions. This fact, along with the rising accuracy requirements, like the AFR control in a narrow range around stoichiometric conditions due to the introduction of the TWC, lead to the phase-out of carburettors as well as to the progressive development of EEMS for engine control tasks.

In terms of hardware, the EEMS consist of an ECU and a wide variety of sensors and actuators, all of them linked via Controller Area Network (CAN) protocols [42]. Concerning the software, EEMS have different modules running in parallel to achieve the driver requirements. Their relevance is huge in modern engines [43], from the driver point of view of course they influence the vehicle drivability and ride comfort, since the engine performance is affected by the control strategies in terms of fuel consumption, pollutant emissions, torque, etc. Moreover, EEMS are also coordinated with other vehicle systems, like ABS, ESP, automated driving systems, etc. But EEMS are mainly developed to 
carry out an extensive amount of tasks in a hidden way for the driver [44], from the idle speed control [45-49], to the control of the aftertreatment systems [50-56], through a wide range of control architectures and systems, like knock control [57-60], ignition timming control [61-64], throttle control [65-68], camshaft control [69-72], turbocharger control [73-76], EGR control [77-81] or AFR control [82-92]. One of the main requirements of the microprocessor-based control systems is their robustness and fault-tolerant design regarding parameter variations originated from ageing, sensors malfunction, production tolerances or variations of external conditions [93-97]. Also their simplicity to provide low computational requirements and being easy to implement and calibrate in automotive standalone systems is crucial. The calibration represents one of the most cost and time consuming tasks during the development of engines and their corresponding EEMS, due to the intensive experimental campaigns in both test bench and road. Different approaches have been developed to reduce the resources required, from Hardware-in-theloop (HIL) techniques in order to check embedded systems [98-102], to Software-in-the-Loop (SIL) methods to pre-calibrate control strategies through modelling [103-109]. 


\section{$2.3 \quad$ AFR and TWC control}

AFR control is one of the most important modules in SI engines, since an accurate control of the mixture is required for the proper performance of the engine. From the combustion process, avoiding misfire or knock, to the reduction of fuel consumption, or even exhaust thermal management, AFR is a key parameter in all of them. But taking into account the high sensitivity of the TWC efficiency to this parameter, an accurate AFR control is also essential from the viewpoint of emissions.

The complexity of the AFR control comes from the number of different systems involved as well as from the wide dynamic range of operating conditions in SI engines. In real driving conditions, the engine speed depends on the vehicle speed and the gear ratio imposed, while the engine load depends on the driver demands. Usually, the limitation in terms of torque under a sudden increase of engine load is the slow dynamic behaviour of the air management systems, since direct fuel injection systems can follow a certain setpoint almost instantaneously, in fact from cycle to cycle. The amount of air entering the engine depends on the wave dynamics inside the intake line (which in turn depends on engine speed), on the turbocharger dynamics or even on the EGR loops. Thus, under a load transient, the amount of fuel injected to keep a certain AFR depends mainly on the air mass flow available, although certain fuel dynamics must also be considered in case of indirect fuel injection systems.

In this sense, there is a wide variety of approaches to estimate the air mass flow admitted. The use of sensors to directly measure the air mass flow, often by means of hot film anemometer sensors, is an option. But due to their transient response, the complementary use of mathematical models is needed. Another typical approach is based on the measurement of temperature and pressure at the intake manifold, which allows to calculate the density of the air, while the volumetric flow rate is estimated taking into account the engine speed, engine displacement and volumetric efficiency. This last parameter is usually implemented as an engine map that depends on the operating conditions, thereby, some uncertainties can be expected again in the air mass flow estimation due to 
sensor errors, wave dynamics effects, or calibration tolerances. Different approaches to improve the air mass flow measurement like estimators based on Kalman filter, or methods to calculate the trapped mass based on cylinder pressure measurements are published [110-113].

Once known the air mass flow estimation, the injection pulse width is set for a desired AFR. However, depending on the injection system used there are additional phenomena to consider. In particular, in port fuelled engines the wall wetting effect must be considered, since all the fuel injected does not necessarily reaches the combustion chamber at the corresponding engine cycle, as it happens with direct injection systems, a fraction of the injected fuel remains in the intake ports and valves instead. A feedforward controller is implemented to compensate and balance the injection pulse width considering: the different paths of air and fuel, sensors time constant, measurement noise, pressure wave dynamics due to the pulsed flow, non-linearities, wall wetting effects, fuel evaporation and mixing processes [114]. It is typically implemented by means of static lookup tables, although more complex model-based approaches can also be used instead [115-117]. In this way the AFR can be controlled in open loop, which represents a fast approach, although some discrepancies are expected due to disturbances and effects that cannot be properly modelled or considered. That is why the measurement of the $\lambda$ sensor located in the exhaust is used to close the loop by means of a feedback controller, which typically consists of a PID. The main advantage of this controller is its relative low tuning and calibration effort as well as the fact that a model is not required. Additional delay compensation strategies are often employed to consider the transport delay of the mixture from the intake until the measurement point at the exhaust, which result helpful to increase the robustness of the controller avoiding to detune the PID. Nevertheless, there are a lot of alternative approaches like adaptive control [118], model predictive control (MPC) [51], recurrent neural network (RNN) [117], Fuzzy control [84], Smith predictor [119], $\mathrm{H}_{\infty}$ control [116], sliding mode control (SMC) [120], etc.

Until this point the engine dynamics regarding AFR control are addressed, however, the TWC dynamics play a key role from the emission viewpoint. For that reason an additional $\lambda$ sensor is located downstream 
of the converter to deal with both dynamic effects and diagnosis purposes, constituting the secondary loop. Of course avoiding AFR disturbances and excursions as much as possible is necessary for the proper operation of the TWC. But in some conditions keeping the AFR upstream of the converter in a narrow window around stoichiometric conditions is not feasible because of external requirements. In other conditions it is not enough to achieve a good conversion efficiency during transient phases, when previous operating conditions have disturbed the catalyst state, and certain correction strategies are required to recover the proper catalyst state as soon as possible. In some cases because of the economic impact of integrating additional sensors, and in other cases because of the required parameters cannot be experimentally measured, state-of-the-art strategies tend towards control-oriented modelling to complement the secondary loop, and to provide an on-line insight of the converter state in terms of storing level, brick temperature, effect of the operating conditions on the catalyst window as well as ageing effects. The consideration of these phenomena play a key role on the fulfilment of current and future emission standards in SI engines. Hence, they are briefly addressed below and specifically discussed along the body of the present dissertation.

\subsubsection{TWC modelling}

TWC modelling has been an open task during last decades but it is still ongoing. There is a wide variety of TWC models published in the literature and they can be classified attending to different criteria. Focusing on the level of complexity, the multi-dimensional, detailed, firstprinciple models [121-128] present excessive computational requirements for control purposes. Other first-principle models in the literature are one-dimensional evolutions of the previous ones, developed with the idea of reducing the computational demand [25, 26, 129-138]. But they often require a considerable amount of time to run simulations, and especially while properly identifying their parameters. Usually, it is due to the fact that complex kinetic approaches are proposed, with a remarkable amount of chemical reactions [134, 139, 140]. On the other hand, lumped-parameter control-oriented models, some of them based on first principles and other ones gray or black-box models based on phenomeno- 
logical correlations [141-152], are fast enough even for on-board applications, but usually their assumptions and simplifications of the physical phenomena do not allow to understand what is actually happening inside the converter.

\subsubsection{Oxygen storage}

The main parameter that drives the transient behaviour in a TWC is its capability to store and release a certain amount of reducing and oxidising species, with the aid of noble metals and ceria. In particular, the oxygen storage is a key property of the TWC, since it imposes certain dynamics that can be helpful to isolate the tail pipe emissions from any unexpected event in terms of AFR upstream of the converter. In real driving conditions, the accurate AFR control around stoichiometric can become a difficult task, since unexpected disturbances can cause AFR excursions. In a converter without oxygen storage, an instantaneous deviation from stoichiometric conditions upstream of the TWC has an immediate consequence in the converter efficiency, leading to a direct penalty on tail pipe emissions. However, in order to fulfil the limits imposed by the current emissions regulation procedures, the aftertreatment control must be able to deal with some AFR excursions. In this sense, the oxygen storage, which is considered a good indicator of the catalysts state $[25$, $150,151]$, helps to filter the consequences of the aforementioned AFR excursions. Hence, the engine should be operated in a narrow window around stoichiometric conditions, hereinafter catalytic window, in order to keep the relative oxygen level within a range even more stringent than that imposed by the catalyst oxygen storage capacity [134, 146, 147, 152]. Unfortunately, the oxygen storing level (OSL) cannot be directly measured by means of on-board sensors. That is why its accurate estimation can help to implement a TWC control strategy not only based on AFR as usual, but also on the catalyst state, that is, the amount of oxygen stored among others. 


\subsubsection{Short-circuit}

With the popularization of small turbocharged four-stroke SI engines during last years, the low-end torque issues have grown in prominence. Thus, the use of scavenging strategies to increase torque at low engine speed are becoming usual. The short-circuit (SC) of fresh air [153] is an essential approach due to the improvements in engine knock resistance, as well as other additional benefits like the increase of the volumetric efficiency or the reduction of the exhaust gas temperature [154, 155]. This is feasible thanks to the use of complex systems such as intake and exhaust variable valve timing (VVT), turbochargers and gasoline direct injection (GDI) systems. Especially the last one plays a fundamental role to harmonise the SC with increasingly stringent pollutant emissions regulations, since GDI allows to ensure that the SC gases are only fresh air, thus without any direct impact on $\mathrm{HC}$ emissions.

Although the engine conditions susceptible to get non-negligible SC rates are restricted to the range of low engine speed and high load, the each time more extended use of downsized engines in higher segments, and thus heavier passenger cars, are focusing the importance of reducing the emissions under SC conditions [156]. In addition to the potential impact of SC on the TWC operation, the fresh air pulses associated to the SC may also affect the AFR control, distorting the lambda sensor measurement and precision, acting as a disturbance to the AFR controller, and then resulting in an abnormal operation of the aftertreatment system.

\subsubsection{Catalyst warm-up}

TWC efficiency is strongly linked to the brick temperature, particularly during the warm-up process of the converter. During the first 40 to 100 seconds just after the engine cold-start, a noticeable amount of pollutant species are emitted, particularly $\mathrm{CO}$ and $\mathrm{HC}$. In fact, during this period the $\mathrm{HC}$ emissions represent a $60-80 \%$ of the total $\mathrm{HC}$ emitted in a regulatory test procedure [157-160]. This is not only a consequence of the low efficiency of TWC at low temperatures, but also of the incomplete combustion that takes place when the engine is below its working temperature [161-163]. 
Different approaches can be followed to deal with this issue, from using additional hardware components in order to heat-up faster the TWC [140, 164-175], to developing specific control strategies like ignition retardation or homogeneous split mode injection, in order to not only heat-up the TWC faster but also reducing HC exhaust raw emissions [176-178]. Ignition retardation allows to delay the combustion process, thereby the combustion remains active even during the exhaust stroke, which helps to speed up the catalyst heating process. Nevertheless, keeping low HC emissions represents a challenge when high levels of ignition retardation are imposed. At this point, homogeneous split mode injection plays a key role, since it enables lean global mixtures but also ensures the ignition. In order to fulfil both requirements the fuel injection is split into two parts. First, a homogeneous lean charge is carried out during the intake stroke. Then, an additional amount of fuel is injected just before the ignition, providing a local rich mixture around the spark plug to ensure a proper ignition of the homogeneous lean charge [179, 180].

Taking into account the low emissions level allowed by current legislation and the future zero emissions trends, the pollutant emissions reduction just after cold-start is imperative. In particular, the effect of water vapour condensation and evaporation is fundamental to properly predict the temperature evolution at the beginning of the catalyst heating up process. Thus, a model capable of taking this issue into account is essential.

\subsubsection{TWC stimulation}

The AFR stimulation, also called $\lambda$ cycling or $\lambda$ modulation, relies on imposing a periodic waveform through the AFR control at TWC inlet, causing slightly leaner and richer pulses than the average. In the past, the AFR control was carried out by using switch-type $\lambda$ sensors, thus $\lambda$ cycling was a natural consequence of controlling AFR in closed-loop, due to the high non-linearity of these sensors $[181,182]$. According to previous works [183-185], the benefits of imposing AFR stimulation in terms of conversion efficiency are quite different and depend on the proportion of noble metals $(\mathrm{Pt} / \mathrm{Pd} / \mathrm{Rh})$ and on the way followed to stabilize ceria, but also on the AFR range around which the TWC is working, as well as 
on the stimulation frequency and amplitude. Therefore, it is difficult to generalize the effects of AFR stimulation on tailpipe emissions. In spite of that, according to the literature, a proper $\lambda$ modulation improves conversion efficiency of reducing species ( $\mathrm{HC}$ and $\mathrm{CO}$ ) at rich conditions and conversion efficiency of oxidizing species $\left(\mathrm{NO}_{\mathrm{x}}\right)$ at lean conditions, thus, widening the AFR range of high conversion efficiency. Nevertheless, the improvement is negligible or even negative around stoichiometric [186192]. There is also accordance about the relation between temperature and $\lambda$ cycling, the lower the temperature the higher the improvement achieved when imposing the proper AFR stimulation [193, 194]. The frequency of $\lambda$ cycling also plays an important role [195], low frequencies $(0.1 \mathrm{~Hz})$ are beneficial before light-off but harmful after that, while higher frequencies $(1 \mathrm{~Hz})$ behaves in an opposite way. Thus, according to literature, AFR stimulation may be useful under transient conditions [196, 197], where some AFR excursions are unavoidable, as well as after cold-starts [140, 198], when catalyst temperature is below light-off.

The impact of AFR stimulation on TWC efficiency was mostly studied during the eighties. In some cases these works were carried out in an engine test bench. However, both catalysts and engines used cannot be considered representative of the current state of the art, because of the hardware evolution regarding oxygen sensors, TWC formulations and even direct injection systems. In other cases, these works were performed in laboratory reactors using pre-heated synthetic gas mixtures to feed a catalyst sample. Therefore, the effect of AFR stimulation on the actual exhaust gas composition and temperature has not been taken into account. Nonetheless, it is important to notice that tailpipe emissions depend on catalyst efficiency as well as on exhaust gas composition and temperature, and all of them are affected by the AFR stimulation.

\subsubsection{Ageing diagnosis}

Three-way catalysts suffer deterioration over time and mileage, usually referred as catalyst ageing. This ageing level depends on the operating conditions at which the converter has been exposed during its lifetime. In this sense, a TWC with few hours but high mileage or vice versa can suffer a strong deterioration either by poisoning (chemical) or thermal 
ageing [199-201]. The poisoning is usually related with the presence of different substances in the exhaust gas, as sulphur or lead from fuels [11-13], or another elements like phosphorus that could come up from an excessive engine oil consumption [202-205]. Poisoning significantly deteriorates TWC performance, but due to the low sulphur and lead content on current fuels used, the poisoning does not play a key role in the converters' ageing in the current European light duty vehicle market.

Concerning thermal ageing, excessive temperatures within the brick lead to the sintering of the noble metals and ceria, significantly reducing the conversion efficiency and the oxygen storing capability (OSC) of the converter [206, 207]. This temperature threshold has been progressively increased during last decades, reducing the need to impose rich air-tofuel ratios to limit the exhaust temperature, thus allowing the engine to run at stoichiometric conditions in a greater area of operating conditions and reducing fuel consumption and emissions. The current maximum temperature at which the TWC is capable to operate without suffering a fast deterioration is around 950 degrees. In spite of that, the thermal ageing is still the main responsible for the TWC degradation.

An estimation of the OSC can be obtained by means of experimental measurements [129] with the aid of $\lambda$ sensors upstream and downstream the converter. According to the related literature, some authors [208] prefer the signal of the switch-type $\lambda$ sensor downstream of the TWC, because its signal is more accurate than the one provided by wideband $\lambda$ sensors, and the transition point that indicates the end of the filling/depleting process is more clear. The typical test lies on $\phi$ steps from rich to lean and vice versa, although there is not too much agreement regarding which step is better, since each one presents some advantages and disadvantages. Also with narrowband $\lambda$ sensors, in Theis [209] the author ensures that the different OSC obtained when filling and depleting are quite similar except for brick temperatures below 450 degrees, while an alternative method is shown in Miyamoto et al. [210].

Other authors suggest the use of wideband $\lambda$ sensors, in Balenovic, Backx, and De Bie [147] a lean to rich step is performed, since in the opposite case the longer the duration at rich conditions the higher OSC value obtained. Wideband $\lambda$ sensors are also used by Ingram and Surnilla 
[211], however, the rich to lean step is proposed, because the error bias of the sensor at lean is smaller than the one at rich conditions, thus the end of the integration is more accurate during the filling process, although the proper correction of the sensor signal is needed in both cases.

The ageing estimation through the integration of the $\lambda$ sensor signals upstream and downstream the TWC presents some drawbacks. In this respect, different strategies are proposed in following sections in order to deal with this issue. From the understanding of the converter's ageing through model-based approaches, to the on-line estimation by using sensor-based strategies. 
Chapter 3

\section{Experimental facility}

Contents

3.1 Test bench ........................ 30

3.2 Internal combustion engine and aftertreatment compo-

nents ......................... 31

3.3 Exhaust gas measurement ............... 34

3.3.1 Short-circuit measurement: Tracer gas method . . . . . . . . . 34

3.3 .2 Brettschneider/Spindt method . . . . . . . . . . . 37 


\subsection{Test bench}

The experimental tests have been performed in the facilities of Institute CMT Motores Térmicos, at the Universitat Politècnica de València. The test bench is equipped with an AC dynamometer (HORIBA DYNAS3), specially suitable to test light-duty petrol and diesel engines due to its high torque and wide speed range.

Two cooling systems are available, the main consists of a closed water network coupled to a tank of $12 \mathrm{~m}^{3}$ at ambient temperature. It allows to cool the engine coolant by means of a liquid-to-liquid heat exchanger, which replaces the original air-to-liquid exchanger of the engine. The secondary system is a glycol network of 200 litres with controlled temperature between -10 degrees and ambient temperature. This system is used specifically to feed the intercooler of the engine and control the intake air temperature downstream of the compressor. An electronic valve along with a PID are used to achieve the set-point temperature of each cooling system.

Concerning the air and fuel mass flows, the former is measured by means of a hot-film flow meter located after the air filter in the engine intake, while for the latter an electronic fuel balance (AVL) is used. Several modules for thermocouples and pressure sensors, as well as for analogical and digital input/output signals are also available. All the signals from sensors (temperatures, pressures, gas analysers, etc), actuators (electronic valves) and controllers (PIDs) are managed with the aid of the software STARS, which controls the operating conditions of the engine. This software also allows dynamic tests imposing for example both engine speed and load profiles, or even simulating driving cycles by configuring a vehicle model and imposing a certain vehicle speed profile. 


\subsection{Internal combustion engine and aftertreatment components}

All test have been performed with a state-of-art, 3-cylinder, turbocharged and Gasoline Direct Injection (GDI) engine whose total displacement is 1.2 litres. Table 3.1 shows the main features of this engine. The Electronic Control Unit (ECU) is open access, thus the calibration of the engine can be modified on demand to perform any type of test. An ETAS ES600 is used to connect the ECU with the calibration software INCA via Can Calibration Protocol (CCP). An ECU bypass has been set up to implement new control strategies. For such a purpose the ECU has an additional hardware, in particular, the calibration interface dSPACE DCI - GSI1. Further control strategies can be executed in real-time with the aid of a dSPACE prototyping system, which is linked to the ECU through LVDS-Ethernet. The software CONTROLDESK is used as interface to manage the signals of the prototyping system, to acquire data, as well as to load the new control strategies previously compiled from Matlab-Simulink code.

\begin{tabular}{cc}
\hline Bore x Stroke & $75 \mathrm{~mm} \times 90.5 \mathrm{~mm}$ \\
Number of cylinder & 3 \\
Total displacement & $1199.9 \mathrm{~cm}^{3}$ \\
Compression ratio & $10.5: 1$ \\
Maximum power & $96 \mathrm{~kW} @ 5500 \mathrm{rpm}$ \\
Maximum torque & $230 \mathrm{Nm} @ 1750-3500 \mathrm{rpm}$ \\
\hline
\end{tabular}

Table 3.1: Engine specifications

The intake and exhaust lines have been instrumented with average pressure and temperature sensors at the inlet and outlet of each element. In-cylinder piezoelectric pressure sensors have been available for some particular studies, thus the original spark plugs have been replaced during some period in order to track the in-cylinder pressure evolution. An encoder has also been used to synchronize these measurements with the crank angle.

The aftertreatment system is made up by two $\lambda$ sensors and a closecoupled TWC. Regarding the sensors, two wideband (Robert Bosch LSU 
4.9) and two switch-type (NTK OZAS S2) $\lambda$ sensors are located upstream and downstream of the converter, thus the engine can take the signal of the wideband sensors or the one of the switch-type $\lambda$ sensors depending on the control strategy used. These sensors have been calibrated according to the values provided by the manufacturer. In particular, an ETAS LA4 Lambda Meter have been used for each wideband $\lambda$ sensor in order to properly control de temperature of the ceramic sensor and conditioning the signal. For the switch-type $\lambda$ sensors, however, these features are already implemented in the ECU. The pressure effects on these sensors have been evaluated previously by using a small vessel with controlled gas composition and pressure. Although the pressure effect can be significant at very lean conditions, it has been neglected in the present work. Since the TWC is located downstream the turbine, the pressure at the inlet of the converter is slightly above atmospheric pressure and air-to-fuel ratio is close to stoichiometric $( \pm 0.1)$ in most of the conditions assessed.

Considering that the TWC is the main element of the aftertreatment system, it has been specifically instrumented in order to measure temperature at several sections along the brick length, as well as gas composition, temperature, pressure and $\lambda$ at the inlet and outlet of the converter. Seven different converters have been used during the development of this thesis, all of them have exactly the same chemical and geometrical features, but different ageing level and brick lengths. Since the ageing of the TWC can be affected by different circumstances during real driving conditions, a environment-controlled procedure is often used to artificially deteriorate the converter. The procedure followed to achieve different ageing consists in keeping the ceramic brick within an oven at 1100 degrees with a controlled atmosphere during different periods of time. High temperatures promote the sintering of the noble metal coating and ceria, thus reducing the conversion efficiency and the storage capability of the converter. Three of the seven converters have the nominal brick length, but different ageing level. One of these three full-length converters has not been aged, thus hereinafter it will be referred as the fresh $T W C$. The $O B D T W C$ however, has been kept in the oven time enough to be detected by the on-board diagnostics system. Therefore its ageing is too high to fulfil the current regulatory vehicles test procedures. An intermediate ageing level has been artificially induced to the from now on called 
aged $T W C$, that is, it has reduced oxidation capability but it can still be used for road driving. Regarding the converters with different brick length, two of them have two thirds of the nominal length, while for the other two their length has been reduced to one third. The only difference between the converters with same length reduction is their ageing level, two of them are fresh, and the other two have been artificially aged in the same extent than the so-called aged $T W C$. In summary, there are three fresh TWCs (full-length, $2 / 3$ and $1 / 3$ ), three aged TWCs (again full-length, $2 / 3$ and $1 / 3$ ) and one $O B D T W C$ (full-length) available. 


\subsection{Exhaust gas measurement}

The main exhaust gas analyser used to measure the concentration of the different species is an Horiba MEXA-ONE. It provides measurements of $\mathrm{CO}_{2}, \mathrm{CO}, \mathrm{NO}, \mathrm{NO}_{2}, \mathrm{NO}_{\mathrm{x}}, \mathrm{O}_{2}$, total $\mathrm{HC}$ (THC), $\mathrm{CH}_{4}$ and non-methane $\mathrm{HC}$ (NMHC). The analyser is calibrated with the composition of the gasoline used, in order to calculate the air-to-fuel ratio according to the Brettschneider/Spindt method [212]. Further details regarding this method can be found in section 3.3.2. This device is reliable and robust, allowing measurements with response time $\left(\mathrm{T}_{10-90}\right)$ below 4.5 seconds depending on the method used to measure each species (NDIR, FID, CLD, etc), but a transport delay must be taken into account due to the length of the line that links the measurement point with the analyser itself. Of course, this line is heated to avoid the condensation of some species in the gas sample, mainly HC.

When a faster measurement is required, the analyser Cambustion NDIR 500 is used to measure $\mathrm{CO}$ and $\mathrm{CO}_{2}$, while the analyser Cambustion CLD 500 is used to measure $\mathrm{NO}_{\mathrm{x}}$. The advantage of these devices lies in the fact that the sensor is located at the measurement point, thus the transport delay is strongly reduced. Moreover, due to its low response time $\left(\mathrm{T}_{10-90}=8\right.$ milliseconds) these sensor are capable of capturing certain dynamics even to in-cycle level, as shown in section 5.2.

\subsubsection{Short-circuit measurement: Tracer gas method}

There are several well-known methods to experimentally measure the short-circuit (SC) of fresh air towards the exhaust in a running engine, like tracer gas or direct sampling among others [213-216]. The tracer gas method has been used in this work, mainly because this method is easier to implement and allows a better quantification of the average SC ratio for a multi-cylinder GDI engine than the direct sampling method, which would require many in-cycle gas samples for evaluating the cyclic dispersion of the engine and the differences between cylinders.

The tracer gas method is based on the following premises to obtain a reliable measurement [217, 218]: 
- The tracer gas is perfectly mixed with the fresh air at the intake manifold.

- The tracer gas has a negligible impact on the normal engine operation

- The tracer gas trapped into the cylinder totally burns

- The tracer gas scavenged towards the exhaust is chemically stable and does not react with the fresh air

- The tracer gas can be accurately measured at both intake and exhaust

To deal with the assumptions stated before, methane $\left(\mathrm{CH}_{4}\right)$ has been chosen as tracer gas in this work. It is injected in small concentrations, specifically $1200 \mathrm{ppm}$, in order to not disturb the normal engine operation, which works with methane concentrations below $0.15 \%$ at the inlet manifold during the short-circuit measurement. The methane is injected at the inlet of the charge air cooler (downstream of the compressor) to ensure a proper mixing with the fresh air. Furthermore, it can be properly measured with the analyser available in the test bench, since Horiba MEXA-ONE separates the sample gas into two different flows to measure hydrocarbons by means of a selective combustion method. On the one hand, a heated flame ionization detector (HFID) provides the total hydrocarbons (THC) measurement, while in parallel, a non-methane cutter (NMC) followed by another FID allows to measure only the methane concentration of the sample. Finally, non-methane hydrocarbons (NMHC) are calculated by using the two previous measurements, $\mathrm{THC}$ and $\mathrm{CH}_{4}$. The NMC is a catalyst that selectively oxidizes all hydrocarbons except $\mathrm{CH}_{4}$ with an oxidation efficiency above $95 \%$ according to manufacturer specifications. The selectivity of the NMC is based on catalyst temperature, exploiting the fact that $\mathrm{CH}_{4}$ is more difficult to burn than other hydrocarbons. This method allows to keep low enough uncertainty levels for methane measurement in the present application, since cross correlations between $\mathrm{CH}_{4}$ and other $\mathrm{HC}$ are avoided. Regarding third and fourth assumptions, it is almost impossible to check whether they are totally fulfilled. If there is not a complete combustion of the tracer gas 
trapped into the cylinder, the method will overestimate the actual SC. On the contrary, if the tracer gas reacts along the exhaust line, the proposed method will underestimate the SC. In this sense, even if they are not completely fulfilled, their effects would reciprocally cancel [219]. Figure 3.1 shows a scheme of the engine instrumentation used:

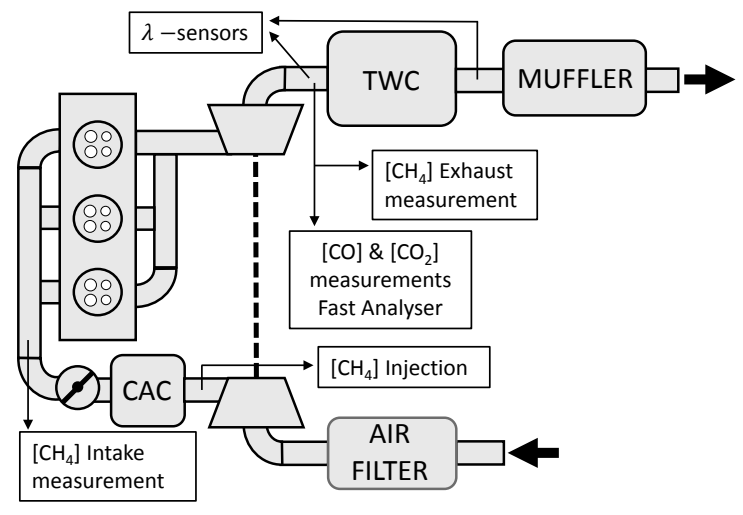

Figure 3.1: Engine instrumentation diagram

Since there is a single methane analyser available in the experimental facility, intake and exhaust methane concentrations cannot be simultaneously measured, thus the sequential procedure carried out for the SC measurement at steady state conditions in this study has been the following:

- $\mathrm{CH}_{4}$ measurement at the TWC inlet, without $\mathrm{CH}_{4}$ injection

- $\mathrm{CH}_{4}$ measurement at the intake manifold, without $\mathrm{CH}_{4}$ injection

- $\mathrm{CH}_{4}$ measurement at the intake manifold, with $\mathrm{CH}_{4}$ injection

- $\mathrm{CH}_{4}$ measurement at the TWC inlet, with $\mathrm{CH}_{4}$ injection

In this sense, the obtained SC measurement is an average value. This fact imposes some limitations as the inability to measure cycle to cycle variations, although in any case, a faster methane analyser than the one available would be needed to capture the in-cycle pulses. The SC rate, that is, the amount of fresh air that goes directly from the intake 
toward the exhaust manifold without taking part in the combustion process divided by the total air mass flow, is calculated from these methane measurements as follows:

$$
S C=\frac{\left(\left[\mathrm{CH}_{4}\right]_{w / i n j}-\left[\mathrm{CH}_{4}\right]_{w / o ~ i n j}\right)^{e x h}}{\left(\left[\mathrm{CH}_{4}\right]_{w / i n j}-\left[\mathrm{CH}_{4}\right]_{w / o ~ i n j}\right)^{i n t}}
$$

The term $\left[\mathrm{CH}_{4}\right]$ refers to the methane concentration, while subscripts $\mathrm{w} /$ inj and w/o inj represent tests with and without methane injection respectively. The superscripts ${ }^{\text {int }}$ and ${ }^{\text {exh }}$ represent engine intake and exhaust manifolds.

\subsubsection{Brettschneider/Spindt method}

Unfortunately the concentration of $\mathrm{H}_{2}, \mathrm{H}_{2} \mathrm{O}$ and $\mathrm{N}_{2}$ are not available by direct measurement, thereby, when needed (for example to feed the physics-based model presented in section 4.1) the Brettschneider/Spindt method [212] has been used to calculate their concentration at the engine exhaust (TWC inlet). In general, the non-stoichiometric fuel combustion reaction can be written as follows:

$$
\begin{aligned}
\mathrm{C}_{x} \mathrm{H}_{y} \mathrm{O}_{z}+n \cdot\left(\mathrm{O}_{2}+\mathrm{A} \cdot \mathrm{N}_{2}+\mathrm{B} \cdot \mathrm{CO}_{2}+\mathrm{C} \cdot \mathrm{H}_{\text {abs }} \cdot \mathrm{H}_{2} \mathrm{O}\right) \rightarrow \\
\rightarrow a \cdot \mathrm{CO}_{2}+b \cdot \mathrm{CO}+\mathrm{c} \cdot \mathrm{H}_{2}+d \cdot \mathrm{H}_{2} \mathrm{O}+ \\
\quad+e \cdot \mathrm{O}_{2}+f \cdot \mathrm{N}_{2}+\mathrm{g} \cdot \mathrm{NO}+h \cdot \mathrm{C}_{x^{\prime}} H_{y^{\prime}} \mathrm{O}_{z^{\prime}}
\end{aligned}
$$

where the number of moles of the ambient air is $n$, and the number of moles of each product are given by $a, b, c, d, e, f, g$ and $h$. The composition of the ambient air is given by $A, B$ and $C$, while $\mathrm{H}_{\text {abs }}$ represents the absolute humidity, all of them known values. The subscripts $x, y$ and $z$ can be obtained from a fuel analysis. However, the subscripts $x$ ', $y$ ' and $z^{\prime}$ are used to represent a particular hydrocarbon that can be considered a representative product of the incomplete fuel oxidation reaction, in this work $\mathrm{C}_{3} \mathrm{H}_{6}$.

Once known the concentration of each species measured in the test bench, that is, $\mathrm{CO}_{2}, \mathrm{CO}, \mathrm{O}_{2}, \mathrm{NO}$, and $\mathrm{HC}$, and then imposing the mass balance 
of each element considered in the combustion reaction (Equation (3.2)), along with the mass balance of the total amount of moles, leads to a system of 10 equations and 10 unknowns. This is known as the Simons method:

$$
\begin{aligned}
a & =\left[\mathrm{CO}_{2}\right] \frac{n_{\mathrm{TOT}}}{1-\left[\mathrm{H}_{2} \mathrm{O}\right]_{\text {cooler }}} \\
b & =[\mathrm{CO}] \frac{n_{T O T}}{1-\left[\mathrm{H}_{2} \mathrm{O}\right]_{\text {cooler }}} \\
e & =\left[\mathrm{O}_{2}\right] \frac{n_{T O T}}{1-\left[\mathrm{H}_{2} \mathrm{O}\right]_{\text {cooler }}} \\
g & =[\mathrm{NO}] \frac{n_{\text {TOT }}}{1-\left[\mathrm{H}_{2} \mathrm{O}\right]_{\text {cooler }}} \\
h & =\frac{\left[\mathrm{C}_{3} H_{6}\right]}{x^{\prime}} \cdot\left(n_{T O T}+d\right)
\end{aligned}
$$

$$
\begin{aligned}
& n_{T O T}=a+b+c+e+f+g+h \\
& x+n \cdot B=a+b+x^{\prime} \cdot h \\
& 2 \cdot n \cdot C \cdot H_{a b s}+y=2 \cdot c+2 \cdot d+y^{\prime} \cdot h \\
& 2 \cdot n \cdot A=2 \cdot f+g \\
& z+2 \cdot n+2 \cdot n \cdot B+n \cdot C \cdot H_{a b s}=2 \cdot a+b+d+2 \cdot e+g+z^{\prime} \cdot h
\end{aligned}
$$

Equations (3.3) to (3.6) consider the fact that these species have been measured in dry conditions. The technique used by the gas analyser to dry the samples consists in cooling the exhaust gas until five degrees, in order to reduce the maximum water content admitted by the gas. However, at 5 degrees the gas is not totally dry, thus the term $\left[\mathrm{H}_{2} \mathrm{O}\right]_{\text {cooler }}$ takes into account the water content of the dry gas. The measurement of hydrocarbons is carried out in wet conditions to avoid their condensation, thereby Equation (3.7) considers the total amount of moles in dry conditions $\left(n_{T O T}\right)$ and the water moles $(d)$. Since the HC molecule considered is $\mathrm{C}_{3} \mathrm{H}_{6}$, its concentration is divided by $x^{\prime}$ to take into account that this molecule have 3 atoms of Carbon. 
Due to the high sensitivity of this method to possible measurement errors, the Brettschneider/Spindt method imposes the condition provided by the equilibrium constant of the water gas reaction (Equation (3.13)), avoiding in this way the use of the Equation (3.8) and (3.11). This method is widely accepted because of being more robust and less sensitive to the measurements errors of the gas species.

$$
K=\frac{b \cdot d}{a \cdot c} \in\left[\begin{array}{ll}
3.5 & 3.8
\end{array}\right]
$$

By solving the non-linear equation system made up by 9 equations and 9 unknowns, the moles of each specie are calculated and their respective concentration can be obtained, even $\mathrm{H}_{2}, \mathrm{H}_{2} \mathrm{O}$ and $\mathrm{N}_{2}$ for which the experimental measurement is not available. Since the Nitrogen balance is neglected in the Brettschneider/Spindt, it can be calculated later if needed, in a second step. 



\section{Chapter 4}

\section{Modelling}

\section{Contents}

4.1 One-Dimensional physics-based three-way catalyst mod-

elling . . . . . . . . . . . . . . . . . . . 42

4.1 .1 Thermal model. . . . . . . . . . . . . . . . . 43

4.1 .2 Chemical model . . . . . . . . . . . . . . . . . . . . . . 44

4.1 .3 Downstream $\lambda$ sensor model. . . . . . . . . . . . . . . . 49

4.1 .4 Numerical solution $\ldots \ldots \ldots \ldots \ldots \ldots \ldots \ldots \ldots \ldots$

4.1 .5 Validation . . . . . . . . . . . . . . . . . . . . . .

catalyst ......................62

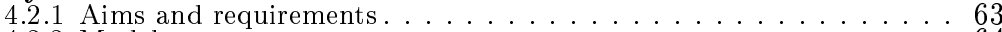

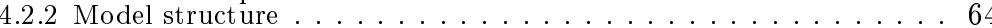

4.2 .3 Model fitting \& validation . . . . . . . . . . . . . . . . . . 74 


\subsection{One-Dimensional physics-based three-way catalyst modelling}

This present model has been created keeping in mind the idea of developing control strategies for the aftertreatment system in SI engines. The development of control strategies requires an important experimental effort to understand, assess and validate the results. This model helps to partially reduce this experimental work by providing reliable estimations about thermal distribution as well as emissions. In this sense, this is not a control-oriented model for on-board applications, but a model for off-line tasks. However, low computational requirements are always an advantage, particularly when complex strategies with hundreds of different cases must be checked. That is why the model complexity have been restricted, although always keeping the first-principle approach, with the aim of creating a model with real-time capabilities. In order to reduce the actual complexity of the physical phenomena involved and fulfil the computational requirements, the following assumptions are made [25, 26, 130, 134, 140, 151, 220]:

- The exhaust gas and flow at catalyst inlet is uniform, that is, the concentration, temperature and velocity are the same for all particles within a cross section. Therefore, the gas velocity as well as the temperature and concentration gradients in the radial direction are neglected. Only axial gradients are considered. However, axial diffusion is not considered in the mass balance because its effect is negligible for the current approach.

- The metal loading in the brick converter is totally homogeneous. Moreover, all channels are impenetrable to gas and have the same diameter. Thus, the behaviour of any individual channel is representative of the entire monolith.

- The number of free vacancies in noble metal (catalyst surface) is constant and all of them are equivalent for all species considered.

- Once the gas is inside the channel, heat radiation and conduction as well as axial diffusion are neglected. Since the effect of convection due to the gas flow prevails over the other ones. 
- The pressure drop along the channel is neglected, thereby the gas density is only a function of the temperature. The effect of the gas composition is not considered.

These simplifications lead to develop a 1D-1Ch approach. The specific features and formulation are detailed in the next sub-sections. A further explanation regarding some particular aspects of catalyst modelling can be found in Guzzella and Onder [220].

\subsubsection{Thermal model}

Two phases have been considered from the heat transfer point of view, the gas phase flowing along the channel and the solid phase that constitutes the walls of the aforementioned channel. A simplified diagram is shown in Figure 4.1.

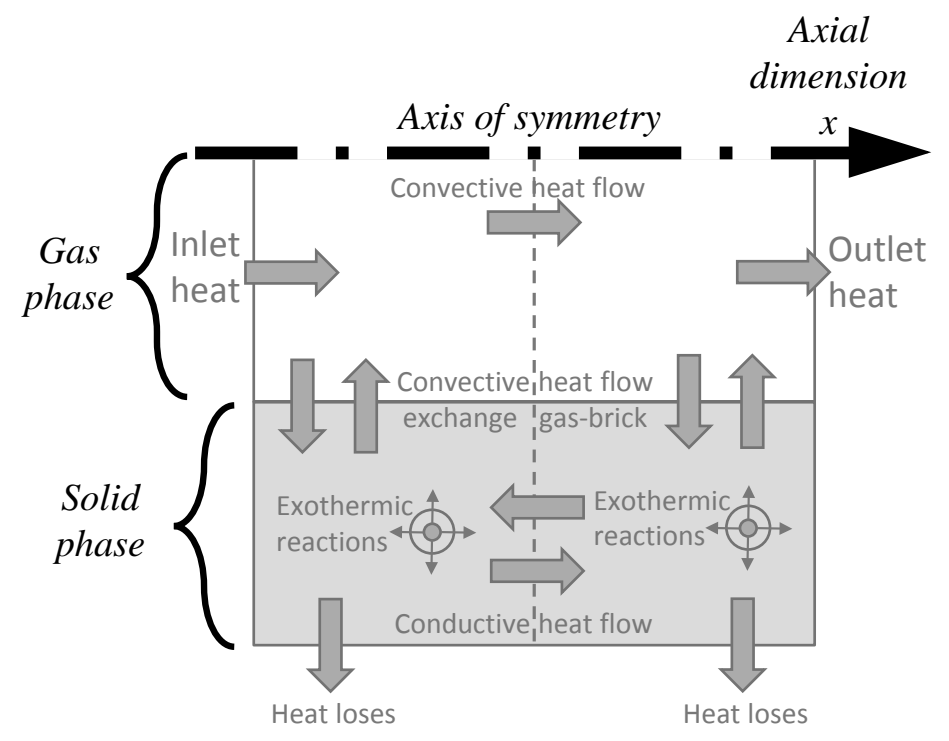

Figure 4.1: Heat transfer diagram of the $1 \mathrm{D}-1 \mathrm{Ch}$ model

The energy balance in the gas phase only accounts for two terms, the axial convection and the heat transfer between the gas and the solid phase, as it is shown in equation (4.1). 


$$
\varepsilon \cdot \rho_{g} \cdot c_{g} \cdot \frac{\partial \vartheta_{g}}{\partial t}=-\alpha \cdot a_{v} \cdot\left(\vartheta_{g}-\vartheta_{b r i c k}\right)-\frac{\dot{m}_{e x h}}{A} \cdot c_{g} \cdot \frac{\partial \vartheta_{g}}{\partial x}
$$

In the solid phase, the energy balance consists of four terms: axial conduction, heat transfer between gas and catalyst surface, heat losses to the environment and heat produced by the exothermic reactions (equation $(4.2))$.

$$
\begin{aligned}
& (1-\varepsilon) \cdot \rho_{\text {brick }} \cdot c_{\text {brick }} \cdot \frac{\partial \vartheta_{\text {brick }}}{\partial t}= \\
& =\gamma_{\text {brick }} \cdot(1-\varepsilon) \cdot \frac{\partial^{2} \vartheta_{\text {brick }}}{\partial x^{2}}+\alpha \cdot a_{v} \cdot\left(\vartheta_{g}-\vartheta_{\text {brick }}\right)+ \\
& \quad+\alpha_{\text {env }} \cdot a_{v, \text { env }} \cdot\left(\vartheta_{\text {brick }}-\vartheta_{\text {env }}\right)+a_{\text {cat }} \cdot C \cdot \sum_{j=1}^{n}\left(-\Delta H_{r_{j}} \cdot r_{j}\right)
\end{aligned}
$$

\subsubsection{Chemical model}

Three layers make up the structure of the chemical model considered as shown in Figure 4.2. Analogously to the structure of the heat transfer model, the outer layer corresponds to the gas that flows inside the channel.

In the gas phase, the mass balance of each species considered $\left({ }_{i}\right)$ consists of only two terms (equation (4.3)), the mass transfer between gas and washcoat pores as well as the convective flow. Axial diffusion is neglected in this approach.

$$
\varepsilon \cdot A \cdot \rho_{g} \cdot \frac{\partial X_{i}}{\partial t}=-\beta_{i} \cdot A \cdot a_{v} \cdot \rho_{g} \cdot\left(X_{i}-Y_{i}\right)-\dot{m}_{e x h} \cdot \frac{\partial X_{i}}{\partial x}
$$

The washcoat pores constitute the second layer of the chemical model. It behaves as an interface between gas and catalyst surface, which in turn is the third layer and the innermost of the chemical model. Here, the species are adsorbed prior to react with the aid of the noble metal coating. Thereby, all the reactions considered follow the Langmuir-Hinshelwood 


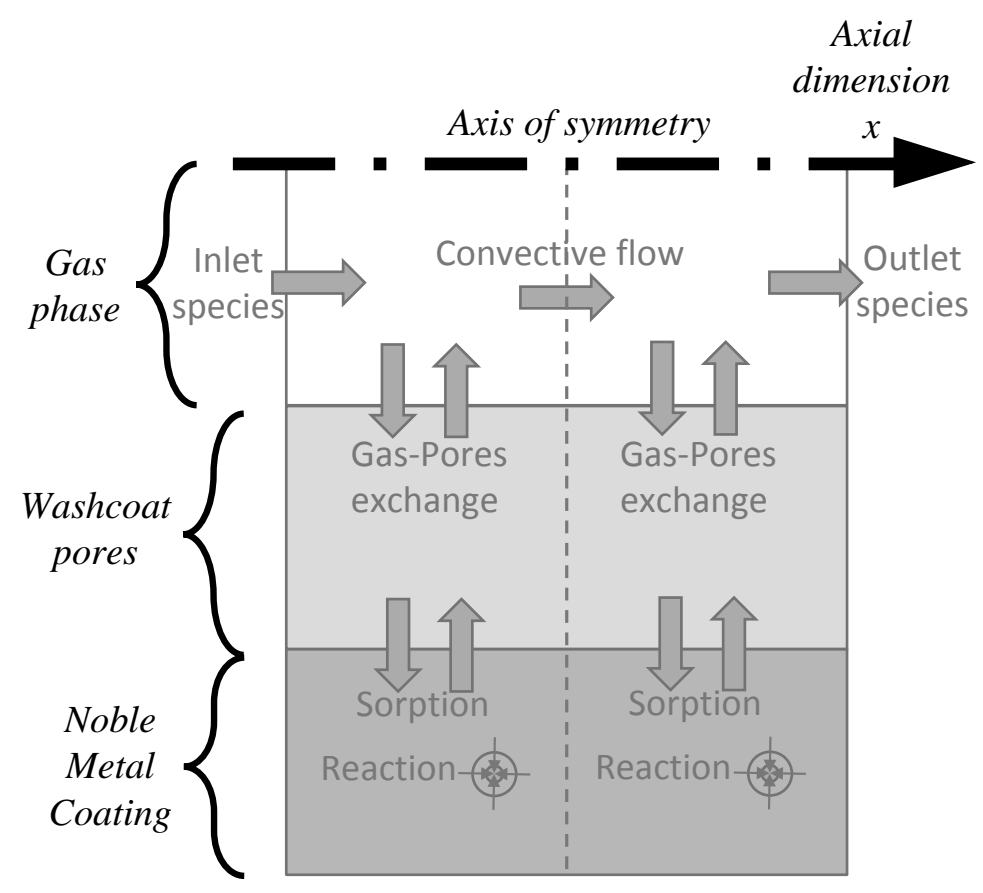

Figure 4.2: Kinetic diagram of the $1 \mathrm{D}-1 \mathrm{Ch}$ model 
mechanism. The mass balance of each species in the washcoat pores also consists of two terms (equation (4.4)), the mass transfer between gas and pores as well as the mass production term. The latter acts like a sink or a source depending on whether the species are being adsorbed or desorbed respectively. There is no mass transfer in axial direction within the solid phase, thus the mass transport along the catalyst is limited to the gas phase.

$$
\begin{aligned}
4 \cdot d_{b} & \cdot d_{w} \cdot \varepsilon_{\text {washcoat }} \cdot \rho_{g} \cdot \frac{\partial Y_{i}}{\partial t}= \\
& =\beta_{i} \cdot A \cdot a_{v} \cdot \rho_{g} \cdot\left(X_{i}-Y_{i}\right)-a_{c a t} \cdot C \cdot A \cdot \sum_{j=1}^{n}\left(r_{j} \cdot v_{i, j} \cdot M_{i}\right)
\end{aligned}
$$

In the third layer, assuming that all vacancies are equivalent, the mass balance (equation (4.5)) of species adsorbed and desorbed (as well as the free vacancies) in the noble metal coating consists of as many terms as reactions $(j)$ in which the considered species $(i)$ takes part.

$$
\frac{\partial \Theta i}{\partial t}=\sum_{j=1}^{n} v_{i, j} \cdot r_{j}
$$

A total of 16 reactions are implemented, Pt represents the vacant sites of noble metal on which the gaseous species can be adsorbed, while Ptrepresents the vacancies occupied by the corresponding species. $\mathrm{CO}, \mathrm{O}_{2}$, $\mathrm{NO}, \mathrm{HC}, \mathrm{H}_{2} \mathrm{O}$ and $\mathrm{H}_{2}$ can be adsorbed or desorbed in the noble metal coating (equations (4.6)-(4.12)). The $\mathrm{HC}$ are split into two species, $\mathrm{CH}_{4}$ and $\mathrm{C}_{3} \mathrm{H}_{6}$. The former can be directly measured in the test bench and represent the more stable fraction of the total $\mathrm{HC}$. While the non- $\mathrm{CH}_{4}$ measured are considered as $\mathrm{C}_{3} \mathrm{H}_{6}$, which usually represents the predominant and easily oxidizing $\mathrm{HC}$ [137]. 


$$
\begin{aligned}
\mathrm{CO}+\mathrm{Pt} & \leftrightarrows \mathrm{PtCO} \\
\mathrm{O}_{2}+2 \mathrm{Pt} & \leftrightarrows 2 \mathrm{PtO} \\
\mathrm{NO}+\mathrm{Pt} & \leftrightarrows \mathrm{PtNO} \\
\mathrm{CH}_{4}+\mathrm{Pt} & \leftrightarrows \mathrm{PtCH} \\
\mathrm{C}_{3} \mathrm{H}_{6}+3 \mathrm{Pt} & \leftrightarrows \mathrm{PtC}_{3} \mathrm{H}_{6} \\
\mathrm{H}_{2} \mathrm{O}+3 \mathrm{Pt} & \leftrightarrows \mathrm{PtO}+2 \mathrm{PtH} \\
\mathrm{H}_{2}+2 \mathrm{Pt} & \leftrightarrows 2 \mathrm{PtH}
\end{aligned}
$$

The oxidation and reduction reactions that take place with the species adsorbed in the noble metal coating are shown in equations (4.13)-(4.16). In all of them the backward reactions are dismissed. The $\mathrm{CO}$ can be oxidized by the $\mathrm{O}_{2}$ but also by the NO, thus contributing to the reduction of the last one. In the present approach the oxygen adsorbed in the noble metal coating is responsible for the oxidation of all the $\mathrm{CH}_{4}$ adsorbed, but it also helps oxidize a fraction of the total $\mathrm{CO}$ and $\mathrm{C}_{3} \mathrm{H}_{6}$ adsorbed. In both cases the oxidation of $\mathrm{HC}$ is lumped in just one reaction for simplicity, although in the case of $\mathrm{C}_{3} \mathrm{H}_{6}$ the oxidation is not complete, thus a fraction of $\mathrm{CO}$ is generated as a result.

$$
\begin{aligned}
\mathrm{PtCO}+\mathrm{PtO} & \rightarrow \mathrm{CO}_{2}+2 \mathrm{Pt} \\
\mathrm{PtCH}_{4}+4 \mathrm{PtO} & \rightarrow \mathrm{CO}_{2}+2 \mathrm{H}_{2} \mathrm{O}+5 \mathrm{Pt} \\
\mathrm{Pt}_{3} \mathrm{C}_{3} \mathrm{H}_{6}+6 \mathrm{PtO} & \rightarrow 3 \mathrm{PtCO}+3 \mathrm{H}_{2} \mathrm{O}+9 \mathrm{Pt} \\
2 \mathrm{PtCO}+2 \mathrm{PtNO} & \rightarrow 2 \mathrm{CO}_{2}+\mathrm{N}_{2}+4 \mathrm{Pt}
\end{aligned}
$$

Equations (4.17)-(4.20) represent the reactions in which ceria is involved. The oxygen can be also adsorbed and desorbed from ceria, which represents the main way to store and release oxygen. Once stored in the catalyst surface, this $\mathrm{O}_{2}$ can oxidize $\mathrm{CO}, \mathrm{C}_{3} \mathrm{H}_{6}$ and $\mathrm{H}_{2}$ even under rich conditions. Again the backward reactions are neglected for the oxidation reactions. 


$$
\begin{aligned}
\mathrm{O}_{2}+2 \mathrm{Ce}_{2} \mathrm{O}_{3} & \leftrightarrows 4 \mathrm{CeO}_{2} \\
\mathrm{PtCO}+2 \mathrm{CeO}_{2} & \rightarrow \mathrm{CO}_{2}+\mathrm{Ce}_{2} \mathrm{O}_{3}+\mathrm{Pt} \\
\mathrm{Pt}_{3} \mathrm{C}_{3} \mathrm{H}_{6}+12 \mathrm{CeO}_{2} & \rightarrow 3 \mathrm{PtCO}+3 \mathrm{H}_{2} \mathrm{O}+6 \mathrm{Ce}_{2} \mathrm{O}_{3} \\
2 \mathrm{PtH}+2 \mathrm{CeO}_{2} & \rightarrow 2 \mathrm{Pt}+\mathrm{H}_{2} \mathrm{O}+\mathrm{Ce}_{2} \mathrm{O}_{3}
\end{aligned}
$$

This and another similar sets of reactions are common and widespread approaches used in previous works $[134,137,140,221]$. This particular set of reactions indirectly allows for water-gas shift (WGSR equation (4.21)) and steam reforming reactions (SRR equation (4.22)) to be taken into account, which in turn helps to reduce the number of reactions. In particular, the WGSR is implicitly considered in reactions (4.11)-(4.13) while the SRR is split in reactions (4.11), (4.12) and (4.15). That is, CO and $\mathrm{C}_{3} \mathrm{H}_{6}$ can be oxidized not only with the oxygen coming from $\mathrm{O}_{2}$ gas, but also with the oxygen available after the adsorption and dissociation of $\mathrm{H}_{2} \mathrm{O}$.

$$
\begin{aligned}
\mathrm{CO}+\mathrm{H}_{2} \mathrm{O} & \leftrightarrows \mathrm{H}_{2}+\mathrm{CO}_{2} \\
\mathrm{C}_{n} \mathrm{H}_{m}+n \mathrm{H}_{2} \mathrm{O} & \leftrightarrows\left(n+\frac{m}{2}\right) \mathrm{H}_{2}+n \mathrm{CO}
\end{aligned}
$$

The forward reaction-rate constants follow the Arrhenius equation (4.23) in the case of oxidation reactions, or the sticking equation (4.24) in the case of adsorption reactions. For the backward reaction-rate constants only the Arrhenius equation is considered.

$$
\begin{gathered}
k_{j}^{f}=A_{r_{j}} \cdot e^{\frac{-E a_{j}}{R \cdot \vartheta_{b r i c k}}} \\
k_{j}^{f}=\frac{1}{C} \cdot \frac{s_{j}}{\sqrt{2 \cdot \pi \cdot M_{i} \cdot R \cdot \vartheta_{g}}}
\end{gathered}
$$

With the aforementioned configuration the model have a total of 23 states: the temperatures in both gas and solid phase, $\vartheta_{\mathrm{g}}$ and $\vartheta_{\text {brick }}$; the concentration of all species considered in gas phase, $\mathrm{X}_{\mathrm{H}_{2} \mathrm{O}}, \mathrm{X}_{\mathrm{O}_{2}}, \mathrm{X}_{\mathrm{CO}}$, 
$\mathrm{X}_{\mathrm{NO}_{\mathrm{x}}}, \mathrm{X}_{\mathrm{CH}_{4}}, \mathrm{X}_{\mathrm{C}_{3} \mathrm{H}_{6}}$ and $\mathrm{X}_{\mathrm{H}_{2}}$; the concentration of all species in the washcoat pores, $\mathrm{Y}_{\mathrm{H}_{2} \mathrm{O}}, \mathrm{Y}_{\mathrm{O}_{2}}, \mathrm{Y}_{\mathrm{CO}}, \mathrm{Y}_{\mathrm{NO}_{\mathrm{x}}}, \mathrm{Y}_{\mathrm{CH}_{4}}, \mathrm{Y}_{\mathrm{C}_{3} \mathrm{H}_{6}}$ and $\mathrm{Y}_{\mathrm{H}_{2}}$; as well as the vacancies occupied by each adsorbed species in the noble metal and ceria coating, $\Theta_{\mathrm{O}_{2}}, \Theta_{\mathrm{CO}}, \Theta_{\mathrm{NO}_{\mathrm{x}}}, \Theta_{\mathrm{CH}_{4}}, \Theta_{\mathrm{C}_{3} \mathrm{H}_{6}}, \Theta_{\mathrm{H}_{2}}$ and $\Theta_{\mathrm{CeO}}$.

\subsubsection{Downstream $\lambda$ sensor model}

Considering the fact that $\lambda$ sensors response time is faster than TWC dynamics, a static narrowband $\lambda$ sensor model has been developed. The voltage provided by the sensor model downstream of the TWC is obtained as the addition of three terms: the first term takes into account the reference voltage, i.e., the one that provides the sensor when it is exposed to a neutral gas. The second and third terms are non-linear functions $\left(\Psi_{L E A N}\right.$ and $\left.\Psi_{R I C H}\right)$ that allow to pull up or down the reference voltage due to the presence of reducing or oxidizing species respectively. In particular, $\mathrm{O}_{2}$ concentration at catalyst outlet is used to push down the reference sensor voltage. On the other hand, $\mathrm{CO}$ and $\mathrm{H}_{2}$ are the reducing species used to pull up the reference voltage due to their good correlation [222-224].

$$
V d w=V_{r e f}+\Psi_{L E A N}\left(O_{2}\right)+\Psi_{R I C H}\left(C O, H_{2}\right)
$$

\subsubsection{Numerical solution}

The present 1D-Ch TWC model constitutes a stiff system of partial differential equations (PDE). In order to implement and solve such a system the numeric method of lines has been used. The idea under this method is based on converting the PDE system into a ordinary differential equations (ODE) system. It is carried out discretizing the spatial derivatives by means of finite differences. Once obtained the equivalent ODE system, it can be solved with any non-linear ODE solver. The difficulties come from the fact that a very stiff system is used in this case, thus not any ODE solver can deal successfully with this sort of systems. In the present approach the numeric method of lines has been implemented in Matlab code, which provides a noticeable variety of non-linear ODE solvers. In particular, an specific function created to deal with stiff sys- 
tems (ode15s) has been adopted. It is a variable-step and variable-order solver based on the numerical differentiation formulas of orders 1 to 5 . Among other options, these functions allows to speed up the model execution by providing the symbolic Jacobian of the system. Thanks to this configuration, the current model is real-time capable.

Concerning the initial and boundary conditions, for all the model states (hereinafter S), the initial conditions of the whole longitudinal domain as well as the inlet values at any time step are known, thereby, Dirichlet conditions are imposed (equation (4.26)). In the case of the conductive heat flow term, which is a second-order spatial derivative, Neumann boundary conditions are imposed (equation (4.27)).

$$
\begin{gathered}
\left\{\begin{array}{l}
S(x, 0)=c_{0}, \quad x \in[0, L] \quad \text { and } \quad t \in[0, T] \\
S(0, t)=f(t), \quad x \in[0, L] \quad \text { and } \quad t \in[0, T]
\end{array}\right. \\
\frac{\partial \vartheta_{\text {brick }}(0, t)}{\partial x}=\frac{\partial \vartheta_{\text {brick }}(L, t)}{\partial x}=0, \quad x \in[0, L] \quad \text { and } \quad t \in[0, T]
\end{gathered}
$$

As a reference to put in context the real-time capabilities, the processor used in this work is an Intel ${ }^{\circledR}$ Core $^{\mathrm{TM}}$ i5-4460 @ $3.2 \mathrm{GHz}$. Regarding the spatial discretization used, the axial domain of the catalyst has been discretized in 5 nodes. The temporal discretization is not constant since, as it has already been mentioned, a variable-step solver is used. Defining the real-time ratio as the elapsed time to perform a simulation divided by the duration of the simulation, the present approach runs below 0.3 $\mathrm{s} / \mathrm{s}$.

\subsubsection{Validation}

The main advantage of this kind of model is its capability to provide insights that help to understand what is really happening in a certain process, particularly during transient conditions. It is partially due to the information that the user can obtain through the model states, since most of them are parameters experimentally unmeasurable, or at least, very difficult to measure with the typical facilities of an engine test bench. 
This is the case, for example, of the vacancies occupied by each species. As show Figure 4.3 and 4.4, in the present approach the vacancies are divided into two main groups; the vacancies of the ceria $\left(\Theta_{\mathrm{Ce}}\right)$, that allows to store oxygen, and the vacancies of the noble metal coating $\left(\Theta_{\mathrm{PT}}\right)$, on which all the species must be adsorbed prior to react. In this figures solid, dashed and dash-dot lines correspond to inlet, middle and outlet sections respectively.

However, the complexity of the set of equations considered in the model (see previous section) presents some disadvantages. For instance, the difficulty to properly identify an important amount of parameters, especially when some of them are related to states of which there are not experimental measurements available. In this sense, the validation can only be conducted by comparing the outlet emissions as well as the temperatures of the gas at different points along the longitudinal TWC axis. Anyway, this is a reasonable approach since gas temperatures and outlet emissions represent the outputs of the system, thus, all of them are strongly affected by the values of the intermediate states of the system. Figure 4.5 and 4.6 show the evolution of the gas temperature and the main species at the catalyst outlet during several AFR transients. A fresh TWC is used in this test, while the engine is kept at $2500 \mathrm{rpm}$ and $75 \mathrm{Nm}$, that is, conditions representative of extra urban driving. The color of the lines is used to differentiate between experimental data (black lines), and model predictions (gray lines). The type of the line allows to distinguish inlet values (solid lines) from outlet values (dash-dot lines)).

At the beginning of the test, the engine is running at steady rich conditions $\left(\phi_{\mathrm{up}}=1.1\right)$. Therefore, the oxygen storing level in ceria is low, as it also happens with the oxidizing species in the noble metal coating (Figure 4.3 and 4.4). However, the level of vacancies occupied by reducing species is high. The case of $\mathrm{C}_{3} \mathrm{H}_{6}$ is particularly relevant, which helps to understand the slow dynamics of this species during the AFR transient. In general, the number of vacancies occupied in the first sections of the converter is greater than in other sections, due to the higher temperature. Which in turn represents more catalytic activity. In the case of $\mathrm{C}_{3} \mathrm{H}_{6}$, the occupancy distribution is opposite, since the lack of oxygen at rich 
conditions limits its oxidation in the second half of the converter. Most of the oxygen is consumed in the first sections of the converter, thereby the amount of vacancies occupied by $\mathrm{HC}$ increases along the converter length.

After the first AFR step the engine is working at lean conditions ( $\phi_{\text {up }}$ $=0.9)$. The reducing species are desorbed and the adsorption of oxidizing species increases as expected. As shown in Figure 4.5 and 4.6, the change from rich to lean is typically a fast transition for the reducing species, partly because of the instantaneous decrease of their concentration at catalyst inlet. The oxidizing species are easily adsorbed, but their consumption during the fast oxidation of the reducing species adsorbed imposes a slower dynamic. After this transition, the occupancy level of the oxidizing species increases, giving as a result the increase of their concentration at catalyst outlet.

The second AFR step switches again from lean to rich conditions. This transition is quite more complex, due to the role of the WGSR as well as to the adsorption of reducing species. In this case, the dynamic shown by the oxidizing species is faster than the one of the reducing species. While at lean conditions the $\mathrm{O}_{2}$ and $\mathrm{NO}$ available are enough to oxidise the reducing species, at rich conditions that is not the case, the oxidation at rich conditions is partially driven by $\mathrm{H}_{2} \mathrm{O}$. After its adsorption and dissociation in oxygen and hydrogen (reaction (4.11)), the oxygen contained in the water allows to oxidise $\mathrm{CO}$ (reaction (4.13)), but also $\mathrm{HC}$ in an indirect way, since the partial oxidation of $\mathrm{C}_{3} \mathrm{H}_{6}$ generates $\mathrm{CO}$ (reaction (4.15) and (4.19)). The slow dynamic shown by $\mathrm{C}_{3} \mathrm{H}_{6}$ in Figure 4.5 is more related with its adsorption and partial oxidation to $\mathrm{CO}$ than with the oxygen storing in ceria (Figure 4.3 and 4.4). Just after the lean to rich step, the outlet concentration of $\mathrm{H}_{2} \mathrm{O}$ increases fast. This peak is due to the fast oxidation of $\mathrm{C}_{3} \mathrm{H}_{6}$ with the oxygen stored in the TWC during the lean period. It is important to notice how the vacancies occupied by CO increases simultaneously, especially in the first section of the converter, although $\mathrm{CO}$ emissions remain low because of the fast adsorption and oxidation of this species. Both $\mathrm{H}_{2} \mathrm{O}$ and $\mathrm{CO}$ are the products of the $\mathrm{C}_{3} \mathrm{H}_{6}$ oxidation reaction. Once depleted the stored oxygen, $\mathrm{CO}$ emissions show a fast increase, unlike $\mathrm{C}_{3} \mathrm{H}_{6}$ emissions that follow a slower dynamic 

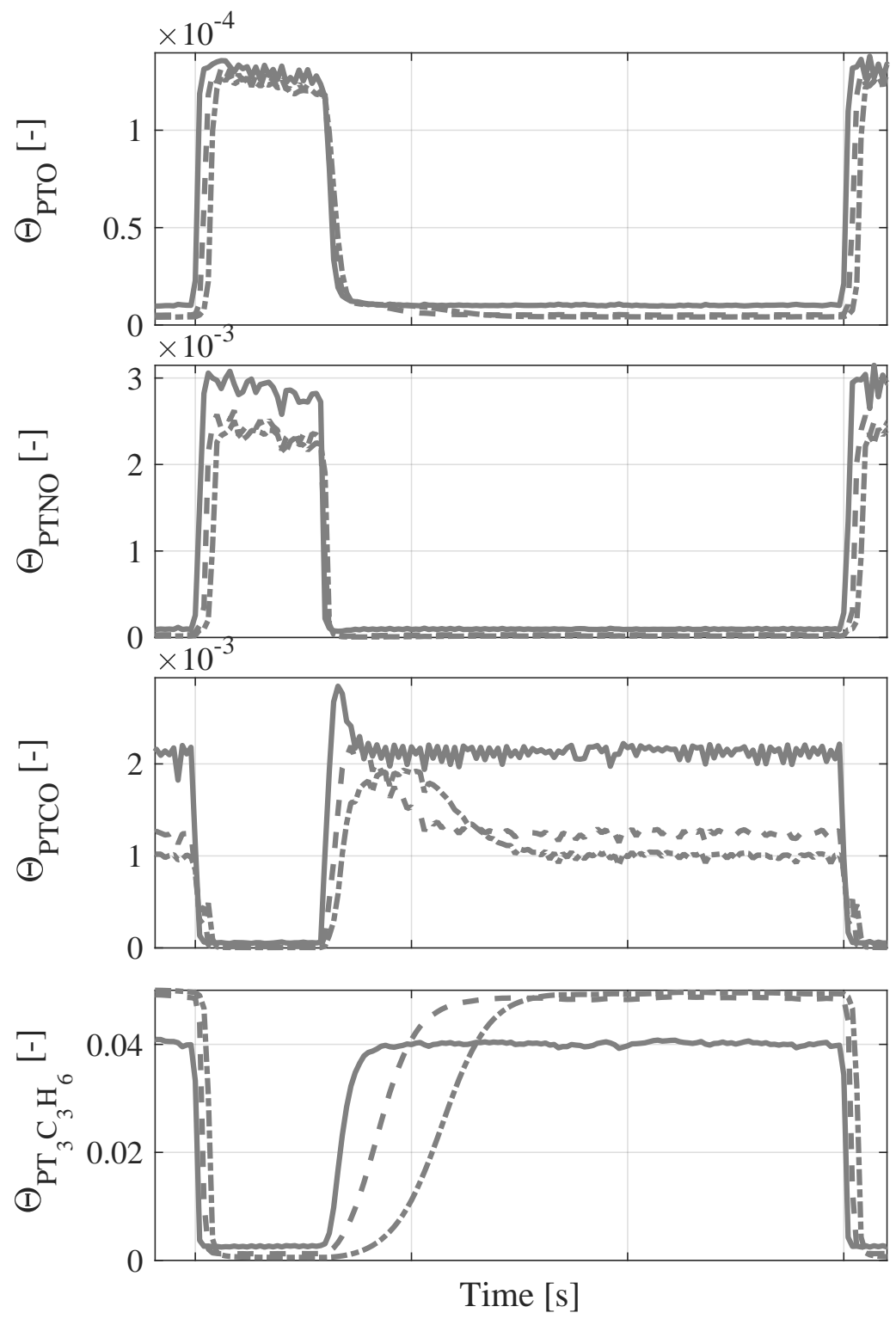

Figure 4.3: TWC behavior under AFR steps. Operating conditions: $2500 \mathrm{rpm}$ and 75 Nm. Fresh TWC. Gray lines are model predictions. Solid (-), dashed (- - -) and dash-dot (-..) lines correspond to inlet, middle and outlet sections respectively 

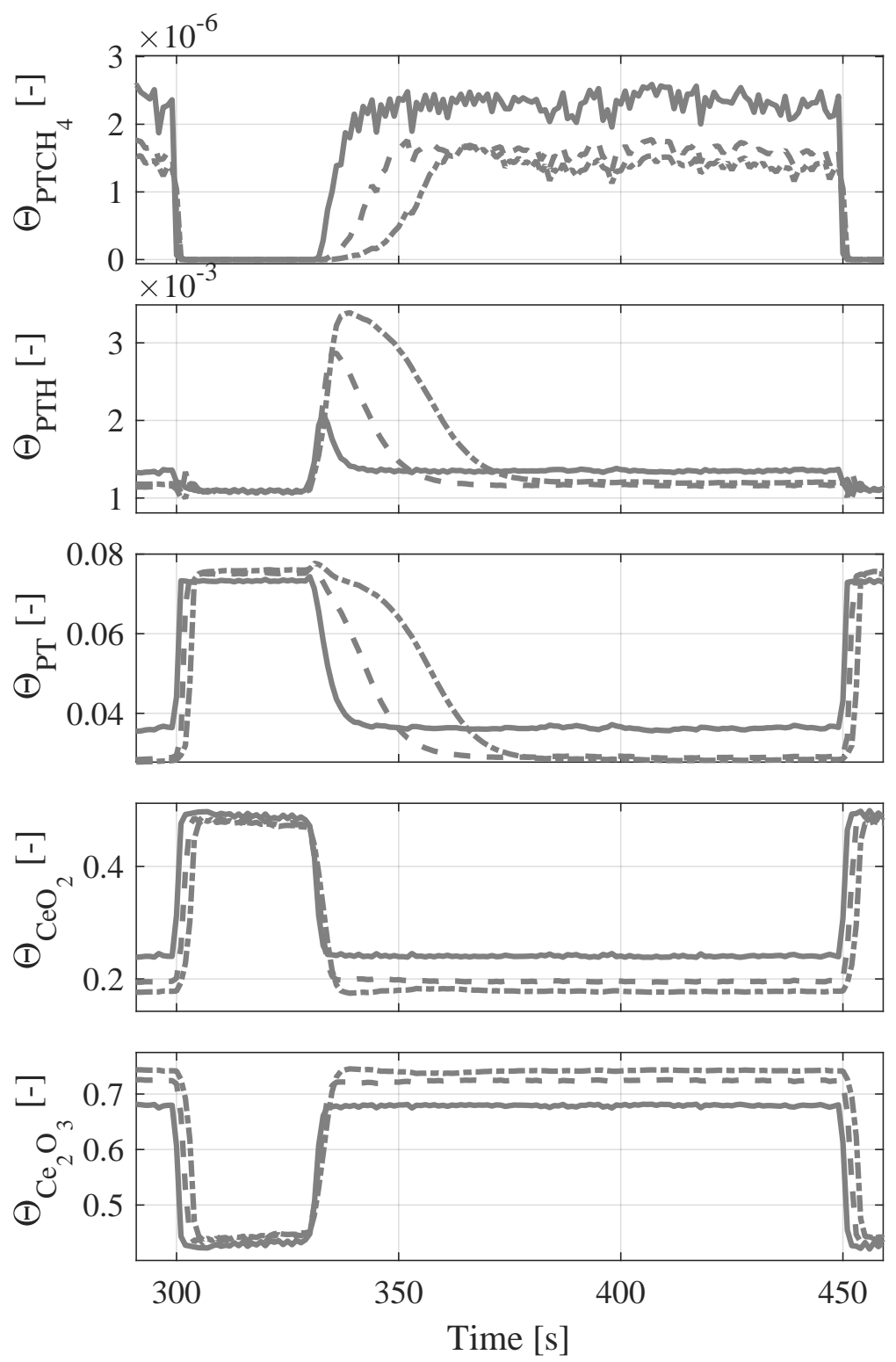

Figure 4.4: TWC behavior under AFR steps. Operating conditions: $2500 \mathrm{rpm}$ and 75 Nm. Fresh TWC. Gray lines are model predictions. Solid (-), dashed (-- -) and dash-dot (-.-) lines correspond to inlet, middle and outlet sections respectively 

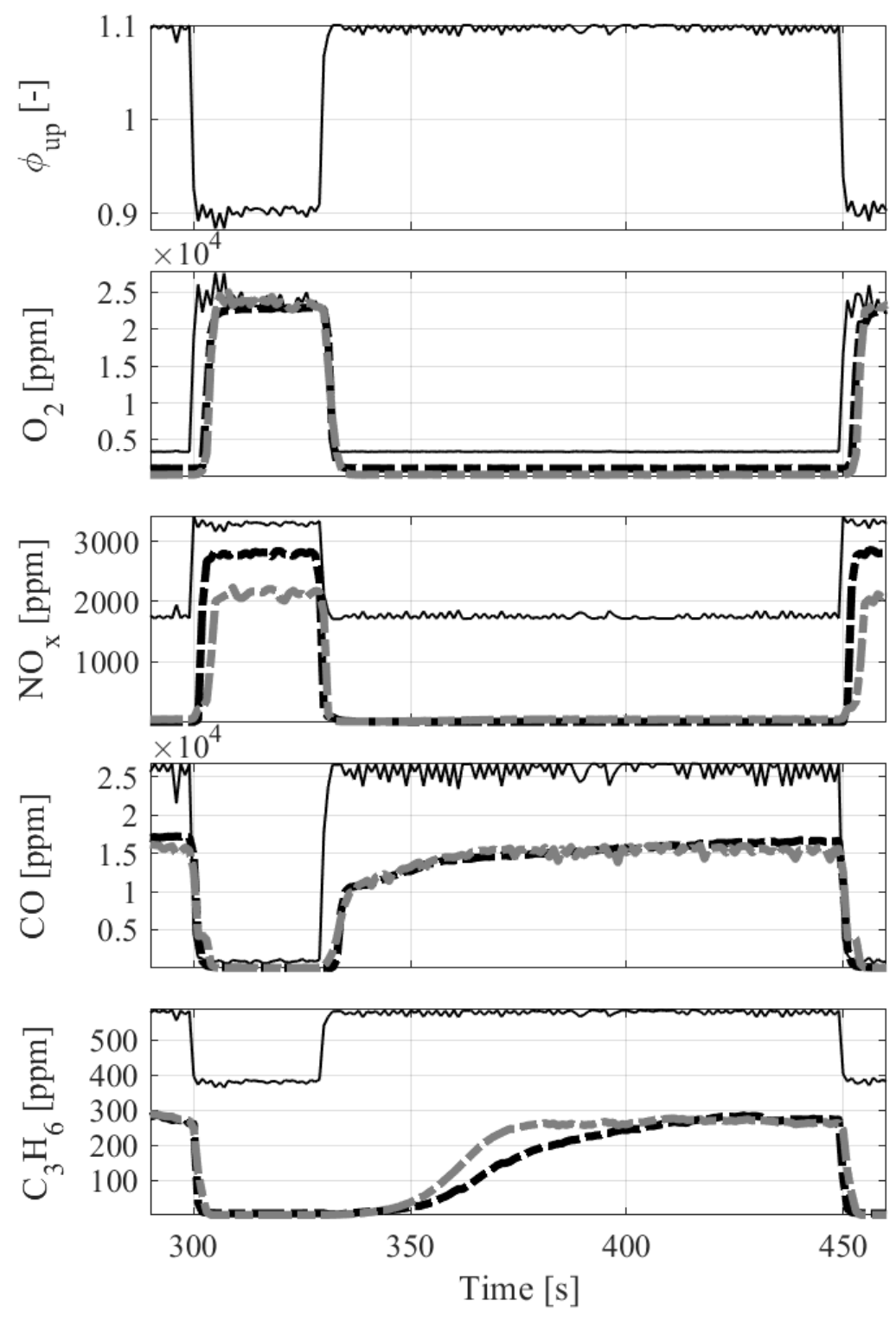

Figure 4.5: TWC behavior under AFR steps. Operating conditions: $2500 \mathrm{rpm}$ and $75 \mathrm{Nm}$. Fresh TWC. Black lines represent experimental data while gray lines are model predictions. Solid (-) and dash-dot (-...) lines correspond to inlet and outlet respectively 

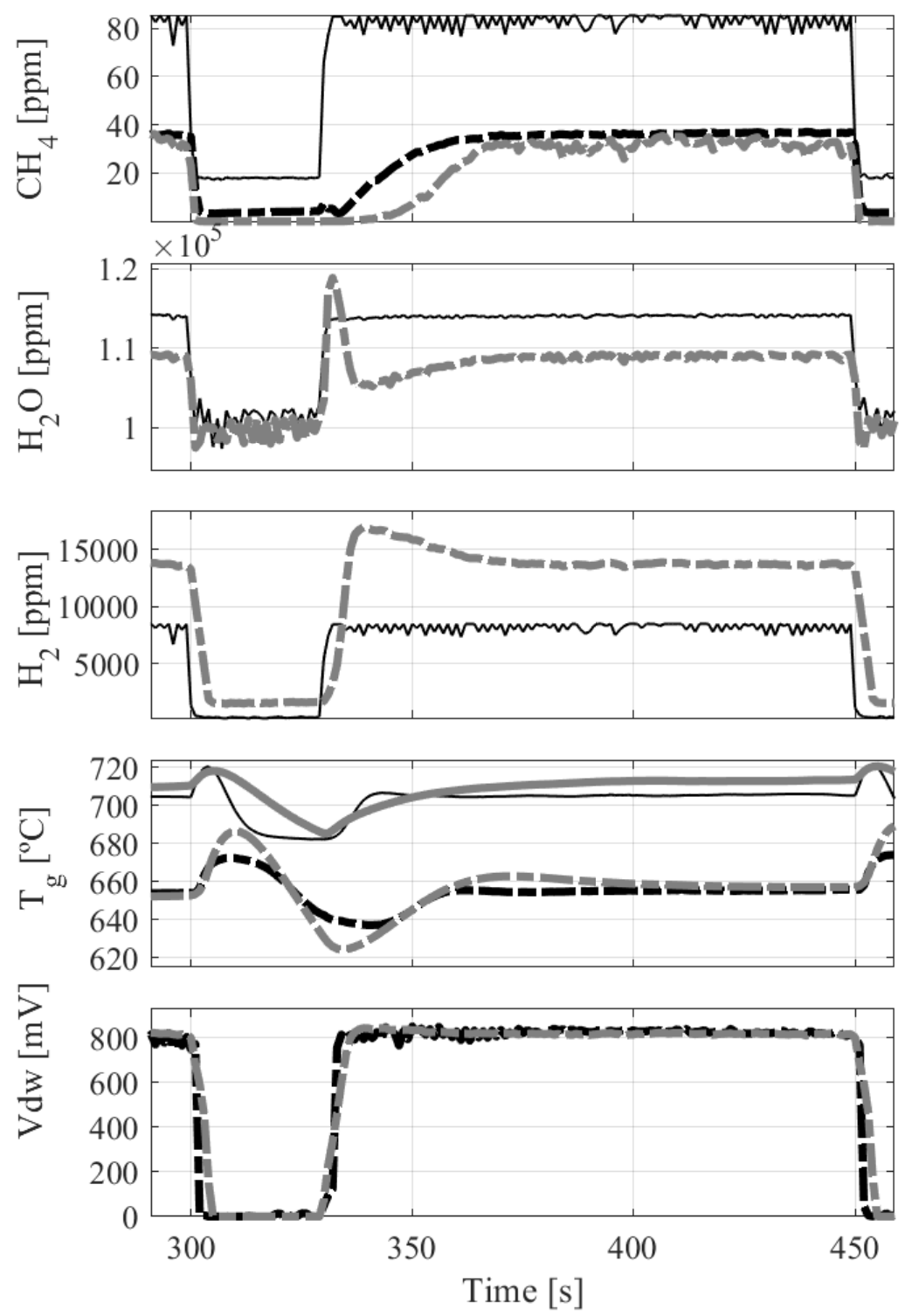

Figure 4.6: TWC behavior under AFR steps. Operating conditions: $2500 \mathrm{rpm}$ and $75 \mathrm{Nm}$. Fresh TWC. Black lines represent experimental data while gray lines are model predictions. Solid (-) and dash-dot (-.-.) lines correspond to inlet and outlet respectively 
behaviour. But none of these species have still reached their steady state values. The WGSR, that had suffered an strong activation due to the simultaneous availability of $\mathrm{CO}$ and $\mathrm{H}_{2} \mathrm{O}$ just after the lean to rich step, follows a slow deactivation after the depletion of the stored oxygen. This phenomena explains the slow increase of $\mathrm{H}_{2} \mathrm{O}$ and $\mathrm{CO}$ (reactants of the WGSR) as well as the decrease of $\mathrm{H}_{2}$ (product of the WGSR) at catalyst outlet. During this process the vacancies occupied by $\mathrm{H}_{2}$ and $\mathrm{CO}$ suffer a temporal increase. The strong adsorption and oxidation of $\mathrm{HC}$ drive the slow transient shown by the $\mathrm{C}_{3} \mathrm{H}_{6}$ emissions at the outlet (Figure 4.3).

The temperature evolution of the exhaust gas is also shown in Figure 4.6. The dash-dot lines represent the values at the outlet as usual. However, in this case the solid lines represent the temperature at the first section of the converter length, instead of the inlet temperature, which is not plotted in the graphs because it has an almost constant value of 620 degrees for this test. That is, lower than the temperature of the gas at any section within the converter. The exhaust gas temperature inside the converter is always above the inlet temperature, which highlight the catalytic activity in both rich and lean conditions. Especially relevant is the fact that the temperature profiles decreases from the inlet to the outlet, since it means that the oxidation is happening mainly in the first sections. While the first section is being cooled by the inlet gas flow, the next sections are exposed to a gas flow pre-heated by the previous sections, as a consequence of the exothermic reactions and the drag effect of the heat flow along the channels. Unlike the inlet temperature, that remains almost constant during the AFR steps, the temperature inside the converter is sensitive to these steps, since they affect the way in which the oxidation takes place. The shape of the temperature profiles is similar in both inlet and outlet, although the axial distribution imposes some difference, mainly in phase and amplitude. The contribution of each species to the global temperature profiles at steady state is different. While CO provides a noticeable amount of energy at rich conditions, its contribution at lean conditions is small. It makes sense according to the inlet concentration of $\mathrm{CO}$, since its value is low at lean conditions. However, the contribution of the $\mathrm{HC}$ oxidation to the energy release within the converter is different. Again, the values of the concentration at the inlet play a key role, since unlike $\mathrm{CO}$, the amount of $\mathrm{HC}$ oxidized 
is similar at rich and lean conditions. Regarding the transient phases, the higher level of vacancies occupied by $\mathrm{C}_{3} \mathrm{H}_{6}$ has a noticeable effect. In this sense, just after the rich to lean step, the temperature increases pushed by the oxidation of stored $\mathrm{C}_{3} \mathrm{H}_{6}$. When this stored $\mathrm{C}_{3} \mathrm{H}_{6}$ is depleted, the temperature drops off driven by the strong deactivation of the $\mathrm{CO}$ oxidation reaction at lean conditions. After the lean to rich step, the temperature increases reaching steady state conditions again.

The validation of the downstream $\lambda$ sensor model is also included in Figure 4.4. It switches from rich to lean and vice versa as a result of the change in the gas composition provided by the TWC model. Despite being an static model, it predicts correctly the transitions, since the dynamic response of this type of sensors is several orders of magnitude faster than the dynamics of the converter. Furthermore, its simplicity makes it suitable to be implemented in a control-oriented model.

Figure 4.7 and 4.8 show the model performance for different operating conditions, $1250 \mathrm{rpm}$ and $25 \mathrm{Nm}$ as well as 3500 and $75 \mathrm{Nm}$ respectively. From the catalyst point of view, these two operating conditions represent extreme cases of the previous operating point. The first of them imposes lower exhaust gas mass flows and temperatures and the second one higher mass flows and temperatures. While higher mass flows tend to decrease the converter efficiency, higher temperatures tend to increase the catalytic activity, thus increasing the converter efficiency. The TWC behaviour in these tests is similar although the effect of the distinct exhaust gas mass flows and temperatures is noticeable. According to Figure 4.7 and 4.8, the effect of the mass flow is stronger, hidden the benefits in terms of emissions that higher temperatures could introduce. At steady state, lower mass flows achieve lower emissions, while during transient phases higher mass flows shorten the converter dynamics in a remarkable way. Finally, the influence of the different operating conditions on the model parameters is shown in Figure 4.9. Most of the model parameters are constant for all the operating conditions assessed, thus only those that have a dependency on the operating conditions are shown. 

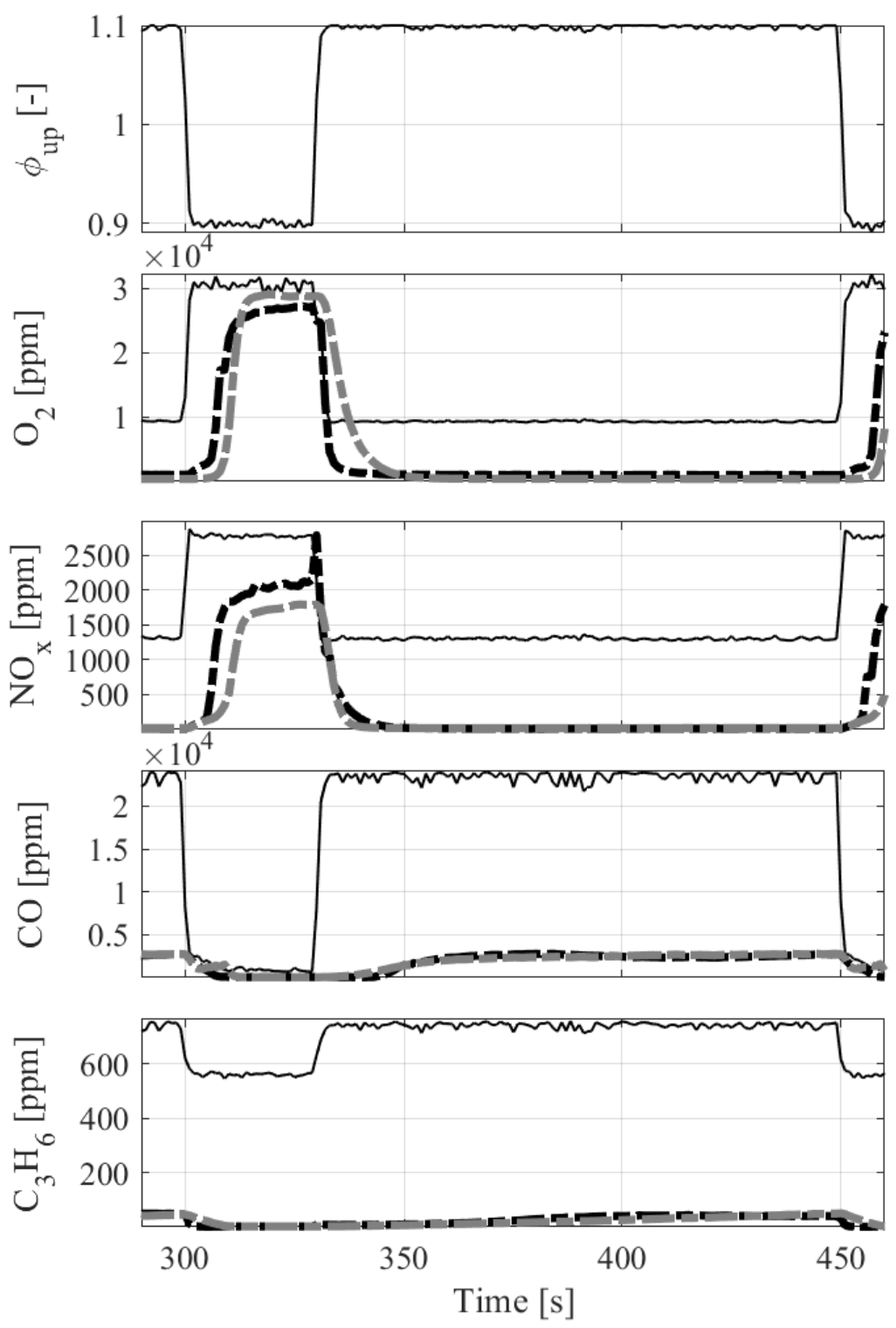

Figure 4.7: TWC behavior under AFR steps. Operating conditions: $1250 \mathrm{rpm}$ and $25 \mathrm{Nm}$. Fresh TWC. Black lines represent experimental data while gray lines are model predictions. Solid (-) and dash-dot (-...) lines correspond to inlet and outlet respectively 

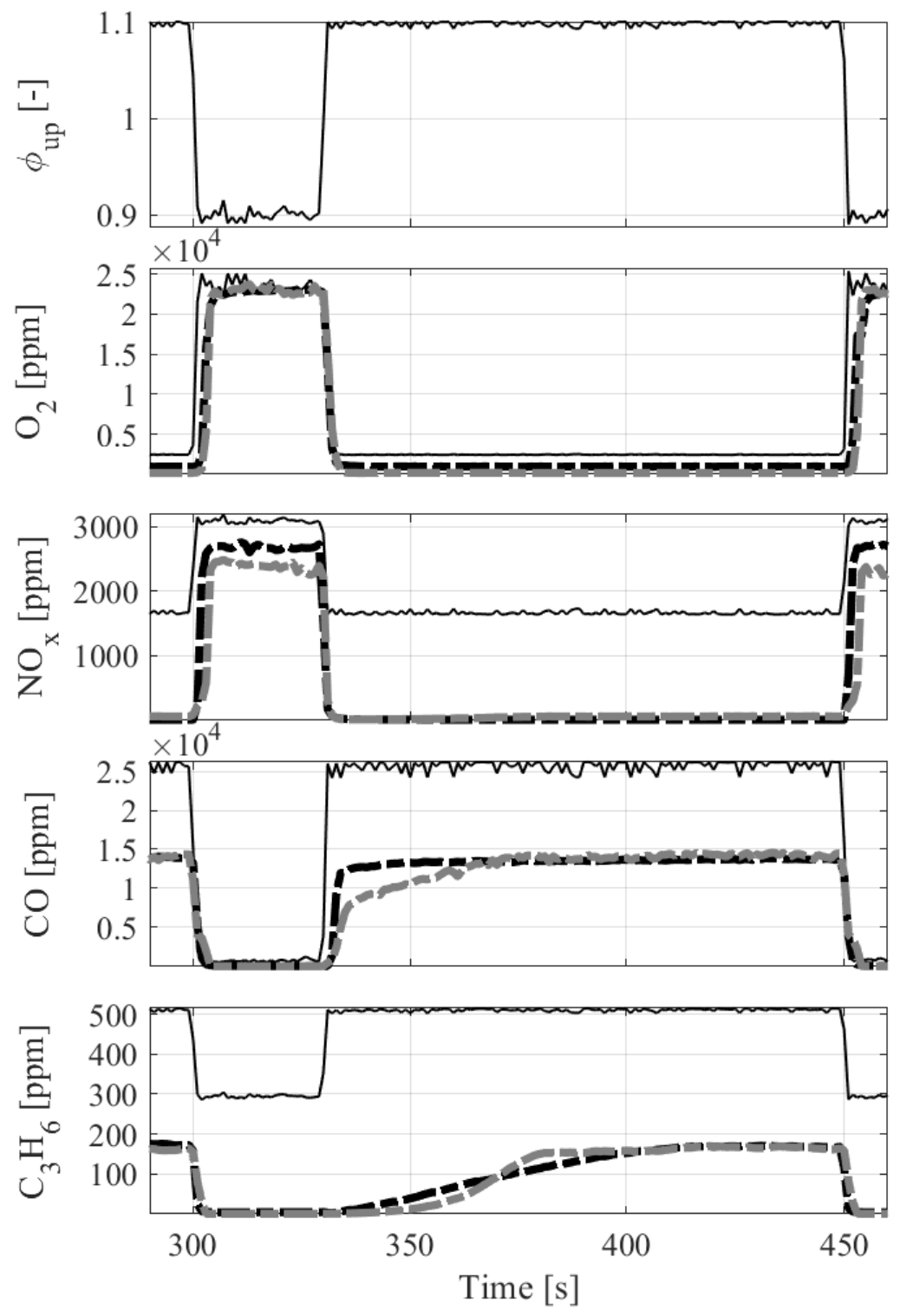

Figure 4.8: TWC behavior under AFR steps. Operating conditions: $3500 \mathrm{rpm}$ and $75 \mathrm{Nm}$. Fresh TWC. Black lines represent experimental data while gray lines are model predictions. Solid (—) and dash-dot (-.-.) lines correspond to inlet and outlet respectively 


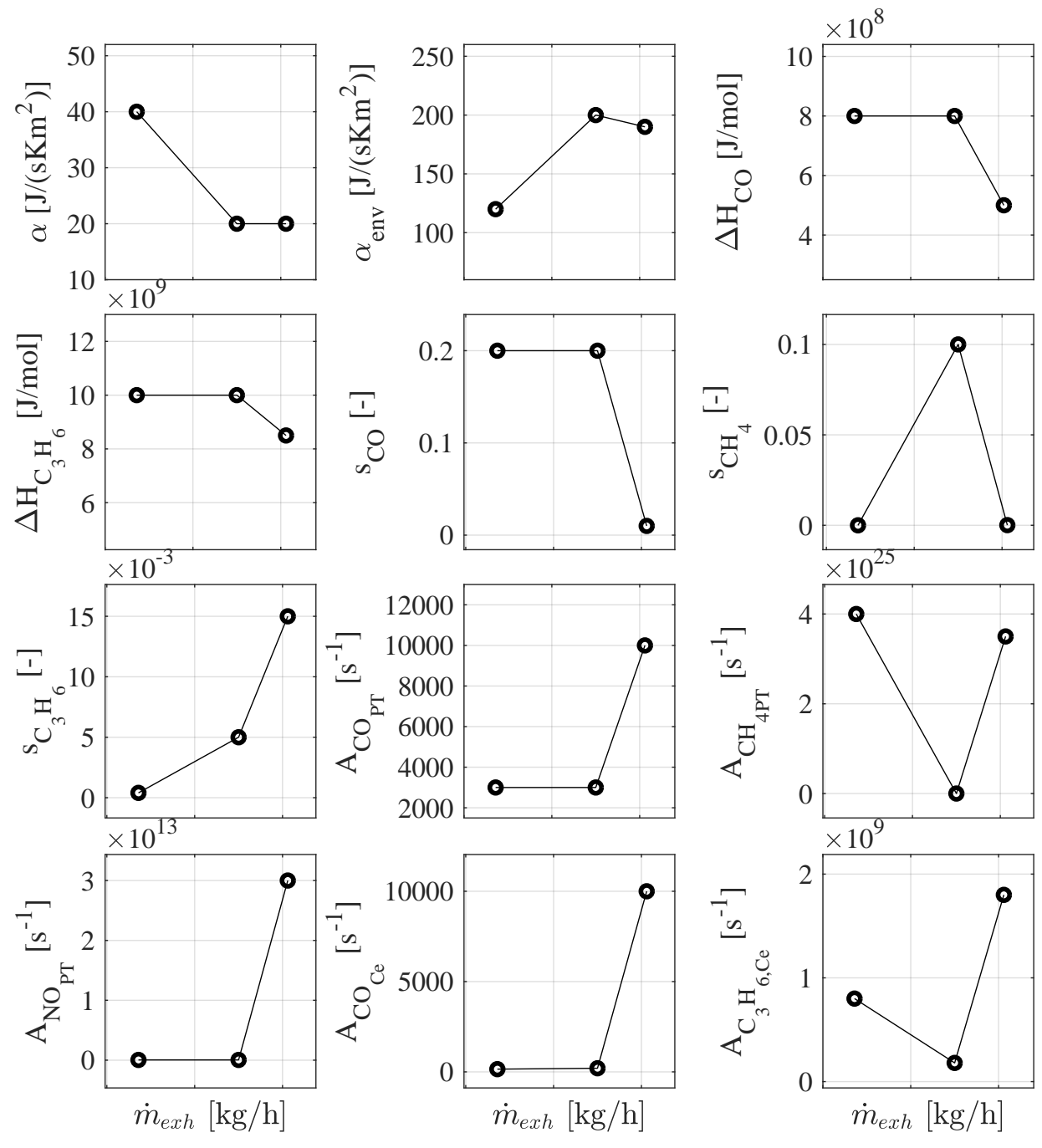

Figure 4.9: Model parameters for fresh TWC 


\subsection{Zero-Dimensional control-oriented modelling of three-way catalyst}

Detailed chemical first-principle models of both, $\lambda$ sensor [224] and TWC have been developed over the past three decades. These models allow a deeper understanding of the phenomena related to the dynamic behaviour of the system, dealing with different complexity levels, from multi-dimensional models [121-127, 225] to more common one-dimensional approaches as [26, 128, 133-140, 226]. Of course, all of them provide wide and accurate information regarding the converter state, but they cannot be used for real-time applications (RTA), which rule them out for control purposes. On the other hand, the integrator-type or black-box models [141, 142, 144-148] were the only feasible option for OSL estimation in RTA some years ago, when the computational capabilities of the common ECUs were rather limited, but they are not accurate enough for today's requirements. For example, with an integrator-type storing model based on the inlet fuel-to-air equivalence ratio $(\phi)$, independently of the previous evolutions, a $\phi$ equal to 1 leads the OSL to reach immediately steady state conditions, since it does not account for the exhaust gas composition at catalyst inlet.

An intermediate approach is followed in other publications [25, 143, 149152], which takes into account a few chemical reactions but keeping the real-time capabilities by means of lumped-parameter models, usually zero-dimensional or quasi-dimensional with one or several nodes axially distributed along the TWC length. They often supply OSL estimations and $\phi$ at the tail pipe with a proper cost-performance trade-off, but not all of them provide information about the concentration of the main pollutant species involved downstream of the TWC. It could be useful in order to implement a control strategy based on emissions, thus controlling the AFR to keep the main pollutant species below a threshold depending on different criteria.

The strategies based on control-oriented modelling are indispensable to fulfil current and future limits of pollutant emissions. In the particular case of three-way catalytic converters (TWC), the key of this approach is supported by its capability to provide insights about the instantaneous 
state of the converter, especially in terms of oxygen storing level (OSL), which is a parameter tightly related with the conversion efficiency during AFR transients. As it usually happens, the restriction in the operating conditions of a system force other coupled subsystems to work out of its operating range. In this regard, some typical driving conditions such as transient phases, injection cut-off or start-stop systems among others, lead to AFRs different from stoichiometric, which forces the TWC to work outside of its design conditions, and thus preventing it from getting proper conversion efficiency [208]. All of them are typical situations in which knowing the TWC state could be really useful to properly control the converter dynamics. Moreover, TWC control oriented modelling is also a key concept from the point of view of the engine aftertreatment diagnosis. For example, to estimate the TWC ageing level, the nominal oxygen storing capability (OSC) can be compared with the corresponding model estimation after some period of time. In conclusion, there is still room for improvement in this field, since OSL is considered a good indicator of the catalyst state $[131,208]$ but it cannot be directly measured by means of on-board sensors, thus a model-based real-time capable estimation can be useful.

\subsubsection{Aims and requirements}

The purpose of this section is to introduce a zero-dimensional controloriented and real-time capable model, with lumped-parameter kinetics, capable to provide not only OSL estimations, but also information about the concentration of the main pollutant species downstream of the TWC. OSL allows to implement a control strategy based not only on AFR but also on the amount of oxygen stored. While an on-line estimation of tail pipe emissions is very useful because it can be used for different purposes: from being used as input signal in order to feed a downstream $\lambda$ sensor sub-model, to directly implementing an emission-based AFR control strategy, thus allowing to choose a certain cost function to weight which species are more harmful depending on driving conditions. In order to fulfil these objectives the model must offer low computational requirements as to be implemented in a rapid prototyping system, and also being accurate enough for the present purposes. 
The model introduced is a simplification of the 1D-1Ch model developed in the previous section. In the current approach, only one node is considered, although the model is ready to deal with a quasi-dimensional extension based on the axial discretization of the TWC with the aid of additional nodes. The validation of the model performance by means of experimental test as well as different practical cases, where the benefits of OSL estimation plays a key role, are shown at the end of this section.

\subsubsection{Model structure}

The model accounts for oxygen storing as well as oxidation and reduction of the main species involved, taking as inputs engine speed, throttle and $\phi$ upstream of the TWC, all of them available in current ECUs. From previous signals, a static feed gas sub-model supplies the inputs for the oxygen storing and thermal sub-models, that is, air mass flow, exhaust gas temperature and composition at TWC inlet. From these signals OSL and brick temperature are calculated as model states. Tail pipe temperature and gas concentration for the main species such as $\mathrm{NO}_{\mathrm{x}}$, $\mathrm{CO}, \mathrm{CO}_{2}, \mathrm{HC}$ and $\mathrm{O}_{2}$ represent the model outputs. Finally, since the response time of the $\lambda$ sensors is faster than TWC dynamics, a static $\lambda$ sensor sub-model estimates the voltage of the narrowband $\lambda$ sensor downstream of the TWC taking as inputs $\mathrm{NO}_{\mathrm{x}}$ and $\mathrm{CO}$ concentrations at catalyst outlet. Therefore, four different sub-models make up the complete structure as it is shown in figure 4.10 .

\section{Feed gas sub-model}

This sub-model provides the inputs for the TWC model as function of the operating conditions. Steady state values of temperature and gas composition previously measured at catalyst inlet are implemented in lookup tables as function of engine speed and load as well as $\phi$. Exhaust gas composition depends on combustion chamber conditions, whose dynamics are much faster than TWC ones, thus neglecting exhaust gas dynamics to estimate emissions upstream of the TWC is a reasonable approach. In spite of that, a first order filter has been fitted to experimental data and added to the outputs of the lookup tables in order to improve the feed gas 


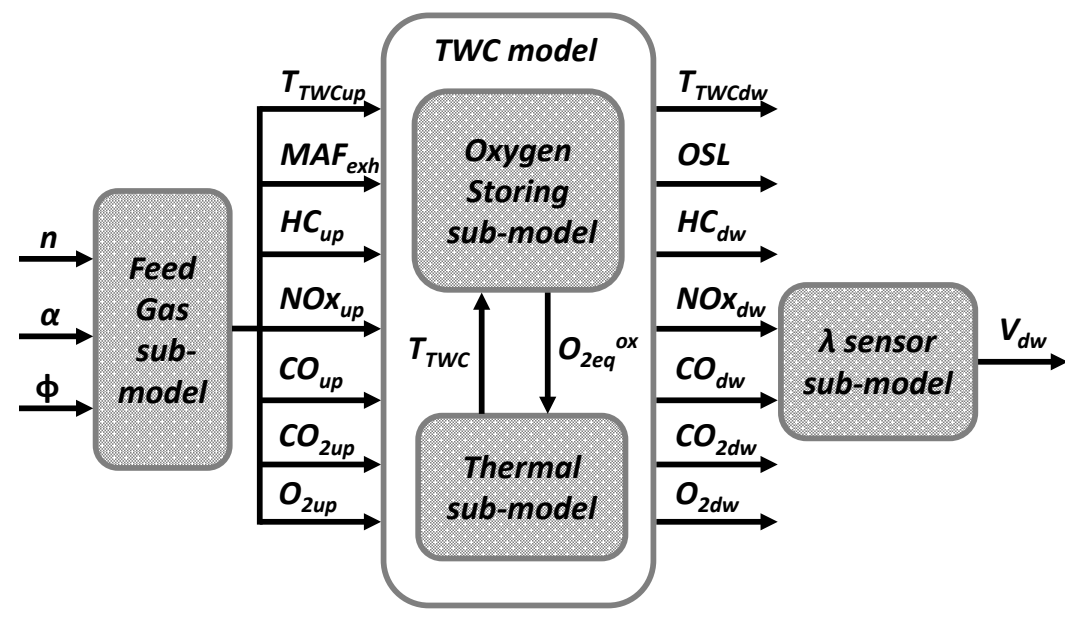

Figure 4.10: Model structure

sub-model performance in transient conditions. The sub-model outputs are TWC inlet temperature, exhaust mass flow and the concentration of the main exhaust species: $\mathrm{NO}_{\text {xup }}, \mathrm{CO}_{u p}, \mathrm{CO}_{2 \mathrm{up}}, \mathrm{HC}_{u p}$ and $\mathrm{O}_{2 u p}$.

In figure 4.11, several $\phi$ steps have been performed with the engine running at $1250 \mathrm{rpm}$ and $25 \mathrm{Nm}$. The values provided by this sub-model are accurate enough at steady state, although in case of bias error, of course this error would be transmitted to the TWC model disturbing the outlet predictions. During transient phases, the outputs of the lookup tables follow directly the dynamics imposed by their inputs, in particular the dynamic of the $\phi$ in figure 4.11. This is a sensible approach for gas composition since, in fact, gas composition drives the $\lambda$ sensors response. But even in that case some discrepancies can appear due to the non-linearity as well as to the different weight of each species on the $\phi$ signal. As shown in this figure, the values provided by lookup tables show a slightly faster response than the measurements, that is why a first order filter is applied to the outputs of the lookup tables. Regarding inlet temperature, the evolution in figure 4.11 shows a low sensitivity of temperature to $\phi$ variations, but that is not the case for engine speed and load. The dynamic behaviour of exhaust temperature is driven by trans- 

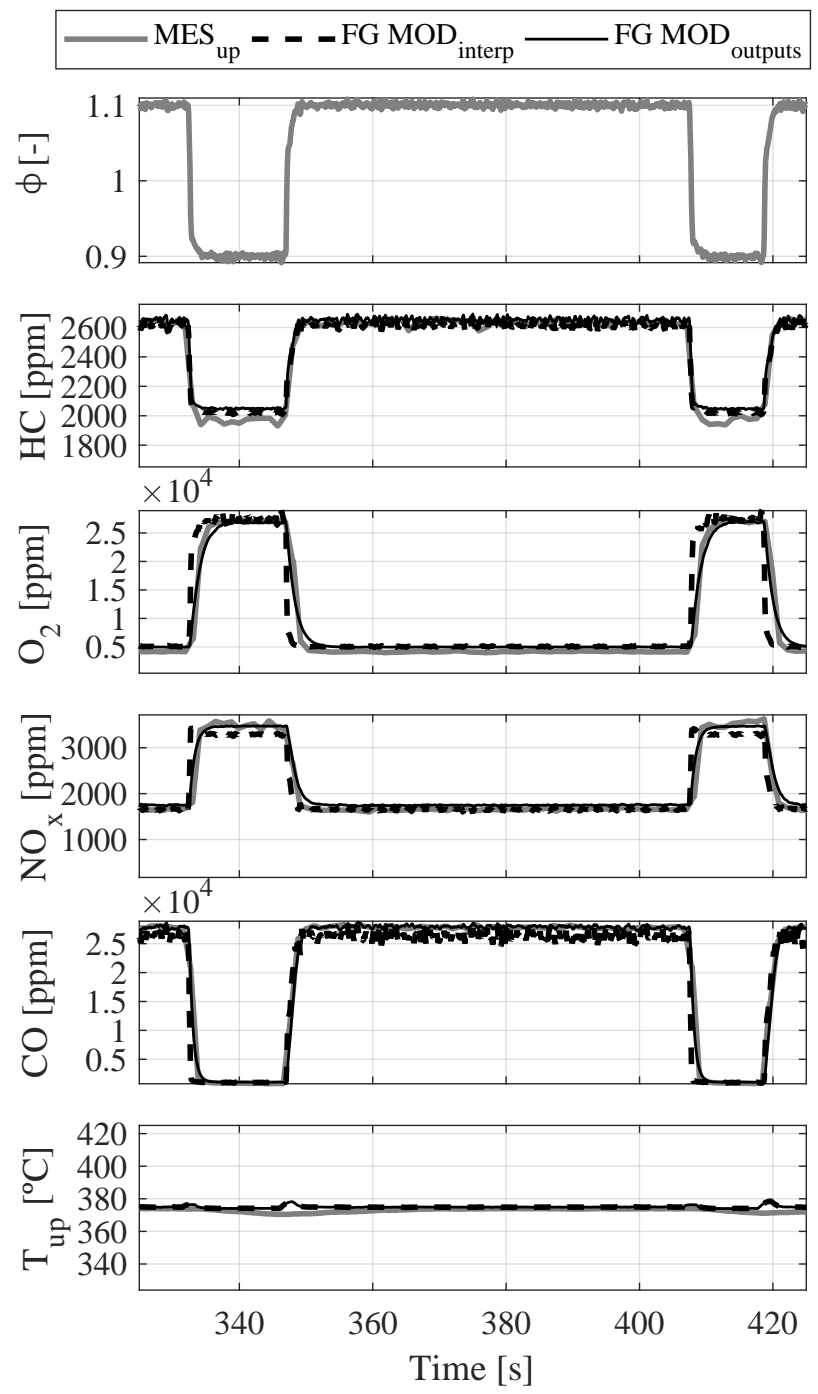

Figure 4.11: Comparison between feed gas sub-model outputs and measurements for $\phi$ steps at $1250 \mathrm{rpm}$ and $25 \mathrm{Nm}$. $\mathrm{MES}_{\mathrm{up}}, \mathrm{FG} \mathrm{MOD}_{\text {interp }}$ and FG MOD $\mathrm{Dutputs}_{\text {sepresent mea- }}$ surements, direct interpolation in lookup tables and outputs of the feed gas sub-model respectively 
port and heat transfer phenomena from exhaust pipes to TWC inlet. A detailed modelling of the exhaust line is out of the scope of the present approach, since the current TWC model is oriented to control purposes. Moreover, whatever the complexity of the approach used, an estimation of the temperature entering the system is needed because there are not temperature sensors available on-board along the exhaust. Therefore, in order to estimate the catalyst inlet temperature, the same approach applied for gas composition is chosen. In this case the use of a first order filter is strongly required because the transient response provided by the lookup tables is faster than real, due to the thermal inertia of the exhaust components.

\section{Set of reactions considered}

The model accounts for three reactions in noble metal, namely $\mathrm{HC}$ and $\mathrm{CO}$ oxidation as well as $\mathrm{NO}_{\mathrm{x}}$ reduction:

$$
\begin{aligned}
\mathrm{C}_{x} \mathrm{H}_{y}+\left(x+\frac{y}{4}\right) \mathrm{O}_{2} & \rightarrow \mathrm{CO}_{2}+\frac{y}{2} \mathrm{H}_{2} \mathrm{O} \\
\mathrm{CO}+\frac{1}{2} \mathrm{O}_{2} & \rightarrow \mathrm{CO}_{2} \\
\mathrm{NO}+\mathrm{CO} & \rightarrow \mathrm{CO}_{2}+\frac{1}{2} \mathrm{~N}_{2}
\end{aligned}
$$

Regarding the storing reactions, only oxygen is considered to be able to oxidise ceria, thus ceria oxidation by means of $\mathrm{NO}_{\mathrm{x}}$ is neglected. Nevertheless, for ceria reduction both $\mathrm{HC}$ and $\mathrm{CO}$ are taken into account, while $\mathrm{H}_{2}$ is not considered. This set of reactions is widespread used in the literature [137, 221, 227].

$$
\begin{aligned}
\mathrm{Ce}_{2} \mathrm{O}_{3}+\frac{1}{2} \mathrm{O}_{2} & \rightarrow 2 \mathrm{CeO}_{2} \\
\mathrm{CO}+2 \mathrm{CeO}_{2} & \rightarrow \mathrm{Ce}_{2} \mathrm{O}_{3}+\mathrm{CO}_{2} \\
\mathrm{C}_{x} \mathrm{H}_{y}+(2 x+y) \mathrm{CeO}_{2} & \rightarrow\left(x+\frac{1}{2} y\right) \mathrm{Ce}_{2} \mathrm{O}_{3}+x \mathrm{CO}+\frac{1}{2} y \mathrm{H}_{2} \mathrm{O}
\end{aligned}
$$


In the present approach $\mathrm{O}_{2}, \mathrm{CO}$ and $\mathrm{HC}$ reactions (equations 4.28 and 4.29) follow the Langmuir-Hinshelwood mechanism, that is, their adsorption in the noble metal is needed prior to react. $\mathrm{NO}_{\mathrm{x}}$ reduction (equation 4.30), in turn, is considered as Eley-Riddeal mechanism, thereby it is adsorbed in noble metal and reacts with CO in gas phase. Whether there is still oxygen excess after reacting over noble metal surface (equations 4.28 and 4.29), then oxygen is stored by means of ceria oxidation (equation 4.31). In the same way, when there is a lack of oxygen at catalyst inlet, $\mathrm{CO}$ and $\mathrm{HC}$ are desorbed and the oxygen previously stored is used to oxidise $\mathrm{CO}$ and $\mathrm{HC}$ in gas phase (equations 4.32 and equation 4.33). Thus, the oxidation of reducing species with ceria is also considered that follows the Eley-Riddeal mechanism as in the case of $\mathrm{NO}_{\mathrm{x}}$ reduction. This is conceptually the followed approach, but chemical reaction rates are not really implemented as such. To simplify, an algebraic mass balance is considered for each species instead, thereby the reactions progress depending on the availability of its respective reactants. In this sense HC, $\mathrm{NO}_{\mathrm{x}}$ and $\mathrm{CO}$ are adsorbed and desorbed in the same time step when they cannot react because of the lack of one of the needed reactants, hence $\mathrm{O}_{2}$ is the only species that can be stored (with ceria) during several time steps. Additional reactions as water-gas shift and steam-reforming reactions have been neglected in order to simplify the model complexity, in any case, their practical effects concerning $\mathrm{HC}$ and $\mathrm{CO}$ oxidation after a lean to rich step can be partially replaced by oxygen stored in ceria. In the same way, the effect of $\mathrm{H}_{2}$ on the downstream narrowband $\lambda$ sensor cannot be taken into account. These assumptions as well as its practical consequences will be discussed in next sections.

\section{Oxygen storing sub-model}

The adsorbed mass of each species is calculated by means of their respective adsorption rates $\left(\mu_{x}\right)$, which depend on OSL: 


$$
\begin{aligned}
m_{\mathrm{O}_{2} a d s} & =\mu_{O_{2}}(O S L) \cdot m_{O_{2} u p} \\
m_{N O_{x} a d s} & =\mu_{N O_{x}}(O S L) \cdot m_{N O_{x} u p} \\
m_{C O a d s} & =\mu_{C O}(O S L) \cdot m_{C O u p} \\
m_{H C a d s} & =\mu_{H C}(O S L) \cdot m_{H C u p}
\end{aligned}
$$

All the adsorbed mass of each chemical species does not necessarily reacts as it happens when an efficiency rate is imposed. Instead, the portion of the adsorbed mass that finally reacts depends on the availability of other reactants, thereby the adsorbed mass can be desorbed in the same time step when it does not react with other species. The only exception is $\mathrm{O}_{2}$, that can be stored in ceria during several time steps until being oxidized by $\mathrm{HC}$ or $\mathrm{CO}$, if there is lack of oxygen at catalyst inlet.

The mass balances are based on equivalent species. Since the model only accounts for few reactions while the actual chemistry inside a TWC is quite more complex, the use of stoichiometric rates does not provide good results as expected. That is why equivalence parameters $\left(\kappa_{x}\right)$ have been used to convert each species into its corresponding equivalent:

$$
\begin{aligned}
m_{\mathrm{HC} q} & =\kappa_{(C O \rightarrow H C)} \cdot m_{C O} \\
m_{\mathrm{O}_{2} e q} & =\kappa_{\left(H C \rightarrow O_{2}\right)} \cdot\left(m_{H C}+m_{H C e q}\right) \\
m_{C O e q} & =\kappa_{\left(N O_{x} \rightarrow C O\right)} \cdot m_{N O_{x}}
\end{aligned}
$$

Thus, reactions 4.28-4.33 can be outlined as:

$$
\begin{aligned}
O_{2(S P-N M)}+O_{2 e q(S P)} & \rightarrow C O_{2 e q(G P)} \\
C O_{(G P)}+C O_{e q(S P)} & \rightarrow C O_{2 e q(G P)} \\
O_{2(S P-N M)} & \rightarrow O_{2(S P-C E R I A)} \\
O_{2(S P-C E R I A)}+O_{2 e q(G P)} & \rightarrow C O_{2 e q(G P)}
\end{aligned}
$$

Subscripts 'SP' and 'GP' indicate solid and gas phase respectively, while subscripts 'SP-NM' and 'SP-CERIA' distinguish between oxygen adsorbed in noble metal and oxygen stored in ceria. 
An additional parameter called $\mathrm{OSL}_{r e f}$ has been introduced in order to deal with the fact that oxygen storage is an equilibrium controlled process $[130,228]$. That is, the OSL cannot reach a value equal to 1 or 0 just when there is an oxygen excess or lack respectively but when the chemical equilibrium between solid and gas phases is fulfilled. This parameter symbolizes the OSL value for which the oxygen storing process reaches the chemical equilibrium given a certain exhaust gas composition at steady state. For each operating point in terms of engine speed $(n)$ and load $(\alpha)$, the best parameter to quantify the mentioned exhaust gas composition is $\phi$ upstream of the TWC, therefore the reference OSL value depends on the operating point and $\phi$ at catalyst inlet:

$$
O S L_{r e f}=f(\phi, \alpha, n)
$$

First, the available $\mathrm{O}_{2}$ is compared with the equivalent $\mathrm{HC}$ and $\mathrm{CO}$ to check whether all the reducing species adsorbed can be oxidized or not. When there is enough $\mathrm{O}_{2}$ availability, the mass of $\mathrm{HC}$ and $\mathrm{CO}$ downstream of the TWC is exactly the amount of each one that has not been adsorbed (figure 4.12), thereby in this case the adsorption coefficient is behaving as a conversion efficiency. Next, the adsorbed $\mathrm{NO}_{\mathrm{x}}$ can react with CO in gas phase (figure 4.13), that is, with the proportion of $\mathrm{CO}$ which has not been previously adsorbed and oxidized with $\mathrm{O}_{2}$.

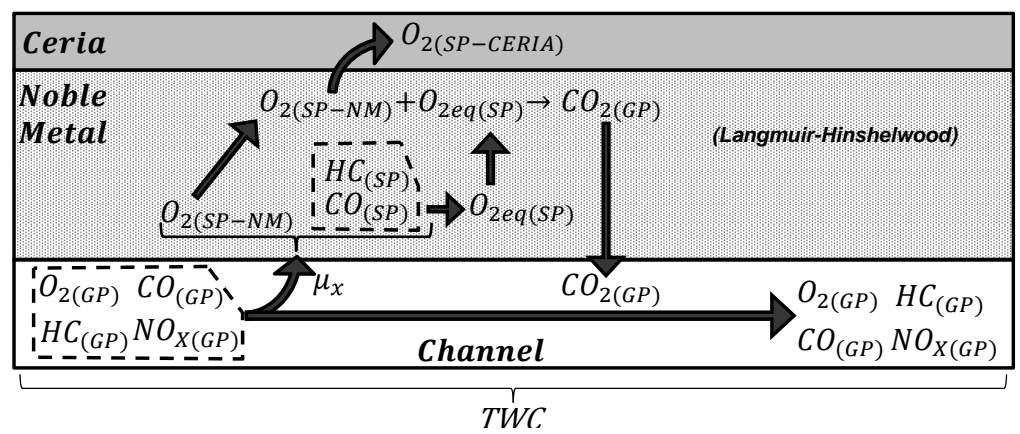

Figure 4.12: Oxidation reactions when there is excess oxygen 
The excess of $\mathrm{O}_{2}$ can be stored in ceria (figure 4.12) as long as the current OSL is lower than the reference OSL $\left(\mathrm{OSL}_{r e f}\right)$ for the corresponding operating conditions.

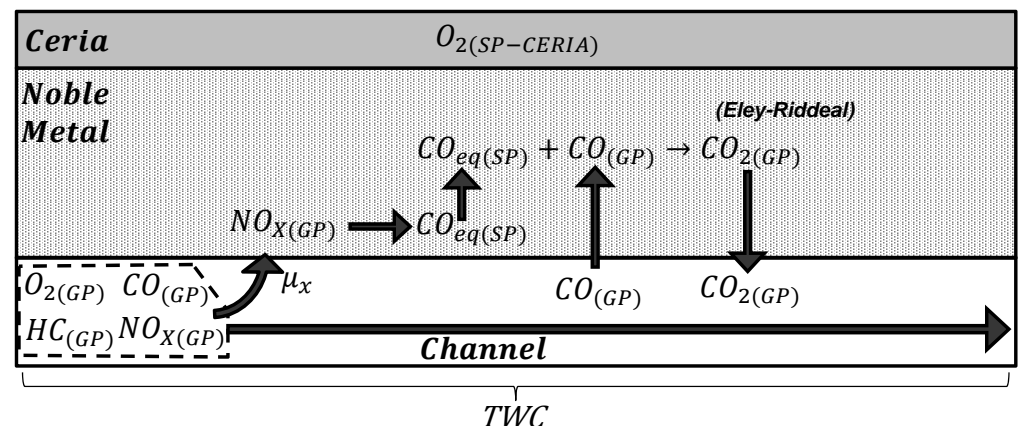

Figure 4.13: Reduction reaction

If that is not the case, then the surplus $\mathrm{O}_{2}$ is desorbed. On the contrary, when there is not enough $\mathrm{O}_{2}$ availability only the proportional amount of equivalent $\mathrm{HC}$ and $\mathrm{CO}$ is oxidized and the rest is desorbed (figure 4.14). Again, the adsorbed $\mathrm{NO}_{\mathrm{x}}$ can react with the $\mathrm{CO}$ in gas phase, that is, the proportion of $\mathrm{CO}$ which has been previously desorbed together with the incoming $\mathrm{CO}$ gas. Under these conditions, the lack of $\mathrm{O}_{2}$ can be compensated by using the previously stored $\mathrm{O}_{2}$ in ceria whether current OSL is higher than $\mathrm{OSL}_{r e f}$, thus oxidizing $\mathrm{HC}$ and $\mathrm{CO}$ in gas phase, either they have not been adsorbed or they have been desorbed due to the lack of $\mathrm{O}_{2}$ in noble metal (figure 4.14).

Finally, $\mathrm{CO}_{2}$ at the outlet is calculated as the addition of two terms, $\mathrm{CO}_{2}$ at the inlet and $\mathrm{CO}_{2}$ generated with the oxidation of $\mathrm{HC}$ and $\mathrm{CO}$. In the same way, $\mathrm{O}_{2}, \mathrm{HC}, \mathrm{CO}$ and $\mathrm{NO}_{\mathrm{x}}$ at catalyst outlet are calculated as the difference of two terms, one of them accounts for the amount of each one upstream the TWC and the other one accounts for the amount of each one which have reacted with other reactants. 


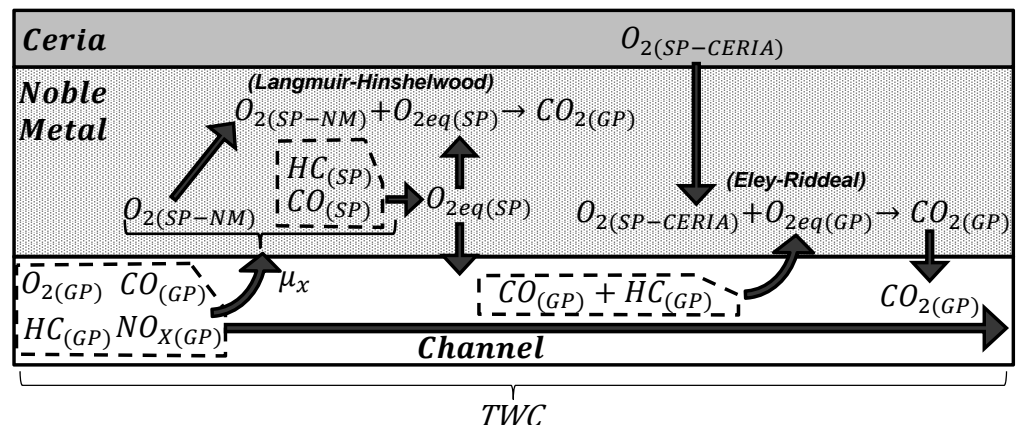

Figure 4.14: Oxidation reactions when there is lack of oxygen

\section{Thermal sub-model}

An accurate prediction of the TWC temperature requires a detailed model based on first principles, since thermal dynamics are strongly dependent on axial distribution, especially during the heating-up process. Therefore a lumped-parameter model as the one presented will not be able to fulfil the requirements if an accurate temperature prediction is needed. The control-oriented model proposed is essentially focused on after heating-up operating conditions, when the requirements in terms of temperature prediction are not so demanding. That is, once the temperature is such that the activation energy of all reactions involved is exceeded, conversion efficiency is mainly dependent on both AFR at catalyst inlet and oxygen stored in ceria. Consequently for the current approach temperature does not play a key role on its capability to predict tailpipe emissions and outlet $\phi$. Particularly, in the present model the temperature prediction is used for two purposes: in order to slightly adjust the conversion efficiency above light-off; as well as to take into account the conversion efficiency drop in case of reaching temperatures below light-off, for example, as a consequence of a long enough period under fuel injection cut-off.

TWC temperature is calculated through an energy balance that accounts for three terms: the energy exchange due to the thermal state of the inlet flow $\left(\mathrm{Q}_{\mathrm{IF}}\right)$, the energy generated inside the TWC due to the oxidation 
processes (Qox) and the energy exchange with the environment by convection $\left(\mathrm{Q}_{\mathrm{ENV}}\right)$.

$$
\frac{\mathrm{d} Q_{T W C}}{\mathrm{~d} t}=Q_{I F}+Q_{O X}+Q_{E N V}
$$

While tailpipe temperature is calculated analogously but just considering the TWC energy and heat loses to the environment.

$$
\frac{\mathrm{d} Q_{T P}}{\mathrm{~d} t}=Q_{T W C}+Q_{E N V}
$$

$\lambda$ sensor sub-model

A static narrowband $\lambda$ sensor model analogous to the one presented in section 4.1.3 has been implemented. Again, the voltage provided by the sensor model downstream of the TWC is obtained as the addition of three terms: the first term takes into account the reference voltage while the second and third terms are non-linear functions $\left(\Psi_{L E A N}\right.$ and $\left.\Psi_{R I C H}\right)$ that allow to pull up or down the reference voltage due to the presence of reducing or oxidizing species respectively. This sensor model has been adapted to be implemented along with the control-oriented model, thus the input signals are slightly different to the ones used in section 4.1.3. Since the control-oriented model neglects the effect of $\mathrm{H}_{2} \mathrm{O}$ and $\mathrm{H}_{2}$, in this case the $\Psi_{R I C H}$ function is fed only with CO, while $\Psi_{L E A N}$ takes $\mathrm{NO}_{\mathrm{x}}$ concentration instead of $\mathrm{O}_{2}$. This last change is based on the fact that $\mathrm{NO}_{\mathrm{x}}$ emissions are the final consequence of an $\mathrm{O}_{2}$ excess. Even at slightly rich conditions could be a non-negligible amount of oxygen downstream of the TWC (non-ideal combustion process), but only when there is a certain amount of $\mathrm{NO}_{\mathrm{x}}$ the TWC is really working at lean conditions. Moreover, from the point of view of the TWC control, $\mathrm{NO}_{\mathrm{x}}$ are the species that the control strategy pretends to limit, not $\mathrm{O}_{2}$.

$$
V d w=V_{r e f}+\Psi_{L E A N}\left(N O_{x}\right)+\Psi_{R I C H}(C O)
$$




\subsubsection{Model fitting \& validation}

For easier understanding of the fitting process, it will be divided into different steps as it is shown in figure 4.15. First, the setting of the equivalence parameter for each chemical reaction $\left(\kappa_{x}\right)$ is carried out in Step 1. Next, in Step 2, the narrowband $\lambda$ sensor parameters are also fitted. Once finished these two steps for any operating point, the parameters obtained are considered valid for any other operating condition, thus no additional iterations are needed. Finally, in order to obtain the curves $O S L_{r e f}\left(\phi_{u p}\right)$ and $\mu_{x}(O S L)$ an iterative process is performed in Step 3. This last step allows to fit these curves for a certain operating point, for any other operating conditions the procedure is the same. A summary of all the fitted parameters during this process is listed in table 4.1.

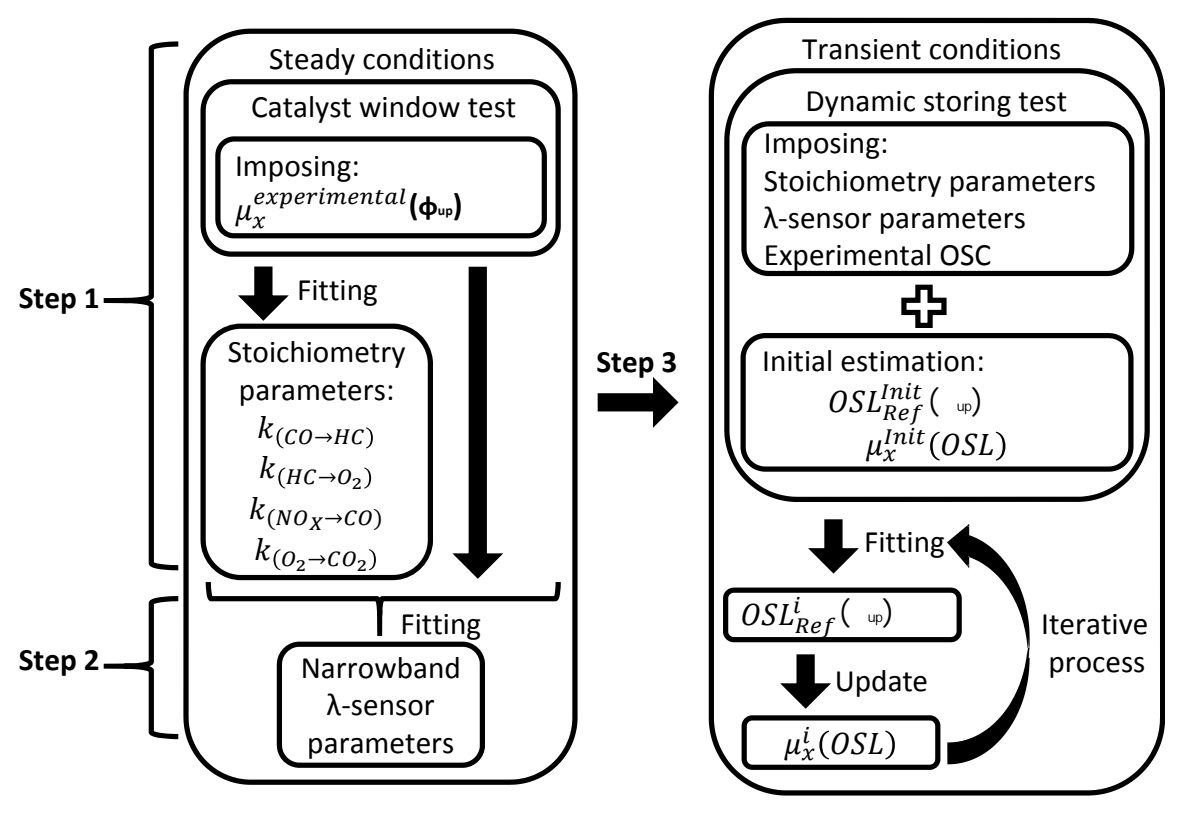

Figure 4.15: Fitting process diagram 


\begin{tabular}{ccc}
\hline & Number of & Description \\
Step & parameters & equivalence parameters $\left(\kappa_{x}\right)$ \\
2 & 4 & $\lambda$-sensor parameters \\
3 & 4 & curves $\mu_{x}(O S L)$ \\
3 & 1 & curve $O S L_{r e f}\left(\phi_{u p}\right)$ \\
\hline
\end{tabular}

Table 4.1: Model parameters

Step 1: Chemical stoichiometry, equivalence parameters $\kappa_{x}$

A specific experimental test has been developed in order to fit the four stoichiometric parameters: $\kappa_{(\mathrm{CO} \rightarrow \mathrm{HC})}, \kappa_{\left(\mathrm{HC} \rightarrow \mathrm{O}_{2}\right)}, \kappa_{\left(\mathrm{NO}_{x} \rightarrow \mathrm{CO}\right)}$ and $\kappa_{\left(\mathrm{O}_{2} \rightarrow \mathrm{CO}_{2}\right)}$. From now on, this test will be referred as catalyst window test, an example of this sort of test is shown in figure 4.16. The test consist of a simple quasi-steady $\phi$ evolution from rich $(\phi=1.1)$ to lean conditions $(\phi=0.9)$, the duration between steps is 30 seconds and each one has an amplitude of 0.01 .

When the model is lunched for first time, the curves $\mu_{x}(O S L)$ and $O S L_{r e f}\left(\phi_{u p}\right)$ are still unknown. However, it is important to notice that adsorption rates behaves as conversion efficiency rates when all the adsorbed mass reacts. Moreover, TWC dynamics have low impact on the catalyst window test because of being a test consisting of a set of steady state points. Therefore, experimental conversion efficiency curves depending on $\phi$ upstream the catalyst can be imposed, instead of using a more proper (but still unknown in this step) adsorption dependence with OSL $\left(\mu_{x}(O S L)\right)$. In that way, the curve $O S L_{r e f}\left(\phi_{u p}\right)$, is still not needed to lunch the model. Following this approach, any non-linear programming solver can be used to fit the equivalence parameter of each species involved by minimizing a certain cost-function. In particular, in this work the root mean square of the prediction of each chemical species has been used. 

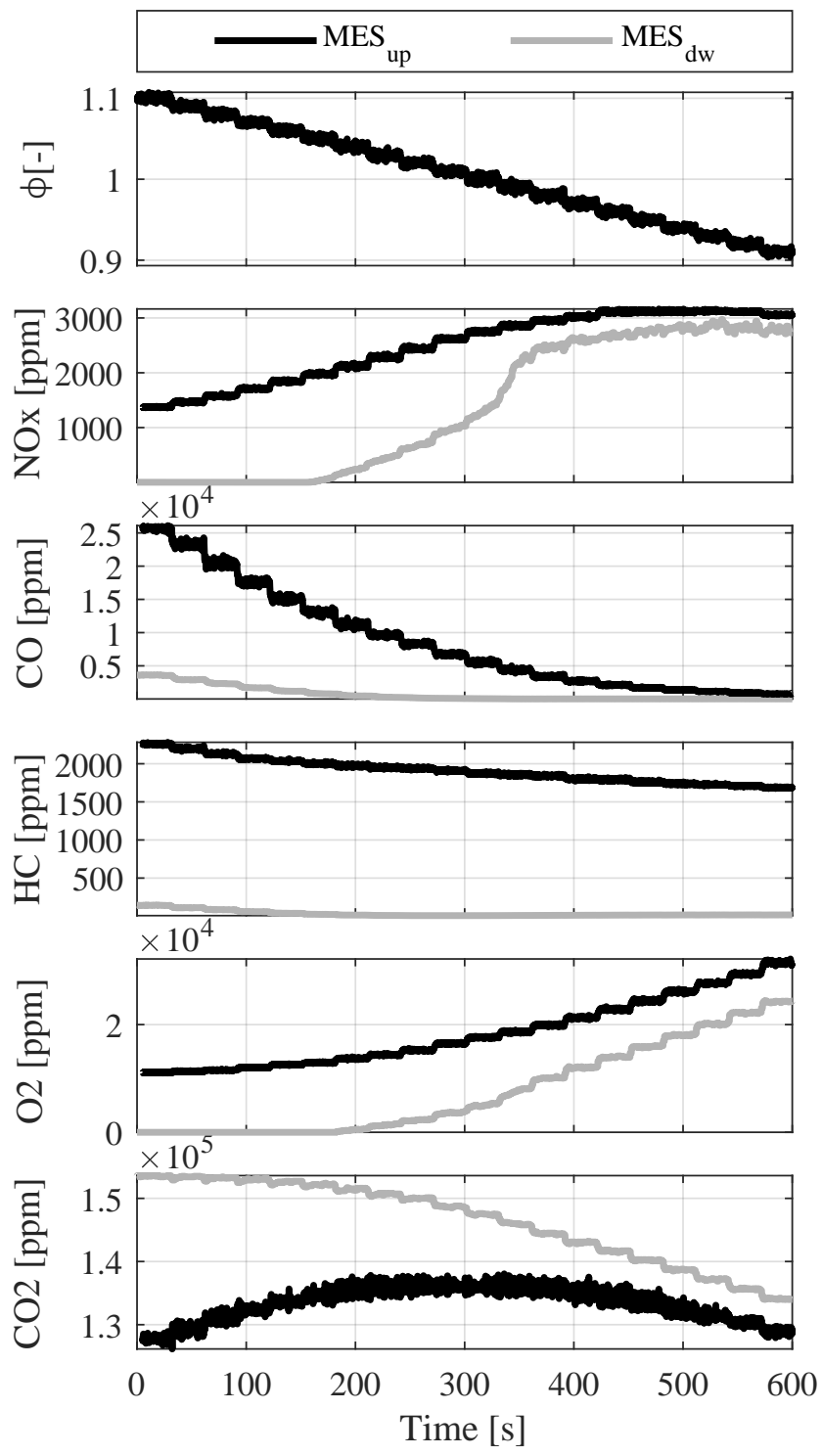

Figure 4.16: Example of catalyst window test at $1250 \mathrm{rpm}$ and $25 \mathrm{Nm}$ with fresh $\boldsymbol{T} \boldsymbol{W} \boldsymbol{C} . \mathrm{MES}_{\mathrm{up}}$ and $\mathrm{MES}_{\mathrm{dw}}$ represent measurements upstream and downstream of the TWC respectively 
Step 2: Downstream narrowband $\lambda$ sensor parameters

Once obtained the equivalence parameters $\left(\kappa_{x}\right)$, the fitting process of the six parameters used in the downstream narrowband $\lambda$ sensor sub-model is analogous to the previous one. The curves $\mu_{x}(O S L)$ and $O S L_{r e f}\left(\phi_{u p}\right)$ are still unknown, thereby experimental conversion efficiency curves depending on $\phi$ upstream the catalyst are imposed again. The only difference is that in this case both TWC model outputs NOx and CO are the inputs of this sub-model, hence the equivalence parameters $\left(\kappa_{x}\right)$ previously obtained are needed in this step. The proper $\lambda$ sensor parameters will be those that minimize the error between the model estimation of the $\phi$ voltage downstream of the TWC and the actual measurement during the catalyst window test.

Step 3: $O S L_{r e f}(\phi)$ and $\mu_{x}(O S L)$ calibration

With the aid of wideband $\lambda$ sensors upstream and downstream the catalyst, the last one properly corrected, the OSC has been measured experimentally by integrating the oxygen stored during the filling process, that is, during the rich to lean step. This approach is further explained in chapter 7. From this OSC experimentally measured, a preliminary estimation of the curves $O S L_{r e f}(\phi)$ and $\mu_{x}(O S L)$ with $x \equiv$ $\left\{\mathrm{HC}, \mathrm{NO}_{\mathrm{x}}, \mathrm{CO}, \mathrm{O}_{2}\right\}$ is needed. The former can be estimated by imposing a linear correlation between $\phi$ upstream TWC and OSL. For example, guessing that the maximum OSL is achieved for the minimum $\phi$ and vice versa. Again considering that adsorption rates behaves as conversion efficiency rates when all the adsorbed mass reacts, a preliminary estimation of the adsorption rate of each species as function of OSL $\left(\mu_{x}(O S L)\right)$ can be obtained. However, experimental conversion efficiency rates are not function of OSL, but function of $\phi$. Therefore, for the first iteration, the experimental conversion efficiency curves of the catalyst window test as function of $\phi$ upstream TWC can be used as function of OSL by using the previous estimation of the curve $O S L_{r e f}(\phi)$ in order to obtain an estimation of the aforementioned curve $\mu_{x}(O S L)$.

To properly calibrate both curves, an iterative process is proposed (figure 4.15). In this case, several experimental dynamic tests have been used, 

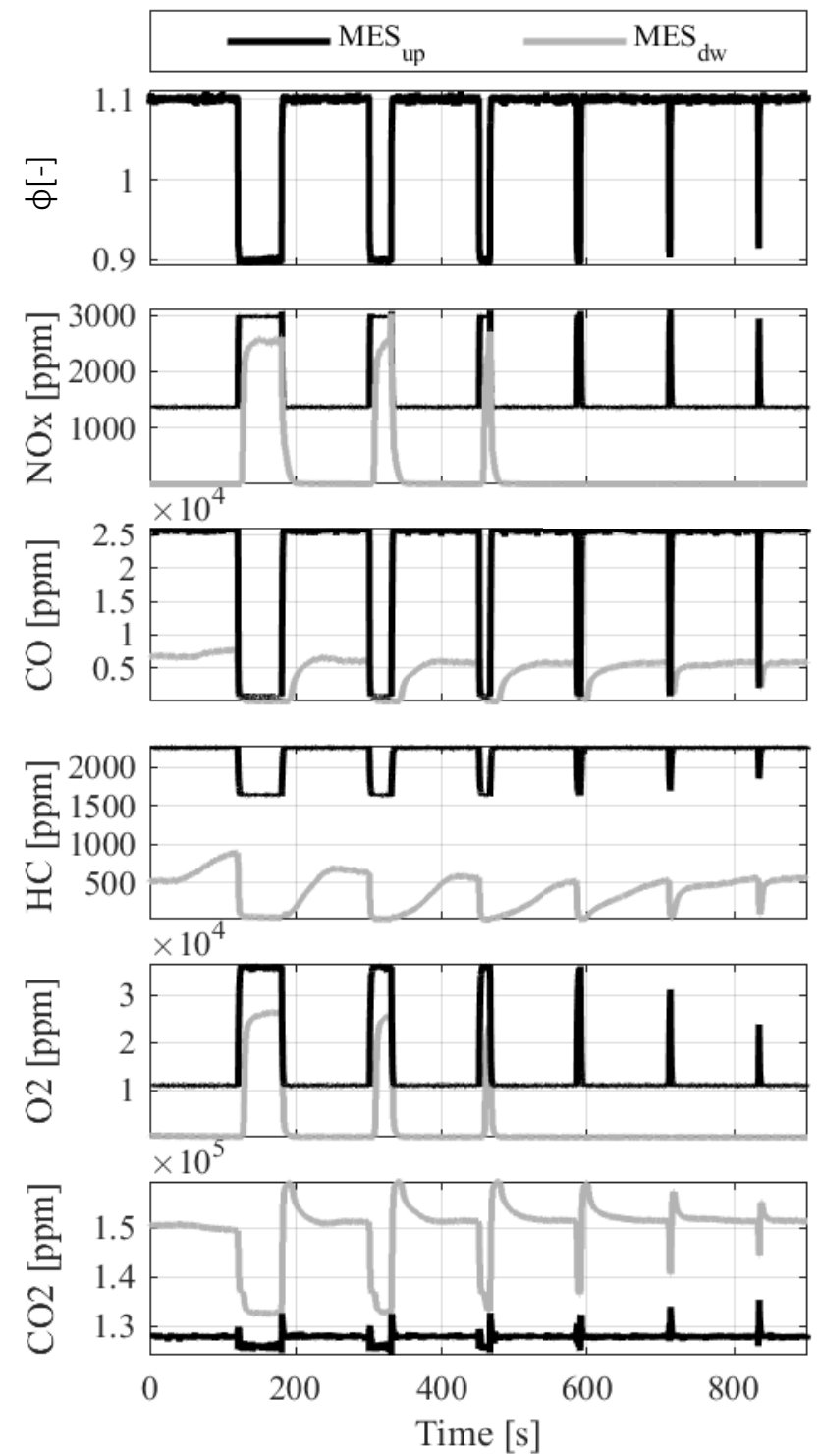

Figure 4.17: Example of dynamic storing test at $1250 \mathrm{rpm}$ and $25 \mathrm{Nm}$ with fresh $\boldsymbol{T} \boldsymbol{W} \boldsymbol{C} . \mathrm{MES}_{\mathrm{up}}$ and $\mathrm{MES}_{\mathrm{dw}}$ represent measurements upstream and downstream of the TWC respectively 
as the one shown in figure 4.17 (hereinafter referred as dynamic storing test). These tests consist of several $\phi$ steps with decreasing period at lean conditions, always between the same upper and lower thresholds in terms of $\phi$. The idea is to impose progressively shorter filling processes beginning with same depleting level. Then repeating the test for different thresholds to completely sweep the interesting range of $\phi$ and OSL. These dynamic storing tests allow to fit properly the curve $O S L_{r e f}(\phi)$ (until now just an initial estimation of this curve had been proposed), which in turn allows to fit the dynamic behaviour of the model. Since the adsorption curves depend on OSL an iterative process can be performed, updating the adsorption curves $\left(\mu_{x}(O S L)\right)$ with the last version of the aforementioned curve $O S L_{r e f}(\phi)$. Finally, this iterative process can be repeated again by using the proposed dynamic storing tests until a good match between model outputs and corresponding measurements is reached. For this step, the cost function must take into account the error in the estimation of at least one oxidizing and one reducing species, for example $\mathrm{NO}_{\mathrm{x}}$ and $\mathrm{CO}$ respectively.

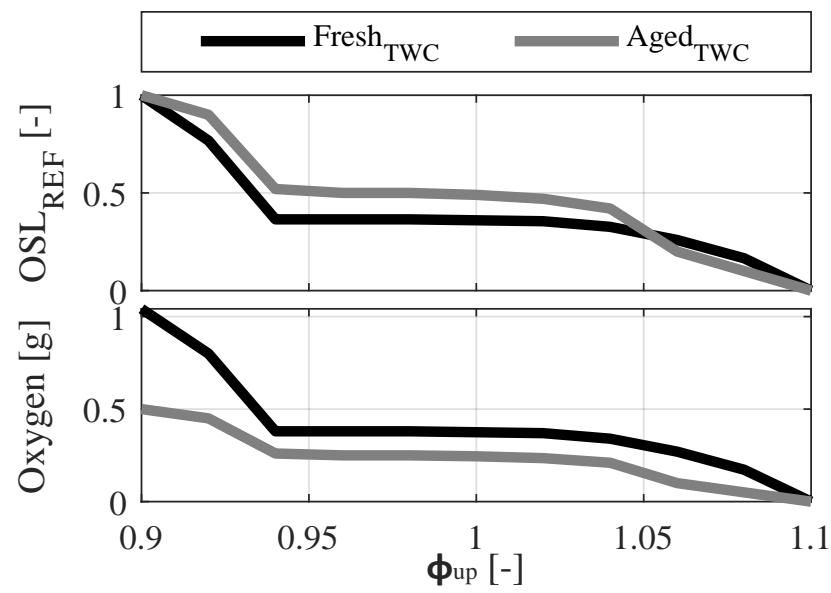

Figure 4.18: Curve $O S L_{\text {ref }}$ (top) and oxygen stored (bottom) for 1250 rpm and low load $\left(25 \mathrm{Nm}\right.$ ) with fresh (Fresh $\mathrm{TWC}_{\mathrm{TC}}$ ) and aged (Aged ${ }_{\mathrm{TWC}}$ ) converters respectively

Figure 4.18 shows the calibration curve $O S L_{r e f}(\phi)$ obtained for the same operating conditions with both the fresh and the aged catalysts. At very lean conditions the catalyst can be completely filled, however, at 
rich conditions its capability to store oxygen is almost null as expected. Within this $\phi$ range, the storing capabilities decrease from lean to rich in a non-linear way, showing a flat plateau around stoichiometric conditions. The shape of these curves is alike, although the ageing level of each catalyst is different, which indicates that the behaviour of both TWC is similar, and the main differences lie in the total OSC as well as in the relative OSL reached for the same exhaust gas composition.

Figure 4.19 shows the result of the fitting process for the dynamic storing test with the aged TWC at $1250 \mathrm{rpm}$ and low load $(25 \mathrm{Nm})$. The fitting process cannot improve the small discrepancies that this figure shows between model outputs and experimental data. In spite of this, the model represent the dynamics of the TWC in transient phase and allows to quantify the concentration of the main pollutant emissions and the downstream narrowband $\lambda$ sensor reasonably. Therefore, the model could be a good estimator of the oxygen storing level. In the case of $\mathrm{CO}$ and $\mathrm{HC}$, the model dynamics during lean to rich steps is faster than experimental results, which could be due to the lack of longitudinal discretization of the model. To take into account this effect, the number of nodes could be increased since currently the model only accounts for one node. The narrowband $\lambda$ sensor model also fits well with experimental data although a bias error appears at rich conditions, considering the $\mathrm{H}_{2}$ effect on $\lambda$ sensor could solve this issue but increasing also the model complexity.

\section{Experimental validation}

Experimental measurements at steady and dynamic conditions of two TWCs with different ageing level have been carried out, for each one, several operating conditions have been assessed. Tables 4.2 and 4.3 summarizes the test used to fit and validate the model respectively.

The parameters related with TWC performance at steady state (Steps 1 and 2 of the fitting process in figure 4.15), that is, the four equivalence parameters $\left(\kappa_{x}\right)$ as well as the six parameters of the narrowband $\lambda$ sensor model, are valid for any operating condition. Of course, the OSC must be obtained experimentally for the corresponding ageing level of the TWC. 

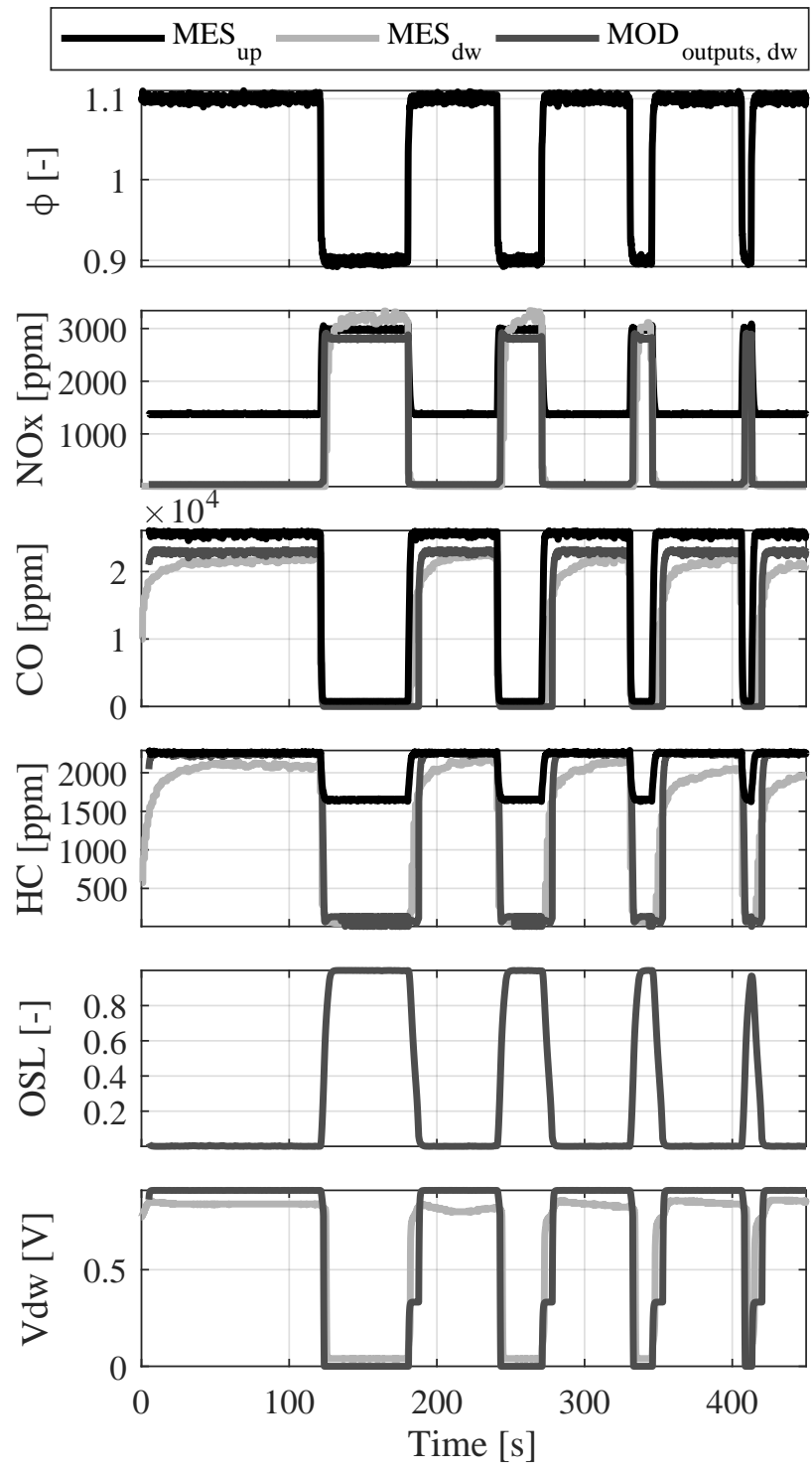

Figure 4.19: Example of the results obtained with the model fitting process. Dynamic storing test at $1250 \mathrm{rpm}$ and $25 \mathrm{Nm}$ with aged $\boldsymbol{T} \boldsymbol{W C} . \mathrm{MES}_{\mathrm{up}}, \mathrm{MES}_{\mathrm{dw}}$ and $\mathrm{MOD}_{\text {outputs,dw }}$ represent measurements upstream of the TWC, measurements downstream of the TWC and model outputs downstream of the TWC respectively. 


\begin{tabular}{clcc}
\hline Param. & Test & Op. cond. & TWC \\
\hline$\kappa_{x}, \lambda$-sensor & $\begin{array}{l}\text { catalyst } \\
\text { window }\end{array}$ & $1250 \mathrm{rpm}-25 \mathrm{Nm}$ & fresh \\
$O S L_{r e f}, \mu_{x}$ & $\begin{array}{l}\text { dynamic } \\
\text { storing }\end{array}$ & $1250 \mathrm{rpm}-25 \mathrm{Nm}$ & fresh \\
$O S L_{r e f}, \mu_{x}$ & $\begin{array}{l}\text { dynamic } \\
\text { storing } \\
\text { dynamic }\end{array}$ & $2500 \mathrm{rpm}-75 \mathrm{Nm}$ & fresh \\
$O S L_{r e f}, \mu_{x}$ & $\begin{array}{l}\text { dyn - 25 Nm } \\
\text { storing } \\
\text { dynamic } \\
\text { storing }\end{array}$ & $2500 \mathrm{rpm}-75 \mathrm{Nm}$ & aged \\
& & \\
\hline
\end{tabular}

Table 4.2: Tests for model fitting

\begin{tabular}{clcc}
\hline Param. & Test & Op. cond. & TWC \\
\hline$\kappa_{x}, \lambda$-sensor & $\begin{array}{l}\text { catalyst } \\
\text { window }\end{array}$ & $1250 \mathrm{rpm}-25 \mathrm{Nm}$ & aged \\
$\kappa_{x}, \lambda$-sensor & $\begin{array}{l}\text { catalyst } \\
\text { window }\end{array}$ & $2500 \mathrm{rpm}-75 \mathrm{Nm}$ & aged \\
$\kappa_{x}, \lambda$-sensor & $\begin{array}{l}\text { catalyst } \\
\text { window }\end{array}$ & $2500 \mathrm{rpm}-75 \mathrm{Nm}$ & fresh \\
$O S L_{r e f}, \mu_{x}$ & $\begin{array}{l}\text { random } \\
\phi \text { steps }\end{array}$ & $1250 \mathrm{rpm}-25 \mathrm{Nm}$ & fresh \\
$O S L_{\text {ref }}, \mu_{x}$ & $\begin{array}{l}\text { TWC } \\
\text { purge }\end{array}$ & $2500 \mathrm{rpm}-75 \mathrm{Nm}$ & aged \\
\hline
\end{tabular}

Table 4.3: Tests for model validation 
In this regard, the figures $4.20,4.21$ and 4.22 show the model validation in the catalyst window test for different ageing levels and operating conditions. All of them have been simulated by using exactly the same calibration for the equivalence parameters $\left(\kappa_{x}\right)$ and for the parameters of the $\lambda$ sensor model, since the Step 1 and 2 of the fitting process have been carried out by using the catalyst window test at $1250 \mathrm{rpm}$ and low load $(25 \mathrm{Nm})$.

Due to the simplicity of the chemical approach followed in this controloriented model (remember that water-gas shift and steam-reforming reactions have been neglected), the model outputs show some discrepancies regarding the experimental measurements. These model errors are especially relevant for the fresh TWC (figure 4.20) at very rich conditions. The issue lies in the fact that the oxygen demand of a fresh catalyst is strongly different when comparing rich with lean conditions. Thus if the equivalence parameter for hydrocarbons to equivalent oxygen $\left(\kappa_{\left(\mathrm{HC} \rightarrow \mathrm{O}_{2}\right)}\right)$ is such that it allows to reach the oxygen level needed to fulfil the oxidation capabilities at lean conditions, then the oxygen availability upstream of the catalyst is not enough at rich conditions and vice versa. It happens mainly with the fresh TWC since the effects of water-gas shift and steam-reforming reactions tend to get deactivated with ageing, thus its oxidation capabilities are higher than the ones of the aged catalyst. In this sense, figures 4.21 and 4.22 show how the aforementioned issue is almost negligible when an aged catalyst is modelled.

The loss of performance in terms of $\mathrm{NO}_{\mathrm{x}}$ reduction at rich conditions is a behaviour observed experimentally in the aged catalyst that the model is not able to represent. The impact of this effect is small as shown in figure 4.22 , however, this kind of chemical deactivation is not considered in the current model.

Despite these two effects, which appear at very rich conditions, the overall model performances at steady state are good. The main effort has been focused on achieving accurate results around stoichiometric conditions, where the transition between rich and lean behaviour shows up. $\mathrm{NO}_{\mathrm{x}}$, $\mathrm{CO}$ and $\mathrm{HC}$ estimations are accurate enough for the implementation to which the model is oriented, that is, control purposes. The model reflects 

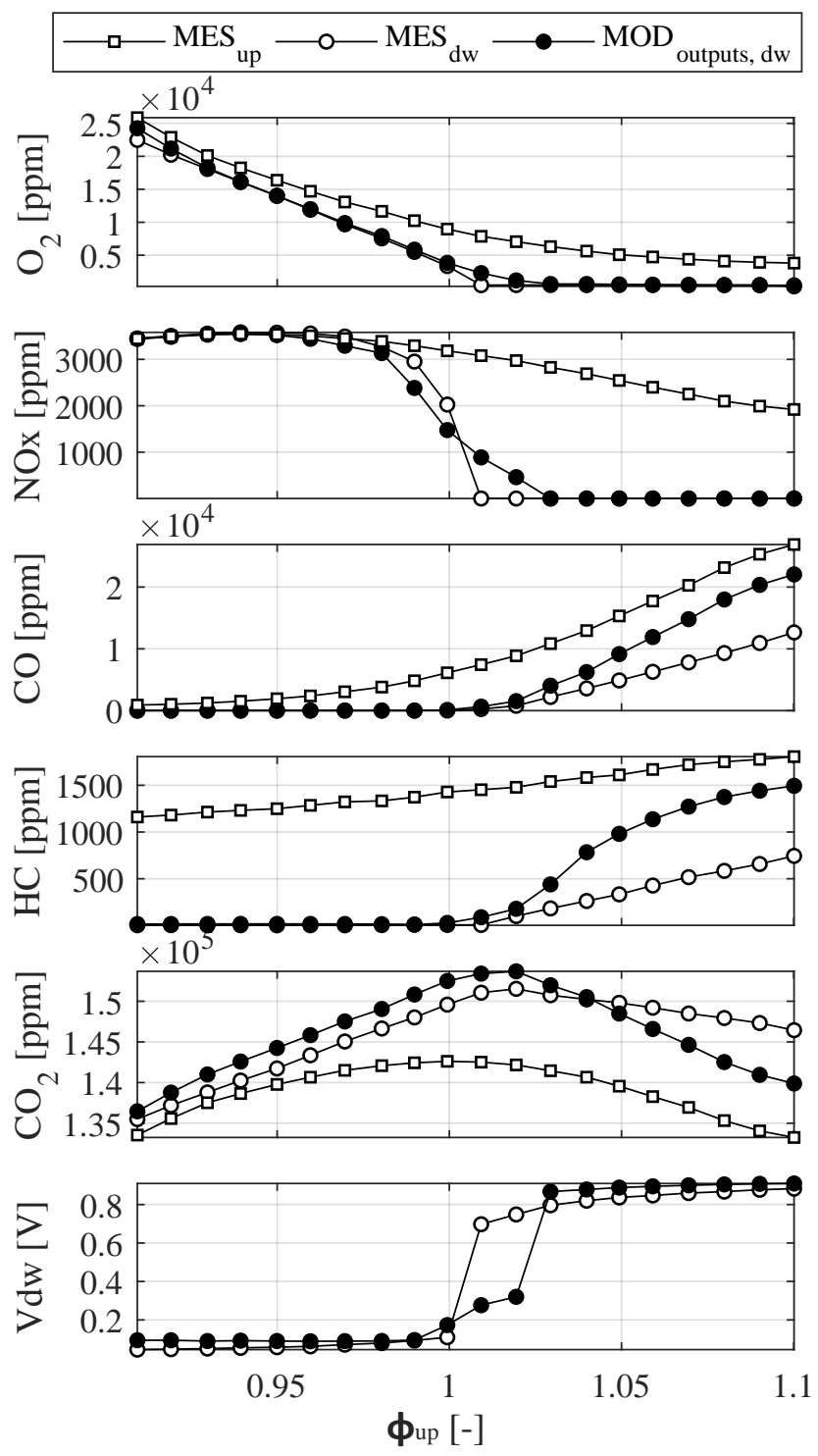

Figure 4.20: Model validation. Catalyst window test at $2500 \mathrm{rpm}$ and low-mid load $\left(75 \mathrm{Nm}\right.$ ) with the fresh $\boldsymbol{T} \boldsymbol{W C} . \mathrm{MES}_{\mathrm{up}}, \mathrm{MES}_{\mathrm{dw}}$ and $\mathrm{MOD}_{\text {outputs,dw }}$ represent measurements upstream of the TWC, measurements downstream of the TWC and model outputs downstream of the TWC respectively 

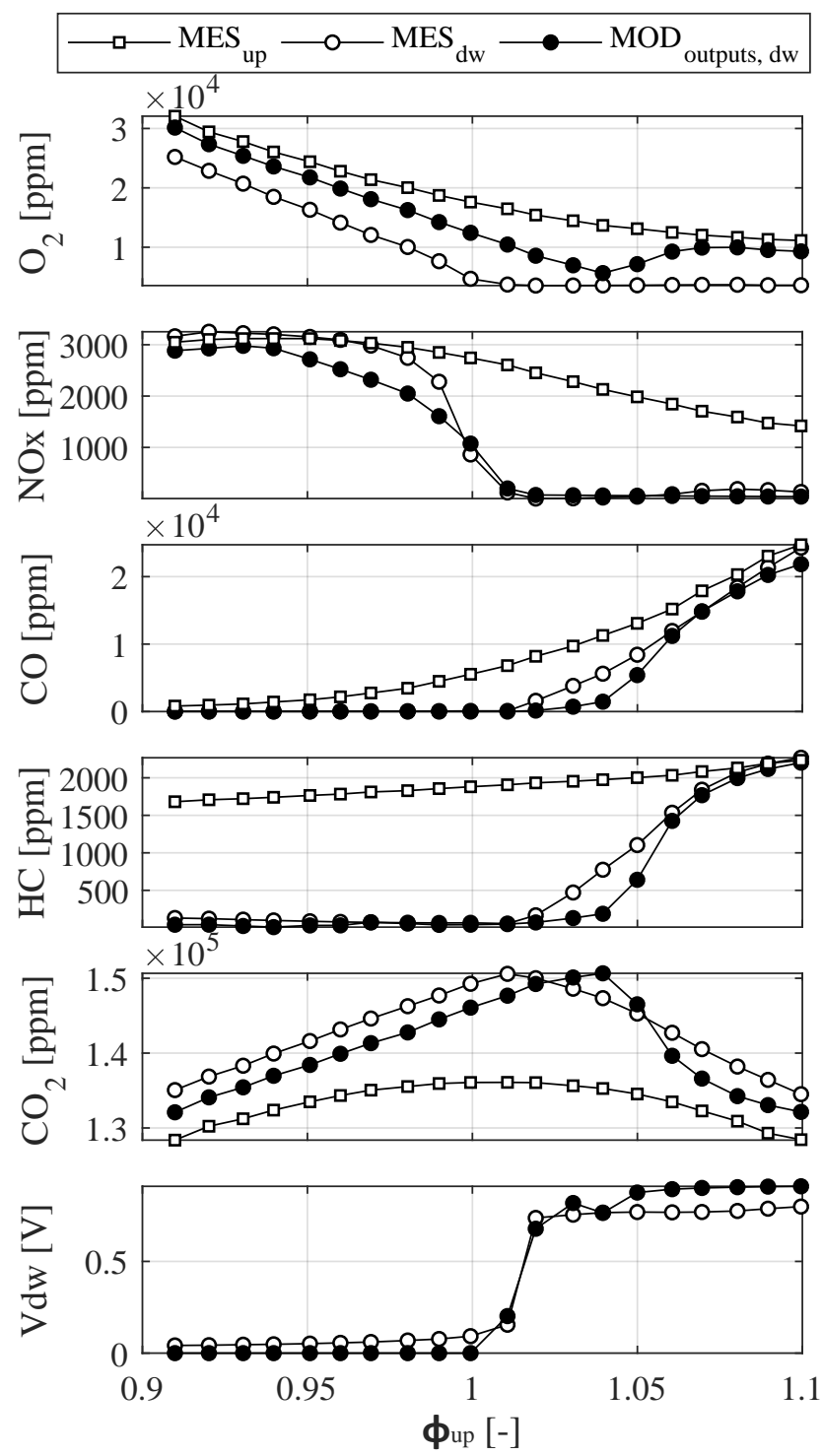

Figure 4.21: Model validation. Catalyst window test at $1250 \mathrm{rpm}$ and low load (25 $\boldsymbol{N m}$ ) with aged $\boldsymbol{T} \boldsymbol{W C}$. $\mathrm{MES}_{\mathrm{up}}, \mathrm{MES}_{\mathrm{dw}}$ and $\mathrm{MOD}_{\text {outputs,dw }}$ represent measurements upstream of the TWC, measurements downstream of the TWC and model outputs downstream of the TWC respectively 

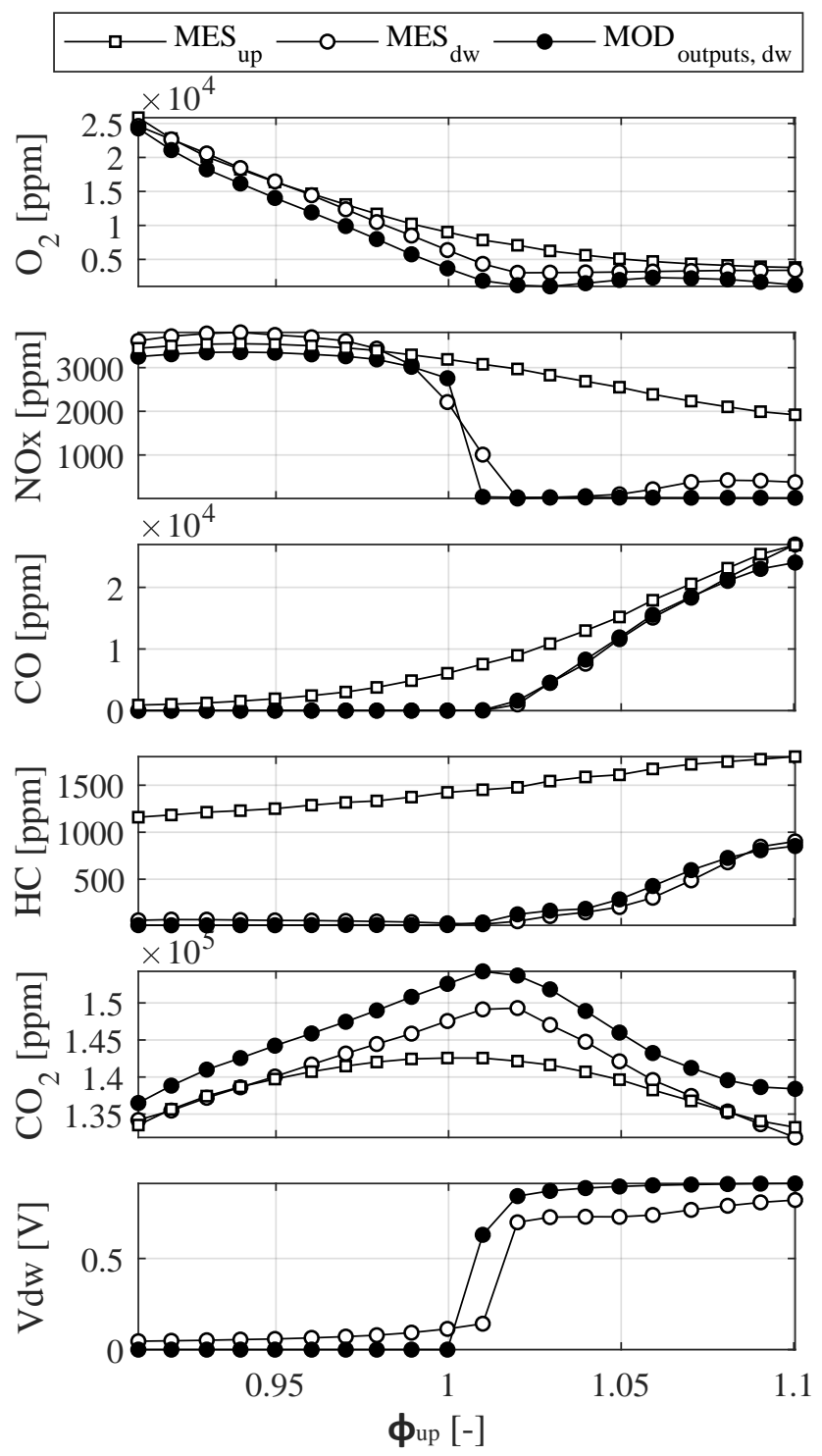

Figure 4.22: Model validation. Catalyst window test at $2500 \mathrm{rpm}$ and low-mid load $\left(75 \mathrm{Nm}\right.$ ) with aged $\boldsymbol{T} \boldsymbol{W C} . \mathrm{MES}_{\mathrm{up}}, \mathrm{MES}_{\mathrm{dw}}$ and $\mathrm{MOD}_{\text {outputs,dw }}$ represent measurements upstream of the TWC, measurements downstream of the TWC and model outputs downstream of the TWC respectively 

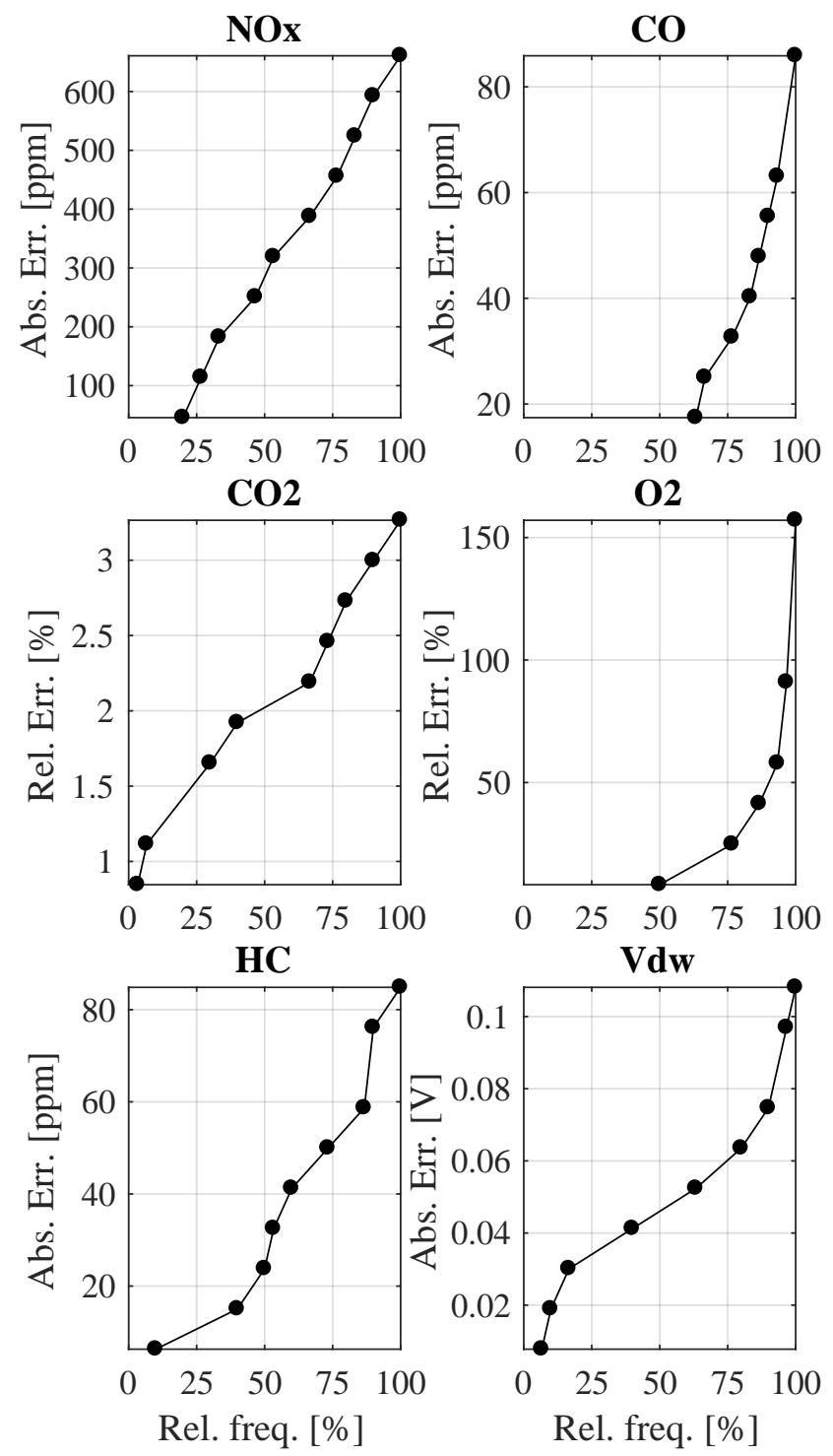

Figure 4.23: Model validation. Error metrics for lean range at steady conditons. $\mathrm{X}$-axis represent the cumulative relative frequency. $\mathrm{Y}$-axis represent the error between measurements and model outputs at catalyst outlet, in terms of absolute error for top and bottom rows as well as in terms of relative error for mid row 

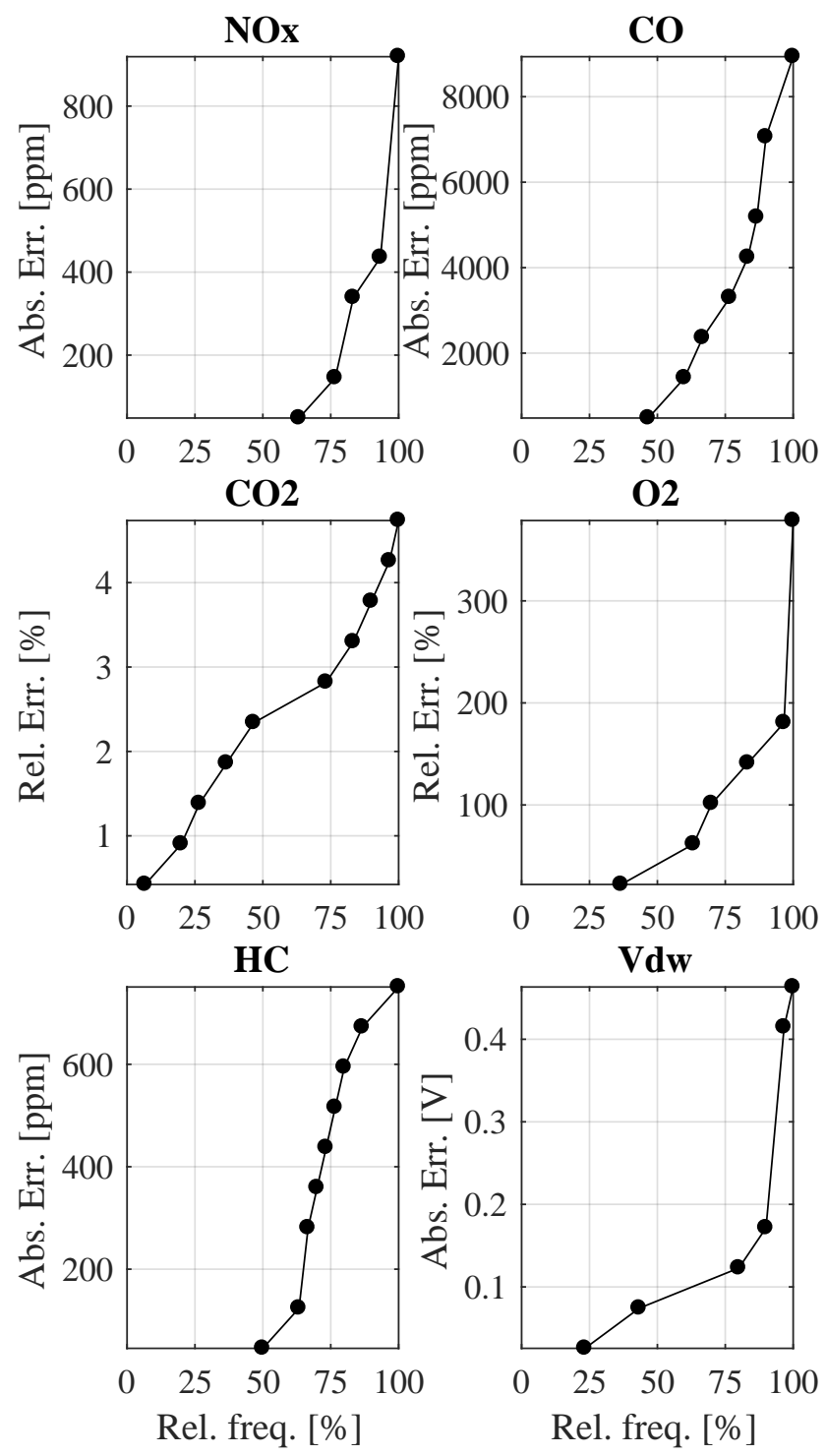

Figure 4.24: Model validation. Error metrics for rich range at steady conditons. $\mathrm{X}$-axis represent the cumulative relative frequency. $\mathrm{Y}$-axis represent the error between measurements and model outputs at catalyst outlet, in terms of absolute error for top and bottom rows as well as in terms of relative error for mid row 
properly the $\phi$ range at which the TWC is more active, as shown by the shape of the $\mathrm{CO}_{2}$ curve downstream of the catalyst.

In the same way, the $\lambda$ sensor model is able to predict correctly the catalyst behaviour in spite of the bias error at rich conditions. Due to the strong non-linearity of these sensors, providing an accurate value at steady when the sensor is in the switching range is really difficult, but the key lies in the fact that the model reflects properly the AFR where the transition happens, since it is fed with the concentration of $\mathrm{NO}_{\mathrm{x}}$ and $\mathrm{CO}$ provided by the converter model at the outlet.

Figures 4.23 and 4.24 show, for each species, the error distribution at steady state, that is, the percentage of samples with an error below a certain threshold for the lean and rich range respectively. $\mathrm{CO}_{2}$ and $\mathrm{O}_{2}$ errors, unlike the rest, are expressed in relative terms, since these species do no reach values near zero ppm at any AFR, with the only exception of $\mathrm{O}_{2}$ at very rich conditions. The main differences between lean and rich conditions are given for the reducing species, mainly because of the aforementioned calibration problems at rich conditions with the fresh TWC. The rest of parameters behaves in a similar way for all AFR tested.

Regarding the dynamic performance of the catalyst model, Figure 4.25 compares the model outputs with the data obtained in an experimental test with the fresh TWC, in which pseudo-random $\phi$ steps at low engine speed and load have been measured. This test reflects the potential of the model to aid in emissions control strategies, since it provides key information about the catalyst state, as well as on the margin available to correct a certain $\phi$ disturbance in time and quantifying the emissions penalty. The OSL together with the $\lambda$ sensor estimations allow to distinguish perfectly between tolerable and unacceptable $\phi$ steps.

Figure 4.26 shows a zoomed view of the same test. At the beginning, the system is working at lean conditions with an OSL around 1 until the moment at which a significant step towards rich is performed. Then, $\mathrm{NO}_{\mathrm{x}}$ emissions drop almost immediately while $\mathrm{CO}$ and $\mathrm{HC}$ remain low despite their increasing inlet values. The OSL shows a fast transition followed by another much slower. Just when the last one reaches steady conditions, $\mathrm{NO}_{\mathrm{x}}$ and $\mathrm{CO}$ emissions reach also their respective steady values and, as 

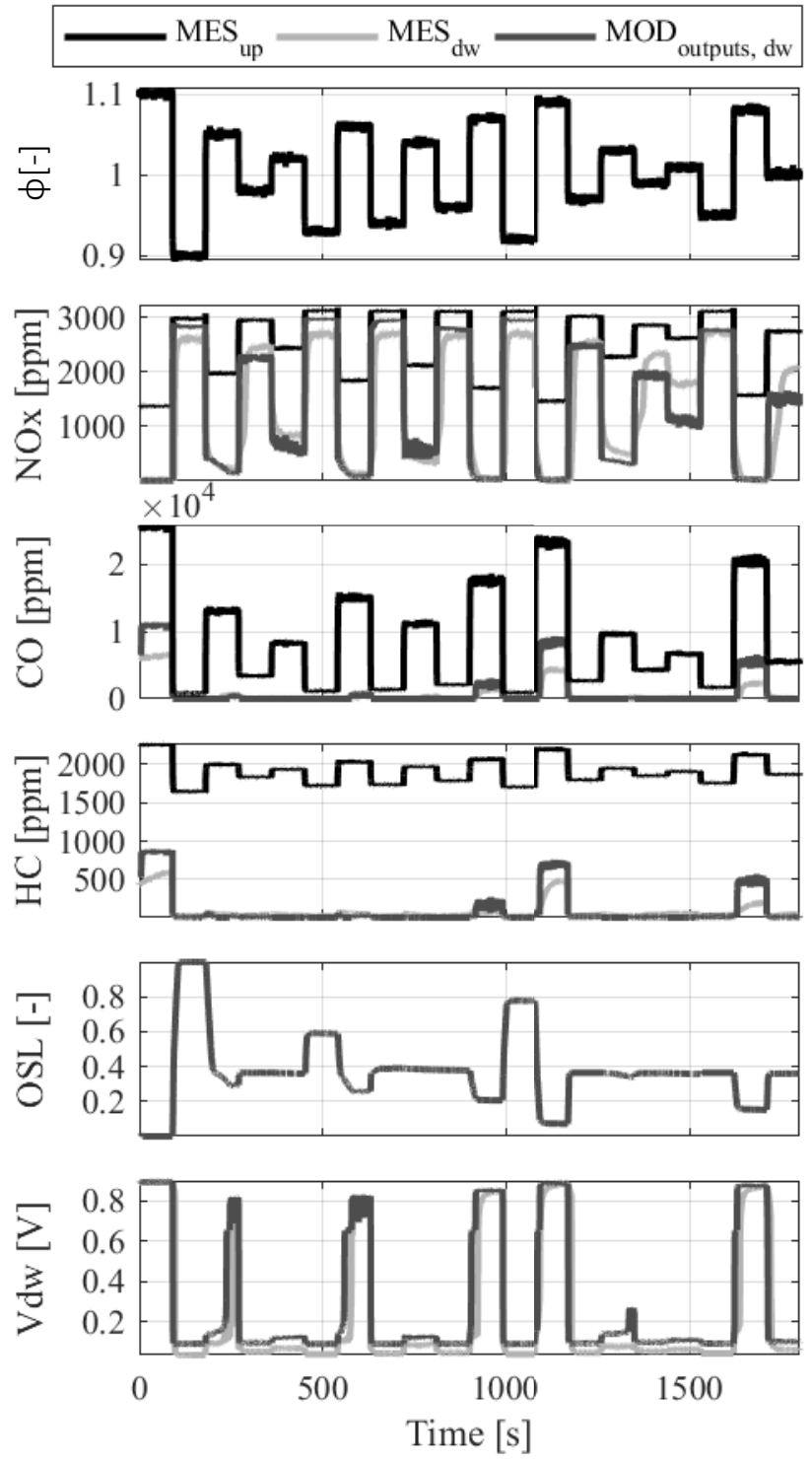

Figure 4.25: Model validation. Pseudo-random $\phi$ evolution test at $1250 \mathrm{rpm}$ and low load $\left(25 \mathrm{Nm}\right.$ ) using the fresh $\mathbf{T} \boldsymbol{W C}$. MES $\mathrm{up}_{\mathrm{up}}, \mathrm{MES}_{\mathrm{dw}}$ and $\mathrm{MOD}_{\text {outputs,dw }}$ represent measurements upstream of the TWC, measurements downstream of the TWC and model outputs downstream of the TWC respectively 

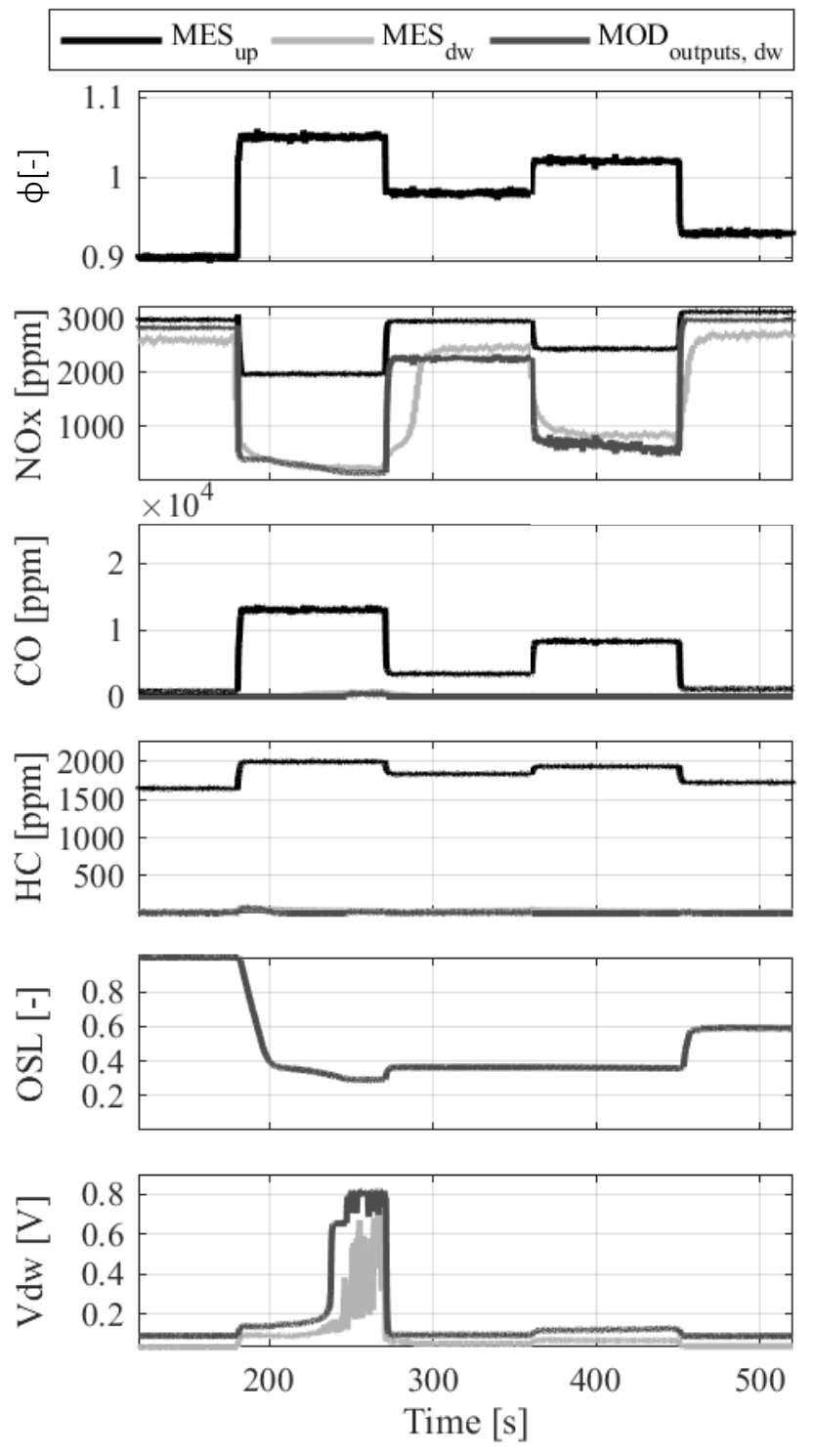

Figure 4.26: Model validation. Zoomed view of pseudo-random $\phi$ evolution test at $1250 \mathrm{rpm}$ and low load $\left(25 \mathrm{Nm}\right.$ ) with fresh $\mathbf{T} \boldsymbol{W C}$. MES $\mathrm{up}_{\mathrm{u}}, \mathrm{MES}_{\mathrm{dw}}$ and $\mathrm{MOD}_{\text {outputs,dw }}$ represent measurements upstream of the TWC, measurements downstream of the TWC and model outputs downstream of the TWC respectively 

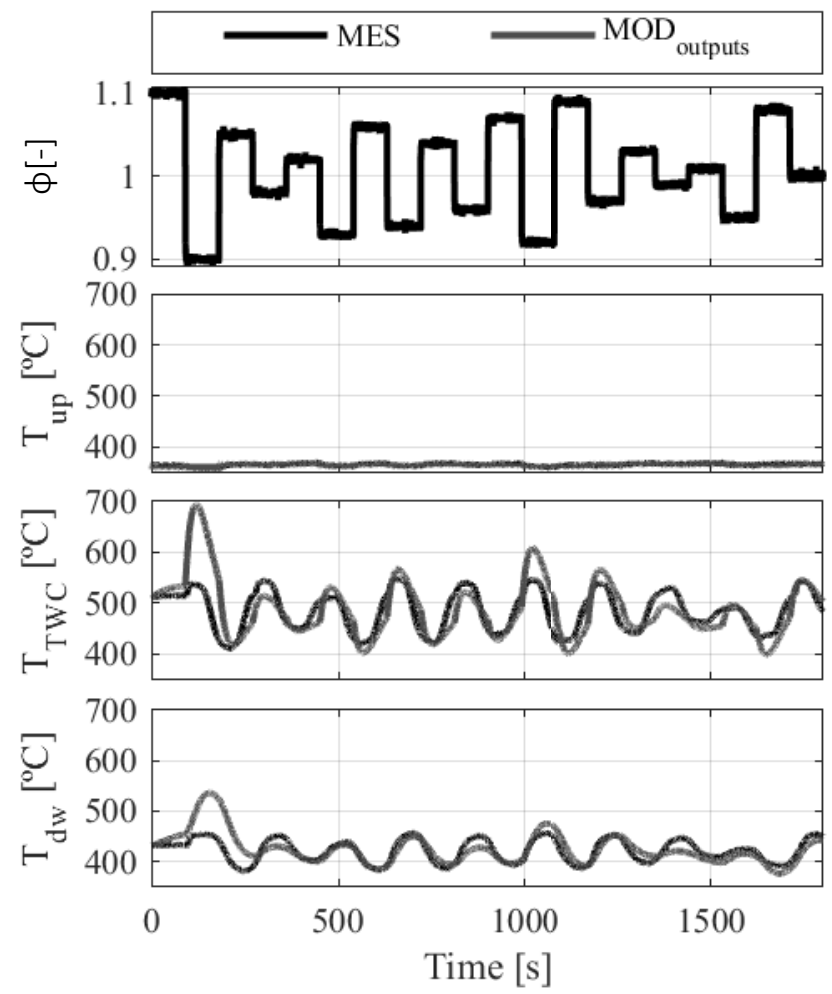

Figure 4.27: Model validation. Temperatures in pseudo-random $\phi$ evolution test at $1250 \mathrm{rpm}$ and low load (25 Nm) using the fresh $\mathbf{T W C}$. MES and MOD outputs represent measurements and model outputs respectively 
a consequence, the switch-type $\lambda$ sensor voltage increases strongly. After that, the additional rich and lean steps of lower amplitude do not affect in a remarkable way the OSL, as it happens with CO and HC emissions. However, these $\phi$ steps are strongly reflected on $\mathrm{NO}_{\mathrm{x}}$ emissions because there is not excess CO.

Figure 4.27 shows the temperature evolution during the same test. The impact of $\phi$ steps on inlet temperature is rather limited, hence it is almost constant around $380{ }^{\circ} \mathrm{C}$ during the whole test. However, brick temperature is markedly affected by $\phi$ evolution in both average and peak values regarding inlet values. The exothermic reactions tend to increase the average value since a certain amount of $\mathrm{HC}$ and $\mathrm{CO}$ is always being oxidized whatever the inlet AFR. In turn, oxygen storing involves temperature pulses during AFR transients, as a consequence of the simultaneous availability of reducing and oxidizing species in significant amounts. Finally, the outlet gas temperature follows the dynamic evolution imposed by brick temperature, but with reduced average values and amplitude oscillations due to heat losses to the environment as well as to the restricted residence time of the gas inside the TWC. The model is able to predict the overall behaviour although in some cases it overestimates or underestimates the actual temperature peaks. This lack of accuracy on temperature prediction is not crucial for the present approach, inasmuch as the temperature effect on catalyst performance is secondary in comparison with the oxygen storing and the inlet gas composition, at least for conditions above light-off temperature. 

Chapter 5

\section{Understanding of TWC \\ behaviour}

Contents

5.1 Oxygen storage in three-way catalyst $\ldots \ldots \ldots \ldots \ldots \ldots$

5.1 .1 TWC behaviour under AFR disturbances . . . . . . . . . . 96

5.1 .2 TWC behaviour during oxygen depletion process . . . . . . . . 100

5.2 Effects of fresh air short-circuit on the aftertreatment

system ........................104

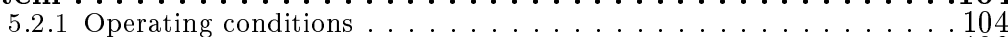

5.2 .2 Short-circuit effect on $\lambda$ sensor . . . . . . . . . . . . . . 106

5.2 .3 Short-circuit effect on three-way catalyst behaviour . . . . . . . . 114

5.3 Three-way catalyst behaviour during cold-start phase. . .122

5.3.1 Model adaptation . . . . . . . . . . . . . . . . . . . . . . . . . 123

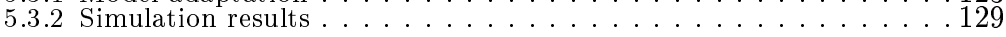




\subsection{Oxygen storage in three-way catalyst}

The oxygen storage is an interesting property of the TWC, since it imposes certain dynamics to the converter behaviour that can be helpful to isolate, until a certain extent, the tail pipe emissions from any unexpected event in terms of AFR upstream of the TWC. According to the TWC behaviour at steady state conditions, and simplifying the phenomena, it could be said that in a converter without oxygen storage an instantaneous deviation from stoichiometric conditions upstream the TWC has an immediate consequence in the converter efficiency, thus imposing a direct impact on tail pipe emissions, increasing either the reducing or the oxidizing emissions depending on the sense of the air-to-fuel ratio deviation. It is a direct consequence of the TWC window, that is, a consequence of the converter efficiency dependence on the proportion of the different species that compose the exhaust gas, which are usually characterized by $\phi$, the proportion of fuel and fresh air regarding the stoichiometric value. The current section focuses on the study of some particular situations, but at the same time very common in real driving conditions, on which the oxygen storage plays a key role for the proper control of the pollutant emissions.

\subsubsection{TWC behaviour under AFR disturbances}

In real driving conditions the accurate control of $\phi$ around stoichiometric conditions can become a difficult task. Due to different issues, some $\phi$ disturbances can happen during the normal engine operation. These disturbances can be due to $\lambda$ sensor errors or being related with engine speed or load transients, like wall-wetting effects of the injected fuel, the different paths of fresh air an fuel within the engine, the dynamics of the turbocharger or even its coupling with the exhaust gas recirculation (EGR) system among others. The oxygen storage helps to filter the consequences of the aforementioned $\phi$ excursions. However, the final impact depends on both the size of the $\phi$ disturbances (in terms of amplitude, duration and exhaust gas mass flow) and the oxygen storage capability of the converter. Of course increasing without boundaries the size of the TWC is not an option due to the strong restrictions in terms of cost, volume and weight in current passenger cars, but also because it has 
some noticeable drawbacks from the emissions point of view as it will be explained in next section.

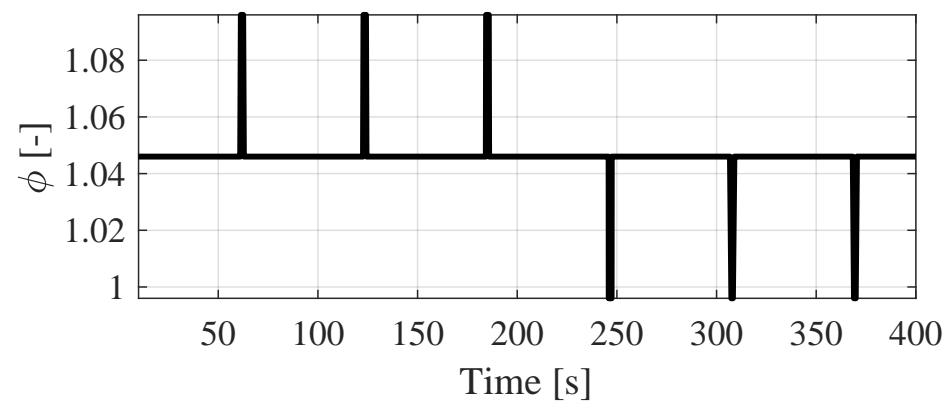

Figure 5.1: Example of experimental test to assess the impact of $\phi$ disturbances on emissions

A set of experimental test has been performed in the test bench in order to study the converter behaviour under $\phi$ disturbances. These tests focus on understanding and quantifying the effects so as to reduce the impact of fast rich and lean excursions. The tests consists of 60 seconds at steady state conditions with constant $\phi$, followed by a rich or lean disturbance of amplitude 0.05 artificially induced, and finally keeping again 60 seconds at steady, as shown in Figure 5.1. Disturbances with different durations have been assessed, from 0.5 to 1.5 seconds. This procedure has been repeated three times to take into account the test dispersion. The engine operating conditions are $2500 \mathrm{rpm}$ and $75 \mathrm{Nm}$ and the fresh TWC has been used. Moreover, the control-oriented model presented in section 4.2 has been implemented in the ECU to on-line monitor the oxygen storing level (OSL).

Figure 5.2 and 5.3 shows the impact of fast AFR disturbances on CO, $\mathrm{HC}$ and $\mathrm{NO}_{\mathrm{x}}$ emissions towards richer and leaner conditions respectively. When $\phi$ is kept at steady state the emissions remain low. Whatever the sense of the disturbance, it involves a simultaneous peak for the reducing species as well as a valley for the oxidizing species and vice versa. When a disturbance towards rich conditions appears (Figure 5.2), CO and $\mathrm{HC}$ emissions rise fast until reaching the maximum peak value a bit after the moment at which the disturbance disappears. However, the emissions take 10 seconds to reach again their steady state value. The 

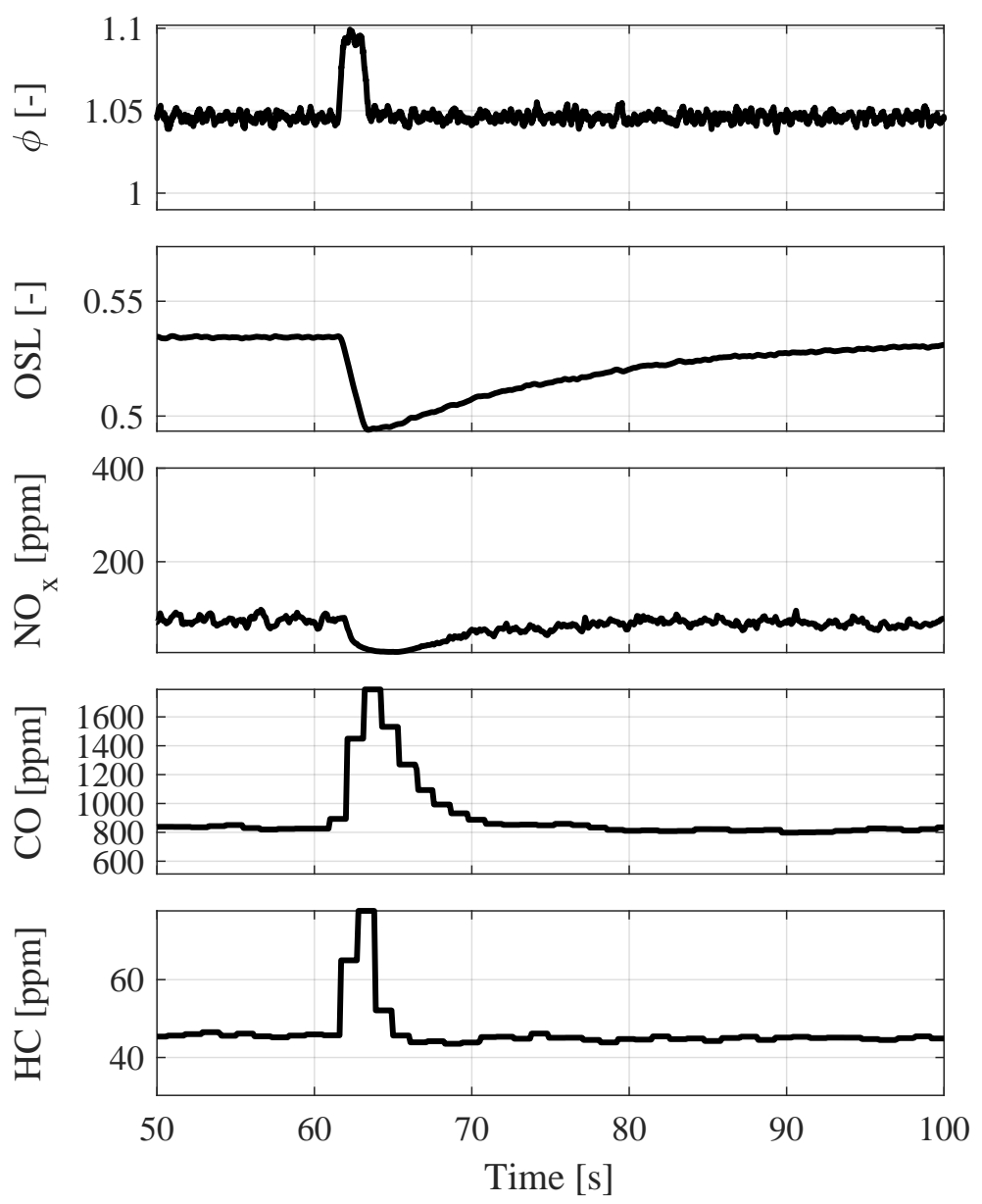

Figure 5.2: Impact of $\phi$ disturbance towards richer conditions on emissions 

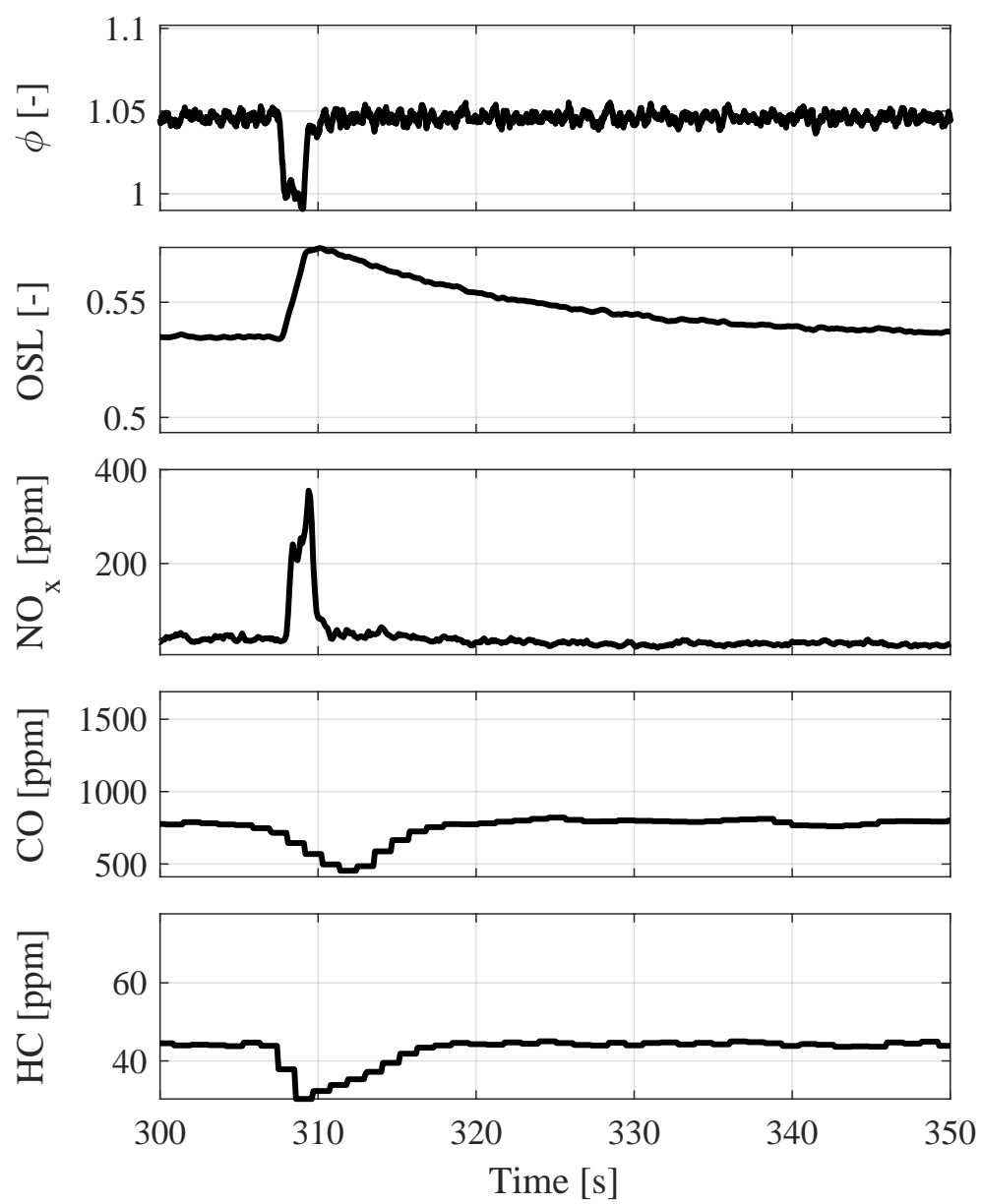

Figure 5.3: Impact of $\phi$ disturbance towards leaner conditions on emissions 
OSL profile provided by the on-line TWC model show a similar dynamic behaviour, decreasing fast because of the rich excursion and then recovering slowly its steady state value. It indicates that the CO efficiency is tightly related to the oxygen storage inside the converter, thus the OSL signal could be used to complement the AFR control strategy. Figure 5.3 shows the opposite case, the $\phi$ excursion imposes leaner AFR than required. Again $\mathrm{CO}$ and $\mathrm{HC}$ emissions evolve slower than $\phi$ as a consequence of the filtering effect of the TWC, although in this case the lean disturbance causes a valley in both species. However, $\mathrm{NO}_{\mathrm{x}}$ emissions show a different behaviour. The $\mathrm{NO}_{\mathrm{x}}$ peak decreases as soon as the $\phi$ disturbance disappears, which suggest a different mechanism, since the $\mathrm{NO}_{\mathrm{x}}$ reduction is mainly carried out by means of $\mathrm{CO}$ oxidation (equation 4.16) instead of $\mathrm{O}_{2}$ as expected.

\subsubsection{TWC behaviour during oxygen depletion process}

As explained in previous section, the oxygen storage plays a key role to improve the TWC performance under unexpected AFR excursions towards rich o lean conditions. However, the oxygen storage can also present some drawbacks under certain circumstances. In fact, it is an important issue during the sizing process for the proper coupling between engine and converter. One of the more common situations on which the oxygen storing of the TWC can be harmful from the emissions point of view is the so-called throttle tip-out/tip-in manoeuvre.

These manoeuvre is a usual driving situation in which the throttle is released during a short period of time while the vehicle is still moving due to its inertia. Thus fuel injection is cut off and the engine is pumping fresh air toward the exhaust, filling the converter with oxygen. Then, the driver press again the throttle to increase the vehicle speed, thus the engine load is recovered and the AFR must evolve from zero (injection cut-off) until the required set-point, allowing the TWC to reach a proper conversion efficiency. Effectively, during cut-off phases, fresh air passes through the TWC then increasing its OSL and afterwards, during the first fractions of the tip-in, the TWC which is full of $\mathrm{O}_{2}$ is not capable of reducing $\mathrm{NO}_{\mathrm{x}}$. Therefore, if the $\phi$ set-point $\left(\phi_{\mathrm{sp}}\right)$ is reached smoothly, a $\mathrm{NO}_{\mathrm{x}}$ penalty appears when fuel injection is re-established. However, $\mathrm{CO}$ 
emissions remain very low during the whole transient due to the oxygen availability. This $\mathrm{NO}_{\mathrm{x}}$ penalty is consequence of the low conversion efficiency of TWC when its vacancies are filled with oxygen, $\mathrm{NO}_{\mathrm{x}}$ reduction reaction is inhibited as a consequence of the lack of $\mathrm{CO}$ available.

The typical solution carried out by the manufacturers consists of calibrating the proper fuel enrichment just after the injection cut-off. In order to avoid $\mathrm{NO}_{\mathrm{x}}$ peaks after fuel cut-off phases, the oxygen level of the TWC needs to be reduced with rich exhaust gas. In that way, the oxygen excess stored inside the converter is depleted as fast as possible. As a counterpart, if the fuel enrichment is too strong, a penalty in $\mathrm{CO}$ emissions appears, besides the corresponding increase in fuel consumption. The fuel enrichment parametrisation is often implemented as a single step of a square wave, characterized with two parameters, the step amplitude $\left(\Delta \phi_{\mathrm{sp}}\right)$ and the step duration $(\Delta \mathrm{T})$, both dependent on the operating conditions. For a better understanding of this situation an specific test has been carried out in the test bench. The test focuses on simulating the throttle tip-out/tip-in manoeuvre to assess the fuel enrichment parametrisation strategy in an accurate way. Low air mass flows are imposed in these tests in order to extend the transient as much as possible (most critical conditions for $\mathrm{NO}_{\mathrm{x}}$ emissions). The operating point chosen is $1250 \mathrm{rpm}$ and $25 \mathrm{Nm}$. The engine is kept at steady state during 180 seconds before each tip-out, which lasts 10 seconds. Figure 5.4 shows an example.

This process is repeated three times to consider the test dispersion. When passing from injection cut-off to steady state conditions, different fuel enrichments are imposed in the $\phi_{\mathrm{sp}}$ profile. In particular, three different durations $(\Delta \mathrm{T})$ and amplitudes $\left(\Delta \phi_{\mathrm{sp}}\right)$ have been assessed, that is, $\Delta \mathrm{T}$ from 2 to 6 seconds and $\Delta \phi_{\mathrm{sp}}$ from 0.02 to 0.06 . Thereby, a total of nine combinations have been performed. Figure 5.5 shows a summary of the results obtained with this strategy, all repetitions of each test have been averaged to obtain more reliable conclusions.

Just at the beginning of the purging phase, a $\mathrm{NO}_{\mathrm{x}}$ peak of almost 3000 ppm can be observed when there is no fuel enrichment applied (black lines). This peak is mainly due to two different factors. On the one hand the aforementioned oxygen stored inhibits the reduction of $\mathrm{NO}_{\mathrm{x}}$. On the 


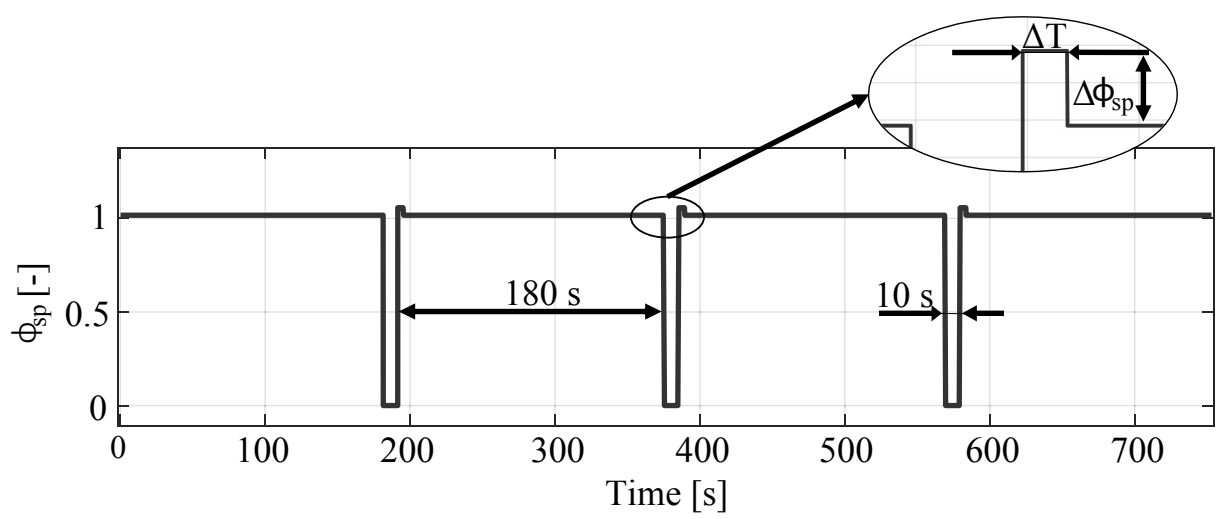

Figure 5.4: Example of experimental test to assess the TWC purge through fuel enrichment parametrization
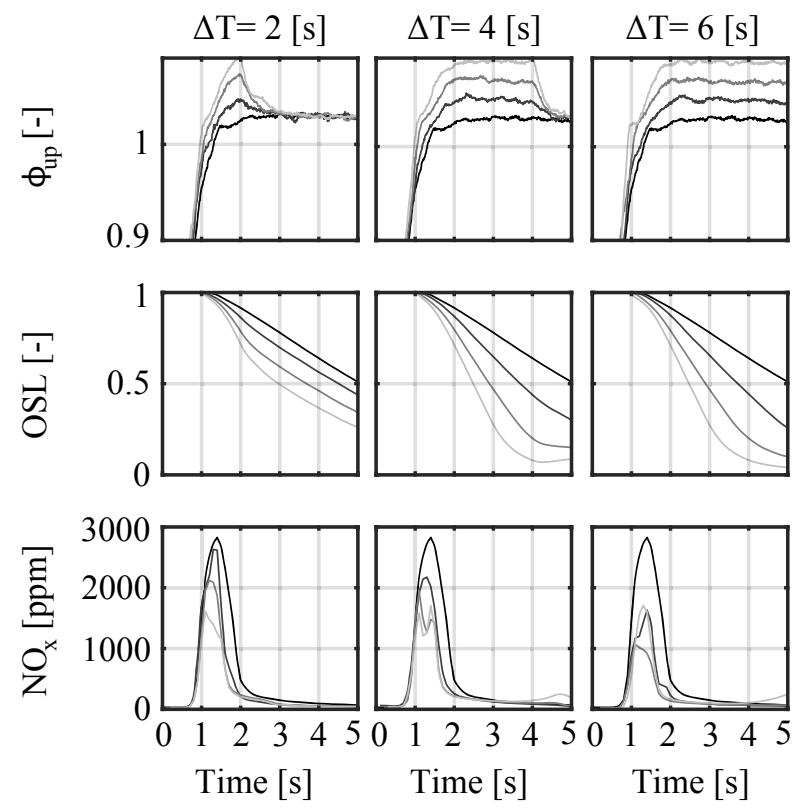

Figure 5.5: Trajectories obtained with the $\phi_{\text {up }}$ enrichment depending on $\Delta \mathrm{T}$ (in columns) and $\Delta \phi_{\mathrm{sp}}$ (in grayscale, ranging from 0 (black) to 0.06 (light grey) 
other hand, the elapsed time needed to pass through the lean range when coming from injection cut-off also contributes to increase the $\mathrm{NO}_{\mathrm{x}}$ emissions. The former can be solved with a proper fuel enrichment, however, the latter imposes a minimum $\mathrm{NO}_{\mathrm{x}}$ penalty that cannot be avoided even imposing stronger fuel enrichments or setting up a faster AFR controller. In this sense, there is an experimentally non-measurable threshold that once surpassed, leads to a CO penalty together with an useless increase in fuel consumption. In order to provide insights regarding that limit, the control-oriented model presented in section 4.2 has been used to obtain an on-line estimation of the OSL. The model predictions are included in Figure 5.5 for all the cases assessed. The $\mathrm{NO}_{\mathrm{x}}$ reduction is remarkable in comparison with the case without fuel enrichment. As expected, results show faster OSL reductions and a substantial reduction in $\mathrm{NO}_{\mathrm{x}}$ as $\Delta \phi_{\mathrm{sp}}$ increases. The effect of the time spent at high $\phi_{\text {up }}$ has less impact on the $\mathrm{NO}_{\mathrm{x}}$ reduction, in fact it may involve some penalty if high $\Delta \mathrm{T}$ is combined with high $\Delta \phi_{\text {sp }}$. The peak shown $(\approx 900 \mathrm{ppm})$ for the cases with higher fuel enrichment (light gray lines) is due to the unavoidable pass through the lean range until reaching the proper $\phi_{\mathrm{sp}}$ with the TWC filled of oxygen, despite the fact that higher $\Delta \phi_{\mathrm{sp}}$ involve faster transients.

The main disadvantage of this approach is the strong calibration effort required, since there is no an on-board sensor that provides any insight regarding the amount of oxygen that must be emptied. Thus, both fuel enrichment parameters $\Delta \mathrm{T}$ and $\Delta \phi_{\mathrm{sp}}$ must be calibrated depending on the operating conditions as well as on the duration of the injection cut-off. In order to solve this issue, a model-based strategy to properly control the TWC purge is proposed in section 6.2. 


\subsection{Effects of fresh air short-circuit on the aftertreatment system}

Pollutant emissions in SI engines are strongly dependent on the TWC efficiency, making indispensable an accurate AFR control [148]. In normal operation and according to the TWC operating principle, $\mathrm{HC}, \mathrm{CO}$ and $\mathrm{NO}_{\mathrm{x}}$ emissions can be reduced significantly only very close to stoichiometry. In this respect, the SC of fresh air affects the aftertreatment system performance in different ways depending on the in-cylinder AFR [229]. An excess of oxygen at TWC inlet is expected if the engine is operated at stoichiometric in-cylinder AFR under SC conditions. This oxygen excess will reduce the $\mathrm{NO}_{\mathrm{x}}$ conversion efficiency. On the contrary, keeping a rich in-cylinder AFR will lead to the simultaneous availability of oxygen and fuel inside the converter, then increasing its exothermic processes. Despite this operation can have positive effects, such as the increase in the $\mathrm{NO}_{\mathrm{x}}$ conversion efficiency of the TWC and the reduction of the catalyst light-off time, it should be controlled to prevent excessive temperatures that may damage the TWC.

Under this scope, the purpose of this section is to analyse the effect of the fresh air SC on both the $\lambda$ sensor measurement and TWC operation, to finally assess the SC impact on engine emissions. Regarding the nomenclature used to refer to the AFR, hereinafter $\phi$ stands for fuelto-air equivalence ratio in the sense of physical magnitude, $\phi_{\lambda}$ refers to the measurement of fuel-to-air equivalence ratio provided by the $\lambda$ sensor upstream the TWC (when measurements of downstream sensor are reported they are specifically indicated) and $\phi_{\mathrm{GA}}$ refers to the measurement of fuel-to-air equivalence ratio provided by the gas analyser of the test bench also upstream of the TWC.

\subsubsection{Operating conditions}

Since create the proper conditions to have SC is not feasible in all the engine operating conditions, the selected point to carry out all the test is $1750 \mathrm{rpm}$ and $65 \%$ load, that is, one belonging to low engine speed and high load area, where $\mathrm{SC}$ is feasible. Under these conditions, the air mass flow and fuel consumption are $90 \mathrm{~kg} / \mathrm{h}$ and $6.4 \mathrm{~kg} / \mathrm{h}$ respectively, while 
the engine provides a torque of $140 \mathrm{Nm}$. The valve overlaps imposed in this work are such that the maximum $\mathrm{SC}$ rate measured is always below $12 \%$ in order to keep the TWC under its thermal limits. The procedure followed to short-circuit some fresh air towards the exhaust consist of gradually increasing the valve overlap from $-21^{\circ}$ to $80^{\circ}$ crank angle, while the waste gate is progressively opened to keep the engine load constant, without exceeding the turbocharger surge limit nor reaching excessive TWC temperatures. In this way, seven valve overlap levels have been tested as shown in Table 5.1.

\begin{tabular}{cccc}
\hline $\begin{array}{c}\text { Valve } \\
\text { Overlap }\end{array}$ & $\begin{array}{c}\text { Waste } \\
\text { Gate }\end{array}$ & Nomenclature & $\begin{array}{c}\text { Averaged } \\
\text { SC rate }\end{array}$ \\
\hline$-21^{\circ}$ & 1 & $\mathrm{a}$ & $0.0 \pm 0.26 \%$ \\
\hline $24.9^{\circ}$ & 0.44 & $\mathrm{~b}$ & $0.8 \pm 0.34 \%$ \\
\hline $37.6^{\circ}$ & 0.43 & $\mathrm{c}$ & $1.9 \pm 0.37 \%$ \\
\hline $50.2^{\circ}$ & 0.405 & $\mathrm{~d}$ & $3.7 \pm 0.42 \%$ \\
\hline $59.9^{\circ}$ & 0.39 & $\mathrm{e}$ & $5.6 \pm 0.52 \%$ \\
\hline $69.6^{\circ}$ & 0.375 & $\mathrm{f}$ & $7.5 \pm 0.34 \%$ \\
\hline $80.1^{\circ}$ & 0.36 & $\mathrm{~g}$ & $9.5 \pm 0.66 \%$ \\
\hline
\end{tabular}

Table 5.1: Operating conditions including Valve Overlap, Waste Gate position and averaged SC measurements

The SC rates shown in Table 5.1 have been calculated by using the tracer gas method described in section 3.3.1, particularly, they are averaged values of different experimental measurements carried out for each position of both actuators, valve overlap and waste gate. Figure 5.6 shows the correlation between the SC measured and valve overlap imposed for 5 different $\phi$ levels, SC ranges from 0.8 up to around $9.5 \%$ when valve overlap is swept from levels "b" to "g". Besides the dispersion of the tracer gas method, it is considered accurate enough for the present approach, since it allows to quantify experimentally the different SC rates that corresponds to each valve overlap. Note that in these measurements there is not a clear influence of $\phi_{\mathrm{GA}}$ on the SC measured. In this sense, it can be considered that the $\mathrm{SC}$ depends mainly on the position of the VVT and the waste gate. 


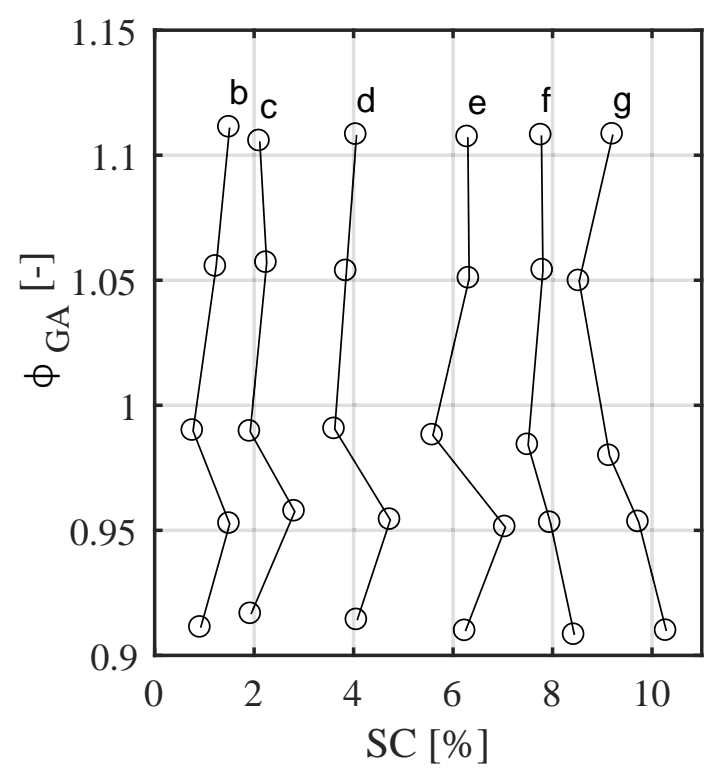

Figure 5.6: Short-circuit measurement.

\subsubsection{Short-circuit effect on $\lambda$ sensor}

Despite the exhaust gas analyser is provided with the composition of the fuel to calculate the AFR according to Brettschneider/Spindt method [212], some discrepancy may be expected due to the fact that two different sensors are used to measure the same variable. Figure 5.7 shows $\phi_{\lambda}$ upstream and downstream of the TWC against $\phi_{\mathrm{GA}}$ upstream for a wide range of AFRs, without $\mathrm{SC}$ and at steady state conditions. The upstream $\lambda$ sensor has a bias error almost constant for this AFR range when comparing with the corresponding measurements provided by the gas analyser, this kind of error is common for wide range $\lambda$ sensors [54, 92, 230]. However, as Figure 5.7 shows, the measurements of the downstream wideband $\lambda$ sensor are also affected by changes in gas composition due to the oxidizing-reducing capabilities of the catalyst [134, 152, 211, 222, $224,231,232$ ], that is why only measurements provided by the upstream $\lambda$ sensor are reported in the present study. 


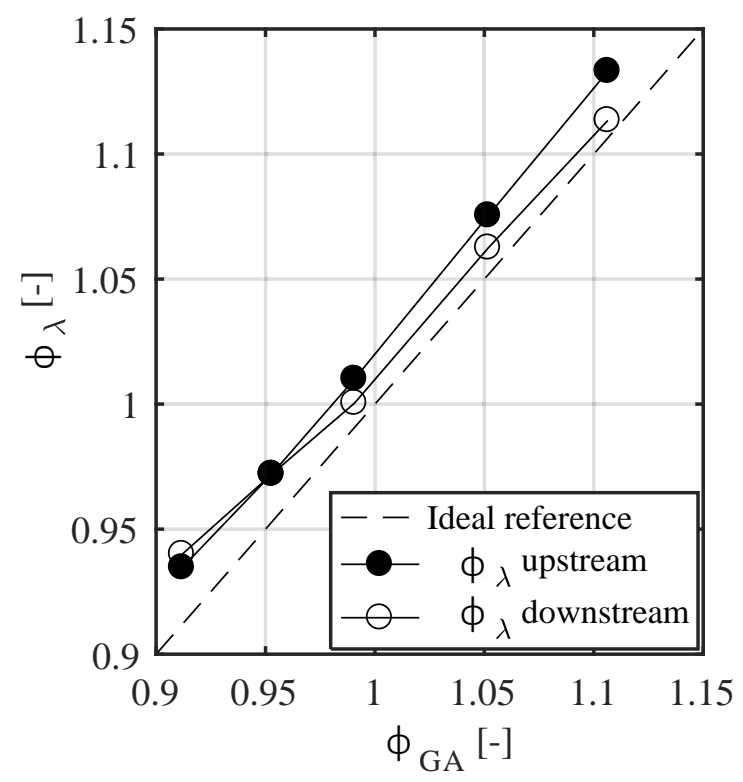

Figure 5.7: AFR measurements without SC

One important difference between both sensors is that, while the upstream $\lambda$ sensor suffers from the exhaust pulsating flow, with continuous changes in gas pressure, temperature and composition that may affect its reading, the volume and the filters before the exhaust gas analyser of the test bench prevent it from suffering these disturbances. In this sense, figure 5.8 shows the error provided by the $\lambda$ sensor $\left(\phi_{\lambda}\right)$ depending on the $\mathrm{SC}$ and the actual $\phi$ measured by the exhaust gas analyser $\left(\phi_{\mathrm{GA}}\right)$. It can be observed how, even in the absence of SC (black circles), there is a bias in the sensor reading of 0.025 that slightly increases with rising $\phi_{\lambda}$. According to some authors [53], this bias is due to non-equilibrium of the exhaust gas composition in the TWC inlet. In any case, this non-linearity in the relation between the actual AFR and that provided by the sensor will lead to an increment in the sensor bias as SC increases, since the rich and lean pulses increase. In fact, even though the $\phi_{\lambda}$ provided by the $\lambda$ sensor is identical for those points which are sharing the same solid line in figure 5.8, as $\mathrm{SC}$ rises their progressive shift towards lean conditions is evident according to $\phi_{\mathrm{GA}}$. Particularly, this effect could be due to the 


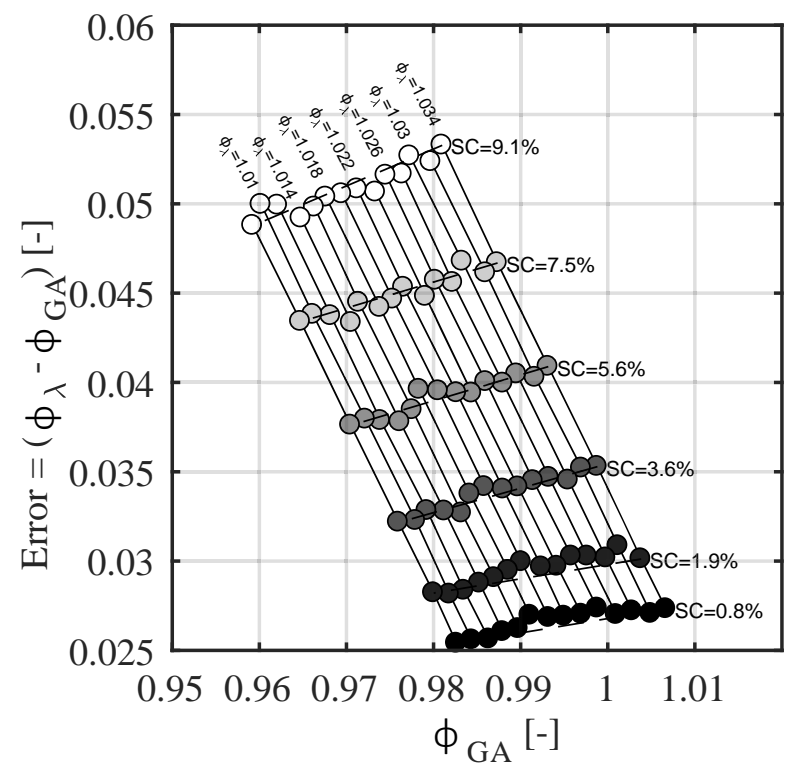

Figure 5.8: SC effect on the error between the $\phi_{\lambda}$ provided by the $\lambda$ sensor and the actual $\phi_{\mathrm{GA}}$ value provided by the exhaust gas analyser. Solid black lines join points with same $\phi_{\lambda}$ 
$\mathrm{CO}$ and $\mathrm{H}_{2}$ correlation with the wide range $\lambda$ sensor [222], because of the strong $\mathrm{CO}$ and $\mathrm{H}_{2}$ increase with $\mathrm{SC}$.

In addition to the non-linearity of the $\lambda$ sensor signal regarding AFR, some authors suggest that the dynamic response of the narrowband $\lambda$ sensor to AFR steps suffers from asymmetry [224]. This effect may also increase the bias in the wideband $\lambda$ sensor signal with SC as a consequence of the pulsating flow. In order to evaluate the effect of exhaust gas pulses on $\lambda$ sensor and its dynamic response, a particular tests in which the AFR has followed a step profile has been carried out at different engine operating conditions. Figure 5.9 shows the dynamic response of the wideband $\lambda$ sensor characterized as a delay plus a response time (Tau) experimentally measured for both increasing and decreasing AFR steps. One can observe that the differences are within the interval defined by the standard deviation, so no significant asymmetry in the sensor dynamic response can be extracted from the experimental results obtained. These results are in line with those of [233], pointing out that there is not a significant asymmetry in the dynamic response of wideband $\lambda$ sensors. Regarding the effect of SC, the slight trend that response time shows is compensated with the gradually increase of delays measured, so it is also negligible.
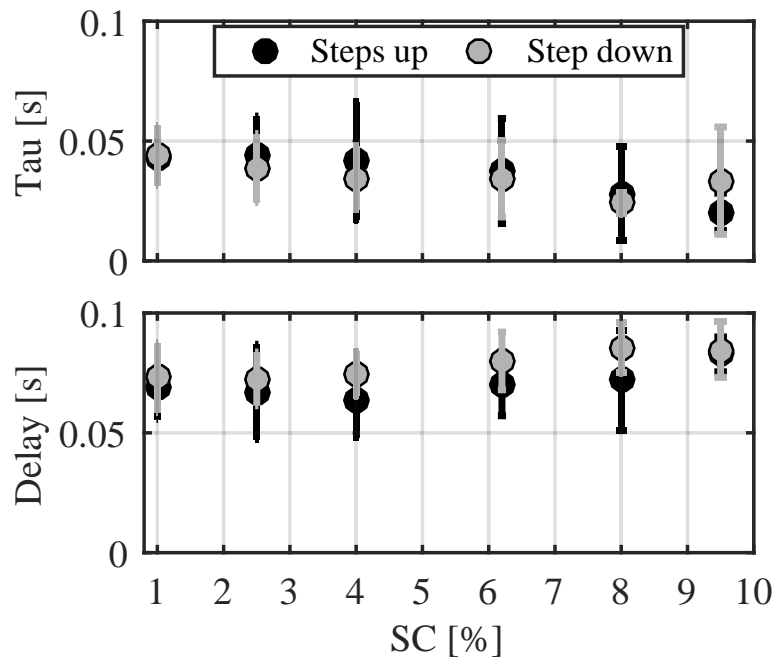

Figure 5.9: Wideband $\lambda$ sensor response time 


\section{In-cycle analysis}

The low response times obtained in previous tests suggest the possibility of using the $\lambda$ sensors to estimate the in-cycle evolution of the exhaust gas composition. To this end, fast $\mathrm{CO}_{2}$ and $\phi_{\lambda}$ data acquisition as well as an one-dimensional wave action model of the engine have been used. Besides $\lambda$ sensor, the catalyst inlet has been also instrumented to measure $\mathrm{CO}_{2}$ concentrations with a fast analyser, the crank angle resolution fixed in the acquisition system for both sensors is $0.25^{\circ}$ per sample, that is 42 $\mathrm{kHz}$ at $1750 \mathrm{rpm}$. The sampling rate used is higher than sensors response to avoid filtering the signals during the acquisition process beyond the filtering imposed by the sensor response. For the $\mathrm{CO}_{2}$ analyser, the step response is below $2.5 \mathrm{~ms}$ to reach the $90 \%$ of the final value according to manufacturer data-sheet, thereby actual AFR and $\mathrm{CO}_{2}$ oscillations should be even higher than those provided by the sensor signals.

Since the engine employed is a 3-cylinder, three different SC pulses are expected within an engine cycle. However, the shape of the exhaust manifold (see engine sketch in figure 3.1), together with the gases transport phenomena as well as the mixing effect along the exhaust line and the filtering effect of the measurement process, result in the $\mathrm{CO}_{2}$ and $\phi_{\lambda}$ waveforms shown in figure 5.10. The reader can appreciate three different pulses with different amplitudes in both the $\mathrm{CO}_{2}$ and $\phi_{\lambda}$ signals.

As the $\mathrm{SC}$ increases, $\mathrm{CO}_{2}$ is progressively diluted and a characteristic waveform appears with rising delays, it is due to an accumulative effect of the fresh air pulses. Although these are produced each $240^{\circ}$ in a different cylinder, each one have to cover paths with different lengths until reaching the TWC inlet due to the exhaust manifold geometry. The behaviour of the in-cycle $\phi_{\lambda}$ evolution is alike, a characteristic waveform similar to that of the $\mathrm{CO}_{2}$ appearing when $\mathrm{SC}$ increases. However, the mean value of the $\phi_{\lambda}$ signal remains constant independently of the SC due to its closed loop control.

The experimental test carried out has been also simulated with a wave action model, imposing exactly the same operating point and valve overlaps. Figures 5.11 and 5.12 show the modelled in-cycle evolution for $\mathrm{CO}_{2}$ 


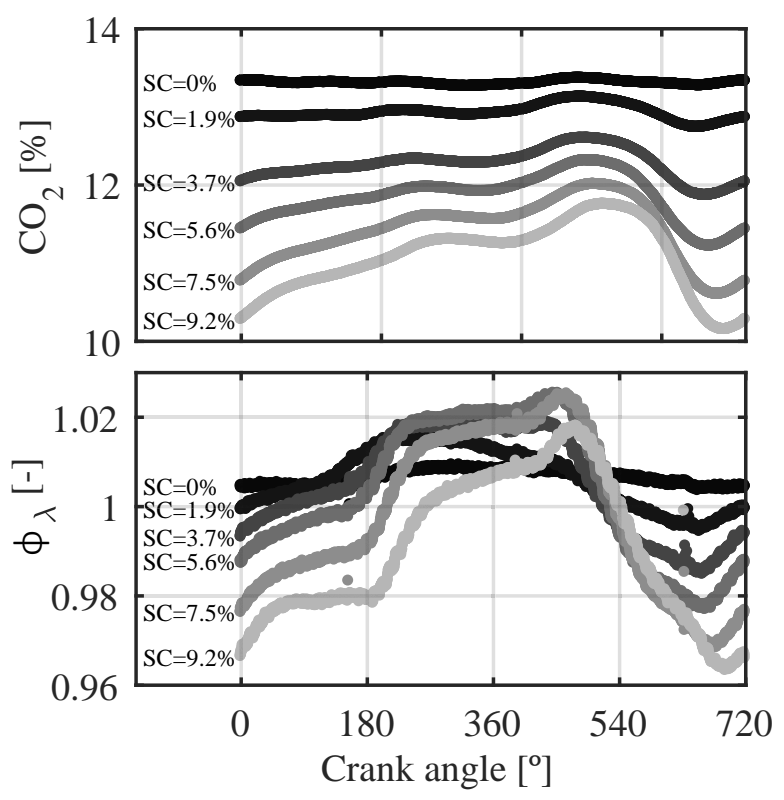

Figure 5.10: In-cycle averaged $\mathrm{CO}_{2}$ and $\lambda$ waveforms measured for each predefined SC

concentration and AFR respectively at several points along the exhaust line, from exhaust pipes to TWC inlet.

On each exhaust pipe (second plot from the top in figure 5.11), there is a plateau with high $\mathrm{CO}_{2}$ concentration during the exhaust stroke of its respective cylinder and then, a sudden decrease appears during the valve overlap when fresh air goes through the pipe. Finally, when the exhaust valves close, the $\mathrm{CO}_{2}$ concentration keeps at low level until the next stroke. In the exhaust manifold (third plot in figures 5.11 and 5.12 ) the main difference is that the mass flow is hardly ever zero, given that fresh air pulses are followed by exhaust gases from next cylinder according to the firing order and there is some diffusion of gases in the manifold. Additionally, as a consequence of the manifold geometry, the path length from each exhaust pipe to the turbine inlet is different, so it is reflected by the amplitude and duration of $\mathrm{CO}_{2}$ and $\phi$ pulses. As the measurement point is relatively far from the cylinders, the mixing effect is stronger, thus the pulses are progressively smaller and delayed as can be observed in the third plot of both figures. 


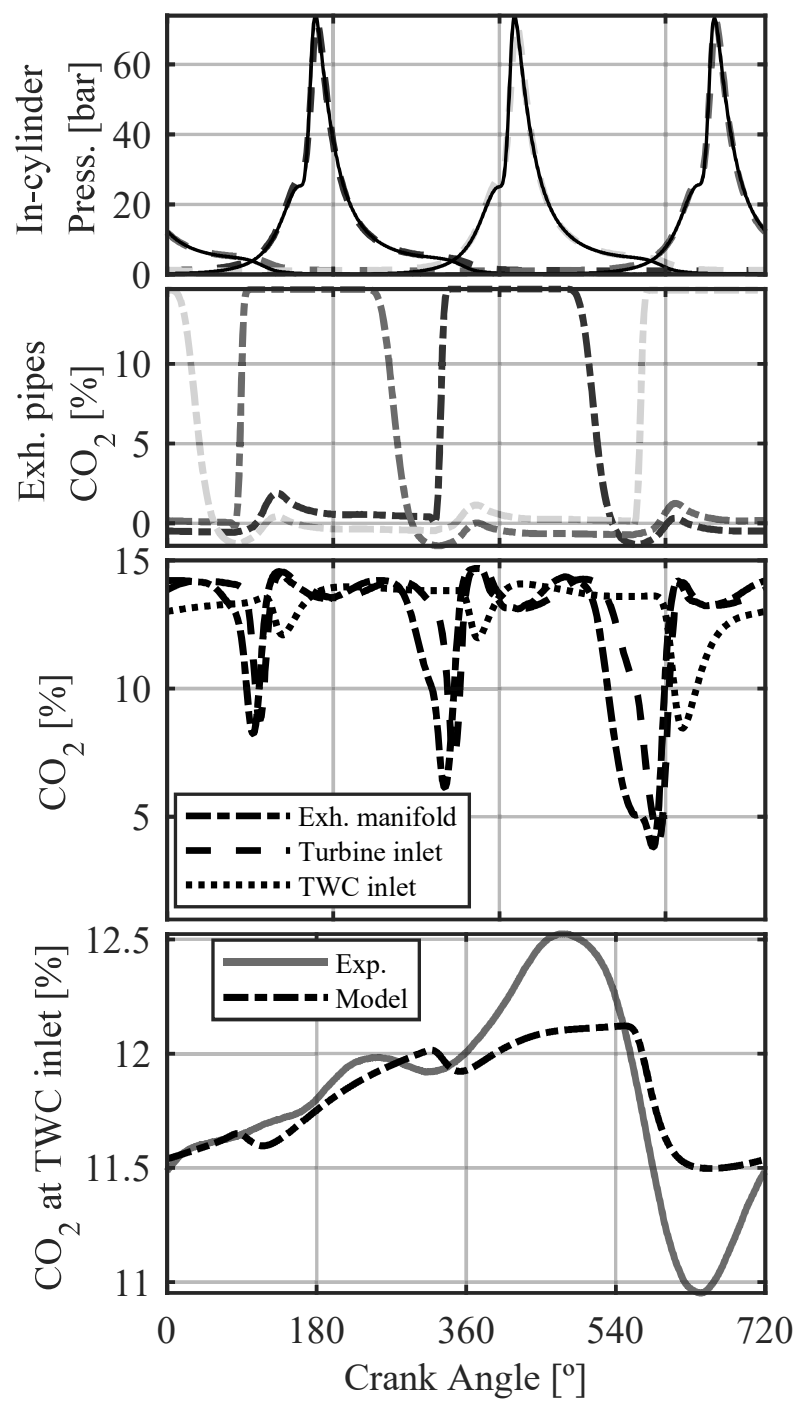

Figure 5.11: $\mathrm{SC}=9.5 \%$ First row: In-cycle pressures, modelled (dashed - - -) versus experimental (solid -); Second row: Modelled in-cycle evolution for $\mathrm{CO}_{2}$ concentration at exhaust pipes; Third row: Modelled in-cycle evolution for $\mathrm{CO}_{2}$ concentration at several points along the exhaust line; Fourth row: $\mathrm{CO}_{2}$ concentration measurement, modelled (dashed - - -) versus experimental (solid - ) 

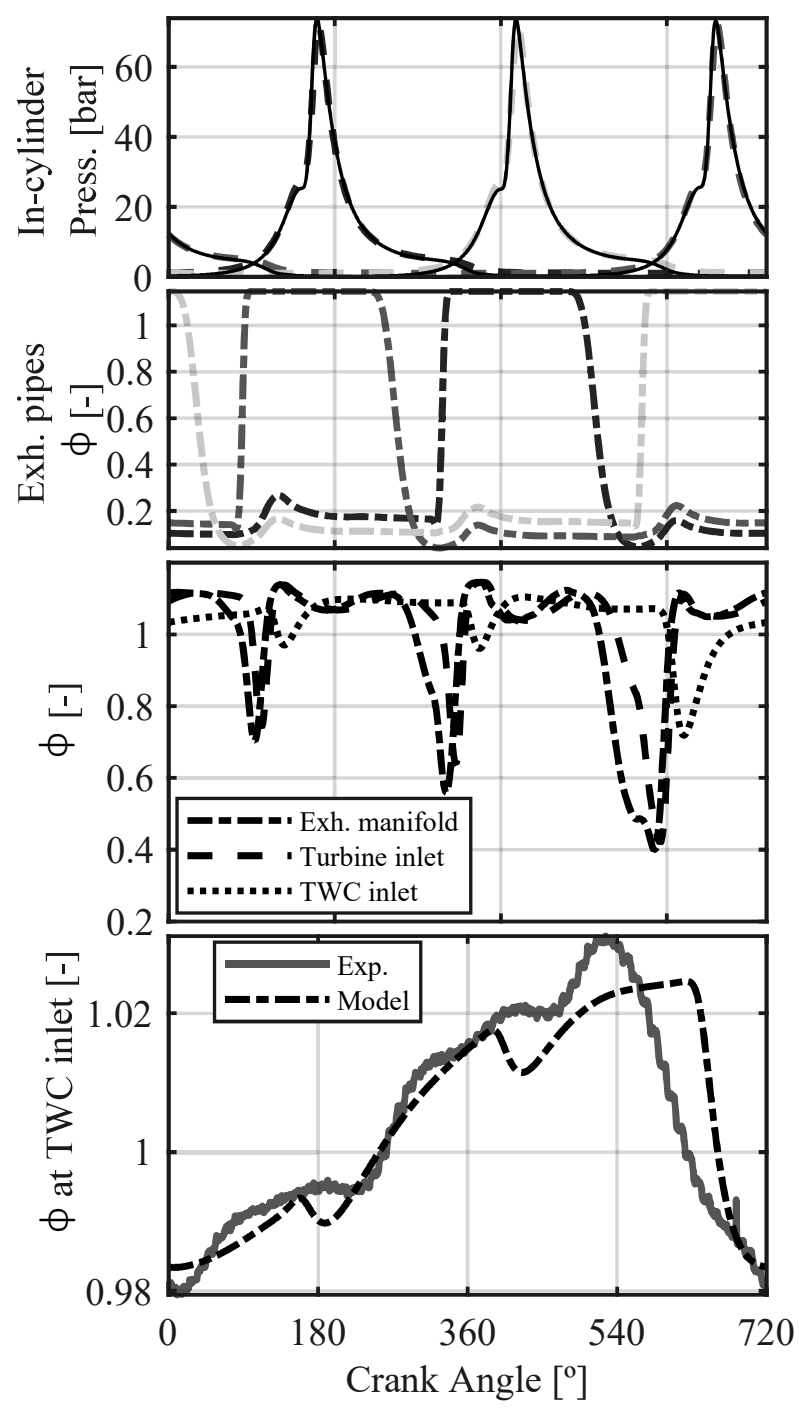

Figure 5.12: $S C=9.5 \%$ First row: In-cycle pressures, modelled (dashed ---) versus experimental (solid -); Second row: Modelled in-cycle evolution for AFR at exhaust pipes; Third row: Modelled in-cycle evolution for AFR at several points along the exhaust line; Fourth row: $\phi_{\lambda}$ measurement, modelled (dashed ---) versus experimental (solid - 
Finally, a first order linear model, which intends to simulate the filtering effect of the sensors, is applied to the instantaneous signals $\left(\mathrm{CO}_{2}\right.$ concentration and $\phi$ ) modelled at TWC inlet, in order to compare them with the experimental measurements at the same point. Even though the model is not perfectly fitted and the filtering effect of the experimental measurement could not be exactly a first order, modelled and measured fit quite good as it is shown in the bottom plot of figures 5.11 and 5.12. In this sense, in-cycle evolutions of $\mathrm{CO}_{2}$ and $\phi_{\lambda}$ shown in figure 5.10 are justified by the fresh air pulses coming from the $\mathrm{SC}$ and the sensor dynamic response. Note that despite the sensor limitations, it is sensitive to $\mathrm{SC}$, since the pulses amplitude is clearly affected by SC.

\subsubsection{Short-circuit effect on three-way catalyst behaviour}

Since the $\lambda$ sensor is the fundamental element in the AFR control of SI engines, the impact of the $\mathrm{SC}$ on the $\lambda$ sensor leads to variations in the operating AFR that involve modifications in the expected engine performance and emissions. Moreover, it should be noted that since the engine control is aimed to keep the $\phi_{\lambda}$ provided by the $\lambda$ sensor around the desired value, the oxygen content that is actually controlled is that at the sensor location, i.e at the TWC inlet. Therefore, even in the case of a perfect correction of the SC effect on the $\lambda$ sensor, the SC will involve some modification of the in-cylinder gas composition. A simple mass balance in the cylinders leads to the following relation between in-cylinder and exhaust gas composition in terms of $\phi$ :

$$
\phi_{c y l}=\phi \cdot \frac{1}{1-S C}
$$

Where $\phi_{\text {cyl }}$ represent the fuel-to-air equivalent ratio at the cylinder and the term $\phi$ refers to the same at the exhaust (before TWC). One can observe that, given a constant exhaust $\phi$, a SC increase involves a rise at the in-cylinder $\phi_{\text {cyl }}$. Since the engine raw emissions are driven by the in-cylinder $\phi_{\text {cyl }}$, an important effect of the SC on the exhaust gas composition at TWC inlet is expected. 
In this sense Figure 5.13 shows the sensitivity of the exhaust gas composition to the SC and the $\phi_{\mathrm{GA}}$. Obviously, for a given $\mathrm{SC}$ level, the higher the $\phi$, the higher the $\mathrm{CO}$ emissions due to incomplete combustion. However, the most remarkable idea of Figure 5.13 is that for a given exhaust $\phi_{\mathrm{GA}}$, a noticeable increase in $\mathrm{CO}$ emissions is obtained when the $\mathrm{SC}$ rises, that is, for a $\phi_{\mathrm{GA}}$ of 0.98 , the $\mathrm{CO}$ emissions increase up to 5 times when the SC increases from 0 to $9.5 \%$. The reason for such an increase is that $\phi_{\text {cyl }}$ should rise to keep constant the exhaust $\phi$ when the engine operates with higher levels of SC. Conversely, the increase of both exhaust $\phi$ and $\mathrm{SC}$ contribute to a reduction in the $\mathrm{NO}_{\mathrm{x}}$ concentration of raw engine exhaust gases, since both entail an increase in $\phi_{\text {cyl }}$.

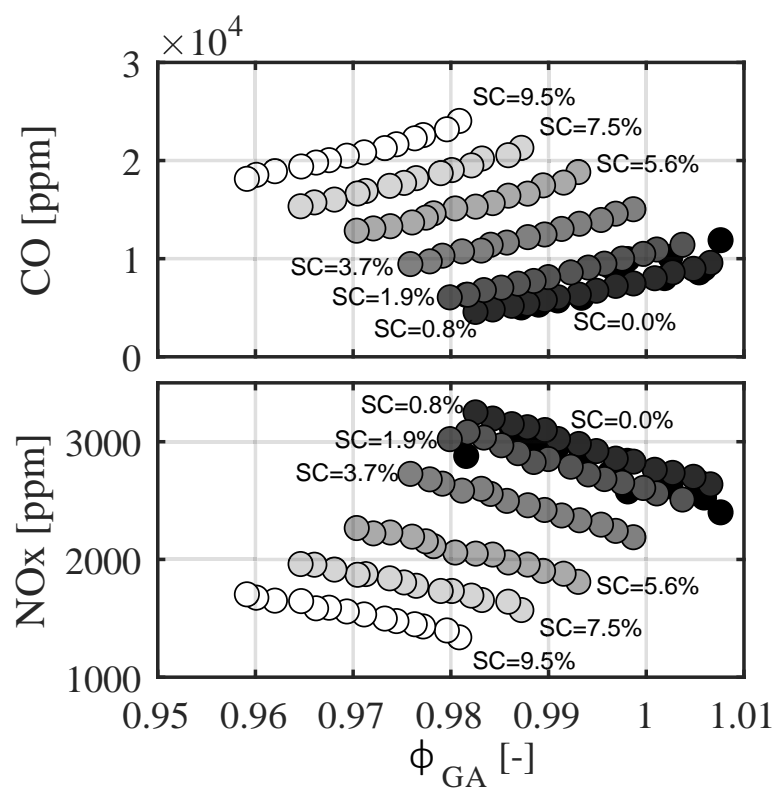

Figure 5.13: Effect of $\phi_{\mathrm{GA}}$ and $\mathrm{SC}$ on engine raw emissions upstream TWC. Top: CO emissions; Bottom: $\mathrm{NO}_{\mathrm{x}}$ emissions

As a consequence of the fact that the in-cylinder AFR is the prime driver of the combustion process, and therefore also of the engine raw emissions, Figure 5.14 displays how $\mathrm{CO}$ and $\mathrm{NO}_{\mathrm{x}}$ emissions collapse in a line when all the measurements are represented against the in-cylinder AFR $\left(\phi_{\mathrm{cyl}, \mathrm{GA}}\right)$ calculated through $\phi_{\mathrm{GA}}$ at the exhaust. Of course within the measurement accuracy margin and neglecting the dilution effect of SC on 
the exhaust mass flow. Some misalignment of the results obtained with $\mathrm{SC}_{\mathrm{a}}$ tests can be observed, this can be justified by the fact that at these conditions the engine operates with a negative valve overlap and therefore, the quality of the engine combustion may be worse, then increasing the residuals and accordingly contributing to higher $\mathrm{CO}$ and lower $\mathrm{NO}_{\mathrm{x}}$ emissions than the general trend.

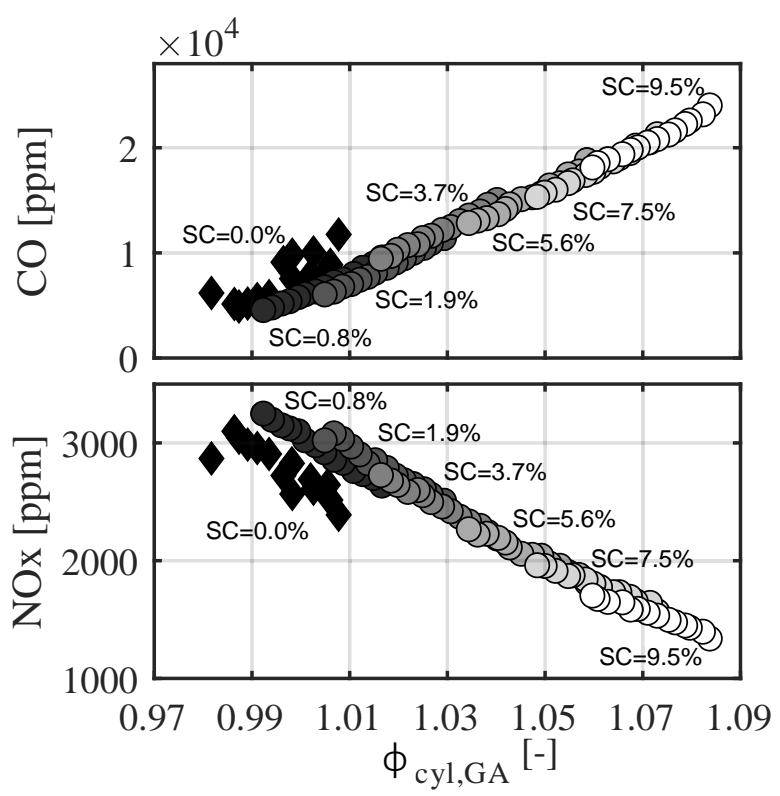

Figure 5.14: Effect of in-cylinder fuel-to-air equivalence ratio $\left(\phi_{\mathrm{cyl}, \mathrm{GA}}\right)$ and $\mathrm{SC}$ on engine emissions upstream the TWC. Top: $\mathrm{CO}$ emissions; Bottom: $\mathrm{NO}_{\mathrm{x}}$ emissions

Once the effect of SC on engine raw emissions has been discussed, it is easier to understand how the emissions downstream the TWC are also affected by SC as shows Figure 5.15. Given a $\phi_{\mathrm{GA}}$, the SC involves an increase in the $\mathrm{CO}$ emissions and a reduction of $\mathrm{NO}_{\mathrm{x}}$. The effect on $\mathrm{CO}$ emissions is more evident from stoichiometric to rich conditions (due to the lower efficiency of the TWC) while the effect on $\mathrm{NO}_{\mathrm{x}}$ becomes more apparent at lean conditions (because of the same reason). In any case, $\mathrm{SC}$ displaces the TWC window towards leaner conditions. According to the results shown in Figure 5.15, $\mathrm{NO}_{\mathrm{x}}$ decreases with $\mathrm{SC}$, while the opposite trend is observed for CO, both facts contribute to shift the TWC window to leaner $\phi_{\mathrm{GA}}$. 

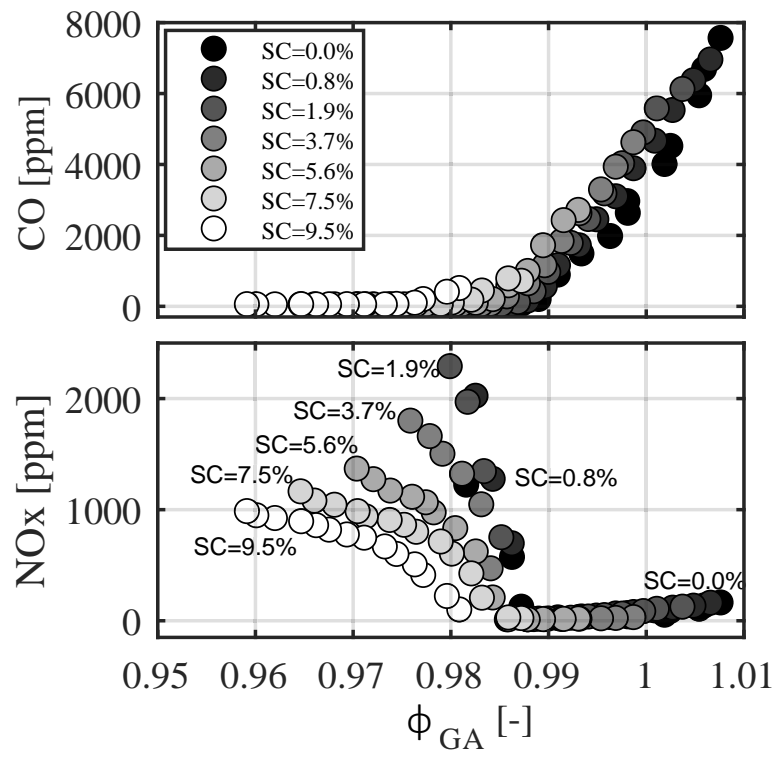

Figure 5.15: Effect of $\phi_{\mathrm{GA}}$ and $\mathrm{SC}$ on engine emissions downstream the TWC. Top: CO emissions; Bottom: $\mathrm{NO}_{\mathrm{x}}$ emissions. 
On the other hand, the TWC itself is affected by SC. The fresh air pulses coming from the SC along with the peaks of $\mathrm{CO}$ concentration coming from the higher $\phi_{\text {cyl }}$ conditions involve a clear loss of efficiency. The TWC efficiency in terms of $\mathrm{CO}$ oxidation and $\mathrm{NO}_{\mathrm{x}}$ reduction is represented against $\phi_{\mathrm{GA}}$ and $\mathrm{SC}$ in Figure 5.16. Experimental results show that the $\mathrm{CO}$ oxidation efficiency around stoichiometric conditions is harmed by $\mathrm{SC}$, the increase in $\mathrm{HC}$ and $\mathrm{CO}$ emissions at TWC inlet due to rich incylinder AFR is not compensated by the availability of fresh air coming from the SC. On the contrary, results point out some improvement in the $\mathrm{NO}_{\mathrm{x}}$ reduction capabilities of the TWC from lean to stoichiometric conditions. The reason for that behaviour may be the pulses with high $\mathrm{CO}$ (and other reducing species such as $\mathrm{H}_{2}$ ) that allow to reduce $\mathrm{NO}_{\mathrm{x}}$ even with global $\phi$ levels below stoichiometric.
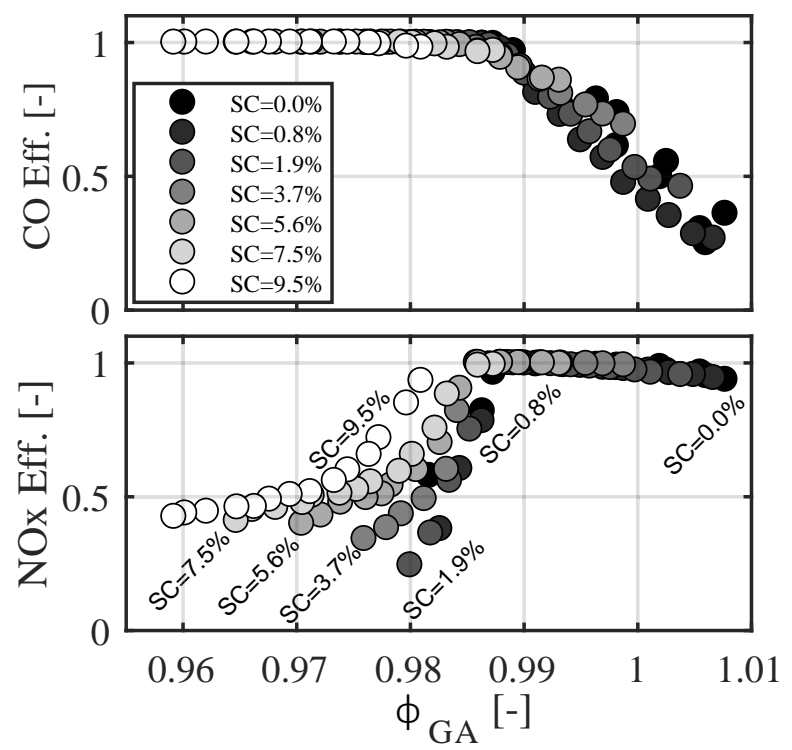

Figure 5.16: Effect of $\phi_{\mathrm{GA}}$ and $\mathrm{SC}$ on TWC efficiency. Top: CO oxidation efficiency; Bottom: $\mathrm{NO}_{\mathrm{x}}$ reduction efficiency

The combination of the impact of SC on engine raw emissions and TWC efficiency leads to a general deterioration of the $\mathrm{CO}$ and $\mathrm{NO}_{\mathrm{x}}$ trade-off as pointed out in Figure 5.17. It can be clearly observed that the increase in SC involves some penalty on emissions since the trade-off is shifted 
from the origin towards higher $\mathrm{CO}$ and $\mathrm{NO}_{\mathrm{x}}$ emissions. In line with previous results, contour lines of constant $\phi_{\mathrm{GA}}$ show that the increase in $\mathrm{SC}$ involves, in general, a reduction in $\mathrm{NO}_{\mathrm{x}}$ emissions at the expense of an increase in $\mathrm{CO}$. In this sense, given the emissions in the reference operating point without $\mathrm{SC}\left(\phi_{\mathrm{GA}}=0.988\right)$ and going toward a $\mathrm{SC}$ of $9.5 \%$ at constant $\phi_{\mathrm{GA}}$, it will involve an increase of the $\mathrm{CO}$ concentration from 100 to $800 \mathrm{ppm}$ at the expense of a small reduction of $\mathrm{NO}_{\mathrm{x}}$ emissions from 80 to $20 \mathrm{ppm}$.

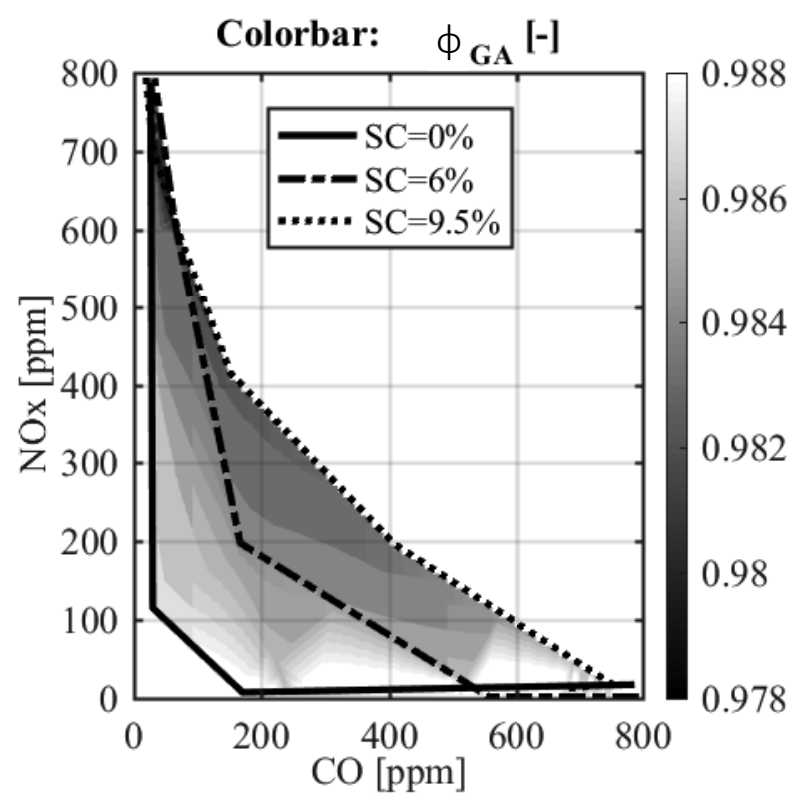

Figure 5.17: Actual fuel-to-air equivalence ratio $\left(\phi_{\mathrm{GA}}\right)$ in the $\mathrm{CO}-\mathrm{NO}_{\mathrm{x}}$ map.

Note that while previous figure shows contour-lines of actual $\phi\left(\phi_{\mathrm{GA}}\right)$, the effect of the $\mathrm{SC}$ on the $\lambda$ sensor prevents the engine to operate at constant $\phi_{\mathrm{GA}}$ when subjected to SC. In this sense, Figure 5.18 shows the contours of constant $\phi_{\lambda}$ in the trade-off $\mathrm{CO}-\mathrm{NO}_{\mathrm{x}}$. One can observe that if the $\phi_{\lambda}$ of the engine operating without $\mathrm{SC}$, that is $\phi_{\lambda}=1.01$, is maintained, when $\mathrm{SC}$ is applied an important shift on $\mathrm{NO}_{\mathrm{x}}$ will appear, passing from 80 to $800 \mathrm{ppm}$ if the SC exceeds a $6 \%$.

As a summary, the result of increasing the SC at constant $\phi_{\lambda}$ in both, the actual $\phi\left(\phi_{\mathrm{GA}}\right)$ and the TWC efficiency (in terms of $\mathrm{NO}_{\mathrm{x}}$ emissions), is 


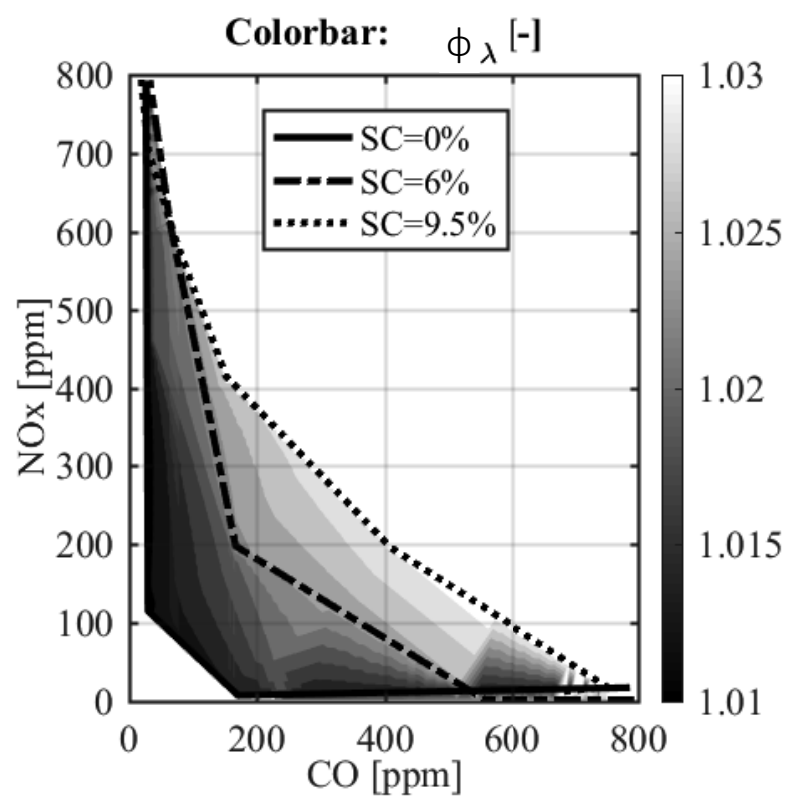

Figure 5.18: $\phi_{\lambda}$ provided by the $\lambda$ sensor in the map CO-NO .

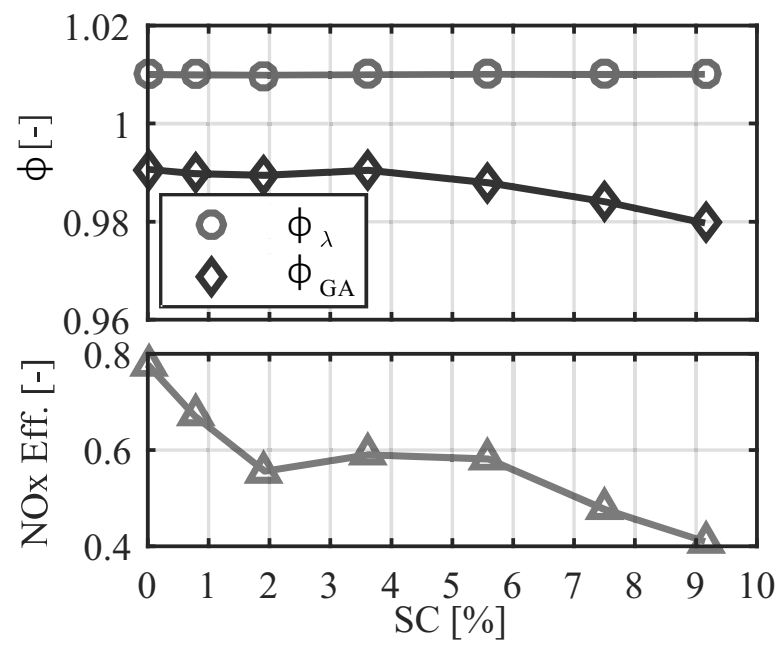

Figure 5.19: Actual $\phi_{\mathrm{GA}}$ and TWC efficiency in terms of $\mathrm{NO}_{\mathrm{x}}$ reduction as $\mathrm{SC}$ increases with standard AFR control strategy 
shown in Figure 5.19, pointing out a noticeable decrease in $\mathrm{NO}_{\mathrm{x}}$ efficiency when SC increases. Previous results lead to the conclusion that, whether emissions at low engine speed and high torque begin to gain relevance, the emissions criteria should take into account the SC calibration. That is, both the effect of SC on the $\lambda$ sensor and TWC operation should be taken into account when designing the AFR control strategy of the engine. 


\subsection{Three-way catalyst behaviour during cold-start phase}

The development of specific control strategies like ignition retardation or homogeneous split mode injection, used to not only heat-up faster the TWC but also reducing $\mathrm{HC}$ exhaust raw emissions after cold-start [176178], needs reliable models to gain insight into the TWC behaviour. It is not common to find a first-principle TWC model with low computational requirements, oriented to predict the converter behaviour under cold-start conditions, experimentally validated and which also takes into account water evaporation and condensation. Most of the models present in literature miss some of these features. The present section aims to cover this room. In particular, the effect of water vapour condensation and evaporation is fundamental to properly predict the temperature evolution at the beginning of the catalyst heating up process. Thus, a model capable of taking this issue into account is essential. That is why the previously presented 1D-1Ch model has been adapted to cope with the converter heating-up process under state-of-the-art cold-start strategies. The thermal model keeps the detailed heat transfer approach proposed, but includes water vapour evaporation and condensation. The kinetic reactions are also based on first principles, accounting for gas transfer between bulk gas and washcoat pores, as well as adsorption and desorption of species on noble metal coating in the catalyst surface. However, a simplified set of reactions is used to reduce the model complexity for this particular approach. The idea is to keep the model as simple as possible in order to preserve low computational requirements, since the consideration of the water vapour evaporation and condensation imposes a discontinuity which does not allow to keep the real-time execution without reducing the model complexity. The next section describes the way followed to adapt the model. Only the sorption of $\mathrm{O}_{2}, \mathrm{HC}$ and $\mathrm{CO}$ as well as their respective oxidation reactions are considered, inasmuch as these are the most relevant species during cold-start. That is why $\mathrm{NO}_{\mathrm{x}}$ reactions and oxygen storing in ceria are neglected. $\mathrm{NO}_{\mathrm{x}}$ raw emissions are expected to be low because of the retarded combustion imposed just after cold-start [176]. While oxygen storing in ceria neither plays a crucial role during cold-start [143, 144], particularly, if AFR is kept at lean 
conditions to maintain low $\mathrm{HC}$ and CO raw emissions [180]. In this sense, the most relevant conditions that characterize the process are:

- Strong dependency between conversion efficiency and temperature.

- Atypical combustion due to retarded ignition and homogeneous split mode injection.

- Lean conditions to reduce as much as possible HC raw emissions.

As a consequence, the engine raw emissions have a particular composition in comparison with normal operation, that is, oxygen availability at catalyst inlet but low NOx emissions. In addition, phenomena such as the water condensation-evaporation that are usually neglected, play here a key role due to the cold conditions of the brick.

\subsubsection{Model adaptation}

As explained in section 4.1 within the description of the 1D-1Ch model, two phases have been considered from the heat transfer point of view, the gas phase flowing along the channel and the solid phase that constitutes the walls of the aforementioned channel. The energy balance in the gas phase (equation (4.1)) is analogous in this case, but now the specific heat of the gas phase is considered as the addition of two terms: the specific heat of the gas itself and the specific heat of the water vapour contained in the gas stream, weighted with the concentration of the water vapour (equation (5.2)).

$$
\begin{aligned}
\varepsilon \cdot \rho_{g} \cdot\left(c_{g}\right. & \left.+X_{w} \cdot c_{w}\right) \cdot \frac{\partial \vartheta_{g}}{\partial t}= \\
& =-\alpha \cdot a_{v} \cdot\left(\vartheta_{g}-\vartheta_{b r i c k}\right)-\frac{\dot{m}_{e x h}}{A} \cdot\left(c_{g}+X_{w} \cdot c_{w}\right) \cdot \frac{\partial \vartheta_{g}}{\partial x}
\end{aligned}
$$

Unlike the 1D-1Ch model presented in section 4.1 (equation (4.2)), in the solid phase the energy balance has an additional term to take into account the latent heat of water vapour that condensates or evaporates in the monolith walls. Thus, the energy balance consists of five terms as shown in equation (5.3): axial conduction, heat transfer between the gas 
and the catalyst surface, heat losses to the environment, heat produced by the exothermic reactions as well as the aforementioned latent heat of the water vapour.

$$
\begin{aligned}
& (1-\varepsilon) \cdot \rho_{\text {brick }} \cdot\left(c_{\text {brick }}+X_{w} \cdot c_{w}\right) \cdot \frac{\partial \vartheta_{\text {brick }}}{\partial t}= \\
& =\gamma_{\text {brick }} \cdot(1-\varepsilon) \cdot \frac{\partial^{2} \vartheta_{\text {brick }}}{\partial x^{2}}+\alpha \cdot a_{v} \cdot\left(\vartheta_{g}-\vartheta_{\text {brick }}\right)+ \\
& \quad+\alpha_{\text {env }} \cdot a_{v, \text { env }} \cdot\left(\vartheta_{\text {brick }}-\vartheta_{\text {env }}\right)+a_{\text {cat }} \cdot C \cdot \sum_{j=1}^{n}\left(-\Delta H_{r_{j}} \cdot r_{j}\right)+ \\
& +\delta \cdot \beta_{w} \cdot a_{v} \cdot \rho_{w} \cdot\left(X_{w}-X_{w, \text { sat }}\right) \cdot\left(\Delta H_{\text {evap }}+c_{w} \cdot\left(\vartheta_{g}-\vartheta_{\text {brick }}\right)\right)
\end{aligned}
$$

The water vapour condensation and evaporation has been considered following the approach proposed in Frauhammer et al. [234]. The associated term is weighted with the step function $\delta$, which is zero except when the water vapour condenses or evaporates. This $1 \mathrm{D}-1 \mathrm{Ch}$ approach requires solving a PDE system, thus, in the case of the 1D-1Ch model described in section 4.1 the method of lines is implemented. However, in this case the symbolic Jacobian cannot be calculated because of the discontinuity introduced by the $\delta$ function. It makes infeasible to run the model in real time unless the model is modified to simplify the chemical complexity as well as to take into account the water vapour condensation and evaporation. Regarding the mass balance, the approach is the same than the one described in equation (4.3), but only 4 species have been considered in this case, $\mathrm{H}_{2} \mathrm{O}, \mathrm{O}_{2}, \mathrm{CO}$ and $\mathrm{HC}$. In the particular case of water vapour (equation (5.4)), the main difference with respect to the other species is that the mass transfer term does not depend on the concentration in the solid phase $\left(\mathrm{Y}_{\mathrm{w}}\right)$, but on the maximum concentration allowed under saturation conditions $\left(\mathrm{X}_{\mathrm{w}, \mathrm{sat}}\right)$ in the gas phase. It is due to the fact that water adsorption is not included but only its evaporation-condensation.

$$
\varepsilon \cdot \rho_{g} \cdot \frac{\partial X_{w}}{\partial t}=-\beta_{w} \cdot \delta \cdot a_{v} \cdot \rho_{g} \cdot\left(X_{w}-X_{w, s a t}\right)-\frac{\dot{m}_{e x h}}{A} \cdot \frac{\partial X_{w}}{\partial x}
$$


The mass balance of each species in the washcoat pores follows the same approach described in equation (4.4). For water vapour (equation (5.5)), again the mass transfer term does not depend on the concentration in the solid phase, but on the maximum concentration allowed under saturation conditions in the gas phase. Moreover, the mass production term is not considered for water vapour since its adsorption in not included.

$$
(1-\varepsilon) \cdot A \cdot \rho_{g} \cdot \frac{\partial Y_{w}}{\partial t}=\beta_{w} \cdot a_{v} \cdot A \cdot \rho_{g} \cdot\left(X_{w}-X_{w, s a t}\right)
$$

All the reactions considered follow the Langmuir-Hinshelwood mechanism, thus $\mathrm{O}_{2}, \mathrm{CO}$ and $\mathrm{HC}$ are adsorbed prior to react with the aid of the noble metal coating. The mass balance in this third layer is analogous to the one described in equation (4.5). The main difference is that in this case only 5 reactions are considered (equations (5.6)-(5.10)). That is, $\mathrm{CO}$ and $\mathrm{HC}$ adsorption and desorption are taken into account, for the $\mathrm{O}_{2}$ only its adsorption is modelled, the desorption is carried out by means of $\mathrm{CO}$ and $\mathrm{HC}$ oxidation. The oxidation of $\mathrm{HC}$ is lumped in just one reaction: propylene $\left(\mathrm{C}_{3} \mathrm{H}_{6}\right)$, which usually represents the predominant and easily oxidizing $\mathrm{HC}$ [137]. The reduction of $\mathrm{NO}_{\mathrm{x}}$ with $\mathrm{CO}$ has been omitted because low $\mathrm{NO}_{\mathrm{x}}$ exhaust raw emissions are expected under very retarded ignition conditions.

$$
\begin{aligned}
\mathrm{O}_{2}+2 \mathrm{Pt} & \rightarrow 2 \mathrm{PtO} \\
\mathrm{CO}+\mathrm{Pt} & \leftrightarrows \mathrm{PtCO} \\
\mathrm{C}_{3} \mathrm{H}_{6}+\mathrm{Pt} & \leftrightarrows \mathrm{PtC}_{3} \mathrm{H}_{6} \\
\mathrm{PtCO}+\mathrm{PtO} & \rightarrow \mathrm{CO}_{2}+2 \mathrm{Pt} \\
\mathrm{PtC}_{3} \mathrm{H}_{6}+9 \mathrm{PtO} & \rightarrow 3 \mathrm{CO}_{2}+3 \mathrm{H}_{2} \mathrm{O}+10 \mathrm{Pt}
\end{aligned}
$$

In this case, forward reaction-rate constants also follow the Arrhenius equation (4.23) in the case of oxidation reactions, or the sticking equation (4.24) in the case of adsorption reactions. In summary, this adapted 1D$1 \mathrm{Ch}$ model consists of 13 states as it is shown in the state vector $\mathrm{S}$ (5.11): temperatures of gas and solid phase $\left(\vartheta_{\mathrm{g}}\right.$ and $\vartheta_{\text {brick }}$ respectively); $\mathrm{H}_{2} \mathrm{O}, \mathrm{O}_{2}, \mathrm{CO}$ and $\mathrm{HC}$ concentration in both gas and washcoat pores $\left(\mathrm{X}_{\mathrm{i}}\right.$ 
and $\mathrm{Y}_{\mathrm{i}}$ respectively); and vacancies occupied by all adsorbed species in the noble metal coating of the catalyst surface $\left(\Theta_{\mathrm{i}}\right)$. For water vapour in solid phase, $\mathrm{Y}_{\mathrm{w}}$ does not represent the concentration in the washcoat pores, since water adsorption is not considered, but the concentration of condensed water over the brick surface.

$$
S=\left[\begin{array}{c}
\vartheta_{g} \\
\vartheta_{b r i c k} \\
X_{C O} \\
X_{O_{2}} \\
X_{H C} \\
X_{w} \\
Y_{C O} \\
Y_{O_{2}} \\
Y_{H C} \\
Y_{w} \\
\Theta_{C O} \\
\Theta_{O_{2}} \\
\Theta_{H C}
\end{array}\right]
$$

The resulting PDE system is solved by discretizing the problem with the finite differences method (FDM), in particular, the Euler forward method is chosen for first-order temporal derivatives (equation (5.12)). For the spatial discretization of first-order derivatives, backward differences are used (equation (5.13)), while the spatial second-order derivative (imposed by the thermal conduction term) is discretized with central differences (equation (5.14)).

$$
\begin{gathered}
\frac{\partial S(x, t)}{\partial t} \approx \frac{S_{k}^{z+1}-S_{k}^{z}}{\Delta t} \\
\frac{\partial S(x, t)}{\partial x} \approx \frac{S_{k}^{z}-S_{k-1}^{z}}{\Delta x} \\
\frac{\partial^{2} S(x, t)}{\partial x^{2}} \approx \frac{S_{k-1}^{z}-2 S_{k}^{z}+S_{k+1}^{z}}{\Delta x^{2}}
\end{gathered}
$$


Accordingly, after some analytical steps, the model can be solved in an explicit way. That is, the state vector for the next temporal step is calculated taking the values of the state vector in the previous temporal step as well as the values for the boundary conditions in the current step. As an example, the application of the FDM to the mass balance in gas phase leads to the following expression.

$$
\varepsilon \cdot \rho_{g} \cdot \frac{X i_{k}^{z+1}-X i_{k}^{z}}{\Delta t}=-\beta_{i} \cdot a_{v} \cdot \rho_{g} \cdot\left(X i_{k}^{z}-Y i_{k}^{z}\right)-\frac{\dot{m}_{e x h}}{A} \cdot \frac{X i_{k}^{z}-X i_{k-1}^{z}}{\Delta x}
$$

Clearing $\mathrm{Xi}_{\mathrm{k}}^{\mathrm{z}+1}$ and defining $\mathrm{C}_{1}$ and $\mathrm{C}_{2}$ as:

$$
\begin{gathered}
C_{1}=\frac{\beta_{i} \cdot a_{v} \cdot \Delta t}{\varepsilon} \\
C_{2}=\frac{\dot{m}_{e x h} \cdot \Delta t}{A \cdot \varepsilon \cdot \rho_{g} \cdot \Delta x}
\end{gathered}
$$

Leads to:

$$
X i_{k}^{z+1}=X i_{k}^{z}-C_{1} \cdot\left(X i_{k}^{z}-Y i_{k}^{z}\right)-C_{2} \cdot\left(X i_{k}^{z}-X i_{k-1}^{z}\right)
$$

Finally, reorganizing terms:

$$
X i_{k}^{z+1}=\left(1-C_{1}-C_{2}\right) \cdot X i_{k}^{z}+C_{2} \cdot X i_{k-1}^{z}+C_{1} \cdot Y i_{k}^{z}
$$

In the same way, the mass balance in the solid phase (equation (5.20)) as well as the energy balance in both gas (equation (5.21)) and solid (equation (5.22)) phase can be written as follows:

$$
\begin{gathered}
Y i_{k}^{z+1}=\left(1-C_{3}\right) \cdot Y i_{k}^{z}+C_{3} \cdot X i_{k}^{z}-C_{4} \\
\vartheta g_{k}^{z+1}=\left(1-C_{5}-C_{6}\right) \cdot \vartheta g_{k}^{z}+C_{5} \cdot \vartheta b r i c k_{k}^{z}+C_{6} \cdot \vartheta g_{k-1}^{z}
\end{gathered}
$$




$$
\begin{array}{r}
\text { Өbrick } k_{k}^{z+1}=\left(1-2 C_{7} \cdot C_{8}-C_{7} \cdot C_{9}-C_{7} \cdot C_{12}\right) \cdot \vartheta b r i c k_{k}^{z}+ \\
+C_{7} \cdot C_{8} \cdot \vartheta b r i c k_{k+1}^{z}+C_{7} \cdot C_{8} \cdot \vartheta b r i c k_{k-1}^{z}+C_{7} \cdot C_{9} \cdot \vartheta g_{k}^{z}+ \\
+C_{7} \cdot C_{10} \cdot+C_{7} \cdot C_{12} \cdot \vartheta_{\text {env }}+C_{7} \cdot C_{11}
\end{array}
$$

Defining $\mathrm{C}_{3}$ to $\mathrm{C}_{10}$ as:

$$
\begin{aligned}
& C_{3}=\frac{\beta_{i} \cdot A \cdot a_{v} \cdot \Delta t}{4 \cdot d_{b} \cdot d_{w} \cdot \varepsilon_{\text {washcoat }}} \\
& C_{4}=\frac{a_{c a t} \cdot C \cdot A \cdot \sum_{j=1}^{n}\left(r_{j} \cdot v_{i, j} \cdot M_{i}\right) \cdot \Delta t}{4 \cdot d_{b} \cdot d_{w} \cdot \varepsilon_{\text {washcoat }} \cdot \rho_{g}} \\
& C_{5}=\frac{\alpha \cdot a_{v} \cdot \Delta t}{\varepsilon \cdot \rho_{g} \cdot\left(c_{g}+c_{w} \cdot X w_{k}^{z}\right)} \\
& C_{6}=\frac{\dot{m}_{e x h} \cdot \Delta t}{\varepsilon \cdot \rho_{g} \cdot A \cdot \Delta x} \\
& C_{7}=\frac{\Delta t}{(1-\varepsilon) \cdot \rho_{b r i c k} \cdot\left(c_{b r i c k}+X w_{k}^{z} \cdot c_{w}\right)} \\
& C_{8}=\frac{\gamma_{b r i c k} \cdot(1-\varepsilon)}{\Delta x^{2}} \\
& C_{9}=\alpha \cdot a_{v} \\
& C_{10}=\delta \cdot \beta_{w} \cdot a_{v} \cdot \rho_{w} \cdot\left(X w_{k}^{z}-X_{w, s a t}\right) \cdot\left(\Delta H_{\text {evap }}+c_{w} \cdot\left(\vartheta g_{k}^{z}-\vartheta b r i c k_{k}^{z}\right)\right) \\
& C_{11}=a_{c a t} \cdot C \cdot \sum_{j=1}^{n}\left(-\Delta H_{r_{j}} \cdot r_{j}\right)
\end{aligned}
$$




$$
C_{12}=\alpha_{e n v} \cdot a_{v, e n v}
$$

Concerning the initial conditions and boundaries, Dirichlet conditions are imposed in spatial and temporal first-order discretizations (equation (4.26)), since the inlet values of gas concentration, temperature and exhaust mass flow are known, as well as the temporal solution of the previous step. Neumann boundary conditions are imposed for the spatial second-order derivative, that is, null conductive heat flow at the inner and outer sections of the solid phase (equation (4.27)).

Defining the real-time ratio as the elapsed time to perform a simulation divided by the duration of the simulation, the present approach runs at $0.35 \mathrm{~s} / \mathrm{s}$, thus, in real time. To put in context this ratio, it is necessary to notice that the spatial discretization is equal to $10 \mathrm{~mm}$, while the temporal discretization is $1 \mathrm{~ms}$. The processor used for such rating is an Intel ${ }^{\circledR}$ Core $^{\mathrm{TM}}$ i5-4460 @ $3.2 \mathrm{GHz}$. Of course, greater spatial discretization could be used to reduce requirements in terms of memory. The temporal discretization could be also slightly bigger to speed up the model execution but the maximum exhaust mass flow must be considered in that case to avoid possible numeric errors. The execution of this model in a prototyping system has not been assessed, but its implementation is straightforward since an explicit solver is used.

\subsubsection{Simulation results}

The simulation results provide information experimentally non-measurable that helps to gain insight into the TWC behaviour during cold-start, which is in fact one of the model purposes. Figures 5.20 and 5.21 show the results provided by the model during a cold-start test. The engine is at idling with an speed of $1200 \mathrm{rpm}$ and lean mixture $(\phi=0.95)$. Furthermore, high ignition retardation is imposed, the center of combustion (CoC) is set to $100 \mathrm{CA}$ degrees ATDC, thus, the combustion efficiency is low. As a consequence, a mass flow of $26 \mathrm{~kg} / \mathrm{h}$ is needed to avoid stalling. The transient from 0 to $1200 \mathrm{rpm}$ takes 1 second, while other operating parameters, as $\phi$ or CoC need 4 seconds to reach steady conditions, basically the time needed by the $\lambda$-sensor to provide a reliable measurement. 
These particular operating conditions are part of a cold-start strategy proposed in Hedinger, Elbert, and Onder [180].

At the very beginning, both the gas and the converter are at ambient temperature, thus the water content of the exhaust stream begins to condensate in the catalyst surface, particularly in the front face of the brick. After five seconds, the inlet gas temperature increases, which heats up the first centimetres of the brick. This temperature increase involves the end of the water condensation in the front face of the catalyst and the starting of the evaporation. The subsequent sections of the brick are warmer than environment but still cold, thus the inlet water vapour along with the water evaporated in the first sections tend to condensate progressively on them. After seven seconds, the inlet brick sections are completely dry. In these sections gas and catalyst temperature increase strongly following the inlet temperature profile with a small delay, while the temperature in the brick sections that are still wet is kept at $50{ }^{\circ} \mathrm{C}$.

The conversion of species is zero during the first 40 seconds, thereby inlet and outlet concentrations are almost identical for CO. However, during the first 15 seconds the $\mathrm{HC}$ emissions behaves in a different way according to the experimental measurements. It seems that at the very beginning of the cold-start the catalyst is able to store $\mathrm{HC}$, since the concentration at the inlet is higher than at the outlet. However, a few seconds later the behaviour is the opposite. The explanation for this phenomenon could be based on the fact that not only water but also HC condensates in the catalyst surface. Of course the model is not able to represent such behaviour, since only water vapour condensation is taken into account. Anyway, from the emissions point of view, this behaviour is negligible because these $\mathrm{HC}$ are not being converted, only stored and released within the first 15 seconds of the cold-start.

After 40 seconds, the front sections of the brick reach the lower threshold of the conversion temperature $\left(240{ }^{\circ} \mathrm{C}\right)$. Because of that, tailpipe $\mathrm{CO}$ emissions begin to decrease. The activation energy for $\mathrm{HC}$ oxidation is slightly higher, thus their conversion begin later. This start of conversion involves a change in the heat transfer phenomenon, until this moment the inlet gas was heating the brick, but from second 40 on, the exothermic reaction of $\mathrm{CO}$ oxidation is heating the first brick sections. Figure 5.22 

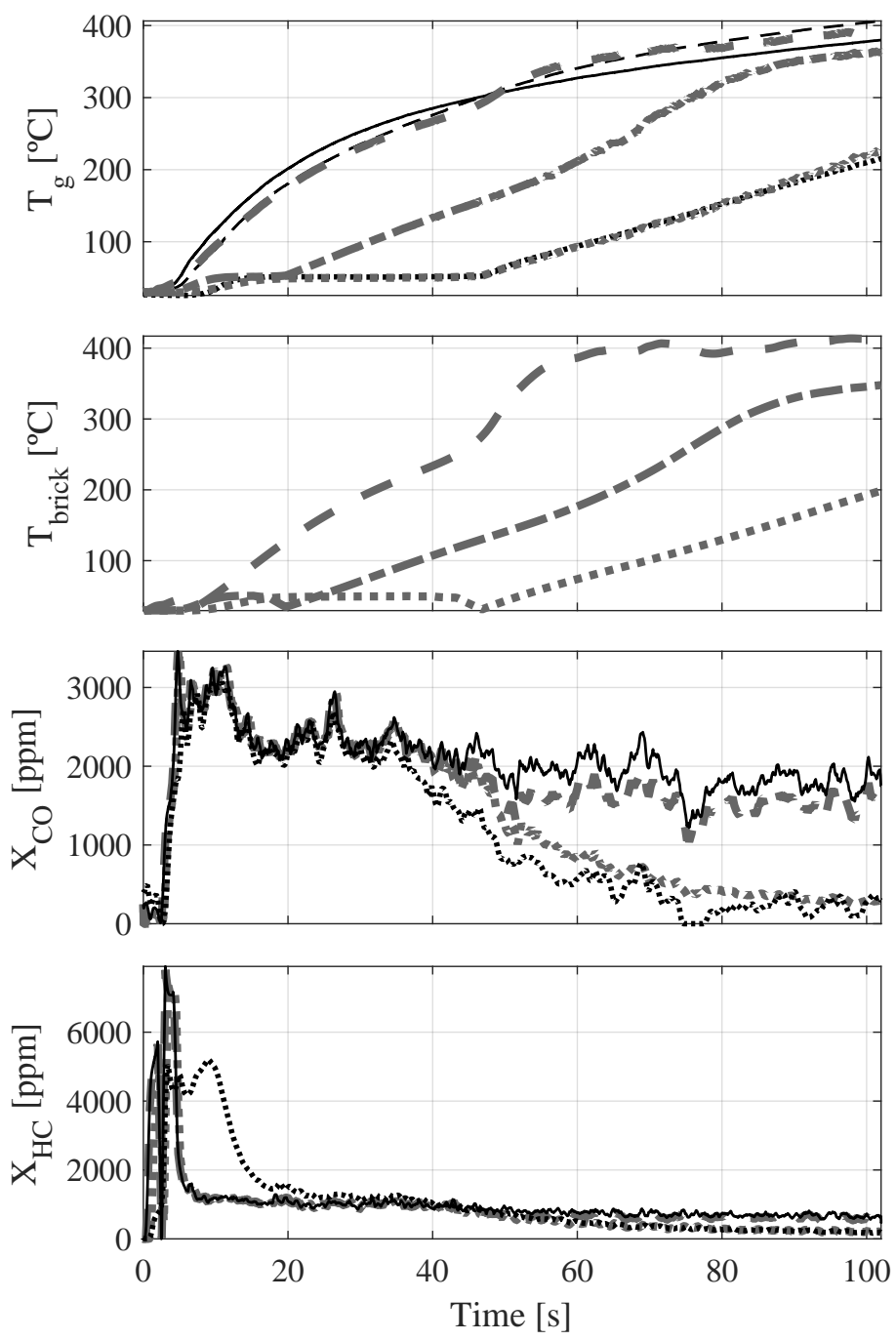

Figure 5.20: Air mass flow equal to $26 \mathrm{~kg} / \mathrm{h}$. Temperatures and emissions evolution. Black lines represent experimental data while gray lines are model predictions. Solid (-), dashed $(---)$, dash-dot (-.-) and dotted $(\cdots \cdots)$ lines correspond to inlet, first section, central section and outlet respectively 

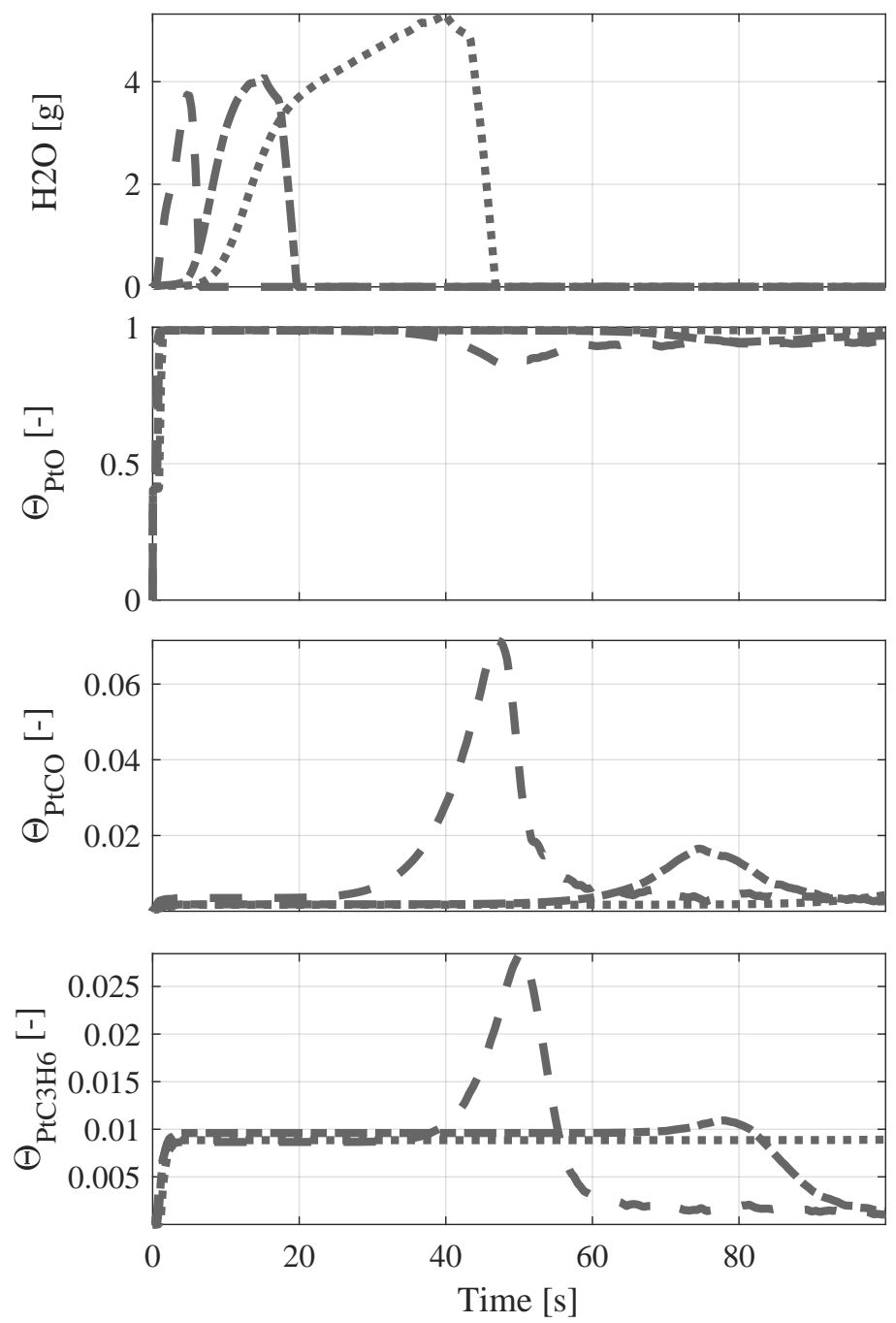

Figure 5.21: Air mass flow equal to $26 \mathrm{~kg} / \mathrm{h}$. Model predictions for water content and sites occupied by the species adsorbed in noble metal. Dashed (- - -), dash-dot (-.-.) and dotted $(\cdots \cdots)$ lines correspond to first section, central section and outlet respectively 
shows this evolution based on the catalyst length for the same test as the previous figures.

The parameter identification indicates that conductive heat flow is negligible in solid phase, which is reasonable, since the heat conduction coefficient of the ceramic is low. Furthermore, the heat transfer surface is very small due to the thin brick walls. However, the exothermic reactions not only heat up the sections at which the reaction is taking place, but also the following ones. It is due to the heat exchange between gas and brick together with the conductive heat flow in gas phase, that drags the reactions heat. According to the model, the temperature at the front face of the converter rises from 240 to $340{ }^{\circ} \mathrm{C}$ in 12 seconds (from 40 to $52 \mathrm{~s}$ ), surpassing the inlet gas temperature. The experimental measurements corroborates the model estimation, since gas temperature in the first section of the converter also exceeds the inlet gas temperature from second 46 onward. By then, the whole brick is dry, as all water vapour has been evaporated. The model simulation matches with the experimental data regarding the duration of the plateau for the outlet temperature. Both heat sources have contributed to this fact, the inlet heat as well as the heat of the exothermic reactions.

In the noble metal coating, the vacancies occupied by the different species show that the TWC is mostly filled with oxygen during the whole test (Figure 5.21) as expected, since lean AFR is applied. The percentage of vacancies occupied by $\mathrm{CO}$ and $\mathrm{HC}$ reaches its maximum just before the beginning of the oxidation reactions, again some seconds earlier for $\mathrm{CO}$ than for HC. After 100 seconds, the conversion efficiency is high for both species considered. However, due to the relatively low air mass flow, only the first two thirds of the catalyst length are above light-off temperature (Figure 5.22). The evolution of the emissions shows how most of the oxidation takes place in the first 10 centimetres. The temperature of the brick also corroborates this fact, since only the first half of the converter's length shows a change of slope in the temperature profiles (Figure 5.20). Figures 5.23 and 5.24 show similar cold-start tests with different air mass flows, 21 and $18 \mathrm{~kg} / \mathrm{h}$ respectively. As a consequence of the mass flow decrease, the duration of the plateau for the outlet temperature increases. The model is able to predict this phenomenon, where water condensation 

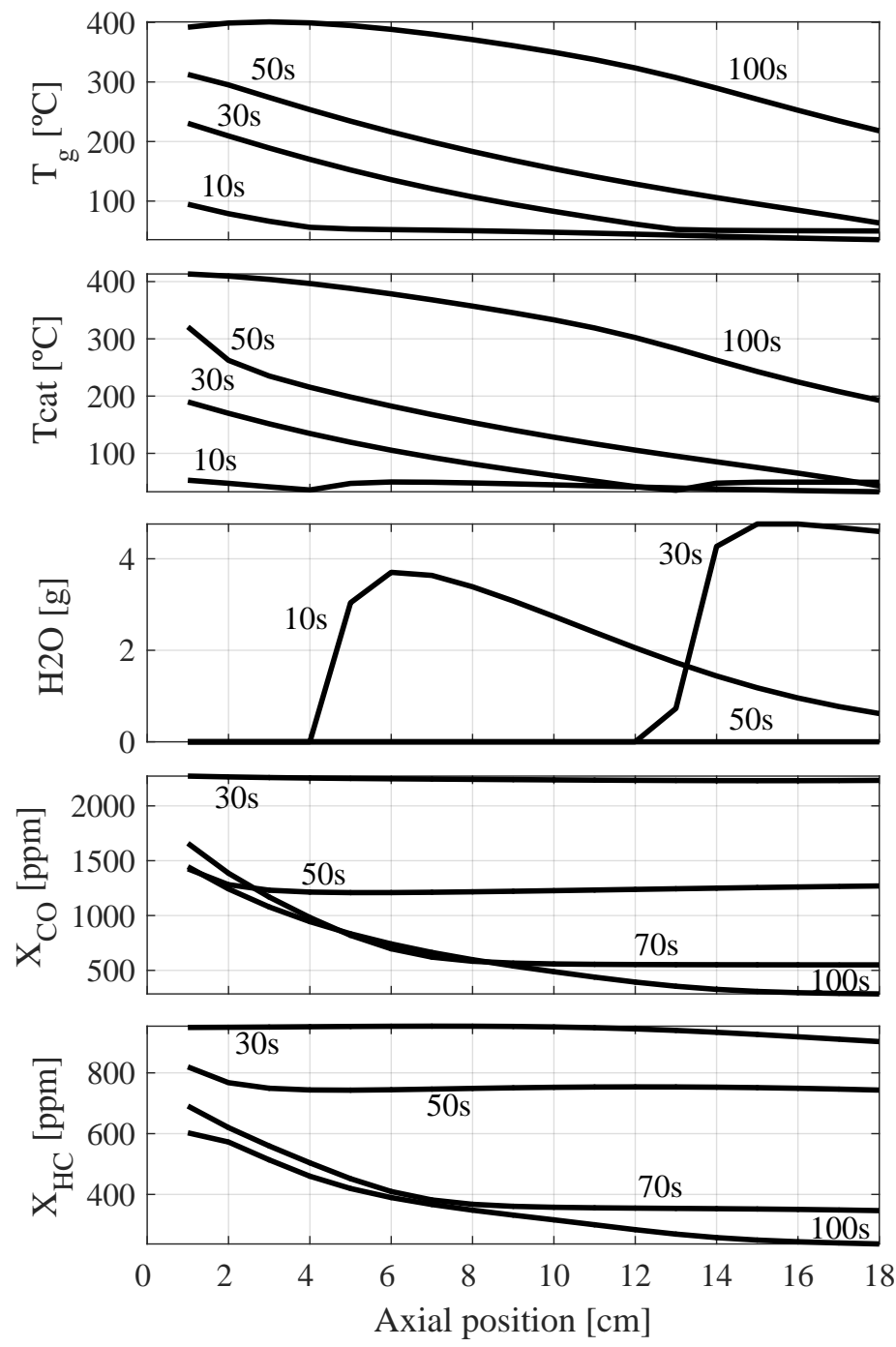

Figure 5.22: Air mass flow equal to $26 \mathrm{~kg} / \mathrm{h}$. Model predictions for temperatures, water content and emissions distribution along the TWC axis 
and evaporation play a key role, as well as the consequent emissions decrease.

The error distribution for temperature, $\mathrm{CO}$ and $\mathrm{HC}$ emissions at catalyst outlet in the three tests shown previously is summarized in Figure 5.26. The $\mathrm{x}$-axis represents the percentage of samples with an error below a certain threshold, while the y-axis represents the corresponding value of the error for each parameter assessed. In particular, during the simulation the $90 \%$ of the samples have an error in the outlet temperature below 23 degrees, as well as below 408 an 212 ppm in the case of CO and $\mathrm{HC}$ emissions respectively. The highest errors in terms of emissions correspond to the first seconds of the tests, when the inlet gas composition changes fast as a consequence of the engine start-up, as well as to the aforementioned $\mathrm{HC}$ condensation.

In Figure 5.25 a double step in air mass flow is performed. It reaches $40 \mathrm{~kg} / \mathrm{h}$ until second 27, then decreases fast until $16 \mathrm{~kg} / \mathrm{h}$. Finally, the air mass flow increases again until $29 \mathrm{~kg} / \mathrm{h}$ at second 50 and it is kept at steady conditions until the end of the test. As a consequence of these changes, the plateau of the outlet temperature is not so well defined, and the model overestimates the outlet temperature. However, the emissions prediction is still good because that temperature is not driving the species conversion, but the temperatures of the front sections. A zerodimensional model would fail if that happens. In contrast to previous tests, the air mass flow evolution involves the change of the slope at the inlet temperature. Both the inlet temperature as well as the temperature in the first section of the converter reach a value above $400{ }^{\circ} \mathrm{C}$ before decreasing again to $300{ }^{\circ} \mathrm{C}$. The $\mathrm{HC}$ conversion is affected by this temperature reduction showing a peak in emissions. However, this is not the case of $\mathrm{CO}$ emissions because of its lower activation energy. The model is also able to predict that peak, although the slight temperature overestimation anticipates the aforementioned emissions increase. 

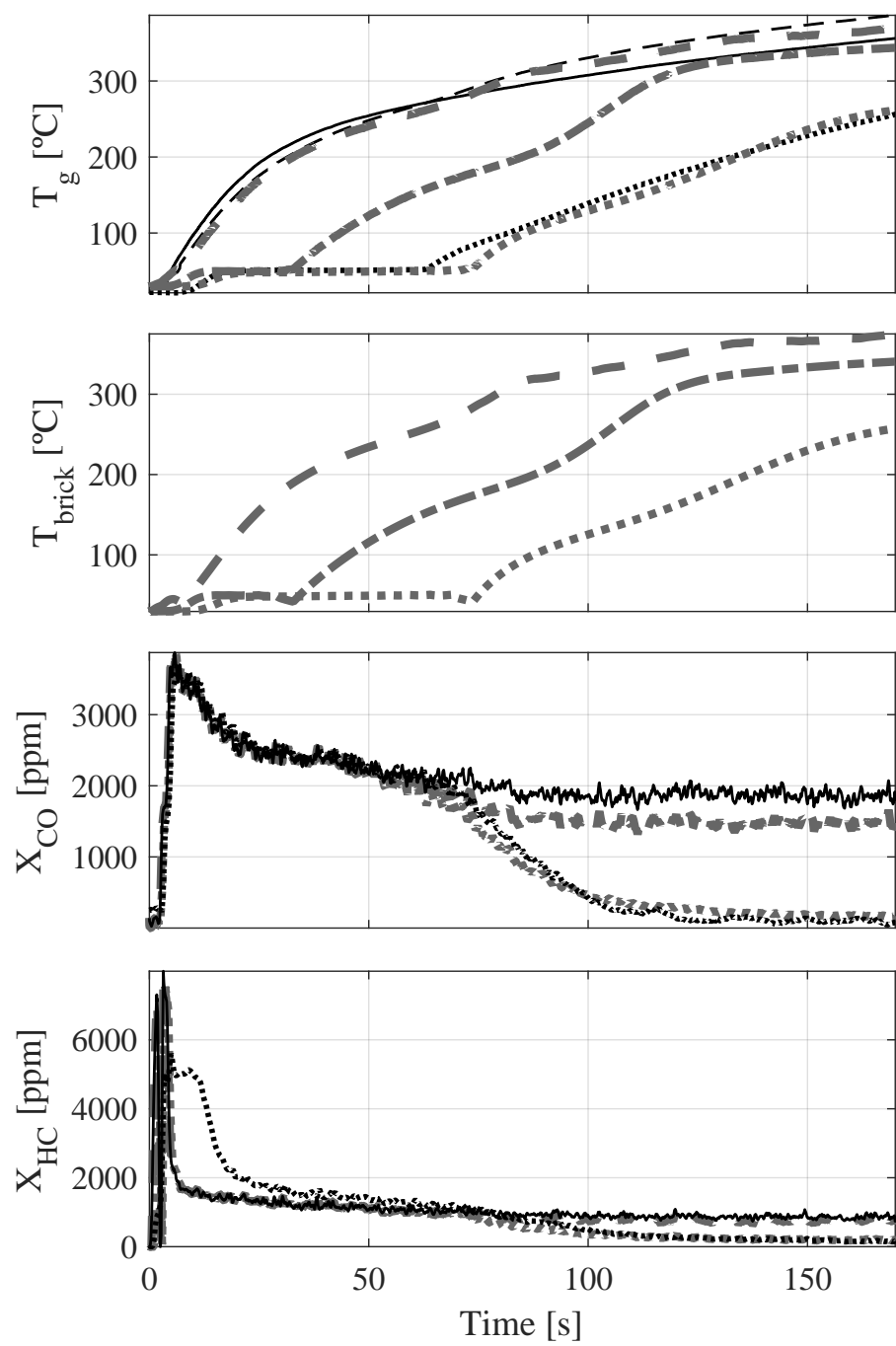

Figure 5.23: Air mass flow equal to $21 \mathrm{~kg} / \mathrm{h}$. Temperatures and emissions evolution. Black lines represent experimental data while gray lines are model predictions. Solid (-), dashed $(---)$, dash-dot (-.-) and dotted $(\cdots \cdots)$ lines correspond to inlet, first section, central section and outlet respectively 

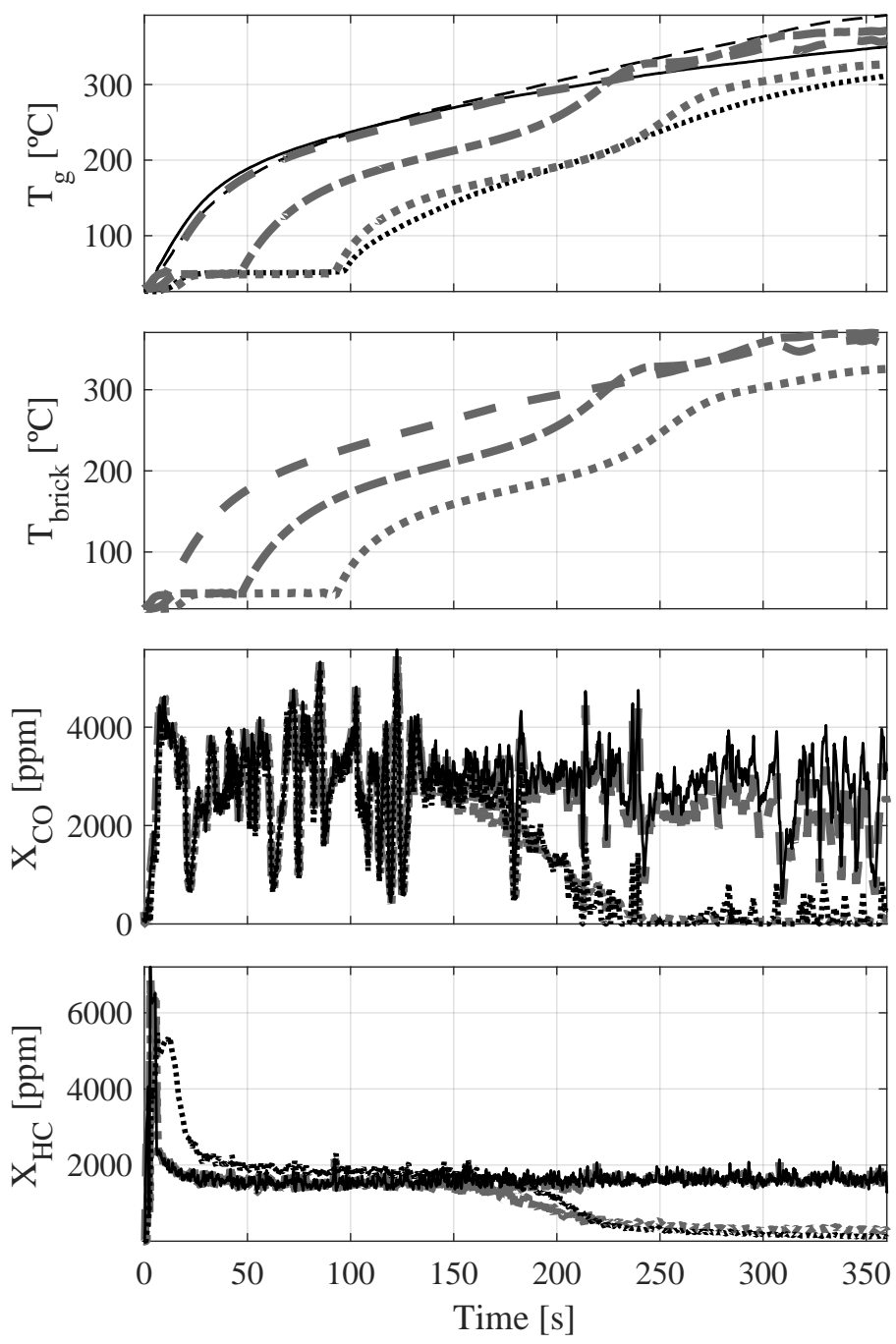

Figure 5.24: Air mass flow equal to $18 \mathrm{~kg} / \mathrm{h}$. Temperatures and emissions evolution. Black lines represent experimental data while gray lines are model predictions. Solid ( - ), dashed $(---)$, dash-dot (-.-) and dotted $(\cdots \cdots)$ lines correspond to inlet, first section, central section and outlet respectively 

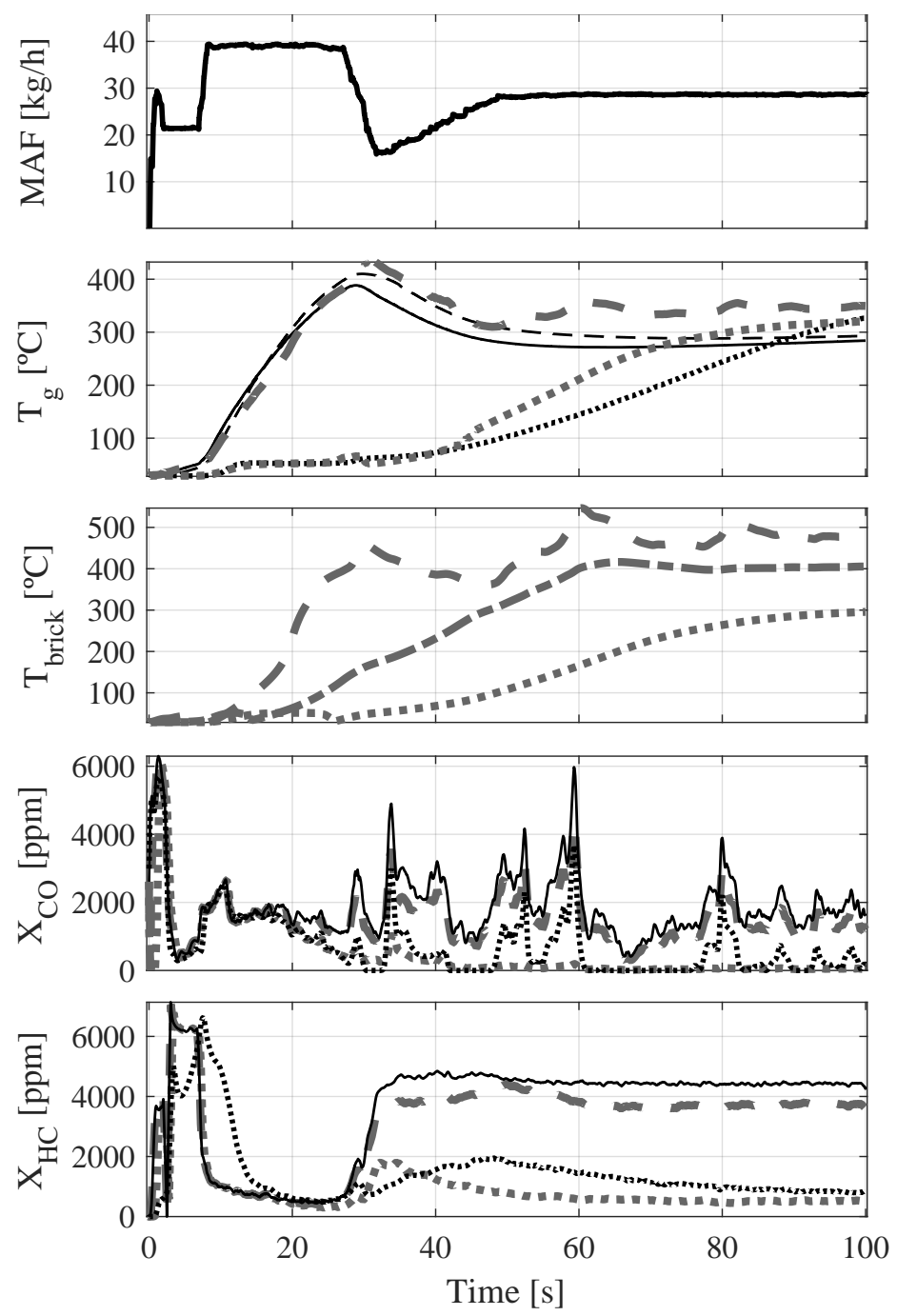

Figure 5.25: Test with air mass flow steps. Temperatures and emissions evolution. Black lines represent experimental data while gray lines are model predictions. Solid (-), dashed $(---)$, dash-dot (-.-) and dotted $(\cdots \cdots)$ lines correspond to inlet, first section, central section and outlet respectively 


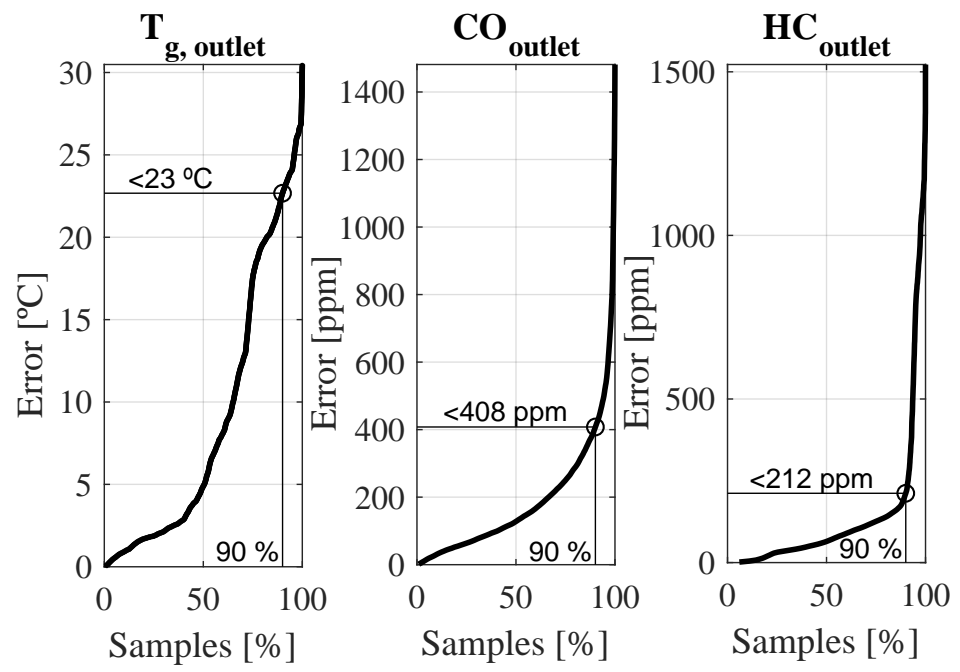

Figure 5.26: Error distribution for temperature, $\mathrm{CO}$ and $\mathrm{HC}$ emissions at catalyst outlet in the three tests shown previously with air mass flows equal to 26,21 and $18 \mathrm{~kg} / \mathrm{h}$ respectively 



\section{Chapter 6}

\section{Three-way catalyst control}

Contents

6.1 Three-way catalyst stimulation through AFR control . . . .142 6.1.1 Effects of stimulation amplitude and frequency on tailpipe emissions . . . . . . . . . . . . . . . . . . . . . . . . 143

6.1 .2 Considerations for aged converters . . . . . . . . . . . 150

6.2 Model-based control at transient conditions . . . . . . . 156 6.2.1 AFR disturbances correction based on on-line OSL estimation. . . . 156 6.2 .2 Optimal three-way catalyst purge strategy . . . . . . . . . . . . . 159 6.2 .3 On-line three-way catalyst purge strategy . . . . . . . . . . . . .166

6.3 AFR control under short-circuit conditions. . . . . . . .169 6.3.1 Problem description. . . . . . . . . . . . . . . . . . . . 170 6.3 .2 Correction strategy of the SC effect . . . . . . . . . . . . 173 6.3 .3 Results and discussion . . . . . . . . . . . . . . . . . . . . . 176 


\subsection{Three-way catalyst stimulation through AFR control}

TWCs are only capable to effectively reduce $\mathrm{NO}_{\mathrm{x}}$ and simultaneously oxidise $\mathrm{CO}$ and $\mathrm{HC}$ in a narrow range of AFRs around stoichiometric conditions, the well-known catalyst window. An interesting question could be, is there any control strategy that allows to widen the catalyst window? Of course, during transient phases, the oxygen storing capability of the TWC (section 5.1) allows to cope with fast excursions towards lean or rich conditions, but is it possible to extend the catalyst window at steady-state conditions?

The present section pretends to deal with these issues by assessing the suitability of the fuel-to air ratio stimulation under steady-state conditions. Regarding stimulation frequency and amplitude, there is a threshold above which the entire catalyst is full or empty of oxygen at each stimulation period [136], that is, low frequencies and high amplitudes. Once reached these conditions, the AFR stimulation will always be detrimental from the emissions point of view. Thereby, these amplitudes and frequencies are out of the scope of this study, only those AFR stimulations that do not saturate the oxygen storing along the whole catalyst length are useful for the present approach. In this sense, oxygen storing is a crucial parameter under oscillating AFR conditions. In fact, the different adsorption and desorption rates of the TWC cause an asymmetric behaviour in the $\mathrm{CO}, \mathrm{HC}$ and $\mathrm{NO}_{\mathrm{x}}$ breakthrough when switching from rich to lean conditions and vice versa [235].

The target of the present study is to gain insights regarding the actual suitability of AFR stimulation in order to decrease tailpipe emission, taking into account not only the TWC behaviour, but also the simultaneous shift of exhaust temperature and gas composition induced by the AFR stimulation. All of it with state-of-the-art hardware in terms of engine and aftertreatment systems. Particularly considering that nowadays, with the use of wideband $\lambda$ sensors, AFR stimulation must be specifically implemented if needed. 


\subsubsection{Effects of stimulation amplitude and frequency on tailpipe emissions}

Three operating points have been chosen to perform this study, $1250 \mathrm{rpm}$ and $25 \mathrm{Nm}$ as representative of low air mass flow (AMF) and temperature conditions, $2500 \mathrm{rpm}$ and $75 \mathrm{Nm}$ as representative of mid-low range and $3500 \mathrm{rpm}$ and $75 \mathrm{Nm}$ as representative of mid-high AMF and temperature conditions. For each one, the stimulation amplitudes evaluated range from $\phi \pm 0$ (without stimulation) to $\phi \pm 0.045$, with steps each 0.005 . The stimulation frequencies assessed are $0.1 \mathrm{~Hz}, 0.5 \mathrm{~Hz}, 1 \mathrm{~Hz}$ and $2 \mathrm{~Hz}$. An example of the $\phi$ profile imposed at catalyst inlet for this type of test is shown in Figure 6.1. This test is repeated in ascendant and descendant order to assess the repeatability. It is split into two parts just to reduce the length of the file, each part sweep a different range of amplitudes. This experiment is used to quantify the effect of AFR stimulation on tailpipe emissions for a wide range of stimulations and frequencies at a certain time-averaged $\phi$. Several time-average $\phi$ levels have been assessed in order to check the influence of the stimulation amplitude and frequency at optimal conditions, as well as at leaner and richer conditions than those of optimal $\phi(\phi *)$. The term optimal conditions refers to those conditions that allow to minimize a predefined cost function (equation 6.1), thus not necessarily stoichiometric conditions, that is, $\phi=1$.

$$
C F=m_{C O}+10 \cdot m_{H C}+16.7 \cdot m_{N O_{x}}
$$

The parameters $m_{x}$ represent the mass flow of each species at catalyst outlet in $\mathrm{mg} / \mathrm{s}$. The objective of this cost function is to weight each species according to the maximum values allowed by the EURO 6 emissions regulation, that is, $1000 \mathrm{mg} / \mathrm{km}$ for $\mathrm{CO}, 100 \mathrm{mg} / \mathrm{km}$ for $\mathrm{HC}$ and $60 \mathrm{mg} / \mathrm{km}$ for $\mathrm{NO}_{\mathrm{x}}$. Therefore, despite being arbitrary, the defined cost function gives an idea of the stimulation effects on the overall emissions.

The emissions measurement at catalyst outlet allows to check the superimposed effect of AFR stimulation on exhaust gas composition (upstream of the TWC) as well as on conversion efficiency. The results obtained in terms of temperatures and emissions downstream of the TWC are summarized in Figure 6.2 to 6.6. Each point of these maps correspond to 


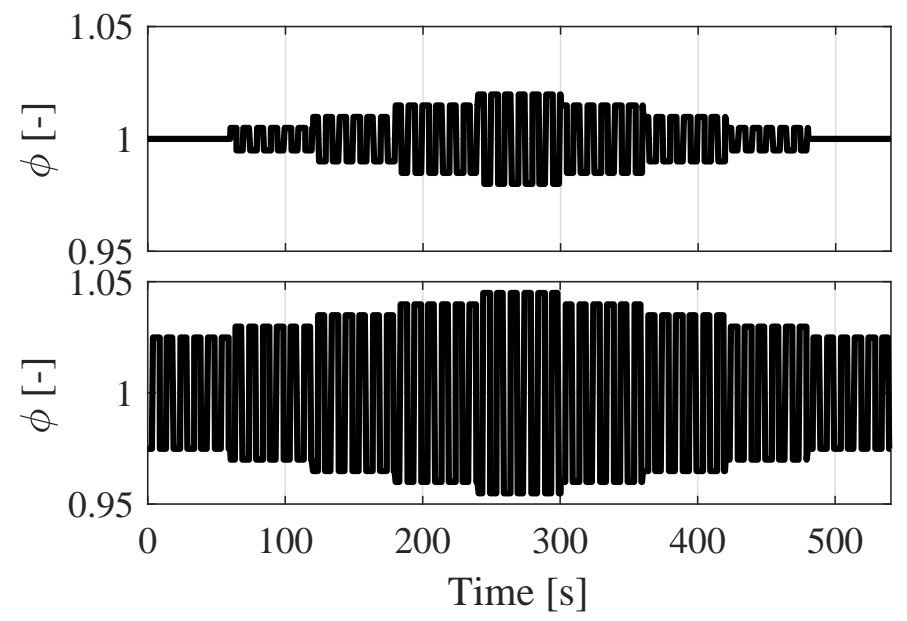

Figure 6.1: Example of AFR stimulation amplitude sweep tests for a certain frequency

average values obtained from the different sweeps of amplitude and frequency carried out experimentally, according to the test shown in Figure 6.1. There are four maps on each figure, $\mathrm{NO}_{\mathrm{x}}$ and $\mathrm{CO}$ concentrations downstream of the catalyst in the top row, as well as temperatures at TWC inlet and inside of the converter in the bottom row. Gray scales quantify the parameter indicated above each map. X-axis represent conditions without stimulation, as the amplitude is zero for all the frequencies. In some cases, the values of the maps are not exactly equal along the mentioned axis due to the dispersion of the experimental tests. However, the measurements can be considered accurate enough for the present analysis, since this dispersion is small enough as to not disturb the overall trends (8 ppm for $\mathrm{NO}_{\mathrm{x}}$ emissions in Figure 6.2). In the case of low AMF, high amplitudes are not achieved at high frequencies. This is due to the slow dynamic of the $\phi$ set-point for this conditions, which prevents reaching the AFR set-point in such a short time. This effect is smaller in the other two operating conditions assessed (i.e., mid-low and mid-high AMF), since the dynamics of the AFR set-point are faster when AMF increases. 

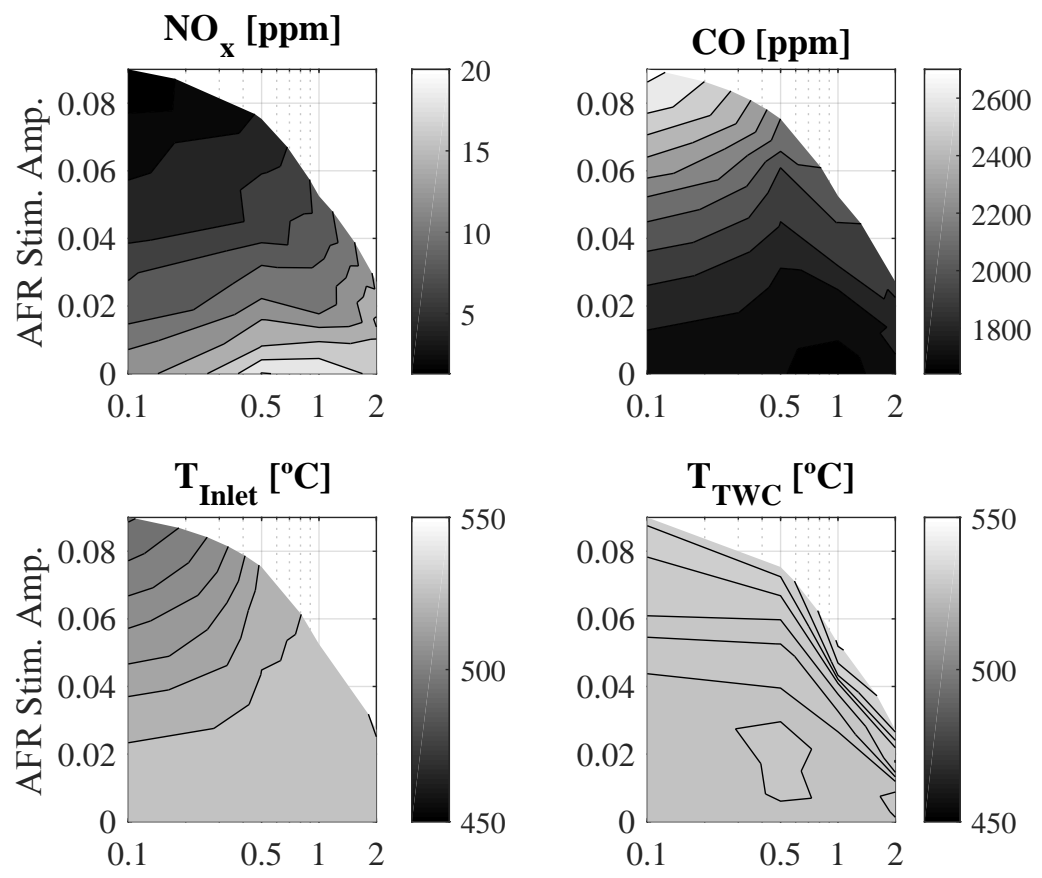

AFR Stim. Freq. [Hz]

AFR Stim. Freq. [Hz]

Figure 6.2: Effect of AFR stimulation amplitude and frequency on pollutant emissions. Operating point of $1250 \mathrm{rpm}$ and $25 \mathrm{Nm}$ for optimal $\phi(\phi *=1.063)$ with fresh TWC 
Figure 6.2 shows operating conditions of low temperature and AMF for optimal $\phi(\phi *=1.063$ for these conditions $)$. The AFR stimulation induces a small reduction in $\mathrm{NO}_{\mathrm{x}}$ emissions, since $\mathrm{NO}_{\mathrm{x}}$ conversion is already high at $\phi *$. The effect of the frequency is smaller than the one of the amplitude. The increase in $\mathrm{CO}$ emissions is noticeable when amplitude raises. Regarding temperature, at the inlet it decreases for high amplitudes, nevertheless, catalyst temperature is not affected in that way, probably because of the increase in TWC activity. Figure 6.3 and 6.4 show similar results for different operating conditions, i.e., mid-low and mid-high AMF respectively with $\phi *$.
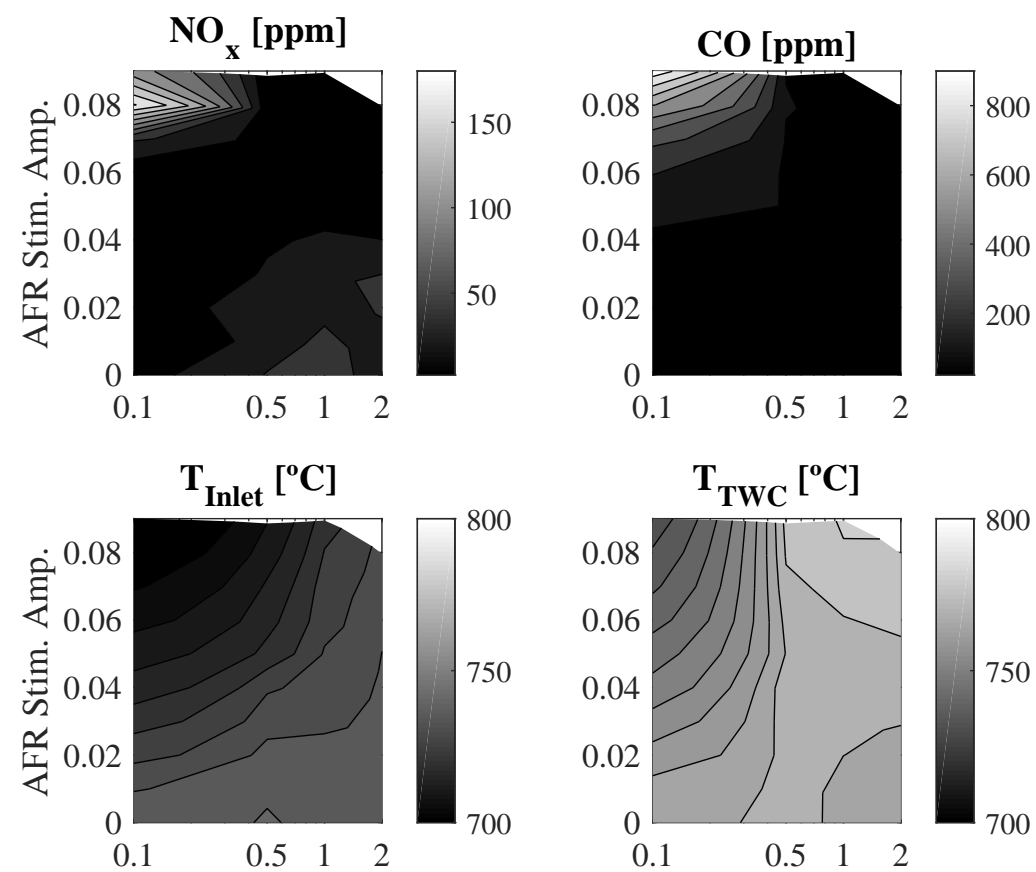

AFR Stim. Freq. [Hz]

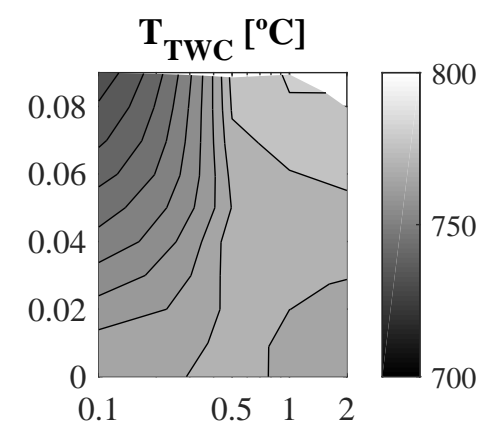

AFR Stim. Freq. [Hz]

Figure 6.3: Effect of AFR stimulation amplitude and frequency on pollutant emissions. Operating point of $2500 \mathrm{rpm}$ and $75 \mathrm{Nm}$ for optimal $\phi(\phi *=1.016)$ with fresh TWC

According to the literature, the lower the temperature the higher the improvement on emissions achieved by imposing the proper AFR stimulation [193]. However, the benefits of AFR stimulation on emissions 
shown in Figure 6.2 are negligible for $\mathrm{NO}_{\mathrm{x}}$, while the effect on $\mathrm{CO}$ is harmful, even though for this operating point the temperature at catalyst inlet is low (but widely above light-off temperature). This behaviour agrees with the extended idea about the negligible enhancement of conversion efficiency that $\lambda$ cycling provides around the $\phi$ range of minimal emissions [183]. Figure 6.3 and 6.4 corroborate this idea, the impact of AFR stimulation on emissions at $\phi *$ is almost negligible for a wide range of amplitudes and frequencies. Moreover, different combinations of both parameters achieve the same tailpipe emissions [236].
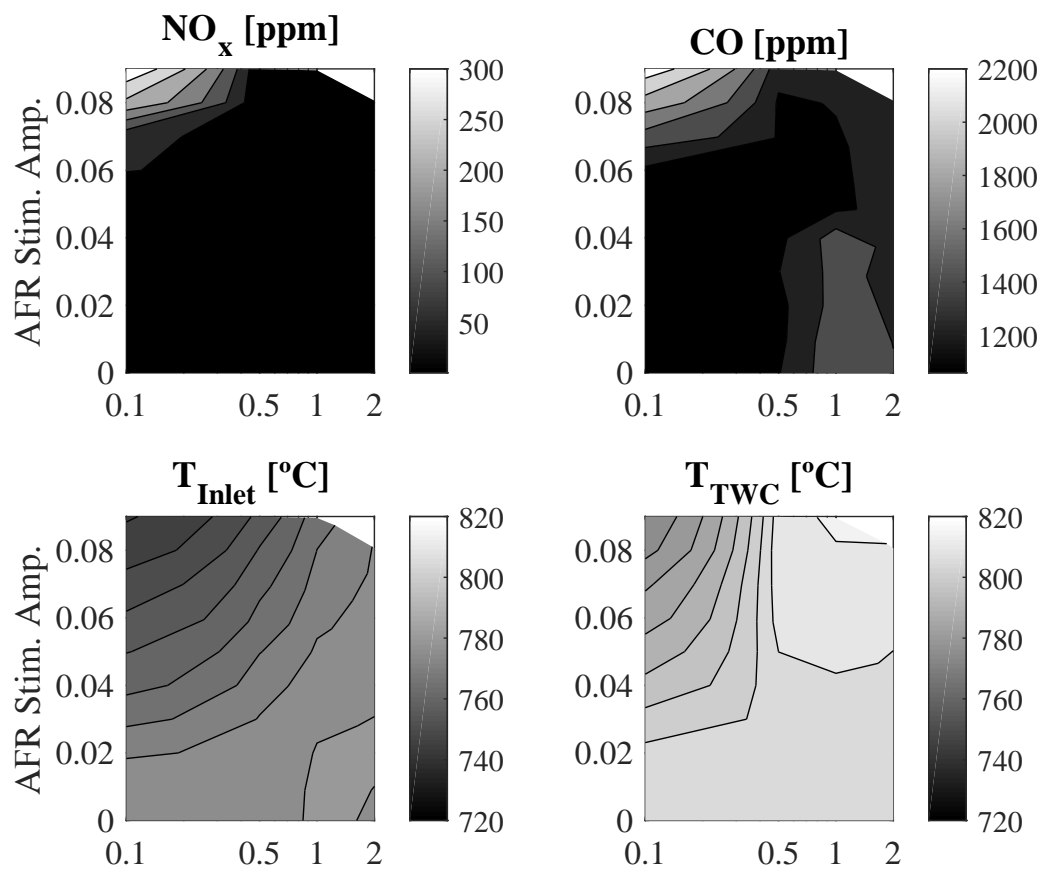

AFR Stim. Freq. [Hz]

AFR Stim. Freq. [Hz]

Figure 6.4: Effect of AFR stimulation amplitude and frequency on pollutant emissions. Operating point of $3500 \mathrm{rpm}$ and $75 \mathrm{Nm}$ for optimal $\phi(\phi *=1.023)$ with fresh TWC

Only when an excessive amplitude is imposed at low frequencies, the stimulation causes a simultaneous increase in both $\mathrm{CO}$ and $\mathrm{NO}_{\mathrm{x}}$ emissions. This effect could be related to the temperature drop inside the TWC. In all cases high amplitudes and low frequencies promotes the 
decrease of the inlet temperature. However, in case of higher AMF (Figure 6.3 and 6.4 ) the temperature drop of the inlet flow induces also the decrease of the TWC temperature, reducing the catalyst activity.

Figures 6.5 and 6.6 show the same study addressed previously but imposing leaner AFR than that needed to achieve optimal emissions, for operating points of low and mid-high AMF respectively. An important decrease in $\mathrm{NO}_{\mathrm{x}}$ emissions arises as stimulation amplitude rises for $\phi$ leaner than $\phi *$. This phenomena agrees with the extended idea about the benefits of $\lambda$ cycling at lean conditions for $\mathrm{NO}_{\mathrm{x}}$ conversion [183], which is justified by CO inhibition [236, 237].
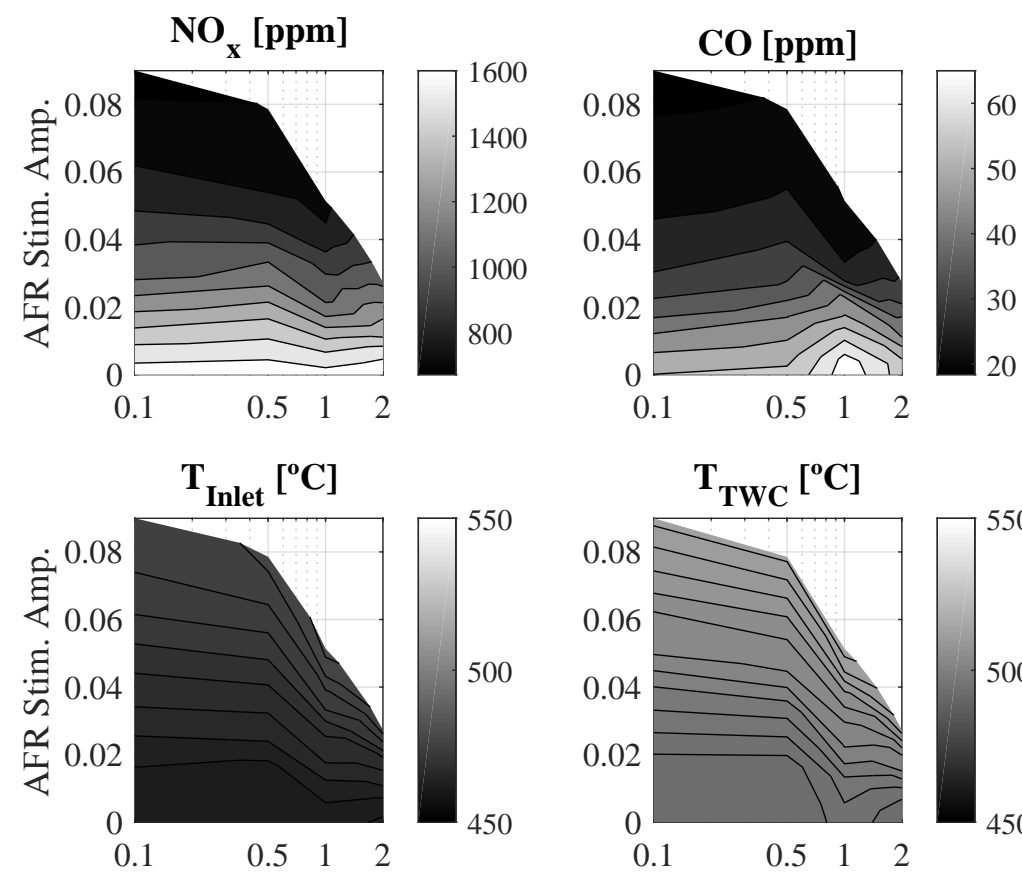

AFR Stim. Freq. [Hz]

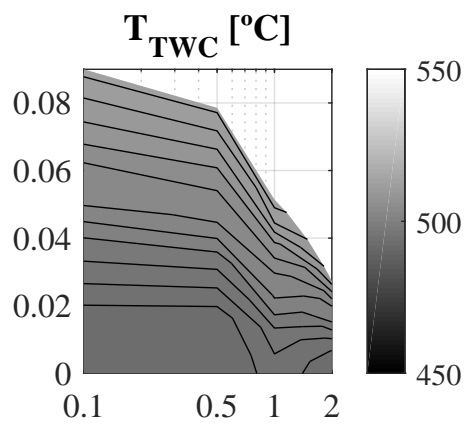

AFR Stim. Freq. [Hz]

Figure 6.5: Effect of AFR stimulation amplitude and frequency on pollutant emissions. Operating point of $1250 \mathrm{rpm}$ and $25 \mathrm{Nm}$ for $\phi=1.010(\leq \phi *=1.063)$ with fresh TWC

The aforementioned phenomena could be also due to the change of the gas composition at catalyst inlet when AFR stimulation is performed. This idea lies on the non-linearity of the concentration of each species 
of the exhaust gas at certain AFR ranges. Basically, in a GDI engine, the $\mathrm{NO}_{\mathrm{x}}$ concentration increases as in-cylinder AFR increases, but the maximum value is delimited by a plateau around $4000 \mathrm{ppm}$ (this value is slightly dependent on the engine operating conditions). Nevertheless, CO concentration increases almost exponentially at rich conditions, reaching concentrations really high in comparison with those typical of $\mathrm{NO}_{\mathrm{x}}$ emissions (almost an order of magnitude greater). As a result, when the stimulation is imposed, the time-averaged value of each species is different from those typical of steady state, decreasing in the case of $\mathrm{NO}_{\mathrm{x}}$ and increasing in the case of CO. Consequently, the time-averaged gas composition at catalyst inlet under AFR stimulation is richer than without AFR stimulation. Therefore, the potential to reduce $\mathrm{NO}_{\mathrm{x}}$ by means of its reaction with $\mathrm{CO}$ is higher.
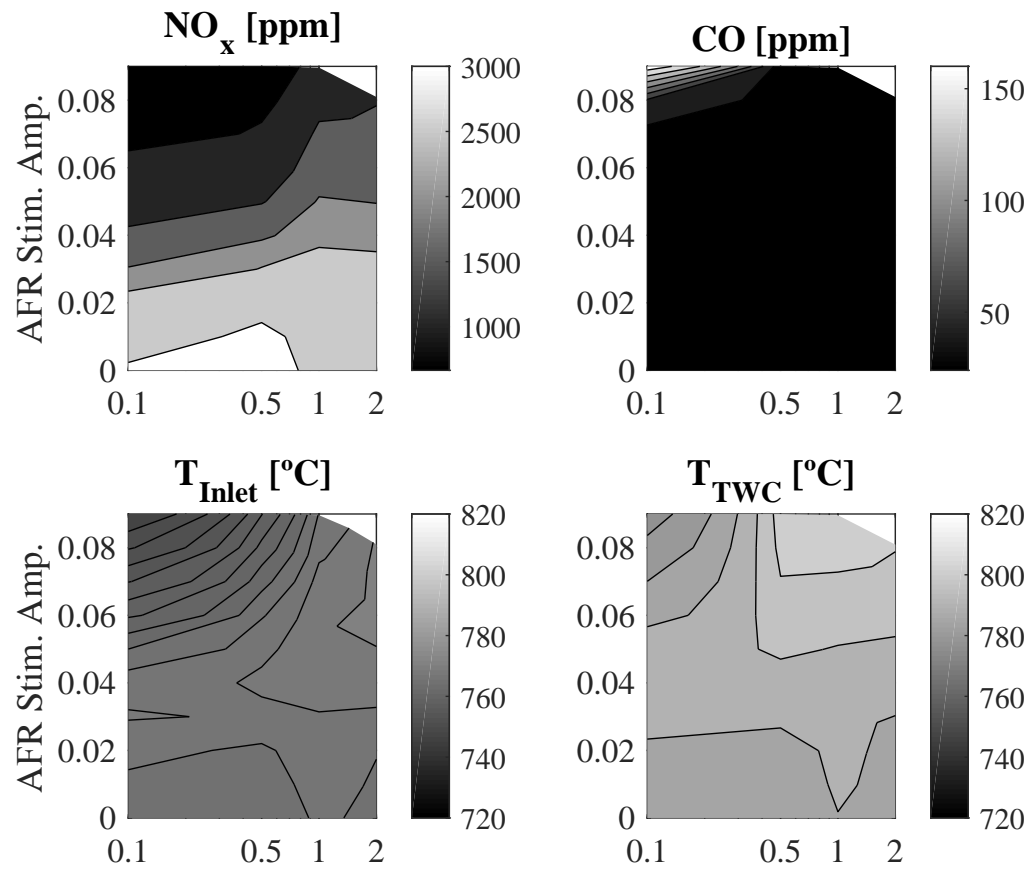

AFR Stim. Freq. [Hz]

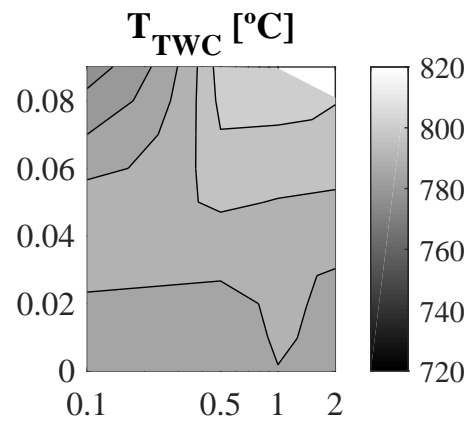

AFR Stim. Freq. [Hz]

Figure 6.6: Effect of AFR stimulation amplitude and frequency on pollutant emissions. Operating point of $3500 \mathrm{rpm}$ and $75 \mathrm{Nm}$ for $\phi=1.000(\leq \phi *=1.023)$ with fresh TWC 
Figure 6.7 and 6.8 show the summary of the results obtained for a wide range of average $\phi$, for the range of amplitudes represented in the gray scale and frequency equal to $1 \mathrm{~Hz}$. The different values of the gray scales in both figures are due to the aforementioned difference in the dynamic of the $\phi$ set-point for each AMF. First, second and third rows represent $\mathrm{NO}_{\mathrm{x}}$, CO emissions and the values provided by the $\mathrm{CF}$ defined in equation (6.1), respectively. The decrease of tailpipe $\mathrm{NO}_{\mathrm{x}}$ emissions with $\mathrm{AFR}$ stimulation is strong in the lean range. CO emissions are not affected in that range since their conversion efficiency is high. In the rich range, $\mathrm{NO}_{\mathrm{x}}$ emissions are not affected by the AFR stimulation in a noticeable way. However, the effect of the AFR stimulation is harmful for tailpipe $\mathrm{CO}$ emissions in the rich range. The weights of each pollutant specie in the proposed $\mathrm{CF}$ make that the reduction of $\mathrm{NO}_{\mathrm{x}}$ emissions induced by the AFR stimulation shifts $\phi *$ towards slightly leaner conditions than those obtained without stimulation. That is, widening the AFR range of minimal emissions of the TWC.

Most of the results obtained regarding the effect of stimulation amplitude and frequency are in accordance with the ones described in literature [238]. A proper $\lambda$ modulation improves conversion efficiency of oxidizing species $\left(\mathrm{NO}_{\mathrm{x}}\right)$ at leaner conditions than those of $\phi *$, but around $\phi *$ the improvement is negligible. However, in the present study the reduction of tailpipe $\mathrm{CO}$ emissions as a consequence of AFR stimulation at rich conditions has not been observed, despite the improvement in $\mathrm{CO}$ conversion efficiency reported in the literature [183]. It could be due to the superimposed effect of AFR stimulation on exhaust gas composition, that is, to the increase of $\mathrm{CO}$ concentration at catalyst inlet because of the non-linearity of the concentration of each species depending on the AFR.

\subsubsection{Considerations for aged converters}

The previous section focuses on the effect of AFR stimulation on the fresh TWC. Figure 6.9 and 6.10 are equivalent to Figure 6.7 and 6.8 in terms of operating conditions, but using the aged TWC instead of the fresh one. As a consequence of the TWC ageing, its oxidation capabilities drop strongly comparing emissions in both the aged and the fresh TWC 


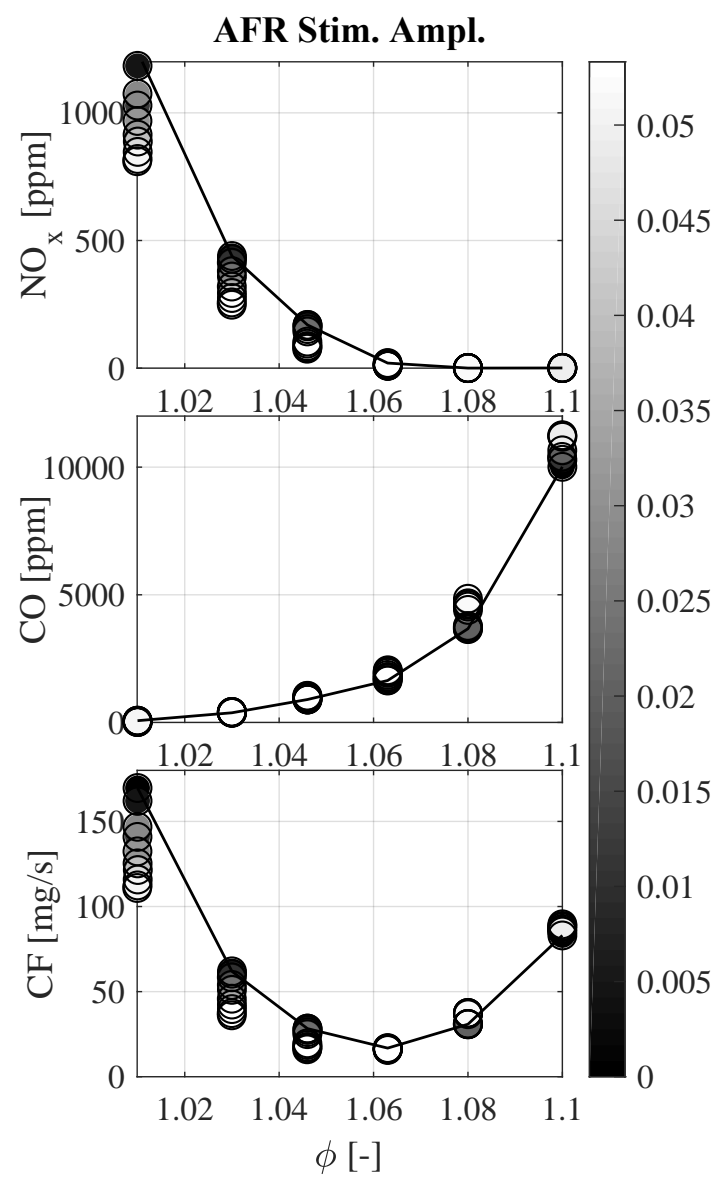

Figure 6.7: Summary of AFR stimulation effect on pollutant emissions for stimulation frequency equal to $1 \mathrm{~Hz}$. The gray scale represents the stimulation amplitude. Operating point of $1250 \mathrm{rpm}$ and $25 \mathrm{Nm}$ with fresh TWC 


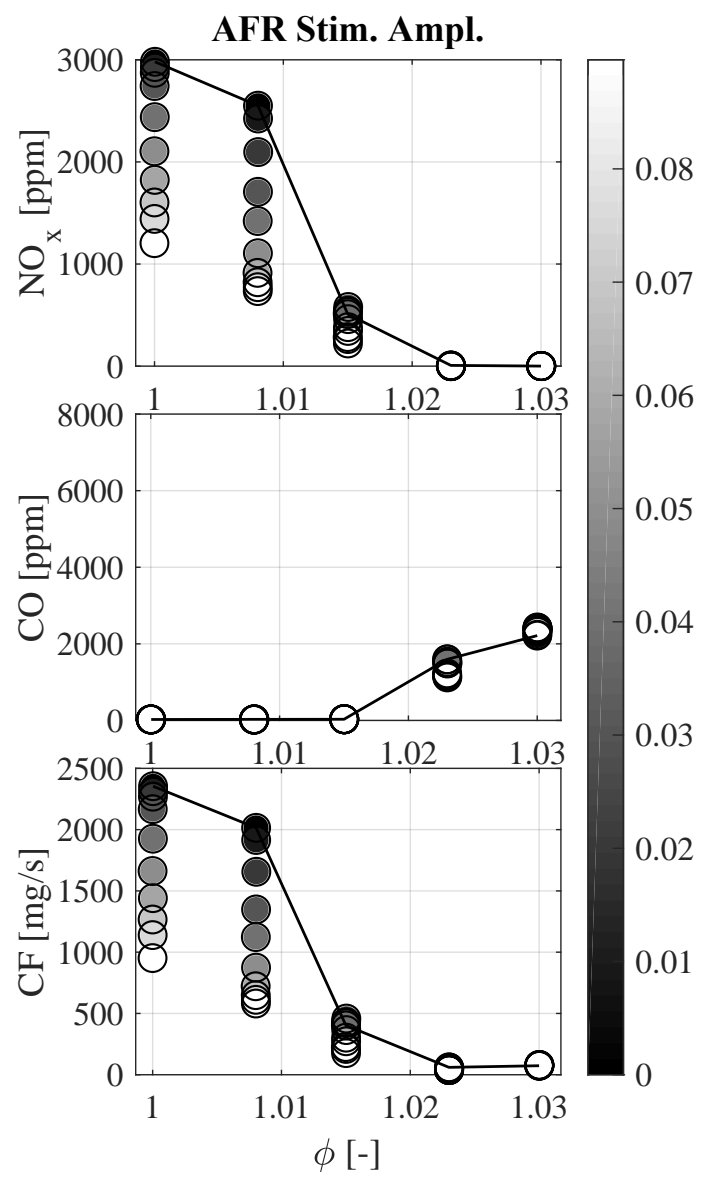

Figure 6.8: Summary of AFR stimulation effect on pollutant emissions for stimulation frequency equal to $1 \mathrm{~Hz}$. The gray scale represents the stimulation amplitude. Operating point of $3500 \mathrm{rpm}$ and $75 \mathrm{Nm}$ with fresh TWC 


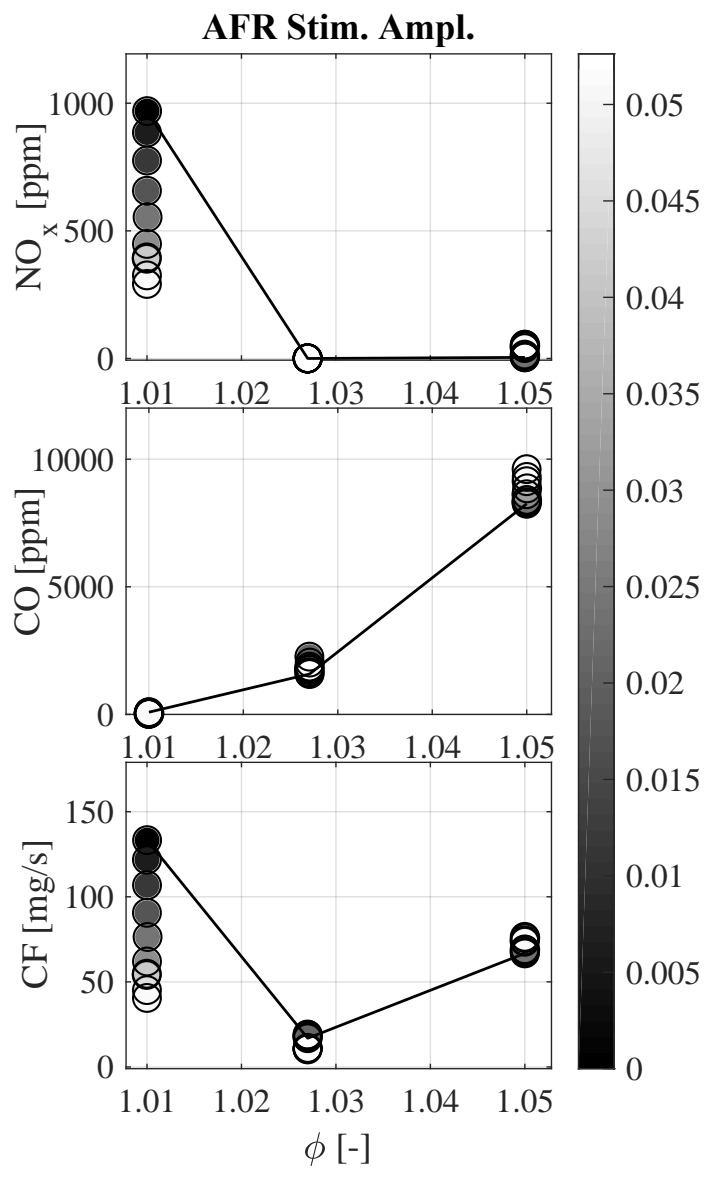

Figure 6.9: Summary of AFR stimulation effect on pollutant emissions for stimulation frequency equal to $1 \mathrm{~Hz}$. The gray scale represents the stimulation amplitude. Operating point of $1250 \mathrm{rpm}$ and $25 \mathrm{Nm}$ with the aged TWC 


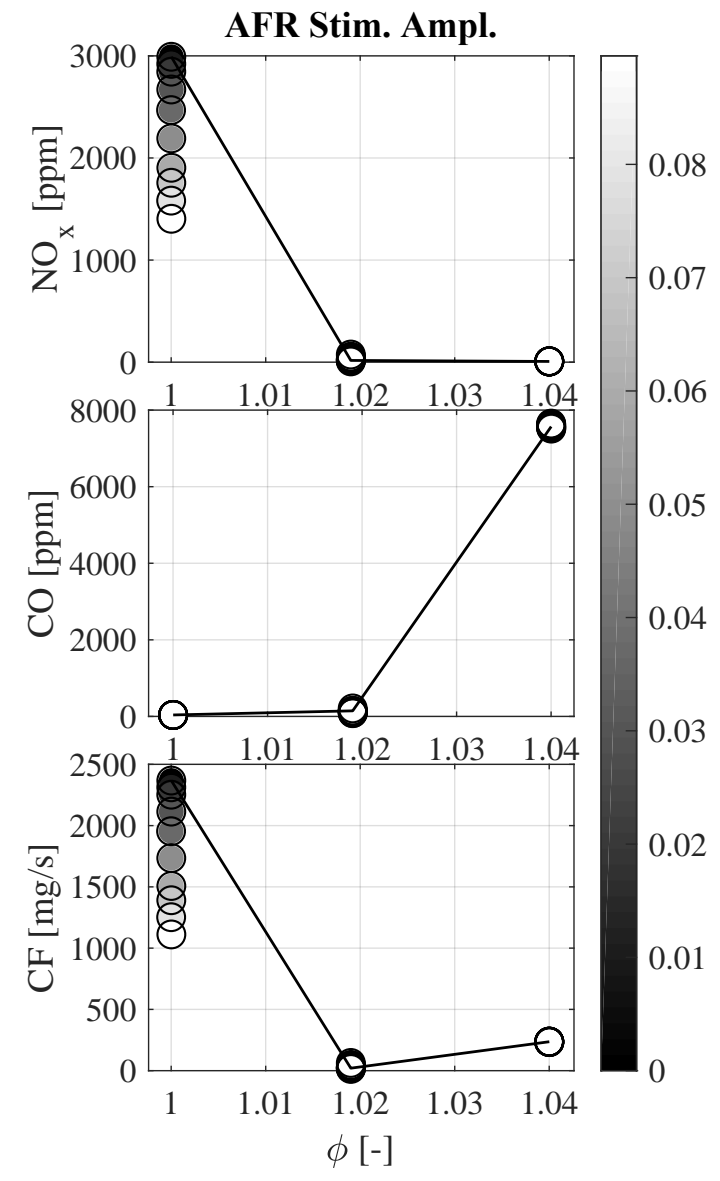

Figure 6.10: Summary of AFR stimulation effect on pollutant emissions for stimulation frequency equal to $1 \mathrm{~Hz}$. The gray scale represents the stimulation amplitude. Operating point of $3500 \mathrm{rpm}$ and $75 \mathrm{Nm}$ with the aged TWC 
at the same $\phi$. This effect is particularly relevant at low AMF (Figure 6.7 and 6.9). The practical consequence is the shift of $\phi *$ towards leaner conditions. The decrease of the $\mathrm{CO}$ oxidation by means of oxygen in the TWC (equation (6.2)) is responsible of a high availability of $\mathrm{CO}$, which in turn increases the reducing capabilities of $\mathrm{NO}_{\mathrm{x}}$ by means of $\mathrm{CO}$ oxidation (equation (6.3)). That is why $\mathrm{NO}_{\mathrm{x}}$ emissions are equal or even lower in the aged TWC compared with the fresh one.

$$
\begin{aligned}
\mathrm{CO}+\mathrm{O}_{2} & \rightarrow \mathrm{CO}_{2} \\
\mathrm{CO}+\mathrm{NO} & \rightarrow \mathrm{CO}_{2}+\frac{1}{2} \mathrm{~N}_{2}
\end{aligned}
$$

By and large, the effect of AFR stimulation in the aged converter is the same as that observed with the fresh one. The main differences are due to the aforementioned effect of ageing on $\mathrm{CO}$ and $\mathrm{NO}_{\mathrm{x}}$ reactions. For a given $\mathrm{AFR}$ in the rich range, the $\lambda$ cycling induces a stronger penalty in $\mathrm{CO}$ emissions with the aged TWC, in comparison with the effect observed in the new TWC. However, the decrease of $\mathrm{NO}_{\mathrm{x}}$ emissions under $\lambda$ cycling in the lean range is smaller for the aged TWC than for the fresh one. Despite of that, the drop of $\mathrm{NO}_{\mathrm{x}}$ emissions with AFR stimulation is still very important in the aged TWC, as it is shown in Figure 6.9 and 6.10. Again, $\phi *$ is shifted towards leaner conditions than those obtained without stimulation because of the reduction of $\mathrm{NO}_{\mathrm{x}}$ emissions induced by AFR stimulation, according to the values provided by the $\mathrm{CF}$. 


\subsection{Model-based control at transient conditions}

To fulfil the limits imposed by the current emissions regulation procedures, the aftertreatment control must be able to deal with some unexpected AFR excursions, since these disturbances have a non-negligible impact on emissions as shown in section 5.1.1. The main parameter that drives the transient dynamics in current TWCs is their capability to store and release a certain amount of reducing and oxidising species, with the aid of noble metals and ceria, then allowing to oxidise some pollutant species such as $\mathrm{CO}$ or $\mathrm{HC}$ even at rich conditions during short periods of time. On the contrary, it is also the responsible of $\mathrm{NO}_{\mathrm{x}}$ penalties when performing a tip-in after a cut-off phase (section 5.1.2). In particular, the oxygen storing level (OSL) is considered a good indicator of the catalysts state [25, 150, 151], unfortunately, it cannot be directly measured by means of on-board sensors. An accurate estimation of the OSL allows to implement a AFR control strategy based not only on AFR as usual, but also on the amount of oxygen stored. Thus, a model based and realtime capable estimation (section 4.2) is needed to control the TWC in a further accurate way than currently, thereby reducing pollutant emissions during transient phases. The current section is aimed to study its potential to reduce pollutant emissions under usual transient conditions such as AFR disturbances, as well as catalyst oxygen purging.

\subsubsection{AFR disturbances correction based on on-line OSL estimation}

This strategy is based on the on-line OSL estimation provided by the the control-oriented model shown in section 4.2. At each time step, the AFR control system takes the information of the modelled OSL and corrects the baseline $\phi_{\mathrm{sp}}$ with a term proportional to the deviation of the actual OSL from its set-point $\mathrm{OSL}_{\mathrm{sp}}$, that corresponds to the desired steady state value for the given operating conditions:

$$
\Delta \phi_{s p}=k \cdot\left(O S L(t)-O S L_{s p}\right)
$$


The test performed in section 5.1.1 have been repeated in order to compare the performance of the control strategy with and without the information provided by the control-oriented model. Figure 6.11 and 6.12 represent the two main possibilities, a AFR disturbance towards rich and lean conditions respectively.
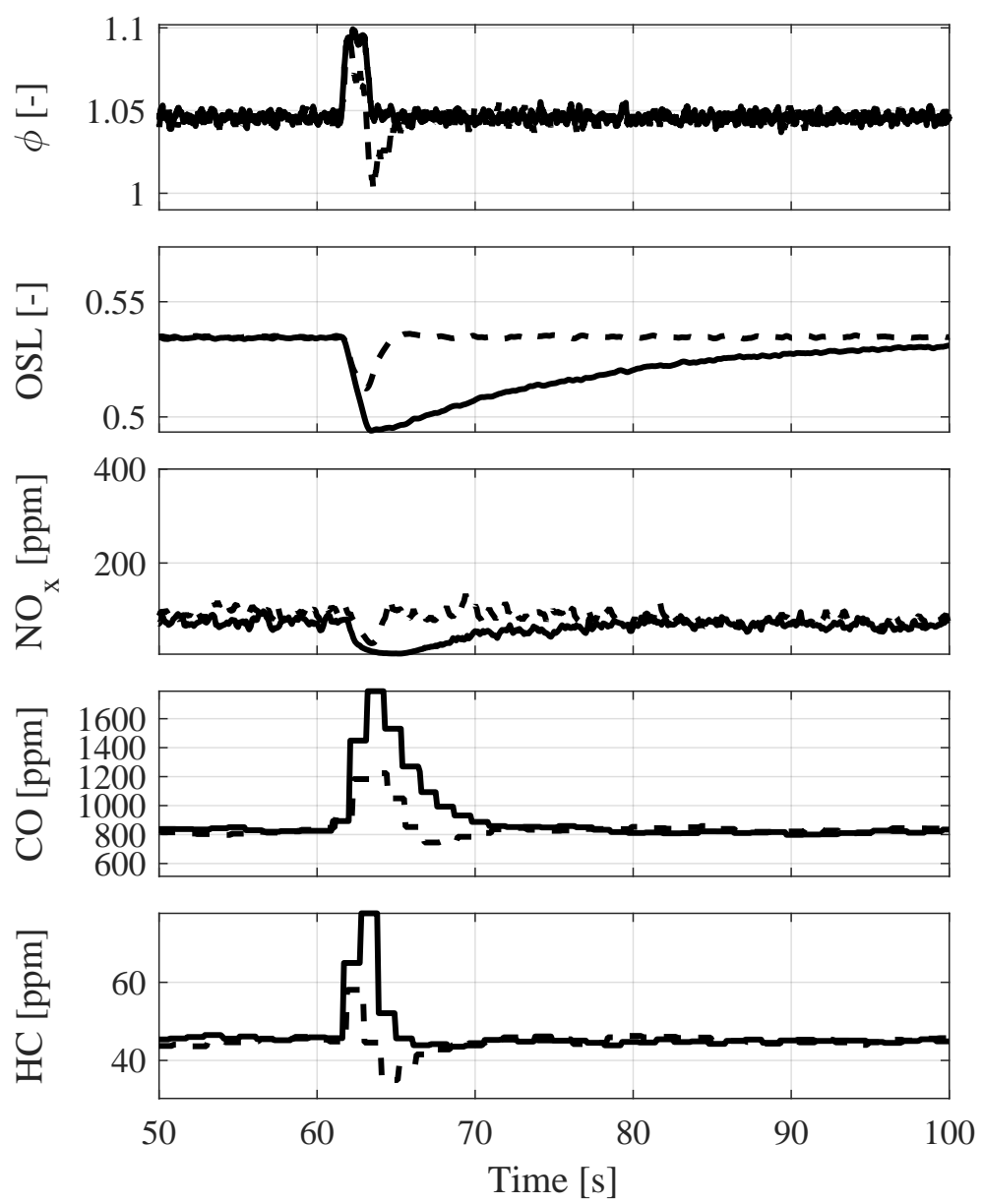

Figure 6.11: Comparison between rich $\phi$ disturbance with (dashed line - - -) and without (solid line -) on-line OSL-based correction

At the beginning of the test the operating conditions are kept constant to stabilize the main parameters involved, thus both engine and converter 

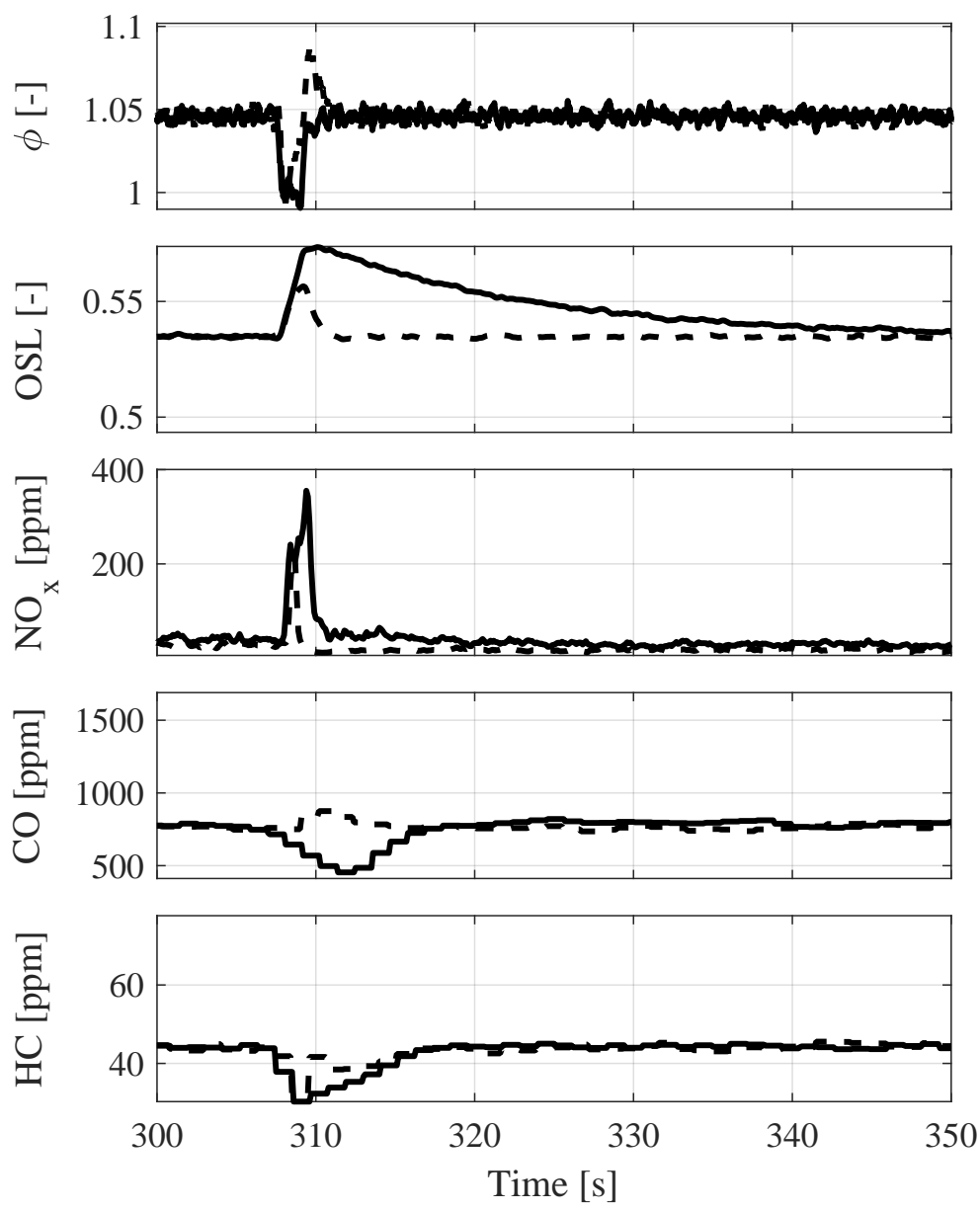

Figure 6.12: Comparison between lean $\phi$ disturbance with (dashed line - - -) and without (solid line -) on-line OSL-based correction 
are at steady state conditions before the AFR excursion is imposed. In case of a disturbance towards rich conditions, the OSL suffers a fast reduction, and then the $\phi$ correction imposes leaner AFR to avoid the emissions breakthrough. Figure 6.11 shows how the controller imposes a $\phi$ even leaner than the steady state set-point in order to recover as soon as possible the OSL reference. As a consequence of this control action, the $\mathrm{CO}$ and $\mathrm{HC}$ penalty is noticeably reduced in both amplitude and duration. CO emissions drops from 1800 to $1200 \mathrm{ppm}$ compared to the case without model-based correction. Regarding $\mathrm{NO}_{\mathrm{x}}$ emissions, the valley caused by the rich disturbance is smaller when the OSL correction strategy is applied, however, there is no penalty in comparison with the steady state value. In case of a disturbance towards lean conditions (Figure 6.12) the behaviour is analogous. The OSL control limits the oxygen excess imposing a richer $\phi$, leading to an important reduction in the $\mathrm{NO}_{\mathrm{x}}$ penalty and keeping almost constant the $\mathrm{CO}$ and $\mathrm{HC}$ emissions.

\subsubsection{Optimal three-way catalyst purge strategy}

As shown in section 5.1.2, when the fresh air passes through the TWC during cut-off phases the OSL increases strongly, thereby the catalyst cannot convert the $\mathrm{NO}_{\mathrm{x}}$ emissions that reach the converter after the throttle tip-in. In this section the information about emissions provided by the model presented in section 4.2 will be used to off-line study the optimal OSL depletion, taking into account minimum fuel consumption together with $\mathrm{NO}_{\mathrm{x}}$ limitations. The analysis of the off-line optimal control of the TWC will be then used to define and calibrate real-time control strategies based on the on-line OSL estimation provided by the controloriented model.

The objective of the present section is to propose control strategies that besides minimising fuel consumption are capable to keep $\mathrm{NO}_{\mathrm{x}}$ emissions within certain limits. HC and $\mathrm{CO}$ emissions, in turn, are being considered indirectly as they are coupled to fuel consumption. It can be easily observed that this objective perfectly matches with an Optimal Control approach. Accordingly, the previously described control-oriented model will be combined with Optimal Control methods to fulfil that objective. In particular, the aim of this section may be described as finding the 
control law ( $\phi_{\text {sp }}$ sequence) that minimises the fuel consumption during a tip-in starting with OSL $=1$ and keeping $\mathrm{NO}_{\mathrm{x}}$ emissions below certain limit. In addition to the previous statement, the optimal control law should fulfil the following constraints:

- The control action $\left(\phi_{\mathrm{sp}}\right)$ cannot take any arbitrary value, it is bounded in the case at hand, between the value provided in the engine calibration $\left(\phi_{\mathrm{sp}}=1.027\right)$ and a maximum $\phi_{\mathrm{sp}}=1.2$

- After a defined time $(T)$, in the present work 10 seconds, the system must reach the steady state point provided in the engine calibration $\left(\phi_{\mathrm{sp}}=1.027\right.$, which leads to an OSL $\left.=0.15\right)$

To deal with the previous objective, consider the following general dynamic equation of the system:

$$
\frac{d x}{d t}=f(x, u, t)
$$

where the state vector, $\mathrm{x}=\left\{\phi_{\mathrm{up}}, \mathrm{OSL}, \mathrm{T}_{\mathrm{TWC}}\right\}$, and $f$ is a generic function containing the differential equations and the rest of non-linear algebraic equations of the model described in section 4.2.2. Due to $\mathrm{C}^{1}$ requirements of the optimisation method, some affine functions of the model implemented in the prototyping system have been replaced by algebraic expressions. Regarding the control action, $u$ is the relative fuel to air ratio set point $\phi_{\mathrm{sp}}$. The cost function to minimise is:

$$
J=\int_{0}^{T} L(x, u, t) \cdot d t
$$

where $L$ is the so-called Lagrangian function of the problem. Since the function $J$ represents fuel consumption after time $T$, the associated Lagrangian function $L$ may be defined as:

$$
L(x, t)=\dot{m}_{f}=\frac{\dot{m}_{e x h}(\phi)}{1+\frac{A F R_{s t}}{\phi}}
$$


where $\dot{\mathrm{m}}_{\text {exh }}$ is the exhaust mass flow obtained from the TWC feed-gas model as a function of the state $\phi_{\mathrm{up}}$ and $\mathrm{AFR}_{\mathrm{st}}$ is the stoichiometric AFR, in the present work 14.35. Note that, in the case at hand, the Lagrangian is only dependent on one state $\left(\phi_{\mathrm{up}}\right)$ and independent of the control variable $\phi_{\mathrm{sp}}$.

The optimal $\phi_{\mathrm{sp}}$ (hereinafter $\phi *_{\mathrm{sp}}$ ) should drive the system states and particularly $\phi_{\text {up }}$ in such a way that minimises the function (equation (6.6)) but also holds the following constraints:

- Bounded control actions: $1.027 \leq \phi_{\mathrm{sp}} \leq 1.2$

- Constraint in the final state. Reaching the steady state conditions defined in the engine standard calibration in a given time $T$ :

$$
\begin{aligned}
\phi_{u p}(T) & =1.027 \\
O S L_{u p}(T) & =0.150
\end{aligned}
$$

- Integral constraint. $\mathrm{NO}_{\mathrm{x}}$ emissions should be below certain limit $\left(\mathrm{NO}_{\mathrm{x}}^{\max }\right)$ :

$$
\int_{0}^{T} \dot{m}_{N O_{x, d w}}(x, t) \cdot d t \leq N O_{x}^{\max }
$$

where $\dot{\mathrm{m}}_{\mathrm{NO}_{\mathrm{x}, \mathrm{dw}}}$ is the instantaneous mass flow of $\mathrm{NO}_{\mathrm{x}}$ downstream the TWC, which only depends on the system states $\left(\phi_{\text {up }}\right.$, OSL, and $\left.\mathrm{T}_{\mathrm{TWC}}\right)$.

Since Optimal Control, in general, becomes more and more difficult as the number of states increases, taking into account that the TWC temperature stays fairly above the light-off temperature during all the test study, the effect of the temperature on the TWC reactions has been neglected. In this sense, the state $\mathrm{T}_{\mathrm{TWC}}$ has been removed. In any case, due to the model complexity, the number of states (2) and the need of introduce an integral constraint, an implementation of a Direct Method (DM) has been preferred to other methods such as Dynamic Programming or Potryagin's Minimum Principle. The DM is a family of optimal control methods that are based on transcribing an Optimal Control Problem 
(OCP) into a large but sparse non-linear programming (NLP) problem. The last is much easier to solve and there are commercial and freeware NLP solvers that make use of advanced and effcient state-of-the-art algorithms to find an optimal solution [239]. Amongst the different methods to transcribe a continuous OCP into a finite NLP, Euler's collocation method is used since it is a first order numerical method and thus only two terms are needed to approximate an ordinary differential equation (ODE), then contributing to the sparsity of the problem matrix. States $x$ and actuators $u$ are approximated as piecewise functions that are evaluated at times $t_{i}$ :

$$
\begin{aligned}
& x=\left[x_{0}, x_{1}, \ldots, x_{n-1}, x_{n}\right] \\
& u=\left[u_{0}, u_{1}, \ldots, u_{n-1}\right]
\end{aligned}
$$

where $\mathrm{x}_{\mathrm{i}}=\mathrm{x}\left(\mathrm{t}_{\mathrm{i}}\right)$ and $\mathrm{u}_{\mathrm{i}}=\mathrm{u}\left(\mathrm{t}_{\mathrm{i}}\right)$. With such a discretization and applying Euler's collocation method, ODEs are evaluated at any time $t_{i}$ as:

$$
\frac{d x}{d t}=\frac{x_{i+1}-x_{i}}{t_{i+1}-t_{i}}=f\left(\frac{x_{i+1}+x_{i}}{2}, t_{i}\right)
$$

Accordingly, the ODEs and constraints may be transcribed in a large but sparse problem with unknowns $\left[\mathrm{x}_{0}, \mathrm{x}_{1}, \ldots, \mathrm{x}_{\mathrm{n}-1}, \mathrm{x}_{\mathrm{n}}, \mathrm{u}_{0}, \mathrm{u}_{1}, \ldots, \mathrm{u}_{\mathrm{n}-1}\right]$ to be solved with a NLP solver. In this case IPOPT [239], an open source solver, has been used. As an example of the sparsity level, the Jacobian's structure of the current NLP is depicted in Figure 6.13 to represent the level of sparsity that DM shows.

\section{Results}

Figure 6.14 shows modelling results about the trajectories of the main variables involved in the optimization process during the tip in. The gray scale represents different $\mathrm{NO}_{\mathrm{x}}^{\max }$ values increasing from light grey to black. Results show that as $\mathrm{NO}_{\mathrm{x}}^{\max }$ is reduced a faster $\phi_{\text {up }}$ climb is required and also, higher $\phi_{\text {up }}$ are achieved. This faster increase in $\phi_{\text {up }}$ reduces $\mathrm{NO}_{\mathrm{x}}$ emissions in two ways: on the one hand, the time spent 


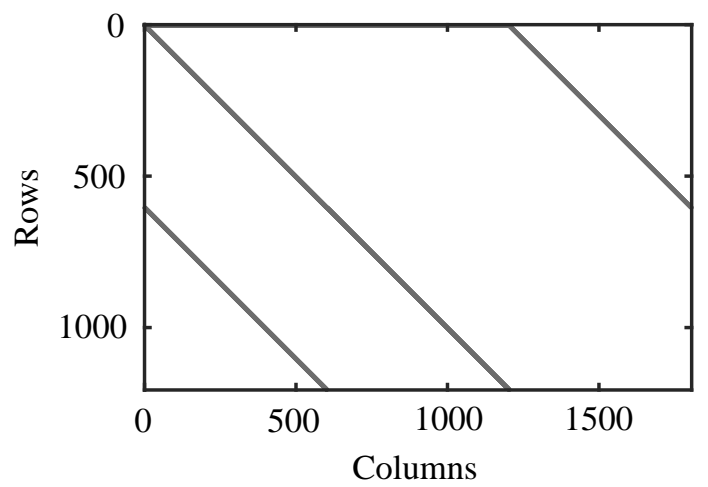

Figure 6.13: Jacobian matrix for the described NLP. Dots are the non-zero elements of the matrix

at lean conditions is reduced so the engine $\mathrm{NO}_{\mathrm{x}}$ formation and the $\mathrm{O}_{2}$ content in the exhaust flow is reduced.

On the other hand, the OSL is reduced faster with richer exhaust gas as soon as fuel is injected. Both effects lead to a reduction in the $\mathrm{NO}_{\mathrm{x}}$ emissions as can be checked in the third plot of Figure 6.14, of course, at the expense of some fuel consumption penalty ( $\phi_{\text {up }}$ increase) and eventually, a $\mathrm{CO}$ and $\mathrm{HC}$ increase.

The trade-off between fuel enrichment $\left(\phi_{\text {up }}\right)$ and $\mathrm{NO}_{\mathrm{x}}$ emissions is represented in Figure 6.15, where the averaged results of both variables are represented. It can be observed how the averaged $\mathrm{NO}_{\mathrm{x}}$ emissions during the first seconds of the transient can be reduced at the expense of some fuel enrichment up to $200 \mathrm{ppm}$. Below that limit $\mathrm{NO}_{\mathrm{x}}$ are hardly reduced despite fuel enrichment. In addition to the simulation results in black, the grey dot represents experimental results obtained with the standard engine calibration that substantially leads to a constant $\phi_{\mathrm{sp}}=1.027$ during all the test. It is somehow evident that this is an optimal strategy to minimise fuel consumption if there is not a $\mathrm{NO}_{\mathrm{x}}$ constraint and the control action is bounded within the range $1.027 \leq \phi_{\mathrm{sp}} \leq 1.2$. In this sense, the experimental result is almost included in the Pareto front. Particularly, the simulation point with maximum average $\mathrm{NO}_{\mathrm{x}}$ is the one obtained from the optimisation process without $\mathrm{NO}_{\mathrm{x}}$ constraint, so differ- 

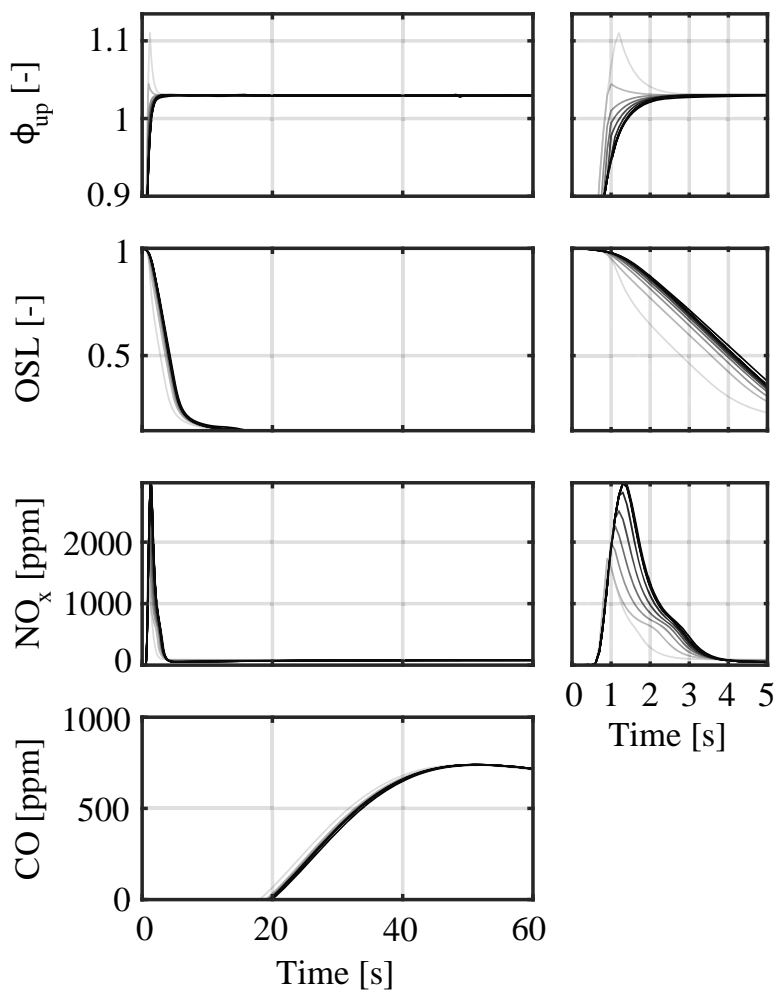

Time $[\mathrm{s}]$

Figure 6.14: Trajectories minimizing $\phi_{\text {up }}$ subject to different $\mathrm{NO}_{\mathrm{x}}$ maximum emission limits $\left(\mathrm{NO}_{\mathrm{x}}^{\max }\right)$ ranging from low (light grey) to high (black) values. Right: zoom of the first 5 seconds 


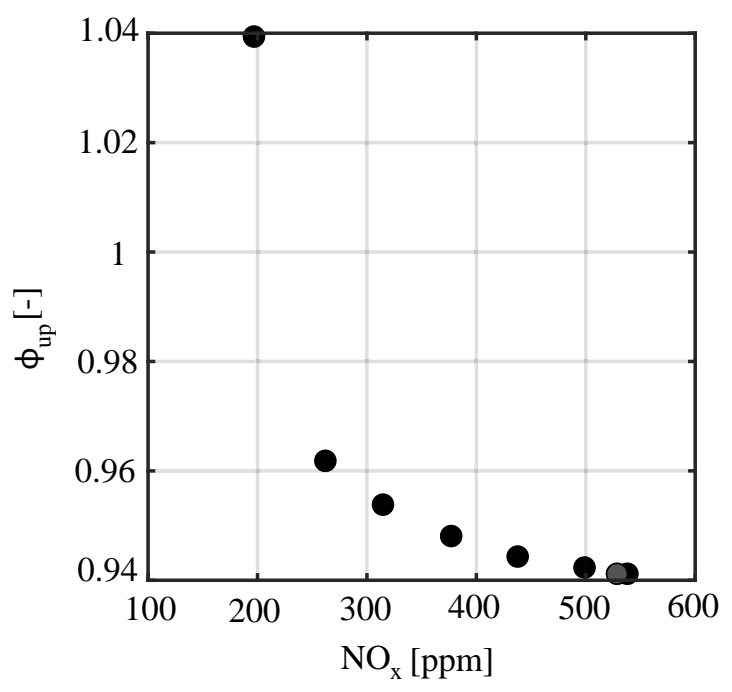

Figure 6.15: Trade-off between $\mathrm{NO}_{\mathrm{x}}$ emissions and $\phi_{\text {up }}$ enrichment averaged during the first 5 seconds of the transient. The black dots represent solutions of the Optimal Control problem with different $\mathrm{NO}_{\mathrm{x}}$ restrictions while the grey dot represents measurement results of the standard calibration 
ences between this point and the experimental one are due to modelling uncertainties.

\subsubsection{On-line three-way catalyst purge strategy}

One of the drawbacks of the Optimal Control is that, in general, it provides a sequence of control actions rather than a control policy that can be written as a set of rules and therefore be calibrated. In addition, Optimal Control algorithms are usually computationally consuming so real time applications become difficult. That is why the strategy presented in the previous section makes impossible an on-line implementation. Nevertheless, the analysis of the Optimal Control Problem solution allows to propose different approximations that are implementable.
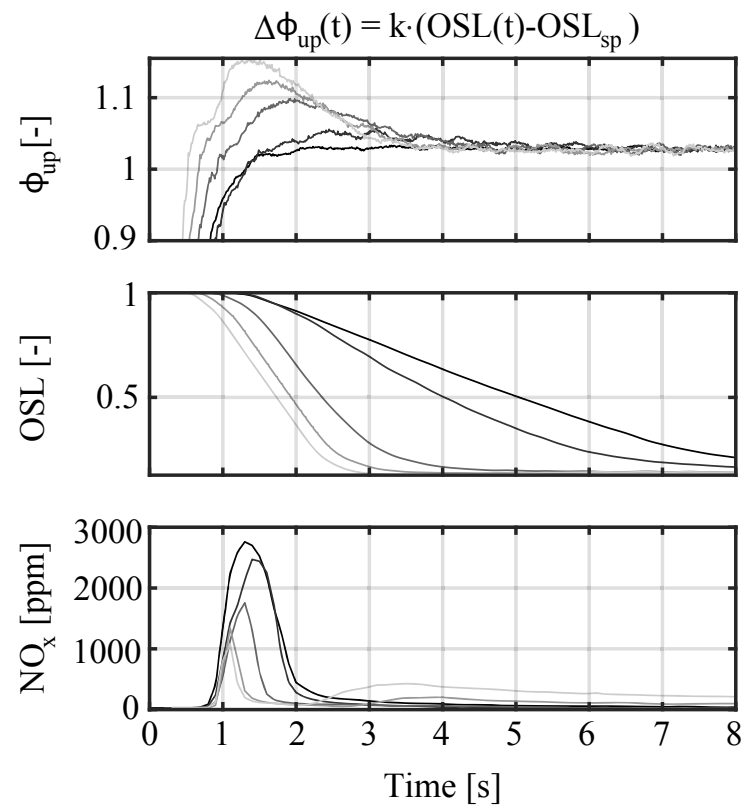

Figure 6.16: Trajectories obtained with the $\phi_{\text {up }}$ enrichment depending on OSL. Grayscale represents the gain $(\mathrm{k})$ value ranging from 0 (black) to 0.2 (light grey)

In fact, from results shown in Figure 6.14 one may infer that the optimal solution for a reduction in the $\mathrm{NO}_{\mathrm{x}}$ limit always entail a fuel enrichment at the beginning of the process that leads to a faster reduction in the 
OSL up to the steady state level. Based on the previous observation, and the availability of a model such as the one presented in section 4.2, which is able to provide an estimation of the OSL, an on-line strategy to purge the TWC depending on OSL has been performed. This strategy is based on the idea proposed in section 6.2.1, that is, a correction of $\phi_{\mathrm{sp}}$ proportional to the difference between the current OSL and the desired OSL (equation (6.4)).

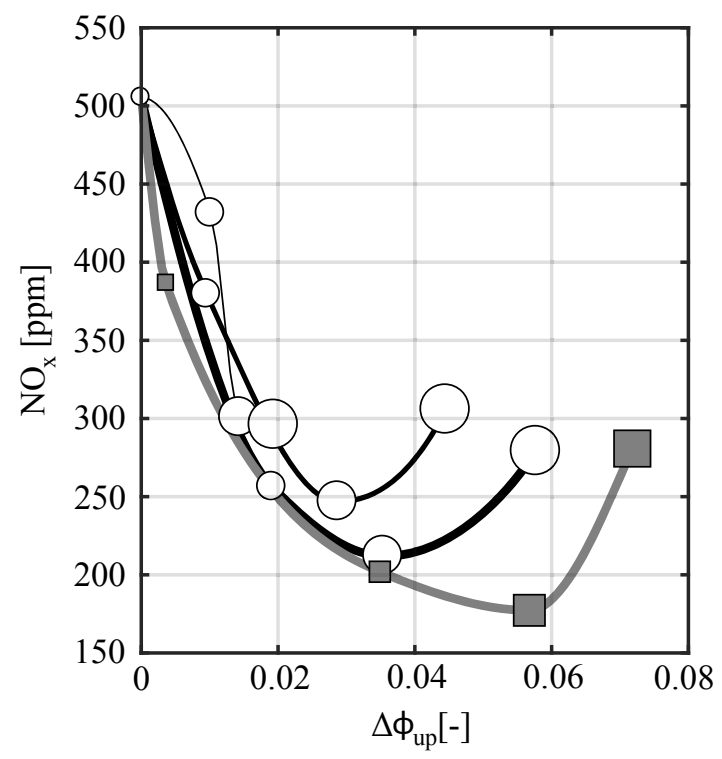

Figure 6.17: Trade-off between $\mathrm{NO}_{\mathrm{x}}$ emissions and $\phi_{\text {up }}$ enrichment averaged during the first 5 seconds of the transient. Black lines represent $\Delta \phi_{s p}-\Delta T$ strategy (line thickness proportional to $\Delta \mathrm{T}$ and marker size proportional to $\Delta \phi_{\mathrm{sp}}$. The grey line represents the $\phi_{\mathrm{up}}$ enrichment strategy depending on OSL with marker size proportional to the gain $(\mathrm{k})$

Figure 6.16 shows the experimental results obtained. The $\phi_{\text {up }}$ profiles follow similar trajectories to those obtained in the optimisation process, with strong enrichments at the beginning of the test that progressively are reduced until reaching the $\phi_{\text {up }}$ and OSL calibrated for steady state. Again, the higher enrichment, the higher $\mathrm{NO}_{\mathrm{x}}$ reduction, but also fuel penalty. As a summary, Figure 6.17 represents the trade-off between $\mathrm{NO}_{\mathrm{x}}$ emissions and $\phi_{\mathrm{up}}$ enrichment averaged during the first 5 seconds of the transient for both, the model-based on-line strategy proposed in this 
section as well as the typical strategy based on fuel enrichment parametrisation $\Delta \phi_{s p}-\Delta T$ (described in section 5.1.2).

The results of the latter are represented by circles, whose size is proportional to the $\Delta \phi_{\mathrm{sp}}$ applied. In addition, the black lines show results obtained with a given $\Delta \mathrm{T}$ (line thickness proportional to $\Delta \mathrm{T}$ ). It can be observed how for a given $\Delta \phi_{\mathrm{sp}}$, increasing $\Delta \mathrm{T}$ involves a higher reduction in $\mathrm{NO}_{\mathrm{x}}$ but also fuel consumption. It can also be observed that there is a maximum enrichment that if it is exceeded, no further benefit in terms of $\mathrm{NO}_{\mathrm{x}}$ is obtained, this is specially evident for cases with $\Delta \mathrm{T}=4=4$ and 6 seconds. The grey squares represent the results obtained with the model-based strategy ( $\phi_{\text {up }}$ enrichment depending on OSL). The marker size shows the gain $(k)$ applied in the correction. It can be clearly observed how in general, higher values of $k$, involve higher enrichment and lower $\mathrm{NO}_{\mathrm{x}}$ emissions. In the same way that happens with the other strategy, there is a level of enrichment where no additional benefits in $\mathrm{NO}_{\mathrm{x}}$ emissions are obtained. Another conclusion that may be derived from Figure 6.17 is that for a given level of enrichment, there is a calibration for both methods that results in similar $\mathrm{NO}_{\mathrm{x}}$ levels. Nevertheless, from the obtained results, it may be deducted a slightly better performance of the OSL based enrichment strategy, probably due to the fact that this strategy forces a higher enrichment during the first phase of the transient, and then progressively reduces it up to the steady state level instead of keeping a constant $\phi_{\mathrm{sp}}$ during a predefined time and then suddenly applying the reference one. 


\subsection{AFR control under short-circuit conditions}

The effect of the short-circuit (SC) of fresh air on both $\lambda$ sensor and TWC performance is pointed out in section 5.2. This section deals with the control of the AFR under SC conditions in order to minimise its negative impact on $\mathrm{NO}_{\mathrm{x}}$ emissions. Note that little is published on this issue since SC is only actively used at low engine speed and high load conditions, which is a very particular operating area. Nevertheless, today it seems very convenient to address the issue of emission control under $\mathrm{SC}$ conditions due to the intensive use of small turbocharged engines that tends to work on this conditions more often [154-156, 240]. In addition, the successive updates of the regulatory procedures force the emissions reduction under a wider range of engine operating conditions.

Typically, state-of-the-art engines have a wideband $\lambda$ sensor upstream and a switch type $\lambda$ sensor downstream of the TWC. The second one is mainly used for two purposes: on-board diagnosis (OBD) and closedloop control at some operating conditions, mainly steady state. Due to the strong non-linearity of that type of sensor, as well as to the storing dynamics of the TWC, the controller must be very slow. Otherwise, the action of the closed-loop control (downstream of the TWC) could cause AFR instabilities. Under transient conditions, the AFR disturbances caused by the different path of fresh air and fuel, like intake manifold dynamics, wall-wetting or short-circuit, exceed the capabilities of the downstream closed-loop control[241, 242].

The AFR control in closed-loop by using the feedback provided by the wideband $\lambda$ sensor upstream of the TWC is the typical approach without short-circuit, that is, in normal operation [54, 92, 115, 116, 146-148, 196, 243-245]. However, when a gasoline direct injection engine is operated under SC conditions, the AFR upstream TWC tends to be leaner as the percentage of SC increases (if in-cylinder AFR is kept stoichiometric), which is not acceptable from the pollutant emissions point of view, due to the behaviour of the TWC ( $\mathrm{NO}_{\mathrm{x}}$ emissions at lean conditions). Thus, stoichiometric AFR at TWC inlet is needed even under SC conditions. This means that in-cylinder AFR must be richer as SC increases in order to compensate for the fresh air pulses and getting stoichiometric AFR 
at TWC inlet. The issue is that, under this conditions, the wideband $\lambda$ sensor upstream of the TWC tends to overestimate the AFR (as seen in section 5.2), which disables this sensor to provide a proper feedback for the closed-loop control. To face AFR control under SC conditions and therefore to avoid negative effects on the aftertreatment system, all the possible solutions pass through an estimation of the SC rate. Of course, if $\mathrm{SC}$ is known, the proper correction of the wide-range $\lambda$ sensor signal may be addressed in order to counteract its effect. One feasible choice goes through mapping the appropriate offset to increase the AFR provided by the $\lambda$ sensor depending on SC. Nevertheless, if SC is just mapped depending on operating conditions, the success of such an approach relies on the accuracy of the calibration and it is subjected to the impact of ageing or any other disturbance, as it happens with all systems based on static calibrations. Controlling with a wideband $\lambda$ sensor downstream the TWC under SC conditions would be another possibility, since the catalyst filters the SC pulses. But then, the TWC dynamics and the effect of the exhaust gas composition downstream the catalyst on the $\lambda$ sensor must be taken into account [222].

\subsubsection{Problem description}

As explained in section 5.2, the SC effect on the aftertreatment system of SI engines can be mainly explained as the superposition of two simultaneous phenomena, one of them related to the $\lambda$ sensor and the other one associated with the TWC. Both are quantitatively dependent on SC amount. On the one hand, the $\lambda$ sensor upstream the catalyst tends to overestimate the actual AFR under SC conditions, presumably because of the impact on the in-cycle dynamics of exhaust gases composition generated by $\mathrm{SC}$ pulses.

On the other hand, the fact that the in-cylinder AFR affects the generation of the main pollutant species, that is, $\mathrm{CO}, \mathrm{NO}_{\mathrm{x}}$ and $\mathrm{HC}$, leads to important changes in the exhaust gas. In particular, in the concentration of these species at TWC inlet, when stoichiometric AFR is imposed in the presence of SC. Under these circumstances the TWC is forced to operate simultaneously with fresh air and exhaust gases whose composition is typical of rich combustion. In order to keep stoichiometric AFR 

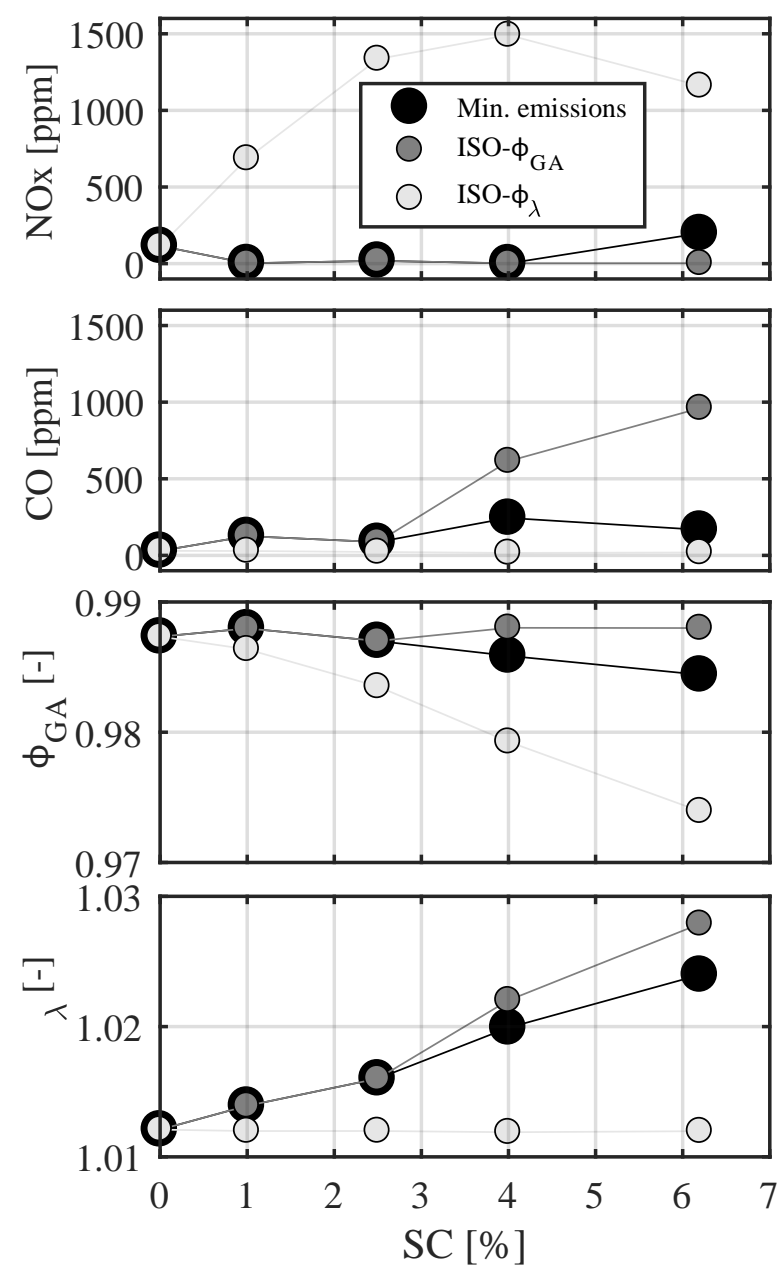

Figure 6.18: $\mathrm{SC}$ effect on $\lambda$ sensor and TWC window. From top to bottom: $\mathrm{NO}_{\mathrm{x}}$ emissions; CO emissions; AFR provided by gas analyser; AFR provided by $\lambda$ sensor 
at TWC inlet under SC conditions, a fairly rich AFR at the cylinder is needed, which leads to high $\mathrm{HC}$ and $\mathrm{CO}$ emissions at TWC inlet. Comparing to an operating point with the same AFR but without $\mathrm{SC}$, the prime consequence experimentally observed of $\mathrm{SC}$ is the improvement of $\mathrm{NO}_{\mathrm{x}}$ efficiency together with the decrease of $\mathrm{CO}$ oxidation capabilities. In this sense the TWC window, that is, the optimal $\phi$ range for TWC performance, is moved on to slightly leaner conditions.

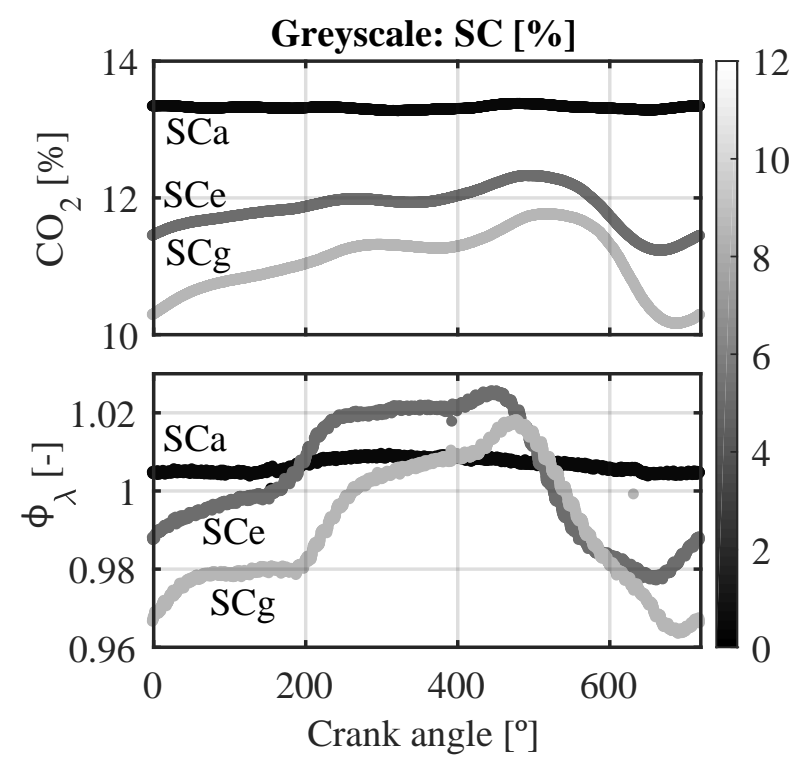

Figure 6.19: In-cycle $\mathrm{CO}_{2}$ and $\lambda$ waveforms measured for each predefined SC

Although the effects explained above behave in an opposite way, it is important to highlight that their consequences do not counteract themselves reciprocally as it is shown in figure 6.18. In this figure, three different approaches have been implemented while making a swept of several SC levels. Light circles corresponds to keeping constant the AFR provided by the $\lambda$ sensor $\left(\phi_{\lambda}\right)$; as SC increases the $\lambda$ sensor overestimates progressively the actual AFR and the TWC operates at leaner conditions, the aftereffect is a noticeable increase in $\mathrm{NO}_{\mathrm{x}}$ emissions. Dark circles display the consequence of keeping constant the AFR provided by the gas analyser $\left(\phi_{\mathrm{GA}}\right)$; the reducing species at the TWC inlet rise with the increase 
of in-cylinder AFR $\left(\phi_{\mathrm{CY}}\right)$, thus the TWC window moves to leaner conditions and $\mathrm{CO}$ emissions increases when SC rises. Finally, black circles are the result of imposing the optimum AFR in order to minimise the pollutant emissions (addition of $\mathrm{CO}$ and $\mathrm{NO}_{\mathrm{x}}$ ), which means to operate with a AFR within the previous cases to compensate both effects.

Under this scope, the on-line estimation of the instantaneous amount of $\mathrm{SC}$ could be really helpful to improve the AFR control. The present section proposes an approach to deal with this issue with the focus on the pollutant emissions reduction. Taking into account the sensitivity of the $\lambda$ sensor to the SC, the idea is to analyse the $\lambda$ sensor signal in two different time scales to estimate both $\phi$ and SC. Figure 6.19 show how SC pulses entail a characteristic waveform in the $\lambda$ sensor signal during each engine cycle. The plot at the top displays the SC effect on in-cycle raw $\mathrm{CO}_{2}$ concentration (measured with the fast $\mathrm{CO}_{2}$ analyser Cambustion NDIR 500), SC fresh air pulses tend to dilute the residual combustion gases, therefore the average $\mathrm{CO}_{2}$ concentration decreases when SC increases, appearing a characteristic waveform because of the gases transport through the asymmetrical exhaust manifold (Figure 3.1). Similarly, the AFR provided by the $\lambda$ sensor at the exhaust (bottom plot) also presents a waveform when SC increases, but in this case the in-cycle value is kept constant due to the SC effect on the sensor and the fact that a closed loop control is carried out. Therefore, the $\lambda$ sensor signal content at the engine frequency may be used to estimate the SC, while the signal content at low frequencies provides a first estimation of the AFR that can be corrected with the value of $\mathrm{SC}$ and the relation shown in figure 6.18.

\subsubsection{Correction strategy of the SC effect}

The scheme of the proposed strategy is shown in Figure 6.20. With the $\lambda$ sensor signal, the amplitude of the frequency content at engine frequency $\left(\widehat{\mathrm{A}}_{\lambda, \mathrm{f0}}\right)$ can be calculated via Discrete Fourier Transform (DFT) as follows:

$$
\widehat{A}_{\lambda, f 0}=\left|D F T_{k}\left(f_{0}\right)\right|_{k=1}^{K}
$$




$$
\operatorname{DFT}_{k}\left(f_{0}\right)=\frac{2}{\widehat{t_{N}^{k}}} \cdot \sum_{n=1}^{N} \widehat{x_{n}^{k}} e^{\left(-2 \pi i f_{0} t_{n}^{k}\right)}
$$

Considering the following nomenclature:

- $\mathrm{f}_{0}$ : engine frequency

- $\widehat{\mathrm{x}_{\mathrm{n}}^{\mathrm{k}}}$ : element $\mathrm{n}$ in the $\lambda$ sensor signal window $\mathrm{k}$

- $\mathrm{N}$ : window size

- $\mathrm{p}=\mathrm{N} \cdot\left(1-\frac{\text { window overlapping[\%] }}{100}\right)$

- L : signal size

- $\mathrm{K}$ : number of windows $=\frac{\mathrm{L}-\mathrm{N}}{\mathrm{p}}$

- $\widehat{\mathrm{t}_{\mathrm{n}}^{\mathrm{k}}}$ : element $\mathrm{n}$ in the time window $\mathrm{k}$

Note that the complete spectrum is not needed, just the harmonic corresponding to the frequency of the engine cycle $\left(f_{0}\right)$ must be calculated. The computational cost of the proposed method is not too demanding and its main advantage is that just a time-based sampling is needed. Of course, if the sampling at crank angle domain is available, another approaches exist with even less computational demand for on-board DFT calculation, as the one shown in $[246,247]$. In such case, the DFT can be calculated in real-time by using a circular buffer in which storing the samples of the signal, in order to calculate the DFT as from its value in the previous step [248]. The size of the buffer must contain an integer number of engine cycles, and the sampling frequency must be proportional to the engine speed. The buffer must be filled orderly, substituting the old samples with the new ones, allowing the calculation of the frequency content of the signal for the corresponding harmonic.

Then, the previous signal $\left(\widehat{\mathrm{A}}_{\lambda, \mathrm{f} 0}\right)$ can be used to estimate the SC with the aid of an experimental correlation, in which the actual SC has been measured by means of tracer gas method (section 3.3.1) at steady state. Once the instantaneous SC is known, the $\lambda$ sensor overestimation can 


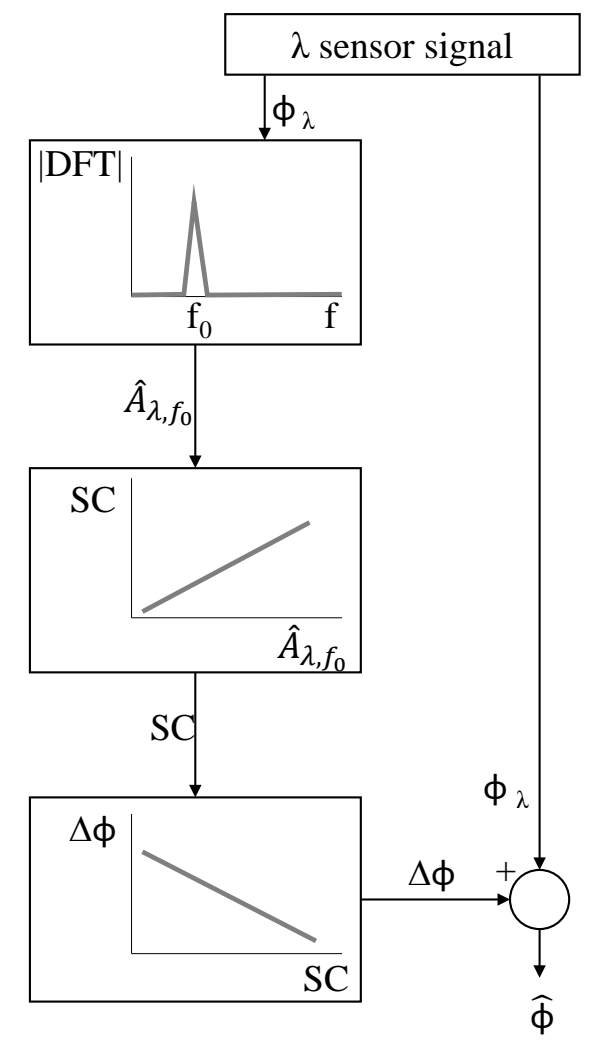

Figure 6.20: Proposed strategy to avoid the SC effect on the AFR control 
be corrected by using the experimental correlation shown in Figure 6.18 (bottom plot), where the $\phi$ error $(\Delta \phi)$ is calibrated as function of the SC level. Finally, the $\phi$ error estimation can be applied over the $\phi$ value provided by the $\lambda$ sensor to get the actual $\phi$.

\subsubsection{Results and discussion}

The SC estimation based on the $\lambda$ sensor has several advantages in comparison with the tracer gas method. On the one hand, it is not intrusive since the introduction of reactive substances is not necessary. On the other hand, it allows to obtain the dynamic evolution of the SC at transient conditions, while the time response of the gas analyser prevents from a proper dynamic evolution. In addition, the $\lambda$ sensor is available in all the automotive SI engines, thus the SC estimation could be done on-line, in contrast to the tracer gas method that needs complex and expensive experimental facilities. Figure 6.21 shows how the correlation between $\mathrm{SC}$ measured with tracer gas method, and the amplitude of the harmonic corresponding to the engine frequency for the $\lambda$ sensor signal fits quite well to a linear approximation, at least in the range of SC tested.

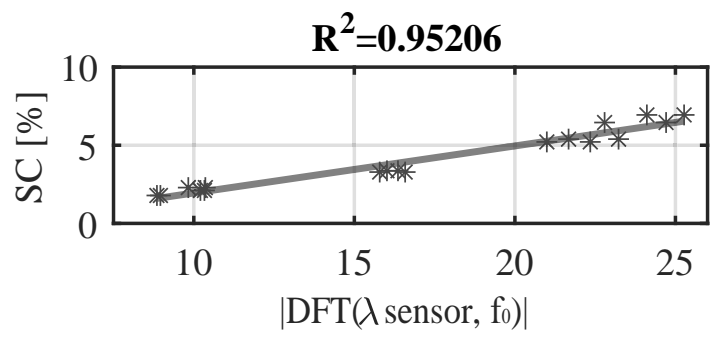

Figure 6.21: Correlation between SC measured with the tracer gas method and the amplitude of the instantaneous frequency content at engine frecuency of the $\lambda$ sensor signal

As first approach, for the implementation of this methodology the SC estimation via $\lambda$ sensor has been calculated off-line. The test shown in Figure 6.22 consist on the transition from valve overlap levels "d" to "e" in two different ways. First, keeping constant the AFR provided by the $\lambda$ sensor around the optimum value for SC level " $\mathrm{d}$ " in terms of emissions (black lines). Next, the test is repeated but the AFR is corrected with the proposed method to take into account the $\lambda$ sensor overestimation 
when SC increases (gray lines). The SC evolution during the transition from "d" to "e" is displayed for both the SC measurement with tracer gas method (dashed line) and the SC estimation provided by the $\lambda$ sensor (solid line).
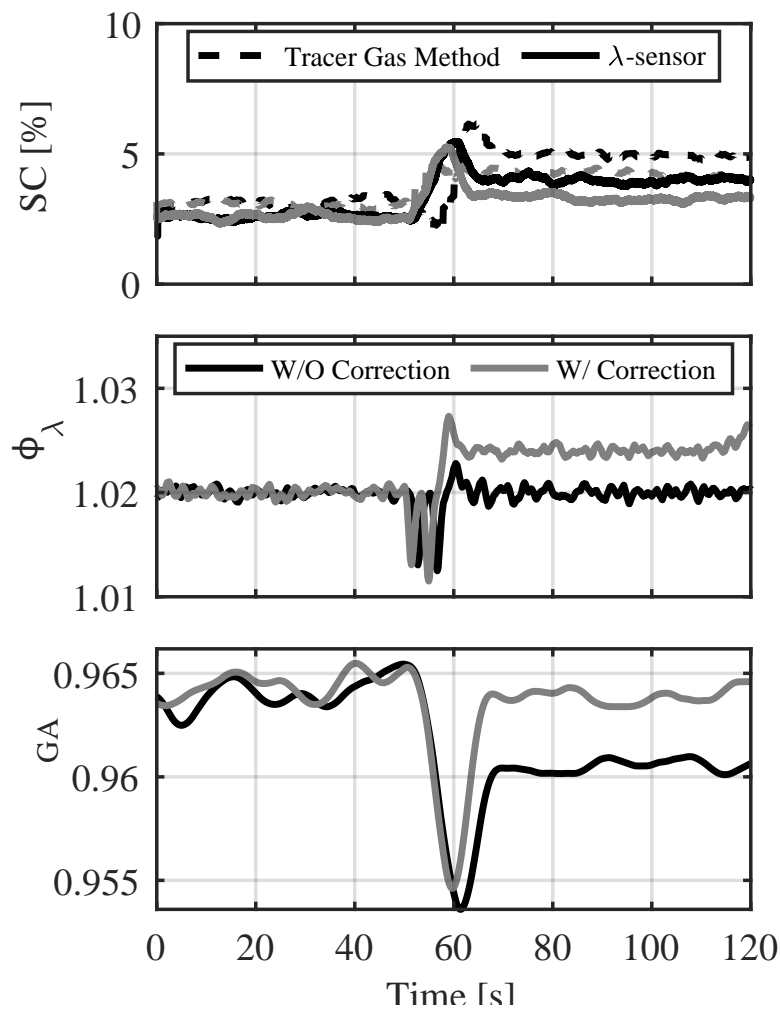

Figure 6.22: Top: SC measurement with tracer gas method (dashed lines - - -) and SC estimation with $\lambda$ sensor via DFT (solid lines -) for two different cases. That is, with and without $\phi$ correction (gray and black lines respectively); Center: $\phi$ provided by the $\lambda$ sensor; Bottom: Actual $\phi$ provided by the gas analyser

Of course, the SC evolution measured with tracer gas method is not useful for on-board control purposes, since it needs the simultaneous measurement of $\mathrm{CH}_{4}$ at intake and exhaust with and without $\mathrm{CH}_{4}$ injection. Moreover, the gas analyser imposes an important delay as displays the top plot in Figure 6.22. In this test, the valve overlap evolution is sequential, increasing gradually the exhaust valve closing retard and then open- 


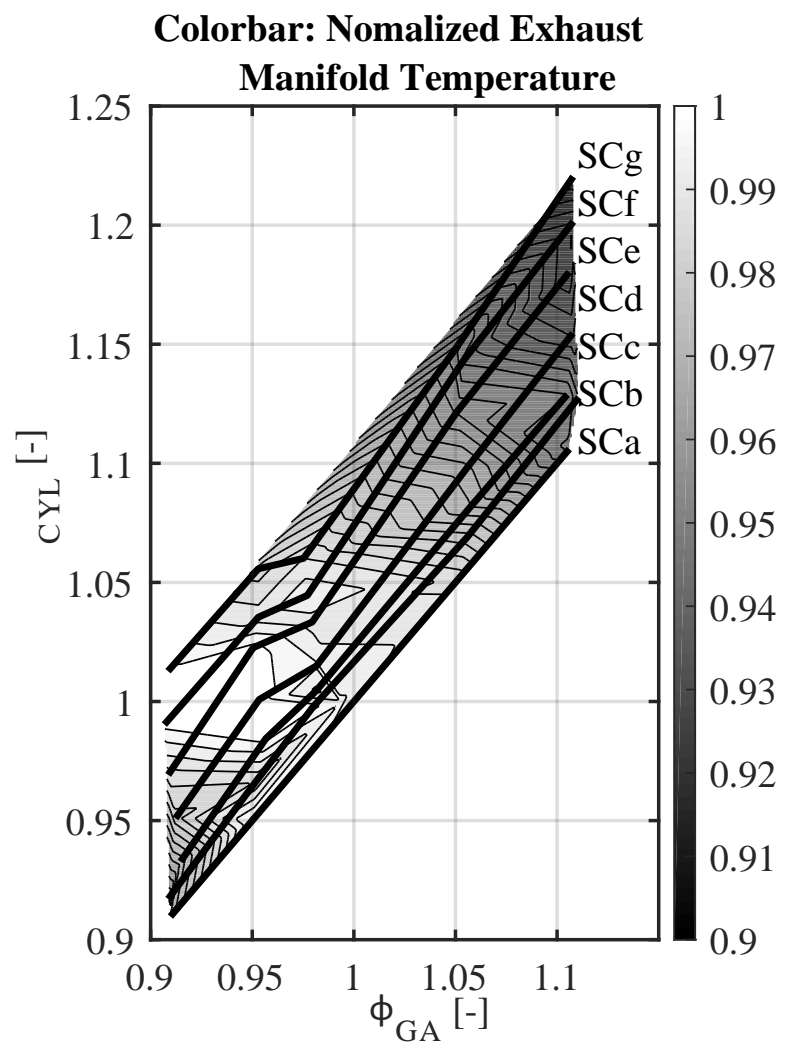

Figure 6.23: AFR effect on exhaust temperature by comparing the $\phi_{\mathrm{GA}}$ provided by the gas analyser at the exhaust with the in-cylinder $\phi_{\mathrm{CYL}}$ for several overlapping levels 
ing slightly the waste gate to keep constant the engine load. Thus both SC measurement (with the tracer gas method) and estimation (through the frequency analysis of the $\lambda$ sensor) are totally consistent with the actuators operation. From "d", SC rises instantaneously when the overlap increases, then SC decreases due to the waste gate operation, since the pressure difference between intake and exhaust drops off slightly, given as a result the SC at "e".

Regarding the case with $\phi$ correction, the test shows how the AFR has a slight impact on the SC level for the same valve overlap. In particular, the $\mathrm{SC}$ is lower when AFR rises according to both the SC measurement and the estimation. It is due to the fact that in-cylinder $\operatorname{AFR}\left(\phi_{\mathrm{CYL}}\right)$ drives the combustion temperature, as shows figure 6.23 , where the normalized exhaust temperature is plotted on the $\phi_{\mathrm{CYL}}-\phi_{\mathrm{GA}}$ map. The maximum temperatures are reached with $\phi_{\mathrm{CYL}} \approx 1$ independently on the exhaust $\phi_{\mathrm{CYL}}$ provided by the gas analyser.

As a consequence, the turbocharging compression ratio $\left(\mathrm{r}_{\mathrm{C}}\right)$ decreases when exhaust temperature $\left(\mathrm{T}_{3}\right)$ is reduced, pushed by rich $\phi_{\mathrm{CYL}}$. Equation 6.10 shows the dependence between $T_{3}$ and $r_{C}$.

$$
r_{C}=\left\{1+(1+F) \cdot C_{1} \cdot \frac{T_{3}}{T_{1}} \cdot \eta \cdot\left[1-\left(\frac{1}{r_{T}}\right)^{C_{2}}\right]\right\}^{C_{3}}
$$

where:

$$
\begin{aligned}
& \mathrm{r}_{\mathrm{C}}=\frac{\mathrm{P}_{2}}{\mathrm{P}_{1}} \Rightarrow \text { compression ratio (compressor) } \\
& \mathrm{r}_{\mathrm{T}}=\frac{\mathrm{P}_{3}}{\mathrm{P}_{4}} \Rightarrow \text { expansion ratio (turbine) } \\
& \eta=\eta_{\mathrm{C}} \cdot \eta_{\mathrm{T}} \cdot \eta_{\mathrm{m}} \Rightarrow \text { overall efficiency } \\
& \mathrm{T}_{3} \Rightarrow \text { turbine inlet temperature } \\
& \mathrm{T}_{1} \Rightarrow \text { compressor inlet temperature } \\
& \mathrm{C}_{1}=\frac{\mathrm{c}_{\mathrm{P}}}{\mathrm{C}_{\mathrm{P}_{\mathrm{C}}}} ; \mathrm{C}_{2}=\frac{\gamma_{\mathrm{T}}-1}{\gamma_{\mathrm{T}}} ; \mathrm{C}_{3}=\frac{\gamma_{\mathrm{C}}}{\gamma_{\mathrm{C}}-1}
\end{aligned}
$$


The enrichment due to the AFR correction with SC involves a decrease on exhaust temperature, which leads to a reduction in the pressure difference between intake and exhaust, hence involving a slight reduction on the SC shown with both tracer gas and frequency analysis methods. That is why, compared with the case without $\phi$ correction, SC decreases slightly when $\phi$ increases to reach the proper TWC window, thereby, reducing $\mathrm{NO}_{\mathrm{x}}$ exhaust raw emissions.

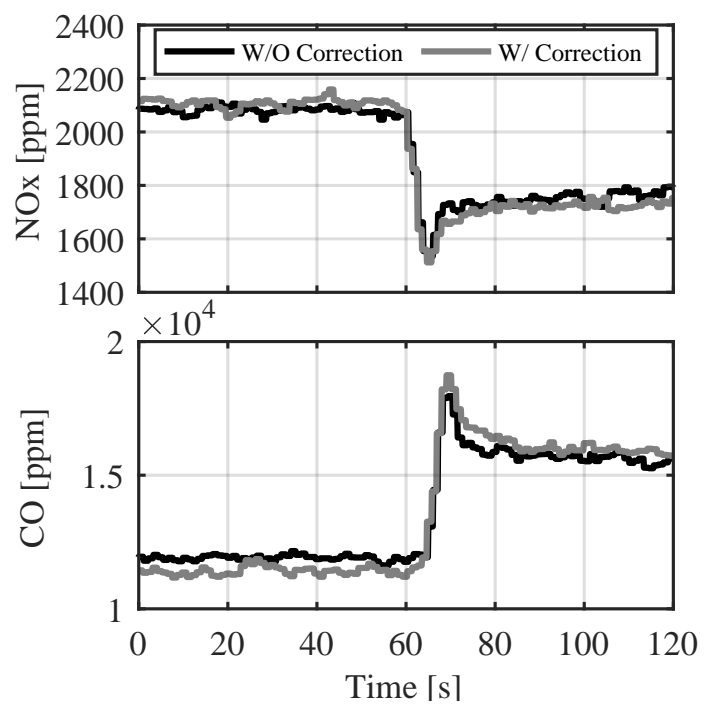

Figure 6.24: Top: $\mathrm{NO}_{\mathrm{x}}$ emissions upstream TWC; Bottom: CO emissions upstream TWC

Figures 6.24 and 6.25 show $\mathrm{NO}_{\mathrm{x}}$ and $\mathrm{CO}$ emissions upstream and downstream the TWC respectively. Since exhaust raw emissions are mainly led by $\phi_{\mathrm{CYL}}$ (section 5.2), when SC rises and $\phi$ upstream TWC is controlled in closed loop, $\mathrm{CO}$ and $\mathrm{NO}_{\mathrm{x}}$ increase and decrease respectively at engine exhaust as expected. In addition, it can be observed how despite upstream TWC emissions are quite similar by comparing the case with and without AFR correction, downstream the TWC the $\lambda$ sensor overestimation causes an important penalty in $\mathrm{NO}_{\mathrm{x}}$ emissions when the effect of $\mathrm{SC}$ on $\lambda$ sensor is not corrected. In this sense, the AFR correction allows to keep the emissions almost constant around the optimum value after the SC step, avoiding the $\phi$ overestimation produced by the SC pulses on the $\lambda$ sensor. 

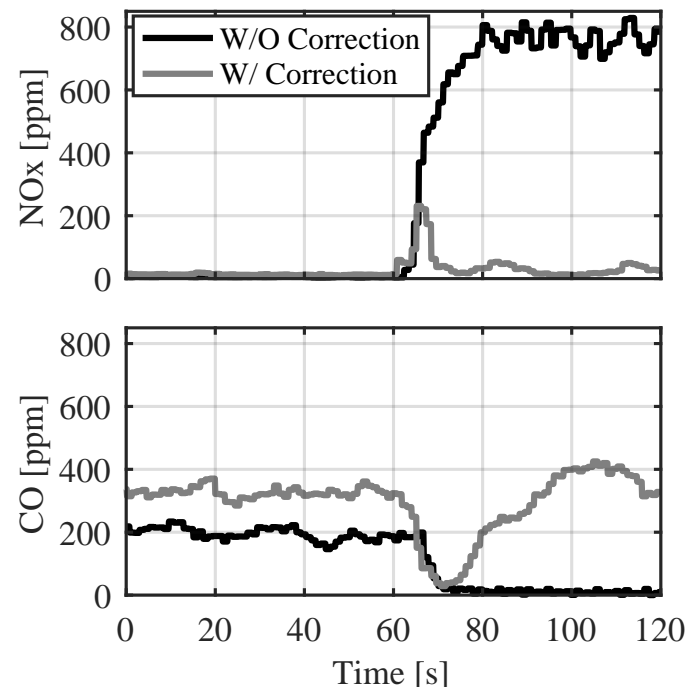

Figure 6.25: Top: $\mathrm{NO}_{\mathrm{x}}$ emissions downstream TWC; Bottom: $\mathrm{CO}$ emissions downstream TWC 

Chapter 7

\section{TWC diagnosis}

Contents

7.1 Model-based approach for three-way catalyst ageing quantification .......................184

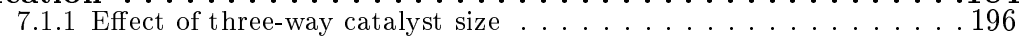

7.2 Three-way catalyst ageing diagnosis through sensor-based

strategy . . . . . . . . . . . . . . . . . . . 200 


\subsection{Model-based approach for three-way catalyst ageing quantification}

TWC ageing causes a reduction of the conversion efficiency at steady state conditions for all the species involved, due to the inhibition of certain reactions, but also a reduction of the storage capability, which affects the transient behaviour of the converter. This loss of storage capability is usually attributed to the oxygen, mainly because it is the most abundant species stored, thanks to the widespread use of ceria in current TWCs. Following this reasoning, the decrease of OSC with ageing can be used to experimentally measure the ageing level of a converter. Quantifying the TWC ageing level is important to properly face the control of the aftertreatment system from the viewpoint of the emissions reduction. For example, the results obtained in section 6.1 show how the TWC window is shifted towards leaner conditions when the converter is aged, mainly due to the loss of oxidation capabilities. Therefore, if the ageing is detected on-board, a $\phi$ compensation can be imposed to reduce emissions penalties.

The ageing estimation through the integration of the $\lambda$ sensor signals upstream and downstream the TWC presents some drawbacks and uncertainties due to different factors. One of the reasons is the strong simplification carried out in the premises of the aforementioned approach. Although the idea is simple, its implementation often reveals some troubles. On the one hand, not only oxygen is being adsorbed and desorbed, but also all the different species are adsorbed prior to react in the noble metal coating. Thereby, attributing all the difference in the dynamic response of TWCs with different ageing levels to their respective OSC is not totally right, since also the adsorption and desorption of other species different from oxygen are playing a certain role. Moreover, the ageing of the TWC follows complex mechanisms, which deactivates each chemical reaction at different extents. Therefore, an aged converter does not behaves exactly equal than a fresh converter but with lower OSC, as suggests the aforementioned approach. On the other hand, wideband $\lambda$ sensors also called universal exhaust-gas oxygen (UEGO) sensors, are not only sensitive to oxygen, but also to other species as $\mathrm{CO}$ or $\mathrm{H}_{2}$. Taking into account this fact together with the non-homogeneous lost of 
conversion efficiency as well as storage capability of the TWCs, some discrepancies and uncertainties when applying the aforementioned method are expected. That is why the results often depend on the sense of the AFR step performed, on the level of the average AFR imposed or on the correction of the downstream $\lambda$ sensors carried out. Of course it does not mean that the approach is useless, because the values obtained when integrating the difference between the signals provided by the sensor upstream and downstream of the TWC during a $\phi$ step should be somehow proportional to the storage capability of the converter, but if this strategy is applied, then the test must be perfectly defined and being repetitive to get consistent results.

An alternative approach for the ageing quantification can be followed when there is a TWC model available. This section studies the TWC ageing by using the physics-based 1-D model presented in section 4.1, showing the results obtained for three converters with different ageing level. Figure 7.1 to 7.8 show experimental data and model results for two different converters, the aged and the OBD TWC, during a double $\phi$ step analogous to that performed with the fresh TWC in section 4.1.5 (from Figure 4.3 to 4.6 ). The operating point in all cases is $2500 \mathrm{rpm}$ and $75 \mathrm{Nm}$. Focusing first on the concentration of $\mathrm{O}_{2}, \mathrm{NO}_{\mathrm{x}}, \mathrm{CO}$, and $\mathrm{C}_{3} \mathrm{H}_{6}$ in gas phase (Figure 4.5, 7.3 and 7.7 for fresh, aged and OBD converters respectively), the ageing effect on the conversion efficiency of each species show that the deterioration is not homogeneous as expected.

The main differences are found in the rich phase. At steady state conditions, the oxidation of $\mathrm{CO}$ is the most affected by the thermal deactivation. In particular, at rich conditions the $\mathrm{CO}$ emissions at the outlet of the OBD TWC reach almost the same value than at the inlet. However, the deactivation of the $\mathrm{NO}_{\mathrm{x}}$ reduction is much lower, the three catalysts keep high conversion levels with differences within $\pm 150 \mathrm{ppm}$. It is due to the high availability of $\mathrm{CO}$. In case of $\mathrm{C}_{3} \mathrm{H}_{6}$ the results are surprising, since the oxidation achieved in all cases is very similar, in fact, the increase of the ageing level causes a slight decrease of emissions at steady state conditions during the rich period $( \pm 50 \mathrm{ppm})$. These results prove the higher selectivity of the TWC towards $\mathrm{HC}$ in comparison with $\mathrm{CO}$, which makes sense since $\mathrm{CO}$ is a product of the partial $\mathrm{C}_{3} \mathrm{H}_{6}$ oxidation 

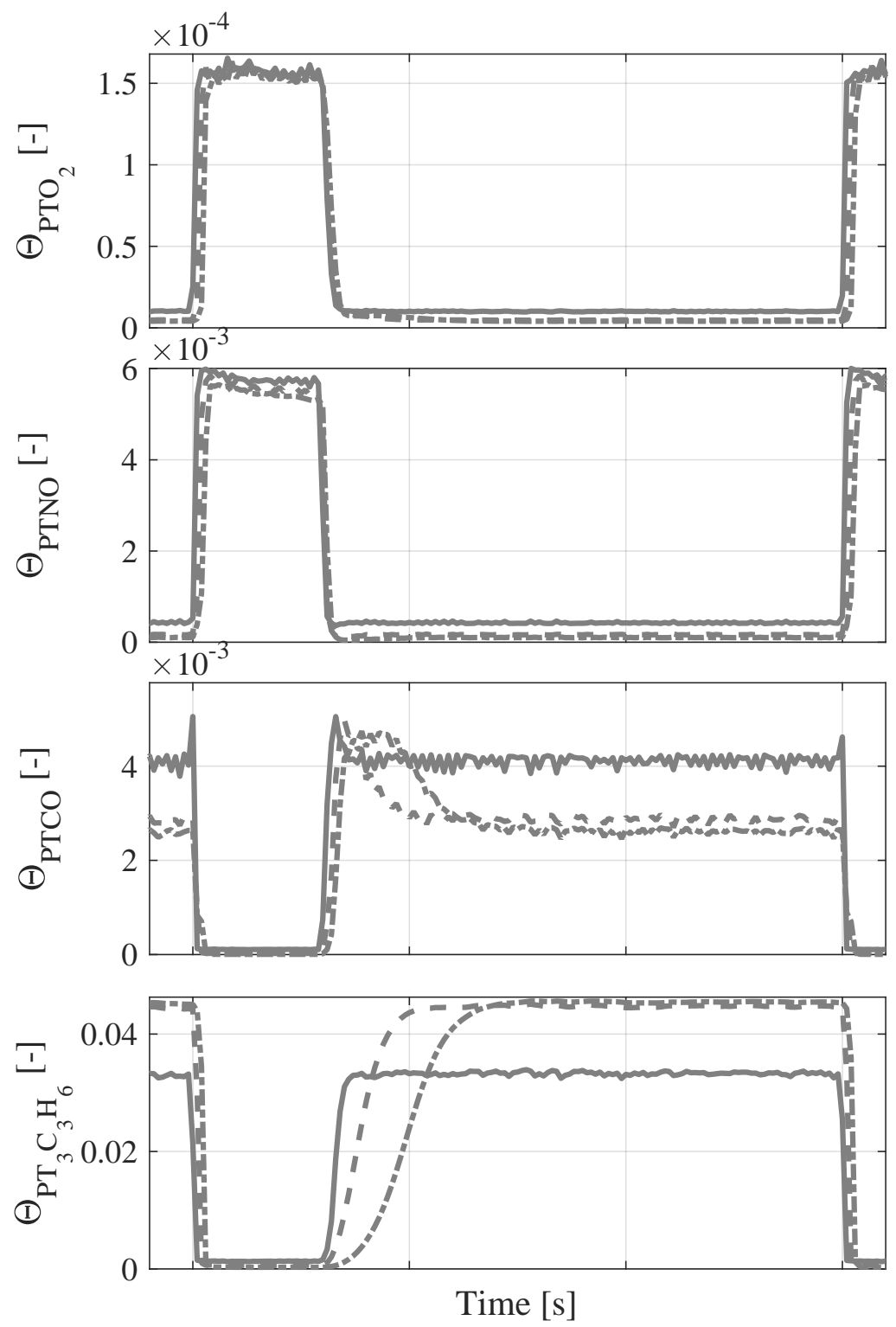

Figure 7.1: TWC behavior under AFR steps. Operating conditions: $2500 \mathrm{rpm}$ and 75 Nm. Aged TWC. Gray lines are model predictions. Solid (-), dashed (-- -) and dash-dot (-.-) lines correspond to inlet, middle and outlet sections respectively 

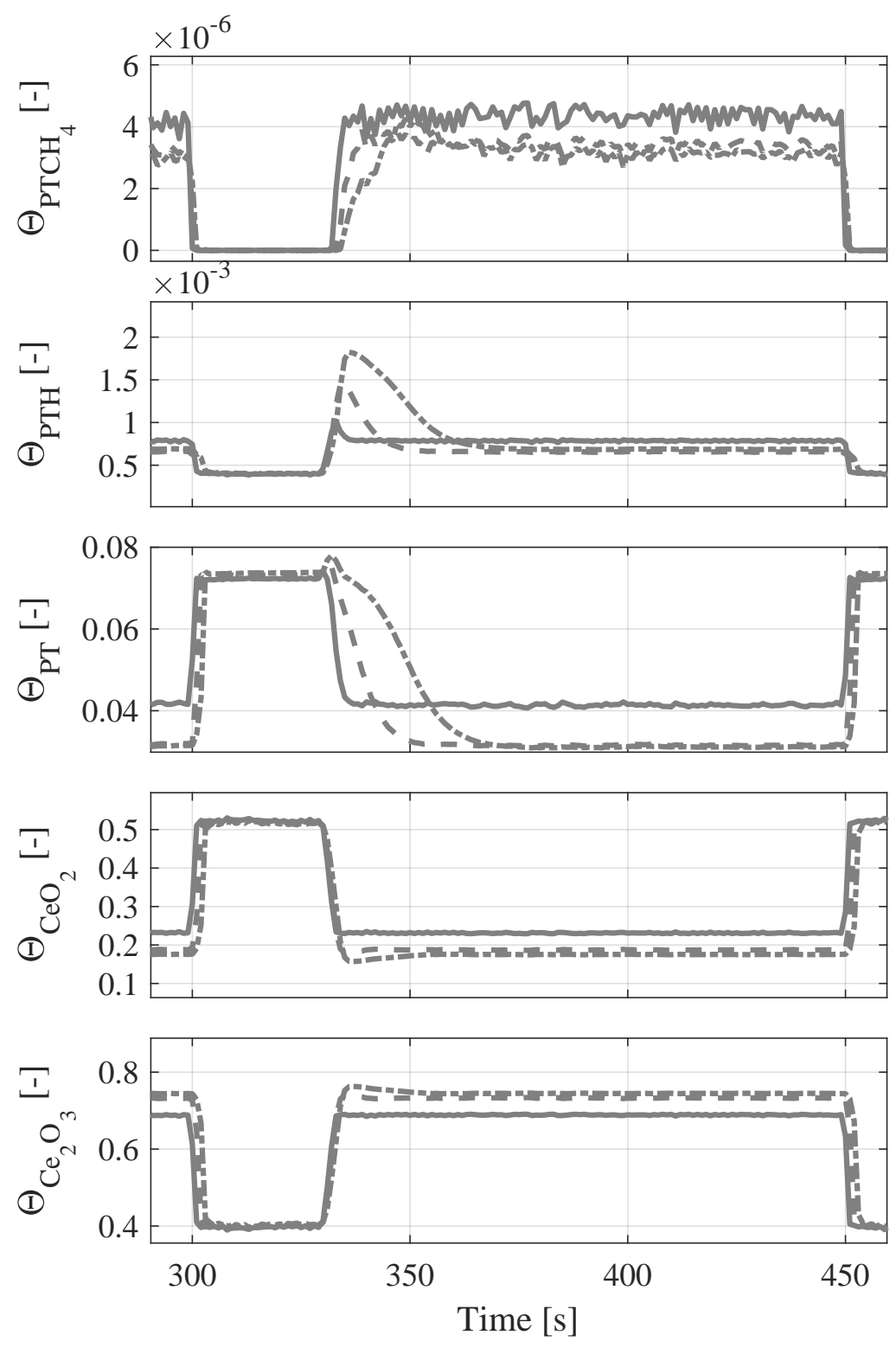

Figure 7.2: TWC behavior under AFR steps. Operating conditions: $2500 \mathrm{rpm}$ and 75 Nm. Aged TWC. Gray lines are model predictions. Solid (-), dashed (-- -) and dash-dot $(-\cdot-\cdot)$ lines correspond to inlet, middle and outlet sections respectively 

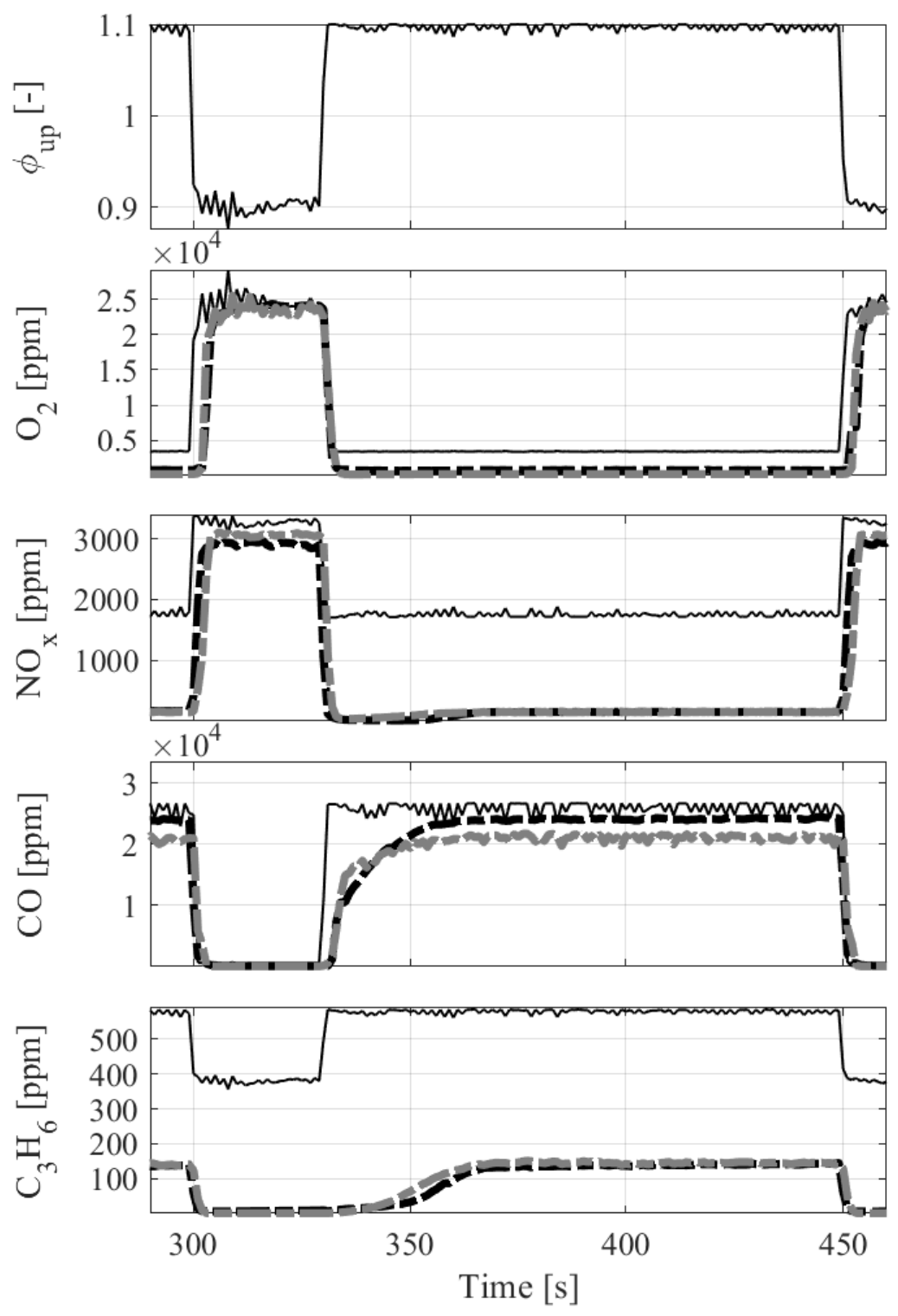

Figure 7.3: TWC behavior under AFR steps. Operating conditions: $2500 \mathrm{rpm}$ and $75 \mathrm{Nm}$. Aged TWC. Black lines represent experimental data while gray lines are model predictions. Solid (—) and dash-dot (-...) lines correspond to inlet and outlet respectively 

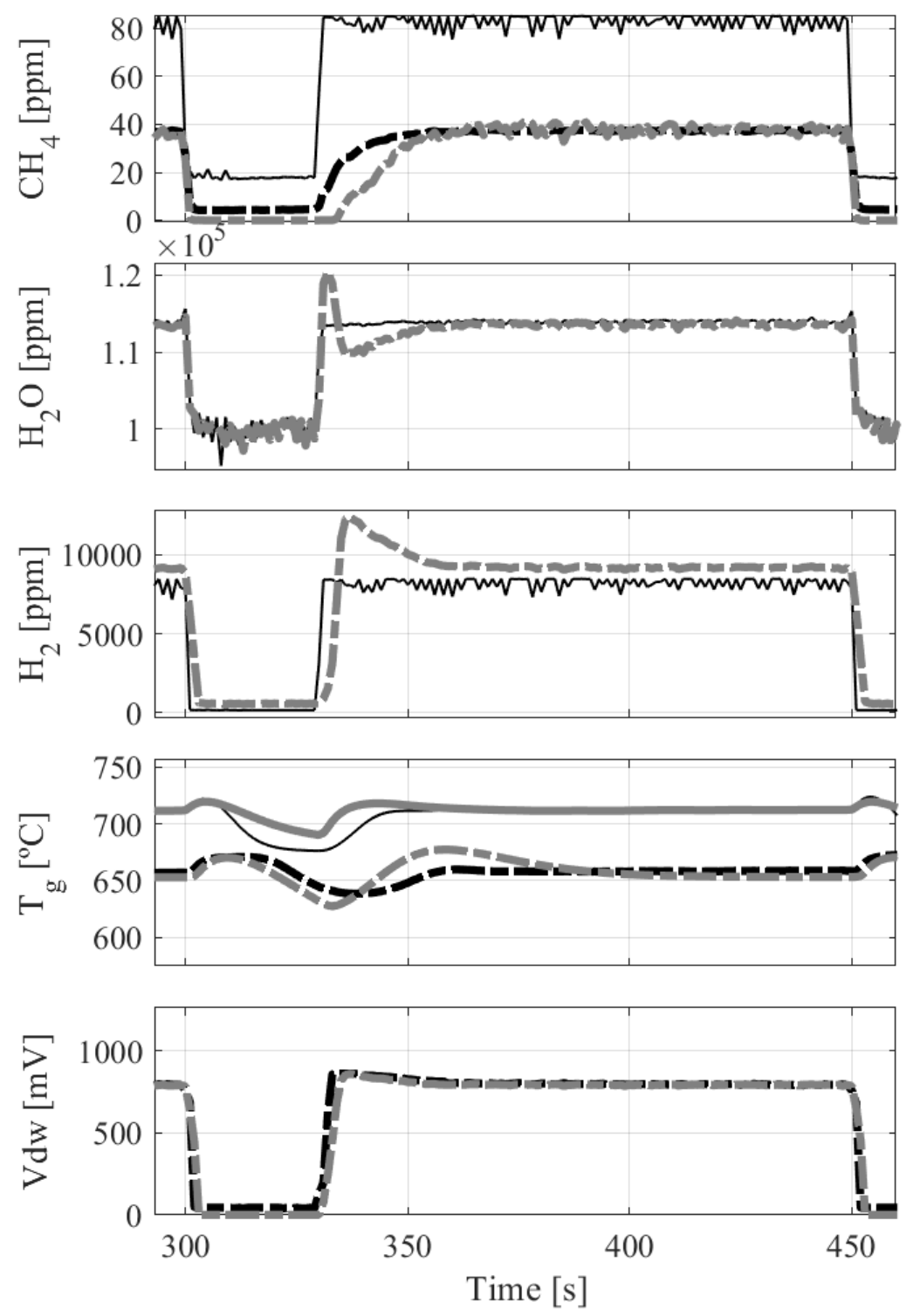

Figure 7.4: TWC behavior under AFR steps. Operating conditions: $2500 \mathrm{rpm}$ and $75 \mathrm{Nm}$. Aged TWC. Black lines represent experimental data while gray lines are model predictions. Solid (-) and dash-dot (-.-.) lines correspond to inlet and outlet respectively 

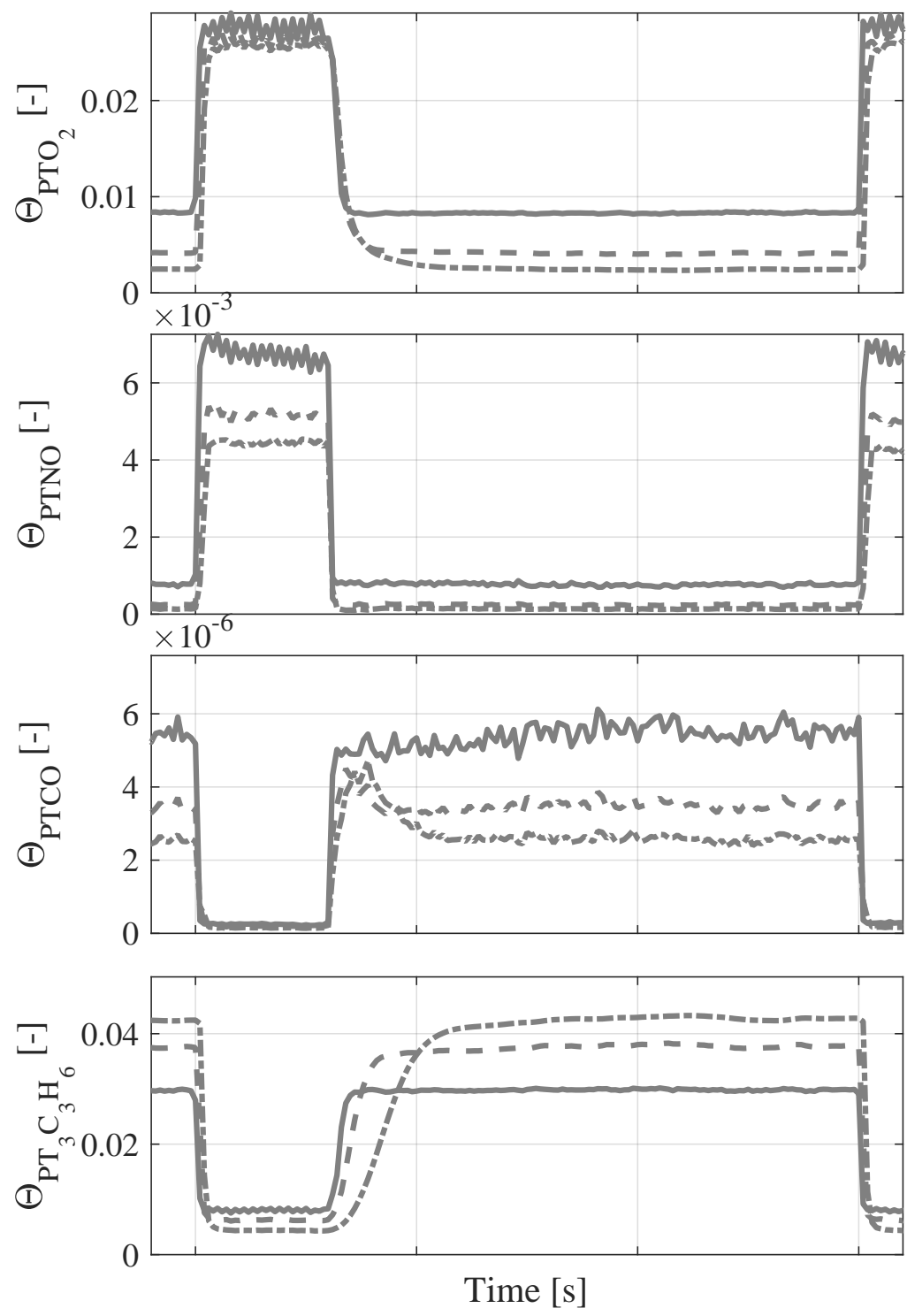

Figure 7.5: TWC behavior under AFR steps. Operating conditions: $2500 \mathrm{rpm}$ and 75 Nm. OBD TWC. Gray lines are model predictions. Solid (-), dashed (-- -) and dash-dot (--.) lines correspond to inlet, middle and outlet sections respectively 

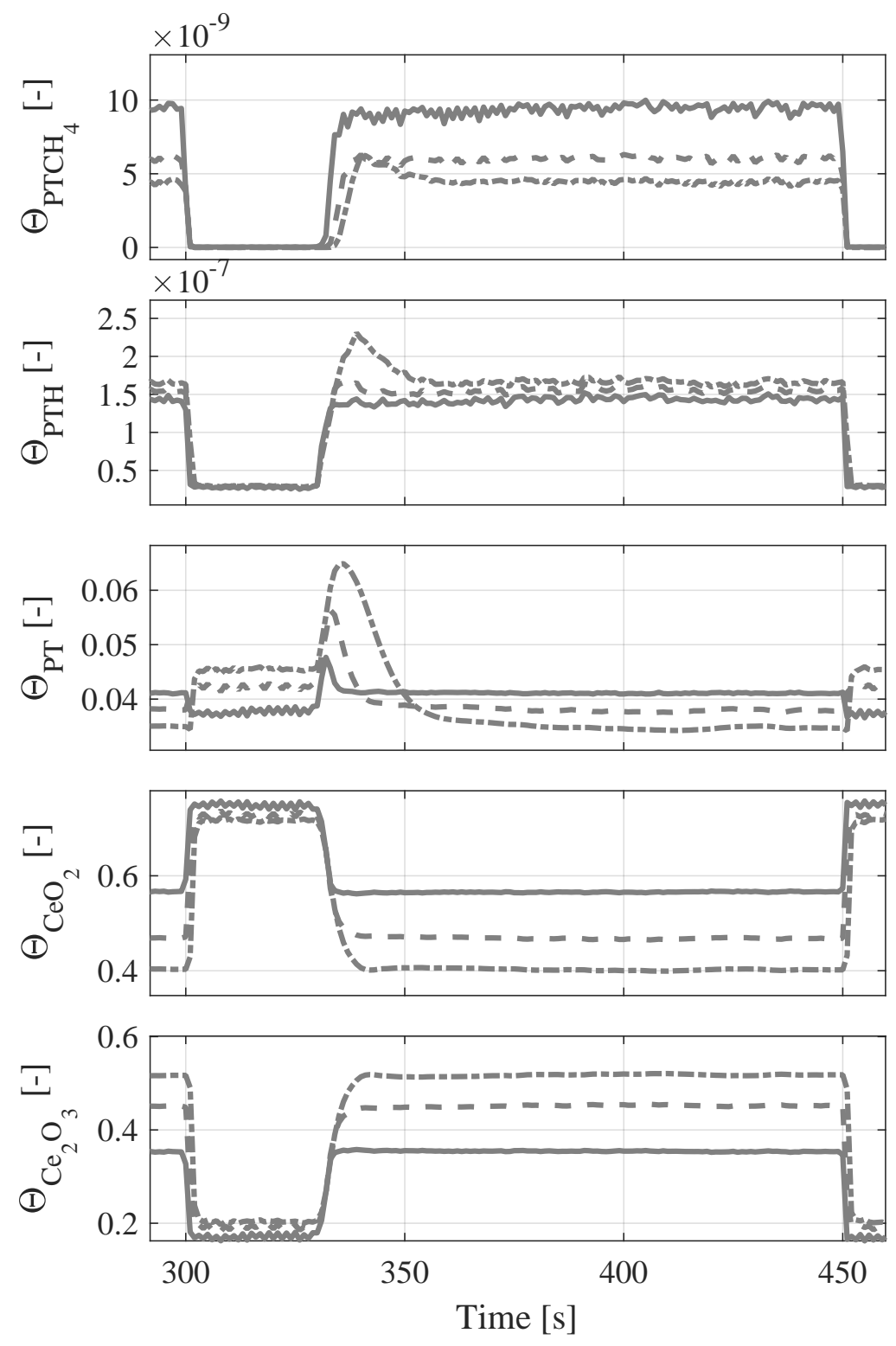

Figure 7.6: TWC behavior under AFR steps. Operating conditions: $2500 \mathrm{rpm}$ and 75 Nm. OBD TWC. Gray lines are model predictions. Solid (-), dashed (-- -) and dash-dot $(-\cdot-\cdot)$ lines correspond to inlet, middle and outlet sections respectively 

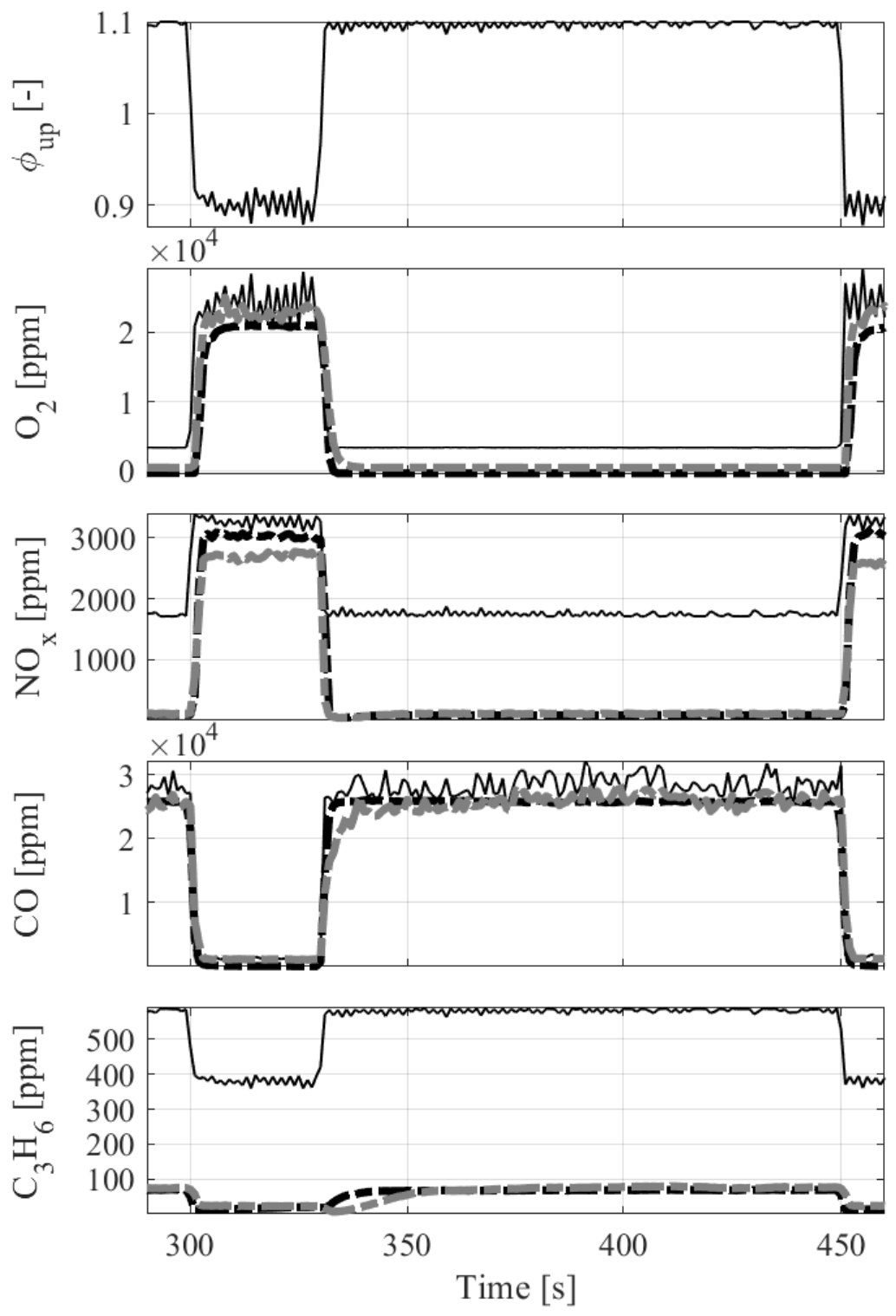

Figure 7.7: TWC behavior under AFR steps. Operating conditions: $2500 \mathrm{rpm}$ and $75 \mathrm{Nm}$. OBD TWC. Black lines represent experimental data while gray lines are model predictions. Solid (—) and dash-dot (-...) lines correspond to inlet and outlet respectively 

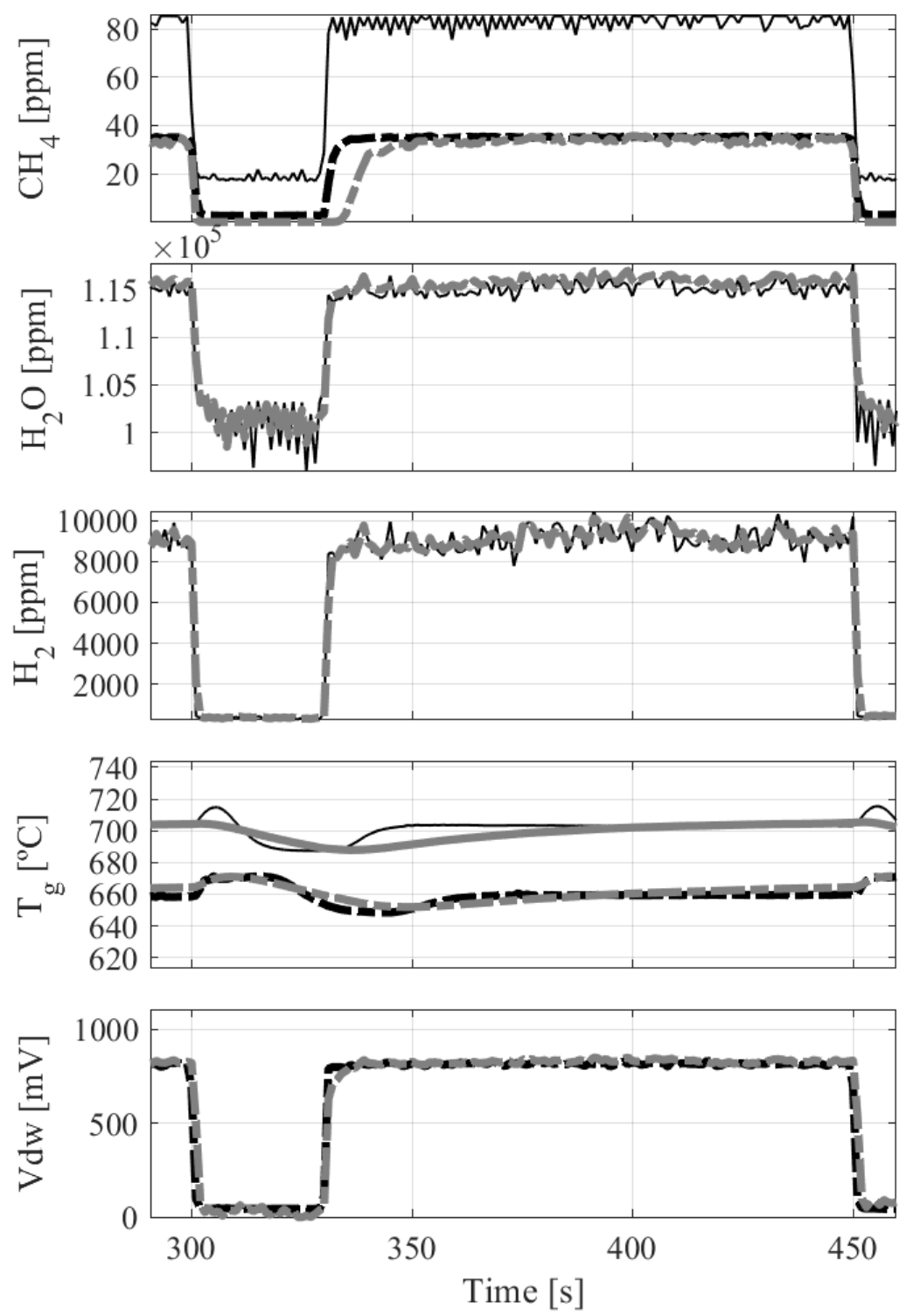

Figure 7.8: TWC behavior under AFR steps. Operating conditions: $2500 \mathrm{rpm}$ and $75 \mathrm{Nm}$. OBD TWC. Black lines represent experimental data while gray lines are model predictions. Solid (-) and dash-dot (-.-.) lines correspond to inlet and outlet respectively 
and its concentration in the exhaust gas is much higher. Regarding $\mathrm{O}_{2}$ all the converters show similar output levels at steady state in both rich and lean conditions.

During transient phases the dynamic behaviour is much more predictable, the ageing causes the decrease of the storage capability not only for oxygen, but for all the species, which causes faster dynamics and thus shorter transients. Particularly remarkable is the case of the OBD TWC, with similar dynamics at the inlet and at the outlet, behaving almost as an empty pipe. As explained in section 4.1.5, the WGSR plays a key role increasing the oxidizing capability of the converter at rich conditions, and its role is also important to understand the selectivity of the TWC ageing. The dynamic behaviour of the vacancies occupied by each species (Figure 4.3-4.4, 7.1-7.2 and 7.5-7.6 for fresh, aged and OBD TWC respectively) are useful to realize what is really happening. At the very beginning of the lean to rich step, the oxygen stored during the previous lean phase allows to oxidise $\mathrm{CO}$ and $\mathrm{C}_{3} \mathrm{H}_{6}$, the latter in turn generates $\mathrm{CO}$ and $\mathrm{H}_{2} \mathrm{O}$ as products. As a consequence, the vacancies occupied by CO suffer a fast increase, but this increase is lower when the ageing is stronger, due to the lower OSC. The simultaneous availability of $\mathrm{CO}$ and $\mathrm{H}_{2} \mathrm{O}$ as a result of the $\mathrm{C}_{3} \mathrm{H}_{6}$ oxidation but also of their natural increase due to the $\phi$ step from lean to rich conditions, promote the activation of the WGSR, particularly in the fresh TWC. This is one of the main effects of the ageing, the deactivation of the WGSR. The vacancies occupied by $\mathrm{H}_{2}$, one of the products of this reaction, show how the stronger the ageing the lower the peak value and duration reached. Thus, in aged TWC not only the activation of the WGSR is weaker, but also shorter, giving as a result faster dynamics and lower oxidation capability, especially for $\mathrm{CO}$ emissions. Figures 4.6, 7.4 and 7.8 show this effect in terms of $\mathrm{H}_{2} \mathrm{O}$ and $\mathrm{H}_{2}$ concentration (reactant and product respectively of the WGSR) at the outlet of the converter. Unfortunately, experimental measurements are not available for this species, but the model outputs allow to compare them with the corresponding inlet values (calculated as explained in section 3.3), and model results agree with the published literature. The deactivation of the WGSR promoted by the ageing inhibits the interaction of both species, in the most extreme case (OBD TWC) the outlet and inlet concentrations are very similar. This phenomenon is also reflected 
in the signal of the switch-type $\lambda$ sensor downstream of the TWC just after the lean to rich step. The presence of $\mathrm{H}_{2}$ in higher concentrations increases slightly the voltage provided by the sensor while the WGSR is active, except for the OBD TWC since there is no $\mathrm{H}_{2}$ generation.

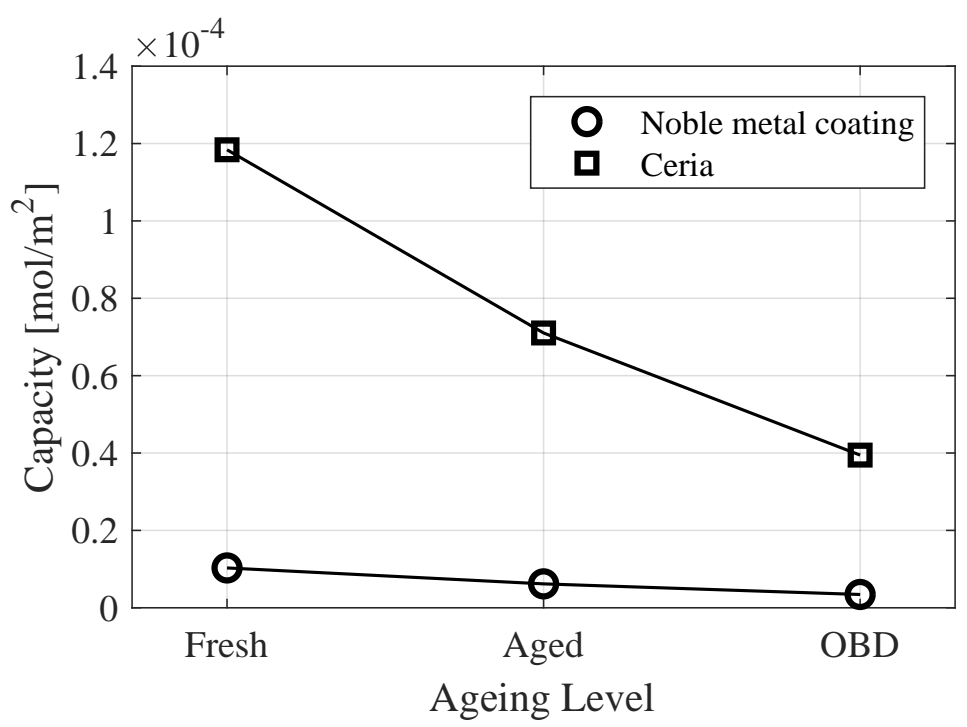

Figure 7.9: TWC storing capacity in both noble metal coating and ceria for different aging levels

Figure 7.9 show the storage capacity according to the one-dimensional model in terms of noble metal and ceria storage, depending on the ageing level for the three converters compared. The storage capacity on ceria is one order of magnitude higher than in noble metal, however, both suffer a remarkable reduction due to the catalyst ageing. According to this results, and considering a linear correlation between OSC and ageing level, that is, ageing equal to $0 \%$ represents maximum storage capability, and ageing $100 \%$ represents null storage capability, the corresponding ageing level for the fresh, aged and OBD TWCs are $0 \%, 42 \%$ and $67 \%$ respectively. 


\subsubsection{Effect of three-way catalyst size}

The sizing is an important factor during the design of the aftertreatment system. Given exactly the same washcoat composition and brick structure, that is, same concentration of noble metals and ceria, same substrate material, channels geometry and cell density, just modifying the external dimensions (diameter and/or length) can be enough to adapt the TWC to the requirements of different powertrains, thus simplifying stocks problems for manufacturers and suppliers as well as reducing costs. Certainly, from the point of view of the engine packaging, compactness and weight are key aspects. However, the range of exhaust gas mass flows covered by the engine can impose some limitations to the minimal size of the converter. On the other hand, larger converters are not synonymous of greater potential to reduce emissions, since under certain circumstances as throttle tip-in after fuel injection cut-off (section 5.1) or catalyst warm-up during cold-start (section 5.3), a converter with great OSC or thermal capacity can be harmful.

In practical terms, reducing the size of the brick could be equivalent to a certain ageing level of the converter. In this regard, the following figures show the behaviour of six converters with different lengths and ageing level during a AFR transient. Two ageing levels have been assessed, fresh and aged in Figure 7.10 and 7.11 respectively. For each one, there are three different lengths, full-size, two thirds and one third of the total length (indicated by the grey scale from light to dark), in this case the diameter as well as the rest of specifications are the same for of all them (section 3.2).

The left column shows the experimental data while the predictions provided by the 1-D model are presented on the right. All the model simulations share the same parameters previously identified for each ageing level, the only difference is the size of the brick, properly adapted to the length of the real brick in each case. According to the results obtained, the length of the converter has similar effects to those shown by the ageing. Although experimental results show higher dispersion, the overall trends are in accordance with the predictions provided by the 1-D model. The dispersion of the experimental tests may be due to inaccuracy while cutting the brick into slices to reduce the length, to the extent of the arti- 

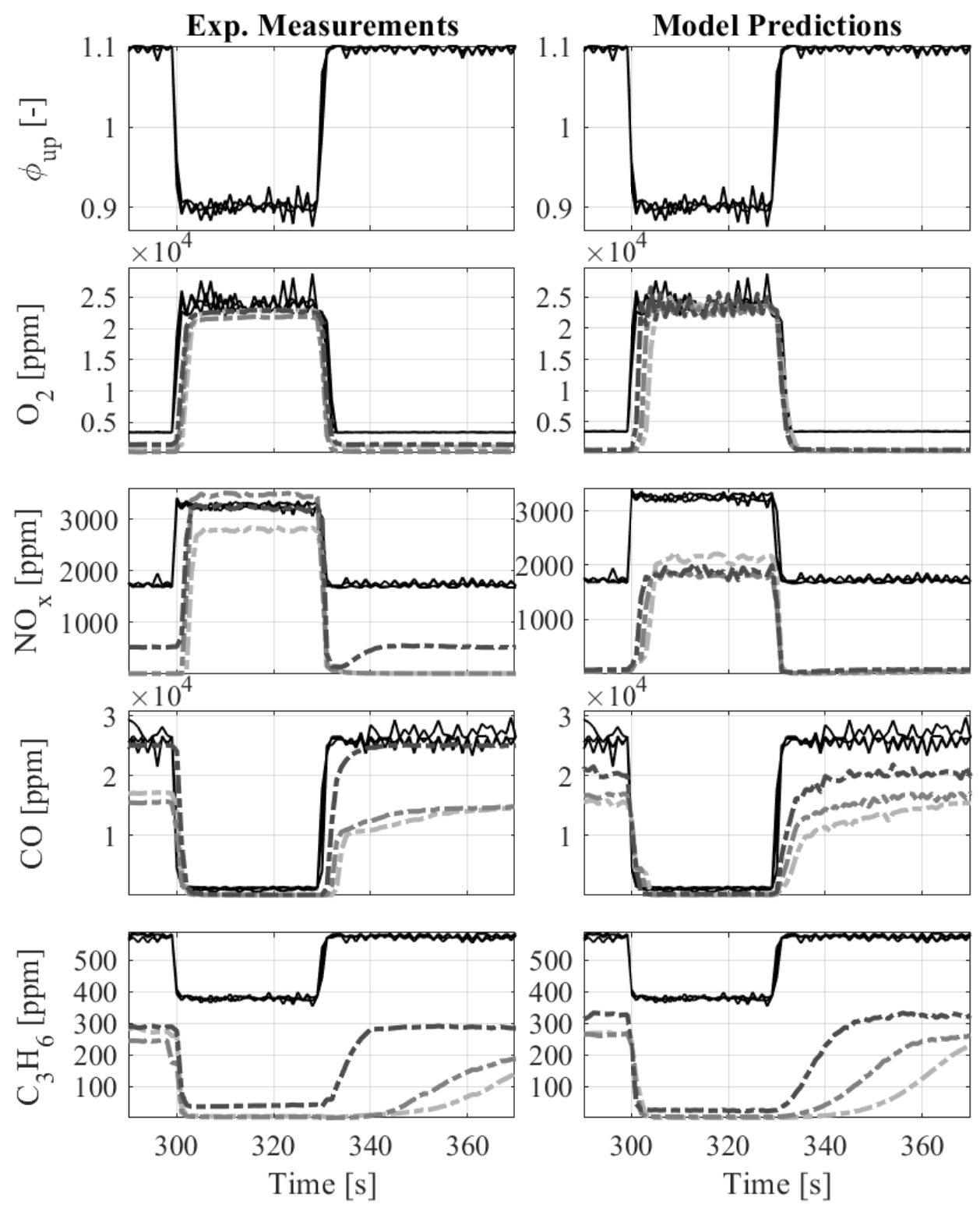

Figure 7.10: Effect of TWC length. Experimental measurements (left) versus model predictions (right). Operating conditions: $2500 \mathrm{rpm}$ and $75 \mathrm{Nm}$. Fresh TWC. Black solid lines (-) represent data upstream the TWC while dash-dot lines (-.-.) are downstream signals. From lighter to darker, the gray scale represent the converter length, full size, $2 / 3$ and $1 / 3$ of the full size respectively 

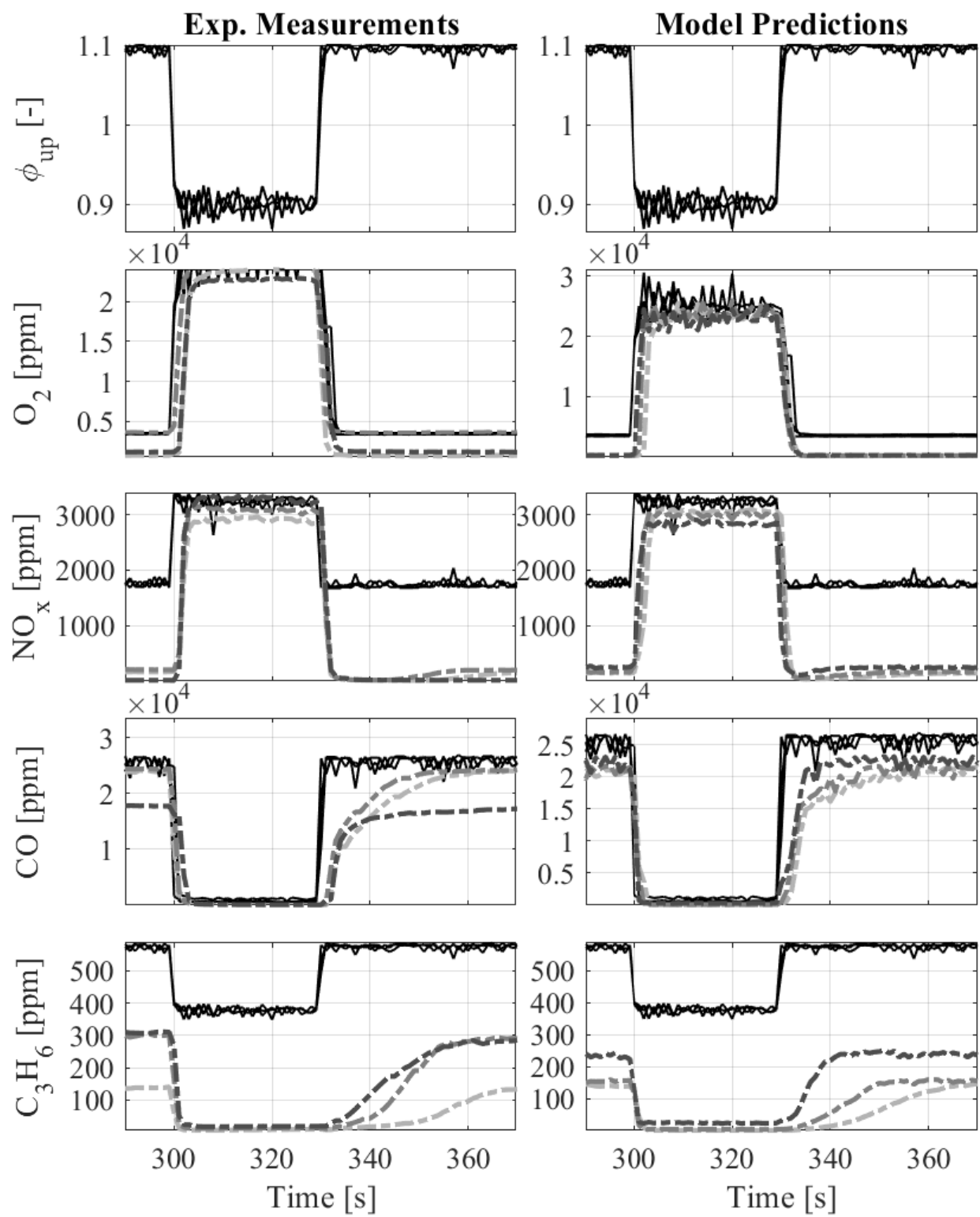

Figure 7.11: Effect of TWC length. Experimental measurements (left) versus model predictions (right). Operating conditions: $2500 \mathrm{rpm}$ and $75 \mathrm{Nm}$. Aged TWC. Black solid lines (-) represent data upstream the TWC while dash-dot lines (-.-.) are downstream signals. From lighter to darker, the gray scale represent the converter length, full size, $2 / 3$ and $1 / 3$ of the full size respectively 
ficial ageing induced, or even to discrepancies in the amount of hours that each converter has been used in the test bench for different purposes. At steady state the conversion efficiency decreases with the reduction of the length, since the active surface is smaller. Also during transient phases the effect of the length reduction is remarkable, decreasing the absolute storage capacity of the converter and thus leading to faster dynamic responses. The pollutant less affected by the size is $\mathrm{NO}_{\mathrm{x}}$, while the effect on $\mathrm{HC}$ emissions is particularly relevant, in this case the decrease of the brick length reduces the duration of the transient phase from lean to rich conditions up to 30 seconds for the fresh TWC and 20 seconds for the aged. 


\subsection{Three-way catalyst ageing diagnosis through sensor-based strategy}

This section focuses on the on-line diagnosis of the TWC ageing level by means of a sensor-based strategy. The idea lies on the attenuation that the converter imposes on the downstream $\lambda$ sensor signal in comparison with the upstream signal, both provided by wideband $\lambda$ sensors. While the converter is fresh this attenuation is stronger, but as the ageing increases this attenuation is progressively softened. In the most extreme situation the effect of the converter on the exhaust gas could become very weak, thus not imposing any change on the gas composition or on the dynamics. In this sense, a converter with a extreme ageing level could behave as a empty pipe, and the difference between the signals provided by the upstream and downstream $\lambda$ sensors would only be a transport delay.

A characteristic and periodic event must be implemented on the upstream $\phi$ signal to check the extent of the attenuation imposed by the converter. However, a low or negligible impact on the normal operating conditions and especially on the proper emissions conversion is desirable. It means that the average value of the $\phi$ signal upstream of the TWC should not be disturbed, at least for the characteristic time constant of the converter. Of course a high frequency signal could fulfil this requirements, but in that case the complete frequency content will be attenuated by the converter independently of the ageing level, since it behaves like a low-pass filter. All this requirements lead to the use of the AFR stimulation, which has also shown additional benefits in terms of $\mathrm{NO}_{\mathrm{x}}$ conversion (section 6.1). Regarding the signal processing tool used to identify and compare the frequency content upstream and downstream of the converter, the Fast Fourier Transform (FFT) has been chosen. The procedure is the same than the one used for the on-line short-circuit estimation (section 6.3.2).

Figure 7.12 shows the overall effect of the TWC ageing on the attenuation of the AFR stimulation depending on the average $\phi$ imposed upstream. The solid black and grey lines represent the amplitude of the FFT for the downstream $\phi$ signal at the AFR stimulation frequency for the fresh 
and the OBD TWCs respectively. This plot shows how around the sweet spot of the converter the filtering effect is stronger for both ageing levels. It is also remarkable how at lean conditions the attenuation is very weak, due to the incapability of the TWC to filter the oxygen pulses once the oxygen storage level within the converter is high. As a consequence, the potential of this approach to diagnose the ageing level in the lean range is rather limited, since the attenuation is very low and with low sensitivity to the ageing level, even taking into account the extreme cases are shown in Figure 7.12.

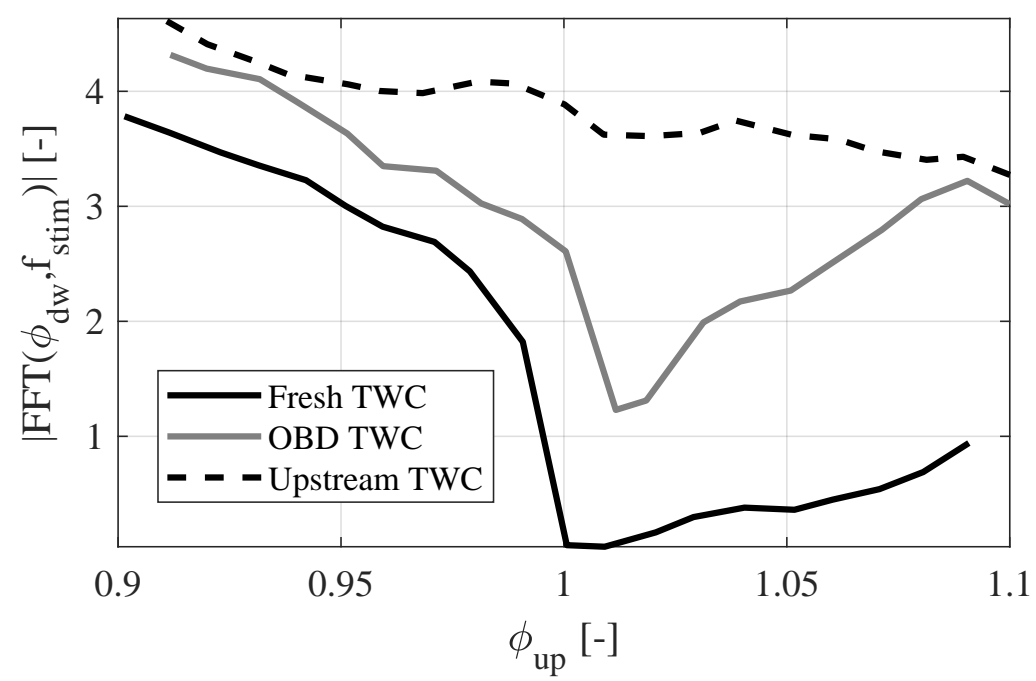

Figure 7.12: Attenuation effect on downstream $\lambda$ sensor signal depending on $\phi$ upstream of the TWC for the two extremes of ageing, the fresh (black line) and the OBD (gray line) TWC

Nonetheless, in the rich range the correlation between ageing and attenuation of the downstream signal is more gradual, allowing the proper diagnosis of the ageing. In the same figure, the dashed line represents the frequency content at the AFR stimulation frequency captured by the upstream $\lambda$ sensor. Intuitively, the dashed line is equivalent to the minimum signal attenuation that a deeply aged TWC would provide in terms of the amplitude of the downstream $\lambda$ sensor for a certain frequency content. Therefore, this signal could be used to represent the maximum 
ageing level, as well as the signal provided by the downstream $\lambda$ sensor with the fresh TWC represents the minimum ageing level (maximum attenuation). However, the signal provided by the downstream $\lambda$ sensor with the OBD TWC will be used hereinafter to represent the maximum ageing level, because it is considered a better approach from a practical point of view. Since the so-called OBD converter (section 3.2) has been artificially aged until reach a level such that it does not fulfil the regulatory vehicles test procedures, resulting in the activation of the on-board diagnostics (OBD) warning. In case of intermediate ageing levels, the values will be interpolated linearly between the aforementioned ageing thresholds.

In order to assess the possible impact of different AFR stimulations on the attenuation of the signal imposed by the converter, Figure 7.13 shows the dependency of the attenuation effect regarding the frequency and amplitude of the AFR stimulation implemented upstream. Each column corresponds to a different ageing level, while each row represents a different average $\phi$ value from lean to rich in ascendant order. The gray scale represents the value of the amplitude provided by the FFT of the downstream $\lambda$ sensor signal at the frequency of the AFR stimulation, divided by the equivalent upstream signal:

$$
\frac{\left|F F T\left(\phi_{d w}, f_{\text {stim }}\right)\right|}{\left|F F T\left(\phi_{\text {up }}, f_{\text {stim }}\right)\right|}
$$

Figure 7.13 shows how, comparing the attenuation at lean conditions (first row) for different ageing levels, the impact of both the stimulation frequency and amplitude is rather limited as expected, since at these conditions the attenuation is always weak, although slightly stronger for the fresh TWC (darker greys).

For the average $\phi$ of minimal emissions or sweet spot (second row), the attenuation is very strong in both ageing levels independently of the amplitude and frequency of the AFR stimulation, showing that even the aged TWC can reach high conversion efficiencies around the proper $\phi$. However, with the aged TWC the effect of the frequency on the attenuation is more evident, particularly in case of low frequencies (from 0.1 to 


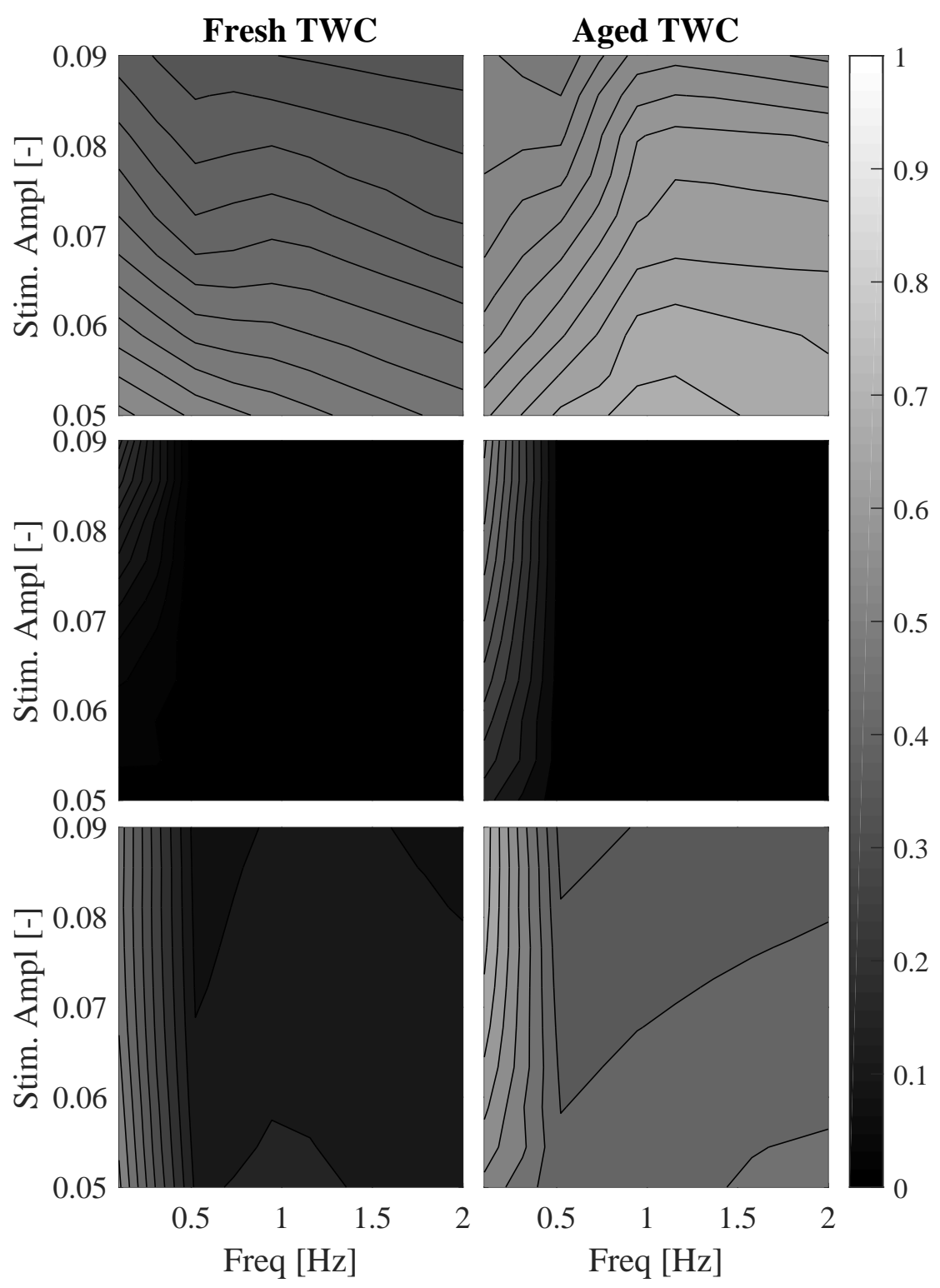

Figure 7.13: Normalized attenuation effect on downstream $\lambda$ sensor signal depending on both the frequency and the amplitude of the upstream AFR stimulation. Each column corresponds to a different ageing level while each row represents a different average $\phi$ value: lean (first row), stoichiometric (second row) and rich conditions (third row) respectively. The gray scale quantifies the degree of attenuation imposed by the converter, a value equal to zero represents attenuation equal to $100 \%$ ) 
$0.5 \mathrm{~Hz}$ ), and this effect gets worse when the amplitude increases. It is due to the smaller storage capability of this converter, which leads to lower attenuation of the inlet signal (lighter greys). At rich conditions (third row), the decrease of the attenuation for low frequencies remains, for any other combination of frequency and amplitude the attenuation is homogeneous, which allows a proper characterization of the catalyst ageing for a wide range of AFR stimulations. An important aspect comparing rich with leaner conditions is the quantitative effect of the converter ageing on the attenuation, which is coherent with the results shown in Figure 7.12. The ageing tends to deteriorate the filtering effect of the converter, reducing the attenuation when compared to a fresh TWC. From now on, for the present ageing diagnosis strategy the AFR stimulation imposed corresponds to a frequency of $1 \mathrm{~Hz}$ and amplitude equal to 0.05 .

Once the impact of the main parameters has been studied and a proper AFR stimulation profile has been defined, the present diagnosis strategy is used to quantify the ageing level of the whole set of TWCs available. That is, a total of 7 converters with three ageing levels artificially induced as well as three different lengths for the fresh and the aged TWC. Due to the effect of the average $\phi$ observed, the diagnosis of the ageing is carried out in the rich range. It has been found that also the air mass flow has some influence on the attenuation obtained while using the same converter and imposing the same average $\phi$ and stimulation profile. In particular, the higher the mass flow the lower the attenuation, which is reasonable since the residence time within the converter channels decreases with the increase of the mass flow, thus reducing the conversion efficiency. That is why in the present approach, the attenuation has been characterized depending on both the average $\phi$ and the exhaust gas mass flow for a certain ageing level. According to the criteria followed the amplitude of the frequency content associated to the $\lambda$ sensor downstream of the fresh TWC is considered equivalent to an ageing level equal to 0 $\%$, while the one of the OBD TWC is considered equivalent to an ageing equal to $100 \%$. For the intermediate ageing cases, the ageing level is linearly interpolated depending on the amplitude of the frequency content obtained. Figure 7.14 shows a summary of the ageing level diagnosed for each converter. The experimental test performed consists of a $\phi$ swept 
with AFR stimulation upstream and constant operating conditions, in particular, $2500 \mathrm{rpm}$ and $75 \mathrm{Nm}$.

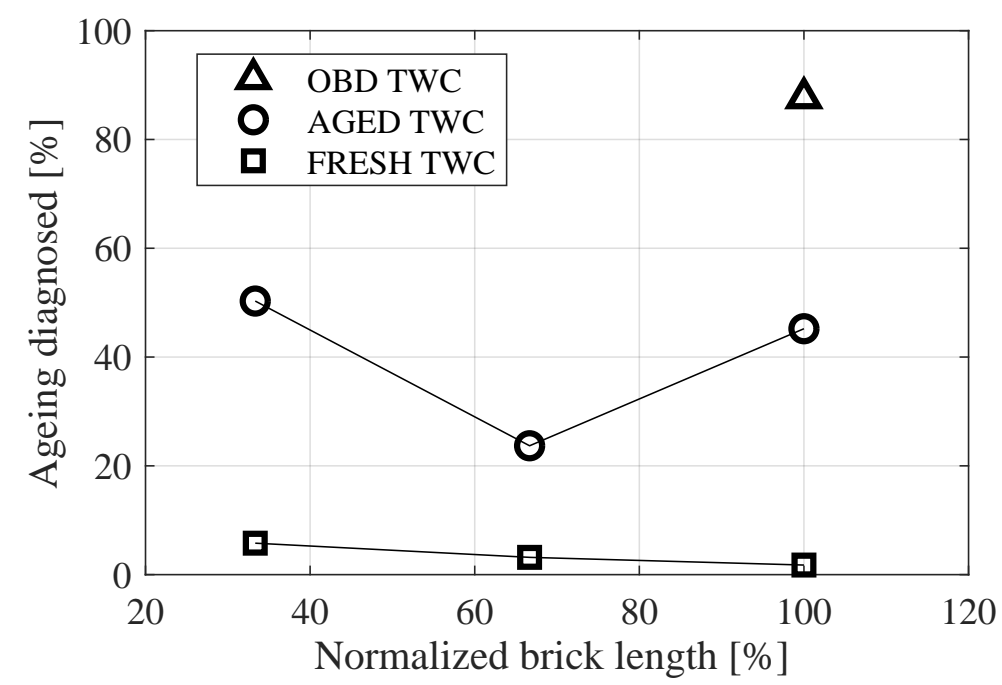

Figure 7.14: Ageing value obtained with the proposed sensor-based diagnosis method for each TWC with different lengths and ageing levels

The result obtained are in coherence with the different ageing and size of each converter. The effect of the thermal ageing artificially induced is stronger than the effect of the length reduction. The ageing diagnosed for the three fresh TWCs with different lengths $(3 / 3,2 / 3$ and $1 / 3$ of the full length respectively) is below $10 \%$. In the case of the three aged converters the ageing ranges between $22 \%$ and $50 \%$. The only discrepancy appears for the full-length aged TWC, for which the diagnosis method provides an ageing level higher than the one obtained by the other aged converters with reduced length. It could be due to the intensive experimental use of this particular converter during the development of this dissertation, thus increasing the initial ageing artificially induced in oven. The OBD converter shows an extreme ageing, far from the values obtained for the rest of converters as expected, even considering the length reduction.

Finally Figure 7.15 shows the result obtained after applying the ageing diagnosis strategy during the high speed phase of the Worldwide har- 

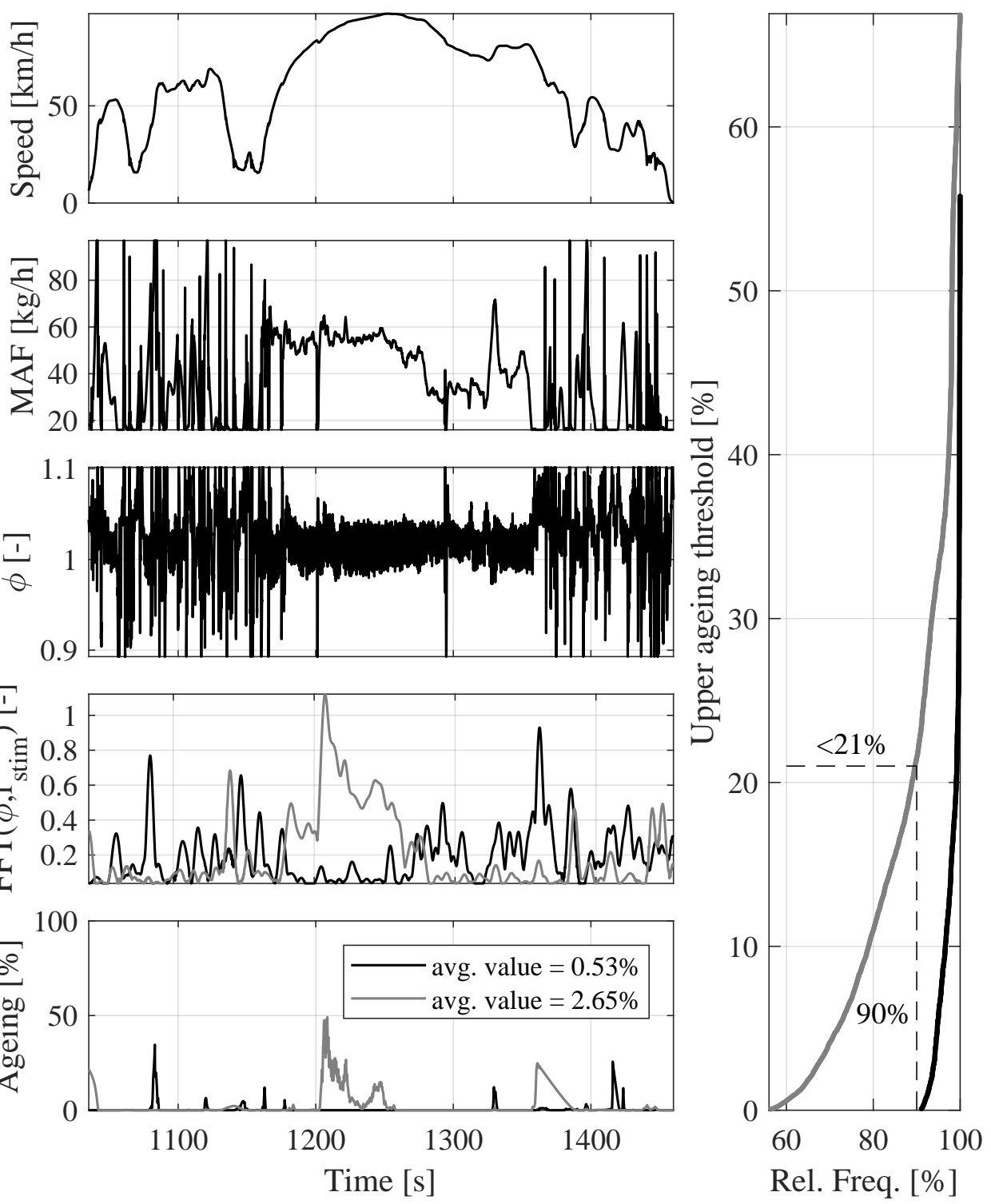

Figure 7.15: Ageing diagnosis strategy comparison for the fresh TWCs with full-length (black lines) and $2 / 3$ of total length (gray lines). The driving cycle used corresponds to the High Speed phase of the WLTC 

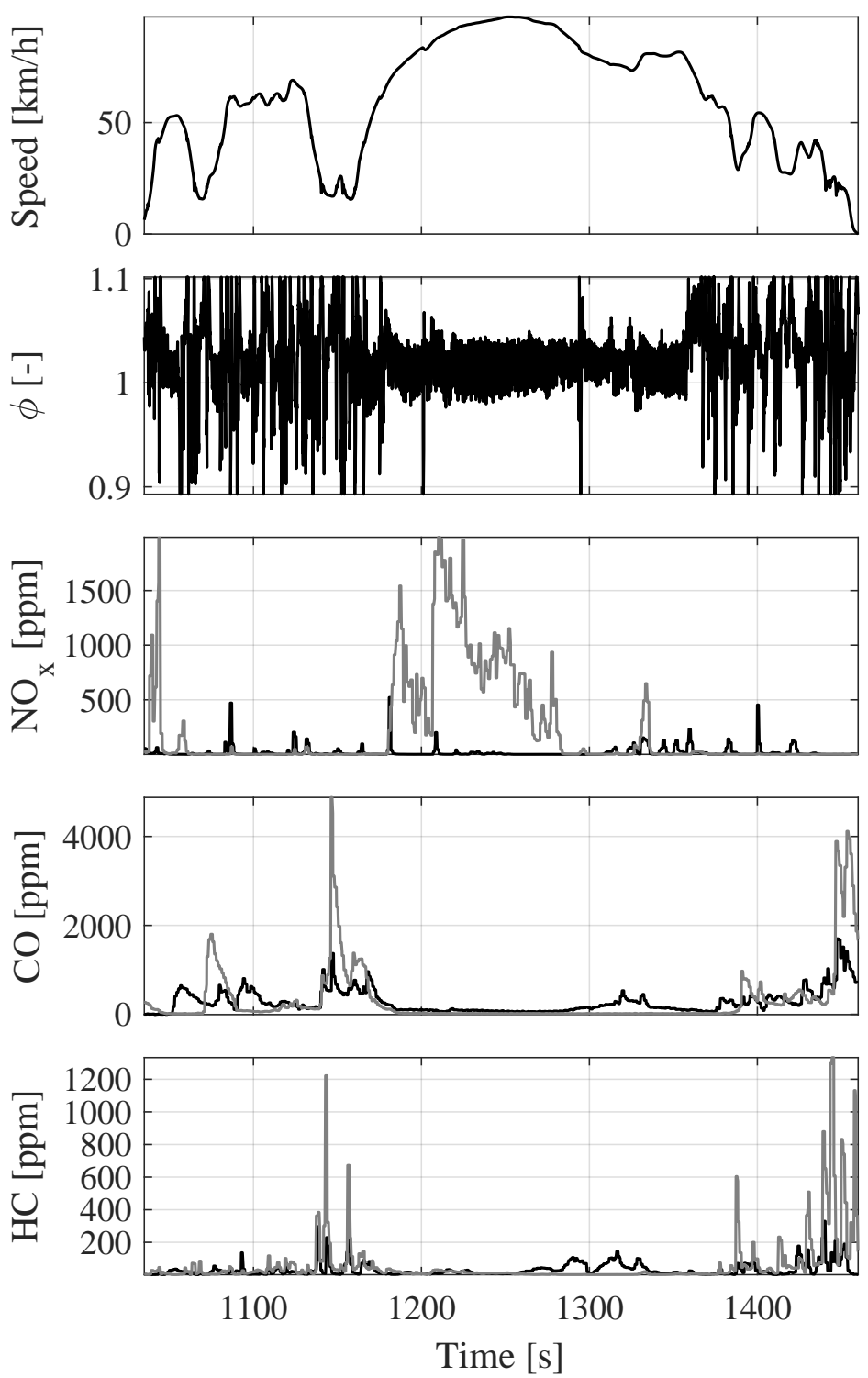

Figure 7.16: Ageing diagnosis strategy comparison for the fresh TWCs with full-length (black lines) and $2 / 3$ of total length (gray lines). Impact on emissions. The driving cycle used corresponds to the High Speed phase of the WLTC 
monized Light vehicles Test Cycle (WLTC). The objective of this test is to assess the capability of the proposed strategy to detect small differences of ageing level in realistic driving conditions. That is why the the fresh converter with full length (black line) and the converter with its length reduced to two thirds (gray line) have been compared. These two converters represent the most critical comparison, since their ageing level is very similar according to the previous results (Figure 7.14). The three upper plots in the left column show vehicle speed, air mass flow and $\phi$. The vehicle speed is calculated according to the vehicle parameters provided to the software of the dynamometer: gearbox ratios, wheels diameter, etc; the air mass flow is measured with a hot-wire sensor at engine intake; and the recorded $\phi$ corresponds to the measurement provided by the wide-range $\lambda$ sensor upstream of the TWC. The data shown for these three upper plots correspond to the test with the full-length converter, since test repeatability is high in this case. Mainly because the speed profile followed as well as the vehicle and engine calibration are the same in both tests, thus the only difference is the TWC used. The fourth plot shows the amplitude of the FFT for the signal provided by the downstream $\lambda$ sensor at the stimulation frequency. The bottom plot shows the instantaneous ageing value provided by the diagnosis strategy, and the plot of the right column represents the accumulated distribution of this instantaneous ageing values depending on their relative frequency.

In the low speed stretches at the beginning and the end of the test, the acceleration changes lead to continuous gear shifts and transient phases, which limits the proper implementation of an homogeneous $\phi$ stimulation. As a result, the instantaneous ageing values provided by the diagnosis strategy are not too consistent in these conditions. Increasing the calibration effort of the dynamometer controller when following the vehicle speed profile would probably improve the results obtained at low speed, since the driver demands are too aggressive. However, during the road cruising at higher speeds the controller behaves in a softer way and the engine works near steady state conditions. Under these circumstances the $\phi$ stimulation can be successfully imposed, and the main differences between both converters arise. For the $90 \%$ of the samples, the ageing of the full-length converter is zero according to the diagnosis strategy, while the ageing is below $21 \%$ for the same percentage of samples in case of 
the converter with $2 / 3$ of the nominal length. Considering the average of all the instantaneous ageing values obtained during this test, the ageing of the $3 / 3$ and $2 / 3$ converters is $0.53 \%$ and $2.65 \%$ respectively, thereby in coherence with the ageing diagnosed in Figure 7.14. The concentration of $\mathrm{NO}_{\mathrm{x}}, \mathrm{CO}$ and $\mathrm{HC}$ for both converters are shown in Figure 7.16. In those moments when the full-length converter suffers small emissions penalties due to $\phi$ excursions either towards rich or lean conditions, the length reduction aggravates these penalties. Particularly relevant is the shift of the sweet spot towards richer conditions for the converter with reduced length, which notably increases $\mathrm{NO}_{\mathrm{x}}$ emissions during the road cruising stretch. It happens because the AFR control is not taking into account the different converter used, since the ageing estimation has been carried out off-line on these tests. 

Chapter 8

\section{Findings and conclusions}

Contents

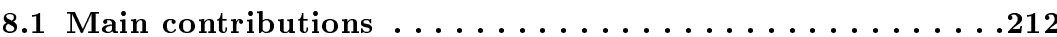

8.1 .1 Modelling .. . . . . . . . . . . . . . . . . . . . . . . . 212

8.1 .2 Understanding of three-way catalyst behaviour . . . . . . . .213

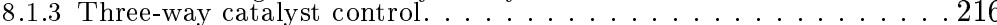

8.1 .4 Three-way catalyst ageing diagnosis . . . . . . . . . . . . . . . . . . .219 


\subsection{Main contributions}

This dissertation addresses the control and diagnosis of aftertreatment systems for pollutant emissions reduction in SI engines, and particularly TWC as its key element. Different topics have been covered along this work, thereby, a summary of the main contributions can be found below.

\subsubsection{Modelling}

One-Dimensional physics-based three-way catalyst modelling

Different TWC models have been developed during this dissertation. Computational cost and model performances depend strongly on the features required as well as on the final purpose of the model. Consequently, it is usual to develop models ad hoc, in order to fulfil the specific requirements of the application. The one-dimensional TWC model developed is capable to represent the behaviour of the three-way catalytic converter in terms of gas composition and temperature in an accurate way. Thanks to the 1D-1Ch approach, not only the outlet values but also the evolution of any state along the whole converter can be monitored. Moreover, the model provides estimations of different experimentally unmeasurable states like the level of vacancies occupied by each species, or the gas concentration in the washcoat pores. These characteristics are very useful in order to improve the understanding of the phenomena related to the TWC behaviour, particularly during transients phases. Especially relevant is the fact that the model keeps relatively low computational requirements, allowing to simulate any experimental test in real time by using a standard PC.

\section{Zero-Dimensional control-oriented modelling of three-way catalyst}

On the other hand, a control-oriented TWC model has been derived form the previous one. The overall model consist of three parts, the upstream feed gas sub-model, the TWC model itself, and the downstream narrowband $\lambda$ sensor sub-model. The present approach is based on the following features: zero-dimensional, lumped-parameter kinetics, real-time capable 
and able to provide reasonable estimations of OSL, brick temperature, $\lambda$ sensor voltage as well as the main chemical species involved at TWC outlet. Of course this approach implies some limitations, such as the inability to deal with complex behaviours as $\mathrm{NO}_{\mathrm{x}}$ reduction deactivation at very rich conditions with aged TWCs, or the lack of accuracy at very rich conditions with fresh catalysts. However, in most usual driving conditions it is fully functional and provides useful information regarding the TWC state, as the real-time estimation of the OSL. Since OSL is considered a good indicator of the catalyst state but it cannot be directly measured on-board, the model can be used for control purposes. In particular during transient phases, where the AFR can be controlled with the aid of the $\lambda$ sensor feedback, but also considering the oxygen stored in the TWC thanks to the information provided by the model. Moreover, the modelled $\lambda$ sensor voltage can be compared with the onboard measurement downstream of the catalyst during a step from rich to lean conditions or vice versa, in order to obtain information regarding the TWC ageing level.

\subsubsection{Understanding of three-way catalyst behaviour}

\section{Oxygen storage in three-way catalyst}

The capability of the TWC to store $\mathrm{O}_{2}$ allows the engine to face $\phi$ excursions without big emissions penalties during transient phases. However, depending on the amplitude and duration of these unavoidable $\phi$ disturbances, the conversion capabilities of the TWC can be exceeded. Moreover, even in case of small disturbances the conversion efficiency is slightly affected, which can be an important issue taking into account the low limits of the emissions regulations as well as the zero emissions trends.

In any case, increasing the OSC to deal with these situations has some non-negligible drawbacks, since the oxygen storage also has an associated cost. When the TWC is filled of $\mathrm{O}_{2}$, it is unable to reduce the $\mathrm{NO}_{\mathrm{x}}$ emissions while facing the lean exhaust gas phase associated to the throttle tip-in after a fuel injection cut-off. 
From the control point of view, the difficulty of the emissions control during transient phases is due to the fact that the converter efficiency is tightly related to the converter state in terms of oxygen storage, but it cannot be directly measured by any on-board sensors.

\section{Effects of fresh air short-circuit on the aftertreatment system}

The widespread downsizing strategy in SI engines and the wider engine areas covered by emission testing procedures have highlighted the importance of controlling accurately the aftertreatment system under SC conditions, which is a subject barely addressed in the literature. In this sense, the impact of SC on emissions in a state-of-art SI engine from an experimental perspective has been assessed. In particular, the effect of the SC on the engine raw emissions as well as on the tail pipe emissions has been analysed. Furthermore, the impact on the main exhaust elements, that is, $\lambda$ sensor and TWC has been addressed.

The experimental results show that the SC process has a non-negligible effect on the in-cycle dynamics of exhaust gas composition. The fresh air pulses short-circuited, in addition to the different paths of the exhaust gas from each cylinder, result in a characteristic $\phi$ waveform. Due to its high frequency as well as to its dependence on the amplitude of the short-circuit rate reached, this $\phi$ dynamic represents a relevant issue for the accurate $\phi$ measurement and control. The sensor bias together with the rich and lean pulses due to SC, induce an overestimation on the measurement provided by the $\lambda$ sensor compared to the actual AFR at TWC inlet. This overestimation causes an actual lean AFR when the signal provided by the $\lambda$ sensor is used as feedback, if SC is not properly considered. This behaviour has a final impact on $\mathrm{NO}_{\mathrm{x}}$ emissions, which increase considerably.

Regarding the TWC operation, the $\mathrm{CO}$ and $\mathrm{H}_{2}$ pulses coming from the rich in-cylinder AFR, which is required to operate the TWC at stoichiometric under $\mathrm{SC}$ conditions, cause an increase in $\mathrm{NO}_{\mathrm{x}}$ reduction efficiency as well as a penalty in the CO oxidation capabilities of the TWC. Moreover, the non-linearity of the combustion process itself involves greater generation of $\mathrm{CO}$ emissions, due to rich in-cylinder AFR. As a result, 
when the engine is operated under SC conditions, the sweet-spot of minimum emissions is shifted towards leaner conditions.

Despite the impact of the SC on the $\lambda$ sensor measurement and the TWC efficiency is somehow opposite, according to the obtained results, they do not cancel each other and the SC should be included in the AFR control strategy, at least from the emissions point of view. This fact justify the interest of developing on-board SC estimation methods that can be used to correct on-line its negative impact on emissions.

\section{Three-way catalyst behavior during cold-start phase}

State-of-the-art approaches for catalyst warm-up during engine cold-start tend to take advantage of direct injection systems in order to operate with very retarded ignition, thanks to homogeneous split mode injection. Because of the atypical combustion imposed and the low in-cylinder temperatures, the TWC has to deal with very particular exhaust gas composition, like oxygen availability but low $\mathrm{NO}_{\mathrm{x}}$, and important amounts of $\mathrm{HC}$ and $\mathrm{CO}$. The condensation of water vapour on the catalyst surface is usually neglected in TWC modelling, but under the aforementioned conditions its consideration is indispensable to properly simulate the catalyst behaviour. As a consequence of the catalyst heating-up process, there is also a strong coupling between catalyst temperatures and conversion efficiency. To deal with all these requirements, a first-principle, 1D-1Ch TWC model oriented to aid in the development of engine control strategies for cold-start conditions has been adapted from the general 1D-1Ch TWC model presented previously.

Water vapour condensation and evaporation are fundamental for the understanding of the TWC behaviour at the very beginning of the heatingup process, since the thermal dynamics during the first minutes are driven by this phenomenon. When the cold converter is fed with hot exhaust gases, the brick surface becomes wet due to the water vapour condensation. After some seconds, the heat transferred from the gas to the brick progressively increases the temperature on each longitudinal section from the inlet to the outlet, which involves the end of the water vapour condensation and the start of the evaporation. During the evaporation process, 
the temperature of the corresponding section remains constant. Then, the temperature of the dry section rises again pushed by the heat transfer from the exhaust gas. This process moves along the brick length and it can take more than 60 seconds, of course, depending on the exhaust gas mass flow and temperature. Meanwhile, the temperature at the inlet sections of the converter can be high enough to allow the start of the oxidation reactions, which in turn increases the heat available to evaporate the water condensed in the subsequent sections, thus speeding up the process. Under this conditions the catalyst temperature evolution exhibits a plateau due to the water evaporation, the developed model is able to represent this evolution along the TWC accurately, and also provides useful estimations for $\mathrm{CO}$ and $\mathrm{HC}$ emissions. According to the results obtained, probably not only water but a mix of water vapour and $\mathrm{HC}$ is condensing at the very beginning of the cold-start. Future works could improve the model capabilities by considering the condensation of different species.

Although the conductive heat flow in solid phase is included in the model, the parameter identification process shows that it could be neglected. This result is coherent with the typical low conduction capabilities of ceramic materials, as well as with the small heat transfer surface, due to the extremely thin brick walls. This fact can be taken into account for future model updates, simplifying the the complexity and speeding up the model.

\subsubsection{Three-way catalyst control}

\section{Three-way catalyst stimulation through AFR control}

The main effects of imposing a stimulation in the AFR control strategy have been assessed experimentally. The experiments have been carried out in two catalysts with the same precious metal loading but different ageing level. The consequences of applying AFR stimulation have been evaluated for a wide range of amplitudes and frequencies.

Results obtained with the fresh TWC indicate that a proper AFR stimulation widens the TWC window towards lean conditions, but in the rich 
range its application is negligible or even detrimental. It is due to the different effects of AFR stimulation on each species. Tailpipe $\mathrm{NO}_{\mathrm{x}}$ emissions decreases with $\lambda$ cycling, but $\mathrm{CO}$ emissions tend to increase. Unlike the benefits of AFR stimulation regarding $\mathrm{NO}_{\mathrm{x}}$, the $\mathrm{CO}$ penalty is not reported in the literature. It is due to the fact that most of the previous works were carried out in laboratory reactors by using pre-heated synthetic gas mixtures to feed a catalyst sample, instead of checking the effect on an engine test bench. Thus, the effect of AFR stimulation on actual exhaust gas composition and temperature had not been taken into account. The penalty in CO emissions found is due to the effect of AFR stimulation on exhaust gas composition. This idea lies on the non-linearity of the concentration of each species of the exhaust gas at certain AFR ranges, the practical consequence is an increase of $\mathrm{CO}$ at catalyst inlet when AFR stimulation is applied. This increase of CO in the exhaust gas exceeds the improvement that AFR stimulation could achieve in terms of TWC conversion efficiency.

The observed behaviour in the aged TWC is similar, the decrease of $\mathrm{NO}_{\mathrm{x}}$ emissions with a proper AFR stimulation is important, despite the fact that ageing tends to deteriorate the benefits that AFR stimulation induces in the fresh TWC. That is, $\lambda$ cycling also widens the TWC window in aged catalysts, but the effect is smaller.

\section{Model-based control at transient conditions}

The potential of different strategies based on a control-oriented modelling for AFR disturbances correction as well as TWC depletion have been assessed. The experimental tests performed with the AFR disturbances correction strategy based on the on-line OSL estimation show promising results. The peak emissions are reduced a $33 \%$ for $\mathrm{CO}$ and a $25 \%$ for $\mathrm{HC}$ in the case of an excursion towards rich conditions, as well as a $42 \%$ for $\mathrm{NO}_{\mathrm{x}}$ when the disturbance progresses towards leaner conditions than expected.

The optimal depletion of the TWC during a tip-in carried out after a injection cut-off, in the sense of minimum fuel consumption subjected to a $\mathrm{NO}_{\mathrm{x}}$ limit, has been evaluated theoretically by means of the appli- 
cation of Optimal Control techniques. In particular, a Direct Method transforming the Optimal Control problem in a non-linear programming (NLP) problem has been applied. The result shows that the optimal $\phi_{\mathrm{sp}}$ trajectories consist of a high fuel enrichment (the lower the $\mathrm{NO}_{\mathrm{x}}$ limit, the higher the fuel enrichment) at the beginning of the test, and then progressively recovering the reference $\phi_{\mathrm{sp}}$ until reaching the steady state.

Based on the previous theoretical results, a real-time strategy based on the OSL level have been designed and evaluated in the test bench. Results show that for the assessed tip in, $\mathrm{NO}_{\mathrm{x}}$ emissions can be reduced to half the baseline level at the expense of a 0.02 increase in $\phi_{\text {up }}$, thus in fuel consumption.

\section{AFR control under $S C$ conditions}

Concerning to SC effects on aftertreatment systems for SI engines, a correction to cope with the $\lambda$ sensor overestimation in the presence of SC has been proposed. The idea arises from the need to measure or at least estimate the $\mathrm{SC}$ on-board, in order to improve the AFR control under these circumstances beyond which it is allowed by mapping the $\mathrm{SC}$ as a static calibration.

The signal provided by the $\lambda$ sensor upstream TWC is employed for two different purposes. As usual, the content at low frequency allows measuring AFR. While the amplitude of the $\lambda$ sensor signal at the engine frequency provides information related to the SC level. In this way, with the strategy proposed it is feasible to correct on-line the $\phi$ overestimation that appears when the engine runs under SC conditions.

Finally, the experimental tests carried out in this study highlight the potential of this approach to reduce pollutant emissions, especially $\mathrm{NO}_{\mathrm{x}}$, since the $\phi$ overestimation entails operating at leaner conditions than expected. 


\subsubsection{Three-way catalyst ageing diagnosis}

Model-based approach for the three-way catalyst ageing quantification

Correlating the storage capability of the TWC with its ageing level is a widespread approach, but some aspects must be considered depending on the method used to estimate the storing capability. The estimation based on integrating the difference of the upstream and downstream $\lambda$ sensors during a $\phi$ step has the advantage of enabling the on-board quantification of the ageing level, but the results provided are very dependent on the operating conditions as well as on the proper correction of the downstream signal.

If a more accurate estimation of the storing capabilities is required, the use of a physics-based 1-D model as the one proposed in this work can be very helpful, not only to quantify the ageing, but also to understand and verify how is ageing the converter.

\section{Three-way catalyst ageing diagnosis through sensor-based strategy}

The main drawback of the latter approach is that it cannot be implemented on-board. However, for this purpose a robust and efficient method to on-line estimate the ageing of the converter has been proposed. It is based on the different attenuation that the converter imposes on the $\lambda$ sensor signal downstream, depending on its ageing level. This attenuation is quantified by calculating the amplitude of the Fast Fourier Transform for the downstream $\lambda$ sensor signal at the frequency of the $\lambda$ stimulation imposed upstream. The validation results of this approach have been presented in this dissertation, showing good performance and high reliability. In particular, the robustness of the on-line quantification proposed has been evaluated during the high speed phase of the WLTC. The method is capable of distinguish the lost of performance suffered by the fresh converter after the reduction of its length (two thirds of the nominal size), in spite of the low difference on the conversion efficiency compared to the fresh converter with nominal length. 



\section{Bibliography}

[1] Todd Litman and David Burwell. "Issues in sustainable transportation". In: International Journal of Global Environmental Issues 6.4 (2006), pp. 331-347 (cit. on p. 2).

[2] Dominic A Notter et al. Contribution of Li-ion batteries to the environmental impact of electric vehicles. 2010 (cit. on pp. 2, 3).

[3] H-O Günther, Matthias Kannegiesser, and Niels Autenrieb. "The role of electric vehicles for supply chain sustainability in the automotive industry". In: Journal of Cleaner Production 90 (2015), pp. 220-233 (cit. on p. 2).

[4] Jane Patterson, Marcus Alexander, and Adam Gurr. Preparing for a life cycle CO2 measure. Ricardo, 2011 (cit. on p. 3).

[5] Lluc Canals Casals et al. "Sustainability analysis of the electric vehicle use in Europe for CO2 emissions reduction". In: Journal of Cleaner Production 127 (2016), pp. 425-437 (cit. on p. 3).

[6] Frank J Kelly and Tong Zhu. "Transport solutions for cleaner air". In: Science 352.6288 (2016), pp. 934-936 (cit. on p. 3). 
[7] David L McCleese and Peter T LaPuma. "Using Monte Carlo simulation in life cycle assessment for electric and internal combustion vehicles". In: The International Journal of Life Cycle Assessment 7.4 (2002), pp. 230236 (cit. on p. 4).

[8] Electric vehicles from life cycle and circular economy perspectives TERM 2018: Transport and Environment Reporting Mechanism (TERM) report. Tech. rep. ISSN 1977-8449. European Environment Agency, 2018 (cit. on p. 4).

[9] Clean Air Act. "42USC7401". In: Public Law (1970), pp. 91-604 (cit. on p. 16).

[10] Eugene J Houdry. Catalytic structure and composition. US Patent 2,742,437. 1956 (cit. on p. 16).

[11] WB Williamson et al. "Deactivation of Three-Way Catalysts by Fuel Contaminants?Lead, Phosphorus and Sulfur". In: SAE Transactions (1979), pp. 3196-3204 (cit. on pp. 16, 27).

[12] HS Gandhi and M Shelef. "Effects of sulphur on noble metal automotive catalysts". In: Applied Catalysis 77.2 (1991), pp. 175-186 (cit. on pp. 16, 27).

[13] W Burton Williamson et al. "Durability of palladium automotive catalysts: Effects of trace lead levels, exhaust composition, and misfueling". In: Industrial $\& 3$ engineering chemistry product research and development 23.4 (1984), pp. 531-536 (cit. on pp. 16, 27).

[14] MS Chattha, WLW Watkins, and HS Gandhi. Three-way catalyst for automotive emission control. Tech. rep. 1992 (cit. on p. 16).

[15] Aleksey A Vedyagin et al. "Effect of metal ratio in alumina-supported Pd-Rh nanoalloys on its performance in three way catalysis". In: Journal of Alloys and Compounds 749 (2018), pp. 155-162 (cit. on p. 16).

[16] Robert J Farrauto, Michel Deeba, and Saeed Alerasool. "Gasoline automobile catalysis and its historical journey to cleaner air". In: Nature Catalysis 2.7 (2019), p. 603 (cit. on p. 16). 
[17] Yuichiro Murata et al. "NOx trap three-way catalyst (N-TWC) concept: TWC with NOx adsorption properties at low temperatures for cold-start emission control". In: SAE International Journal of Fuels and Lubricants 8.2 (2015), pp. $454-459$ (cit. on p. 16).

[18] Jan Schoenhaber et al. Advanced TWC Technology to Cover Future Emission Legislations. Tech. rep. SAE Technical Paper, 2015 (cit. on p. 16).

[19] Christine K Lambert, Todd Toops, and Johannes Schwank. Next Generation Three-Way Catalysts for Future, Highly Efficient Gasoline Engines. Tech. rep. Ford Motor Company, 2018 (cit. on p. 16).

[20] Wendy Lang et al. "Co-oxidation of $\mathrm{CO}$ and propylene on $\mathrm{Pd} / \mathrm{CeO} 2$ $\mathrm{ZrO} 2$ and $\mathrm{Pd} / \mathrm{Al} 2 \mathrm{O} 3$ monolith catalysts: A light-off, kinetics, and mechanistic study". In: Applied Catalysis B: Environmental 218 (2017), pp. 430442 (cit. on p. 16).

[21] A Martínez-Arias et al. "Light-off behaviour of $\mathrm{PdO} /$ gamma-Al2O3 catalysts for stoichiometric CO-O-2 and CO-O-2-NO reactions: a combined catalytic activity-in situ DRIFTS study". In: Journal of Catalysis 221.1 (2004), pp. 85-92 (cit. on p. 16).

[22] Gregory S Bugosh and Michael P Harold. "Impact of Zeolite Beta on Hydrocarbon Trapping and Light-Off Behavior on $\mathrm{Pt} / \mathrm{Pd} / \mathrm{BEA} / \mathrm{Al} 2 \mathrm{O}$ 3 Monolith Catalysts". In: Emission Control Science and Technology 3.2 (2017), pp. 123-134 (cit. on p. 16).

[23] By Hai-Ying Chen and Hsiao-Lan Russell Chang. "Development of low temperature three-way catalysts for future fuel efficient vehicles". In: Johnson Matthey Technology Review 59.1 (2015), pp. 64-67 (cit. on p. 16).

[24] Masaaki Haneda et al. "Improved three-way catalytic activity of bimetallic Ir-Rh catalysts supported on $\mathrm{CeO} 2-\mathrm{ZrO} 2 "$. In: Catalysis Science 83 Technology 5.3 (2015), pp. 1792-1800 (cit. on p. 17). 
[25] J Bickel et al. "Oxygen storage dominated three-way catalyst modeling for fresh catalysts". In: Chemical Engineering Science 160 (2017), pp. 34-53 (cit. on pp. 17, 22, 23, 42, 62, 156).

[26] Stefano Sabatini et al. "Design and experimental validation of a physicsbased oxygen storage?thermal model for three way catalyst including aging". In: Control Engineering Practice 68 (2017), pp. 89-101 (cit. on pp. 17, 22, 42, 62).

[27] Damma Devaiah et al. "Ceria-zirconia mixed oxides: Synthetic methods and applications". In: Catalysis Reviews 60.2 (2018), pp. 177-277 (cit. on p. 17).

[28] K Friese et al. Electro-chemical oxygen sensor, particularly for use in the exhaust system of internal combustion engines. US Patent 3,841,987. 1974 (cit. on p. 17).

[29] Syuichi Nakano et al. Air-fuel ratio sensing element. US Patent 5,811,660. 1998 (cit. on p. 17).

[30] Dieter W Guenther and Juergen Gerhardt. MOTRONIC-torque guided engine management systems to meet future challenges in emissions and fuel consumption reduction. Tech. rep. SAE Technical Paper, 2000 (cit. on p. 18).

[31] Andreas Greff and Torsten Günther. A new approach for a multi-fuel, torque based ECU concept using automatic code generation. Tech. rep. SAE Technical Paper, 2001 (cit. on p. 18).

[32] Christof Hammel et al. A common software architecture for diesel and gasoline engine control systems of the new generation EDC/ME (D) $1 \%$. Tech. rep. SAE Technical Paper, 2003 (cit. on p. 18).

[33] Jurgen Gerhardt, H Hönninger, and H Bischof. "A new approach to functional and software structure for engine management systems-BOSCH ME7". In: SAE transactions (1998), pp. 1173-1184 (cit. on p. 18). 
[34] Guénaël Le Solliec et al. Downsized SI engine control: A torque-based design from simulation to vehicle. Tech. rep. SAE Technical Paper, 2007 (cit. on p. 18).

[35] Wootaik Lee, Seungbum Park, and Myoungho Sunwoo. "Towards a seamless development process for automotive engine-control system". In: Control Engineering Practice 12.8 (2004), pp. 977-986 (cit. on p. 18).

[36] Rolf Isermann. "On the design and control of mechatronic systems-a survey". In: IEEE Transactions on Industrial Electronics 43.1 (1996), pp. $4-15$ (cit. on p. 18).

[37] Michael H Smith and Martin Elbs. "Towards a more efficient approach to automotive embedded control system development". In: Proceedings of the 1999 IEEE International Symposium on Computer Aided Control System Design (Cat. No. 99TH8404). IEEE. 1999, pp. 219-224 (cit. on p. 18).

[38] AR Browne et al. "A prototype framework of design tools for computeraided control engineering". In: Proceedings of IEEE Symposium on ComputerAided Control Systems Design (CACSD). IEEE. 1994, pp. 369-374 (cit. on p. 18).

[39] MS Hajji et al. "The development framework: work in progress towards a real-time control system design environment". In: (1996) (cit. on p. 18).

[40] W Lee, M Yoon, and M Sunwoo. "A cost-and time-effective hardware-inthe-loop simulation platform for automotive engine control systems". In: Proceedings of the Institution of Mechanical Engineers, Part D: Journal of Automobile Engineering 217.1 (2003), pp. 41-52 (cit. on p. 18).

[41] Huang Guojun, Huang Wenqing, and Zhang Youtong. "Actor-Oriented Methodology for Automotive Engine Control System Design". In: 2010 International Conference on E-Product E-Service and E-Entertainment. 2010 (cit. on p. 18).

[42] L-B Fredriksson. "CAN for critical embedded automotive networks". In: Ieee Micro 22.4 (2002), pp. 28-35 (cit. on p. 18). 
[43] Richard K Stobart, Bernard J Challen, and Rob Bowyer. Electronic controls-breeding new engines. Tech. rep. SAE Technical Paper, 2001 (cit. on p. 18).

[44] B Ashok, S Denis Ashok, and C Ramesh Kumar. "A review on control system architecture of a SI engine management system". In: Annual Reviews in Control 41 (2016), pp. 94-118 (cit. on p. 19).

[45] PV Manivannan, M Singaperumal, and A Ramesh. "Development of an idle speed engine model using in-cylinder pressure data and an idle speed controller for a small capacity port fuel injected SI engine". In: International Journal of Automotive Technology 12.1 (2011), pp. 11-20 (cit. on p. 19).

[46] Jiangyan Zhang, Tielong Shen, and Riccardo Marino. "Model-based cold-start speed control scheme for spark ignition engines". In: Control Engineering Practice 18.11 (2010), pp. 1285-1294 (cit. on p. 19).

[47] Jacek Czarnigowski. "A neural network model-based observer for idle speed control of ignition in SI engine". In: Engineering Applications of Artificial Intelligence 23.1 (2010), pp. 1-7 (cit. on p. 19).

[48] Junichi Kako. "SICE benchmark problem: starting speed control of SI engines". In: Control Theory and Technology 17.2 (2019), pp. 138-147 (cit. on p. 19).

[49] S Ali MirMohammadSadeghi et al. "Optimal Idle Speed Control of a Natural Aspirated Gasoline Engine Using Bio-inspired Meta-heuristic Algorithms". In: International Journal of Automotive Engineering 8.3 (2018), pp. 2792-2806 (cit. on p. 19).

[50] Kuo Yang and Pingen Chen. "Model Predictive Air-Fuel Ratio Control for an Integrated Gasoline Engine and Three-Way Catalytic Converter System". In: ASME 2018 Dynamic Systems and Control Conference. American Society of Mechanical Engineers. 2018, V002T26A001V002T26A001 (cit. on p. 19).

[51] Qinghua Lin, Pingen Chen, and Vitaly Y Prikhodko. "Model predictive control of a lean-burn gasoline engine coupled with a passive selec- 
tive catalytic reduction system". In: ASME 2017 Dynamic Systems and Control Conference. American Society of Mechanical Engineers. 2017, V003T34A006-V003T34A006 (cit. on pp. 19, 21).

[52] Kenneth R Muske and James C Peyton Jones. "Estimating the oxygen storage level of a three-way automotive catalyst". In: Proceedings of the 2004 American Control Conference. Vol. 5. IEEE. 2004, pp. 4060-4065 (cit. on p. 19).

[53] Giovanni Fiengo, Jeffrey A Cook, and JW Grizzle. "Fore-aft oxygen storage control". In: Proceedings of the 2002 American Control Conference (IEEE Cat. No. CH37301). Vol. 2. IEEE. 2002, pp. 1401-1406 (cit. on pp. 19, 107).

[54] Michael Tomforde, Wolfgang Drewelow, and Matthias Schultalbers. "Airfuel ratio control with respect to oxygen storage dynamics". In: Methods and Models in Automation and Robotics (MMAR), 2011 16th International Conference on. IEEE. 2011, pp. 242-247 (cit. on pp. 19, 106, 169).

[55] Go Hayashita et al. New Exhaust Emission Control System with Two A/F Sensors. Tech. rep. SAE Technical Paper, 2017 (cit. on p. 19).

[56] Mario Santillo et al. "Mid-ranging control for an automotive three-way catalyst outer loop". In: 2016 American Control Conference (ACC). IEEE. 2016, pp. 4193-4198 (cit. on p. 19).

[57] Wei Luo et al. Stochastic knock detection, control, software integration, and evaluation on a V6 spark-ignition engine under steady-state operation. Tech. rep. SAE Technical Paper, 2014 (cit. on p. 19).

[58] Xudong Zhen et al. "The engine knock analysis-An overview". In: $A p$ plied Energy 92 (2012), pp. 628-636 (cit. on p. 19).

[59] Pau Bares et al. "A new knock event definition for knock detection and control optimization". In: Applied Thermal Engineering 131 (2018), pp. 80-88 (cit. on p. 19). 
[60] James C Peyton Jones, Jill M Spelina, and Jesse Frey. "Likelihood-based control of engine knock". In: IEEE Transactions on Control Systems Technology 21.6 (2013), pp. 2169-2180 (cit. on p. 19).

[61] Mathieu Hillion, Jonathan Chauvin, and Nicolas Petit. "Open-loop combustion timing control of a spark-ignited engine". In: 2008 47th IEEE Conference on Decision and Control. IEEE. 2008, pp. 5635-5642 (cit. on p. 19).

[62] Baitao Xiao, Shu Wang, and Robert G Prucka. A semi-physical artificial neural network for feed forward ignition timing control of multi-fuel SI engines. Tech. rep. SAE Technical Paper, 2013 (cit. on p. 19).

[63] M Beham and DL Yu. "On-line control for optimal ignition timing using the pseudolinear radial basis function and the local linear model tree". In: Proceedings of the Institution of Mechanical Engineers, Part D: Journal of Automobile Engineering 219.2 (2005), pp. 227-240 (cit. on p. 19).

[64] Enrico Corti et al. "Transient spark advance calibration approach". In: Energy Procedia 45 (2014), pp. 967-976 (cit. on p. 19).

[65] Umberto Montanaro, Alessandro Di Gaeta, and Veniero Giglio. "Robust discrete-time MRAC with minimal controller synthesis of an electronic throttle body". In: IEEE/ASME Transactions on Mechatronics 19.2 (2013), pp. 524-537 (cit. on p. 19).

[66] Giulio Panzani, Matteo Corno, and Sergio Matteo Savaresi. "On adaptive electronic throttle control for sport motorcycles". In: Control Engineering Practice 21.1 (2013), pp. 42-53 (cit. on p. 19).

[67] Chi-Hsu Wang and De-Yu Huang. "A new intelligent fuzzy controller for nonlinear hysteretic electronic throttle in modern intelligent automobiles". In: IEEE Transactions on Industrial Electronics 60.6 (2012), pp. 2332-2345 (cit. on p. 19).

[68] Shupeng Zhang, Jie J Yang, and Guoming G Zhu. "LPV Modeling and Mixed Constrained $\mathrm{H}_{2} / \mathrm{H}_{\infty}$ Control of an Electronic Throttle". In: 
IEEE/ASME Transactions on Mechatronics 20.5 (2014), pp. 2120-2132 (cit. on p. 19).

[69] Jamie Charles Hanshaw et al. Oil pressure control for a variable camshaft timing system. US Patent App. 10/202,908. 2019 (cit. on p. 19).

[70] Soo-Whang Baek. "A Study on Improvement of Control Performance of Electric-Continuous Variable Valve Timing System Using BLDC Motor". In: ASME-JSME 2018 Joint International Conference on Information Storage and Processing Systems and Micromechatronics for Information and Precision Equipment. American Society of Mechanical Engineers. 2018, V001T09A006-V001T09A006 (cit. on p. 19).

[71] Anton Gfrerrer and Johann Lang. "Fully Variable Valve Control: A Geometric Approach". In: Journal for geometry and graphics 22.1 (2018), pp. 99-114 (cit. on p. 19).

[72] Zhen Ren and Guoming G Zhu. "Modeling and control of an electric variable valve timing system for SI and HCCI combustion mode transition". In: Proceedings of the 2011 American Control Conference. IEEE. 2011, pp. 979-984 (cit. on p. 19).

[73] Dezong Zhao, Richard Stobart, and Byron Mason. "Real-Time Energy Management of the Electric Turbocharger based on Explicit Model Predictive Control". In: IEEE Transactions on Industrial Electronics (2019) (cit. on p. 19).

[74] Anna Misley et al. A Physics-Based, Control-Oriented Turbocharger Compressor Model for the Prediction of Pressure Ratio at the Limit of Stable Operations. Tech. rep. SAE Technical Paper, 2019 (cit. on p. 19).

[75] Mrdjan Jankovic and Ilya Kolmanovsky. "Constructive Lyapunov control design for turbocharged diesel engines". In: IEEE Transactions on Control Systems Technology 8.2 (2000), pp. 288-299 (cit. on p. 19).

[76] Paul Moraal and Ilya Kolmanovsky. Turbocharger modeling for automotive control applications. Tech. rep. SAE Technical Paper, 1999 (cit. on p. 19). 
[77] Benjamín Pla Moreno. "Análisis del proceso de la recirculación de los gases de escape de baja presión en motores Diesel sobrealimentados." PhD thesis. Universitat Politècnica de València, 2009 (cit. on p. 19).

[78] Hitoshi Yokomura et al. Transient EGR control for a turbocharged heavy duty diesel engine. Tech. rep. SAE Technical Paper, 2004 (cit. on p. 19).

[79] Henk J Dekker and Wilco L Sturm. Simulation and control of a HD diesel engine equipped with new EGR technology. Tech. rep. SAE Technical Paper, 1996 (cit. on p. 19).

[80] Lu Bai and Minggao Yang. "Coordinated control of EGR and VNT in turbocharged diesel engine based on intake air mass observer". In: $S A E$ Transactions (2002), pp. 2152-2161 (cit. on p. 19).

[81] José Manuel Luján et al. "Switching strategy between HP (high pressure)and LPEGR (low pressure exhaust gas recirculation) systems for reduced fuel consumption and emissions". In: Energy 90 (2015), pp. 17901798 (cit. on p. 19).

[82] SW Wang et al. "Adaptive neural network model based predictive control for air-fuel ratio of SI engines". In: Engineering Applications of Artificial Intelligence 19.2 (2006), pp. 189-200 (cit. on p. 19).

[83] Bayadir Abbas Al-Himyari, Azman Yasin, and Horizon Gitano. "Review of air fuel ratio prediction and control methods". In: Asian Journal of Applied Sciences 2.04 (2014), pp. 471-478 (cit. on p. 19).

[84] Anurak Jansri and Pitikhate Sooraksa. "Enhanced model and fuzzy strategy of air to fuel ratio control for spark ignition engines". In: Computers 69 Mathematics with Applications 64.5 (2012), pp. 922-933 (cit. on pp. 19, 21).

[85] Guo Shuai et al. "Injection quantity control for GDI engines". In: 2013 25th Chinese Control and Decision Conference (CCDC). IEEE. 2013, pp. 3593-3597 (cit. on p. 19). 
[86] Sai SV Rajagopalan et al. "A control design and calibration reduction methodology for AFR control in gasoline engines". In: Control Engineering Practice 27 (2014), pp. 42-53 (cit. on p. 19).

[87] T Sardarmehni et al. "Robust predictive control of lambda in internal combustion engines using neural networks". In: Archives of Civil and mechanical Engineering 13.4 (2013), pp. 432-443 (cit. on p. 19).

[88] P Dickinson and AT Shenton. "Dynamic calibration of fuelling in the PFI SI engine". In: Control Engineering Practice 17.1 (2009), pp. 26-38 (cit. on p. 19).

[89] EM Franceschi et al. An adaptive delay-compensated PID air fuel ratio controller. Tech. rep. SAE Technical Paper, 2007 (cit. on p. 19).

[90] Nicolò Cavina, Enrico Corti, and Davide Moro. "Closed-loop individual cylinder air-fuel ratio control via UEGO signal spectral analysis". In: Control Engineering Practice 18.11 (2010), pp. 1295-1306 (cit. on p. 19).

[91] Shuntaro Okazaki et al. "Development of a new model based air-fuel ratio control system". In: SAE International Journal of Engines 2.1 (2009), pp. 335-343 (cit. on p. 19).

[92] Yildiray Yildiz et al. "Spark ignition engine fuel-to-air ratio control: An adaptive control approach". In: Control Engineering Practice 18.12 (2010), pp. 1369-1378 (cit. on pp. 19, 106, 169).

[93] Mogens Blanke, Marcel Staroswiecki, and N Eva Wu. "Concepts and methods in fault-tolerant control". In: Proceedings of the 2001 American Control Conference.(Cat. No. 01CH37148). Vol. 4. IEEE. 2001, pp. 2606-2620 (cit. on p. 19).

[94] Paul M Frank. "Trends in fault-tolerant control of engineering systems". In: IFAC Proceedings Volumes 37.15 (2004), pp. 377-384 (cit. on p. 19).

[95] Youqing Wang et al. "Active fault-tolerant control for a class of nonlinear systems with sensor faults". In: International Journal of Control, Automation, and Systems 6.3 (2008), pp. 339-350 (cit. on p. 19). 
[96] Alireza Nasiri et al. "Passive actuator fault tolerant control for a class of MIMO nonlinear systems with uncertainties". In: International Journal of Control 92.3 (2019), pp. 693-704 (cit. on p. 19).

[97] R Şinca and CS Szász. "Fault-tolerant digital systems development using triple modular redundancy". In: International Review of Applied Sciences and Engineering 8.1 (2017), pp. 3-7 (cit. on p. 19).

[98] Thomas Winsel et al. HiL-calibration of SI engine cold start and warmup using neural real-time model. Tech. rep. SAE Technical Paper, 2004 (cit. on p. 19).

[99] Xiaojian Yang and Guoming G Zhu. "A two-zone control oriented SIHCCI hybrid combustion model for the HIL engine simulation". In: Proceedings of the 2011 American control conference. IEEE. 2011, pp. 973978 (cit. on p. 19).

[100] Harsha Nanjundaswamy et al. Development and calibration of on-boarddiagnostic strategies using a micro-HiL approach. Tech. rep. SAE Technical Paper, 2011 (cit. on p. 19).

[101] A Palladino, G Fiengo, and D Lanzo. "A portable hardware-in-the-loop (HIL) device for automotive diagnostic control systems". In: ISA transactions 51.1 (2012), pp. 229-236 (cit. on p. 19).

[102] Tom Jung et al. "Engine-in-the-Loop: A Method for Efficient Calibration and Virtual Testing of Advanced Diesel Powertrains". In: Simulation und Test 2018. Springer, 2019, pp. 209-224 (cit. on p. 19).

[103] Christian H Mayr et al. "Engine control unit PID controller calibration by means of local model networks". In: Control Engineering Practice 33 (2014), pp. 125-135 (cit. on p. 19).

[104] Hu Desheng, Hu Yunfeng, and Chen Hong. "Model-based calibration for torque control system of gasoline engines". In: 2014 International Conference on Mechatronics and Control (ICMC). IEEE. 2014, pp. 17741779 (cit. on p. 19). 
[105] Rolf Isermann and Michael Hafner. "Mechatronic Combustion Enginesfrom Modeling to Optinlal Control". In: European Journal of control 7.2-3 (2001), pp. 220-247 (cit. on p. 19).

[106] Markus Grahn, Krister Johansson, and Tomas McKelvey. "Model-based diesel Engine Management System optimization for transient engine operation". In: Control Engineering Practice 29 (2014), pp. 103-114 (cit. on p. 19).

[107] Bjoern Lumpp et al. Desktop simulation and calibration of diesel engine ecu software using software-in-the-loop methodology. Tech. rep. SAE Technical Paper, 2014 (cit. on p. 19).

[108] Tomohiko Jimbo and Yoshikazu Hayakawa. "A physical model for engine control design via role state variables". In: Control Engineering Practice 19.3 (2011), pp. 276-286 (cit. on p. 19).

[109] Pak Kin Wong, Lap Mou Tam, and Li Ke. "Automotive engine power performance tuning under numerical and nominal data". In: Control Engineering Practice 20.3 (2012), pp. 300-314 (cit. on p. 19).

[110] Carlos Guardiola et al. "Cycle by cycle trapped mass estimation for diagnosis and control". In: SAE International Journal of Engines 7.3 (2014), pp. 1523-1531 (cit. on p. 21).

[111] José Manuel Luján et al. "Estimation of trapped mass by in-cylinder pressure resonance in HCCI engines". In: Mechanical Systems and Signal Processing 66 (2016), pp. 862-874 (cit. on p. 21).

[112] Alberto Broatch et al. "A direct transform for determining the trapped mass on an internal combustion engine based on the in-cylinder pressure resonance phenomenon". In: Mechanical Systems and Signal Processing 62 (2015), pp. 480-489 (cit. on p. 21).

[113] JM Desantes et al. "Air mass flow estimation in turbocharged diesel engines from in-cylinder pressure measurement". In: Experimental Thermal and Fluid Science 34.1 (2010), pp. 37-47 (cit. on p. 21). 
[114] Charles F Aquino. "Transient A/F control characteristics of the 5 liter central fuel injection engine". In: SAE Transactions (1981), pp. 18191833 (cit. on p. 21).

[115] Chen-Fang Chang et al. "Air-fuel ratio control in spark-ignition engines using estimation theory". In: IEEE Transactions on Control Systems Technology 3.1 (1995), pp. 22-31 (cit. on pp. 21, 169).

[116] CA Roduner, CH Onder, and HP Geering. "Automated design of an air/fuel controller for an SI engine considering the three-way catalytic converter in the $\mathrm{H}^{\infty}$ approach". In: Proceedings of the fifth IEEE Mediterranean Conference on Control and Systems, Paphos, Cyprus. 1997 (cit. on pp. 21, 169).

[117] Ivan Arsie, Cesare Pianese, and Marco Sorrentino. "Development and real-time implementation of recurrent neural networks for AFR prediction and control". In: SAE international journal of passenger carselectronic and electrical systems 1.2008-01-0993 (2009), pp. 403-412. DOI: 10.4271/2008-01-0993 (cit. on p. 21).

[118] Daniel Rupp and Lino Guzzella. "Adaptive internal model control with application to fueling control". In: Control Engineering Practice 18.8 (2010), pp. 873-881 (cit. on p. 21).

[119] Nazli E Kahveci and Mrdjan J Jankovic. "Adaptive controller with delay compensation for Air-Fuel Ratio regulation in SI engines". In: Proceedings of the 2010 American Control Conference. IEEE. 2010, pp. 22362241 (cit. on p. 21).

[120] Shiwei Wang and DL Yu. "An application of second-order sliding mode control for IC engine fuel injection". In: 2006 Canadian Conference on Electrical and Computer Engineering. IEEE. 2006, pp. 1035-1038 (cit. on p. 21).

[121] Haoqi Yang et al. "Optimization of thermoelectric generator (TEG) integrated with three-way catalytic converter (TWC) for harvesting engine?s exhaust waste heat". In: Applied Thermal Engineering 144 (2018), pp. 628-638 (cit. on pp. 22, 62). 
[122] Kurtis Irwin et al. Modelling the Variation in Precious Metal Dispersion in a Three Way Catalytic Converter after Aging. Tech. rep. (No. 201801-0959). SAE Technical Paper, 2018 (cit. on pp. 22, 62).

[123] Kyriacos Zygourakis. "Transient operation of monolith catalytic converters: a two-dimensional reactor model and the effects of radially nonuniform flow distributions". In: Chemical Engineering Science 44.9 (1989), pp. 2075-2086 (cit. on pp. 22, 62).

[124] Joachim Braun et al. Three-dimensional simulation of the transient behavior of a three-way catalytic converter. Tech. rep. No. 2002-01-0065. SAE Technical Paper, 2002 (cit. on pp. 22, 62).

[125] David KS Chen et al. "A three-dimensional model for the analysis of transient thermal and conversion characteristics of monolithic catalytic converters". In: SAE transactions (1988), pp. 177-189 (cit. on pp. 22, $62)$.

[126] H Byrne and J Norbury. "Mathematical modelling of catalytic converters". In: Mathematical engineering in industry 4.1 (1993), pp. 27-48 (cit. on pp. 22,62$)$.

[127] Naoki Baba, Katsuyuki Ohsawa, and Shigeki Sugiura. Numerical approach for improving the conversion characteristics of exhaust catalysts under warming-up condition. Tech. rep. No. 962076. SAE Technical Paper, 1996 (cit. on pp. 22, 62).

[128] G Konstantas and AM Stamatelos. "Modelling three-way catalytic converters: an effort to predict the effect of precious metal loading". In: Proceedings of the Institution of Mechanical Engineers, Part D: Journal of Automobile Engineering 221.3 (2007), pp. 355-373 (cit. on pp. 22, $62)$.

[129] Jian Gong et al. "An experimental and kinetic modeling study of aging impact on surface and subsurface oxygen storage in three-way catalysts". In: Catalysis Today (2017) (cit. on pp. 22, 27).

[130] J Rink et al. "Oxygen storage in three-way-catalysts is an equilibrium controlled process: Experimental investigation of the redox thermody- 
namics". In: Applied Catalysis B: Environmental 206 (2017), pp. 104114 (cit. on pp. 22, 42, 70).

[131] Jian Gong et al. "Dynamic oxygen storage modeling in a three-way catalyst for natural gas engines: A dual-site and shrinking-core diffusion approach". In: Applied Catalysis B: Environmental 203 (2017), pp. 936945 (cit. on pp. 22, 63).

[132] Arthur Josephus Laurentius Nievergeld. "Automotive exhaust gas conversion: reaction kinetics, reactor modelling and control". PhD thesis. Technical University of Eindhoven, Eindhoven, The Netherlands, 1998 (cit. on p. 22).

[133] Johannes Maria Antonius Harmsen. "Kinetic modelling of the dynamic behaviour of an automotive three-way catalyst under cold-start conditions". PhD thesis. Technische Universiteit Eindhoven, Eindhoven, The Netherlands, 2001 (cit. on pp. 22, 62).

[134] Theophil S Auckenthaler et al. "Modeling of a three-way catalytic converter with respect to fast transients of $\lambda$-sensor relevant exhaust gas components". In: Industrial $\mathscr{G}$ engineering chemistry research 43.16 (2004), pp. 4780-4788 (cit. on pp. 22, 23, 42, 48, 62, 106).

[135] Hans J Germann, Christopher H Onder, and Hans P Geering. Fast gas concentration measurements for model validation of catalytic converters. Tech. rep. (No. 950477). SAE Technical Paper, 1995 (cit. on pp. 22, 62).

[136] Pankaj Kumar et al. "Spatio-temporal dynamics of oxygen storage and release in a three-way catalytic converter". In: Chemical Engineering Science 111 (2014), pp. 180-190 (cit. on pp. 22, 62, 142).

[137] GN Pontikakis, GS Konstantas, and AM Stamatelos. "Three-way catalytic converter modeling as a modern engineering design tool". In: Journal of Engineering for Gas Turbines and Power(Transactions of the ASME) 126.4 (2004), pp. 906-923 (cit. on pp. 22, 46, 48, 62, 67, 125).

[138] Se H Oh and James C Cavendish. "Transients of monolithic catalytic converters. Response to step changes in feedstream temperature as related to controlling automobile emissions". In: Industrial \&f Engineering 
Chemistry Product Research and Development 21.1 (1982), pp. 29-37 (cit. on pp. 22, 62).

[139] SH Chan and DL Hoang. "Heat transfer and chemical reactions in exhaust system of a cold-start engine". In: International journal of heat and mass transfer 42.22 (1999), pp. 4165-4183 (cit. on pp. 22, 62).

[140] Mario Balenovic et al. Modeling of an automotive exhaust gas converter at low temperatures aiming at control application. Tech. rep. (No. 199901-3623). SAE Technical Paper, 1999 (cit. on pp. 22, 25, 26, 42, 48, $62)$.

[141] Klemens Schürholz et al. "Modeling of the Three-way Catalytic Converter by Recurrent Neural Networks". In: IFAC-PapersOnLine 51.15 (2018), pp. 742-747 (cit. on pp. 23, 62).

[142] Evangelos Gonatas and Richard Stobart. Prediction of gas concentrations in a three-way catalyst for on-board diagnostic applications. Tech. rep. No. 2005-01-0054. SAE Technical Paper, 2005 (cit. on pp. 23, 62).

[143] Pannag R Sanketi et al. "A simplified catalytic converter model for automotive coldstart applications with adaptive parameter fitting". In: 8th International Symposium on Advanced Vehicle Control, Taipei, Taiwan. 2006 (cit. on pp. 23, 62, 122).

[144] Byron T Shaw II, Gerald D Fischer, and J Karl Hedrick. "A simplified coldstart catalyst thermal model to reduce hydrocarbon emissions". In: IFAC Proceedings Volumes 35.1 (2002), pp. 307-312 (cit. on pp. 23, 62, 122).

[145] Erich P Brandt, Yanying Wang, and Jessy W Grizzle. "Dynamic modeling of a three-way catalyst for SI engine exhaust emission control". In: IEEE Transactions on control systems technology 8.5 (2000), pp. 767776 (cit. on pp. 23, 62).

[146] Mario Balenovic, ACPM Backx, and JHBJ Hoebink. On a model-based control of a three-way catalytic converter. Tech. rep. (No. 2001-01-0937). SAE Technical Paper, 2001 (cit. on pp. 23, 62, 169). 
[147] Mario Balenovic, Ton Backx, and Toon De Bie. Development of a modelbased controller for a three-way catalytic converter. Tech. rep. (No. 200201-0475). SAE Technical Paper, 2002 (cit. on pp. 23, 27, 62, 169).

[148] Esfandiar Shafai, Christian Roduner, and Hans P Geering. Indirect adaptive control of a three-way catalyst. Tech. rep. (No. 961038). SAE Technical Paper, 1996 (cit. on pp. 23, 62, 104, 169).

[149] KN Pattas et al. Transient modeling of 3-way catalytic converters. Tech. rep. (No. 940934). SAE Technical Paper, 1994 (cit. on pp. 23, 62).

[150] Pascal Kiwitz, Christopher Onder, and Lino Guzzella. "Control-oriented modeling of a three-way catalytic converter with observation of the relative oxygen level profile". In: Journal of Process Control 22.6 (2012), pp. 984-994 (cit. on pp. 23, 62, 156).

[151] Pankaj Kumar et al. "A low-dimensional model for describing the oxygen storage capacity and transient behavior of a three-way catalytic converter". In: Chemical engineering science 73 (2012), pp. 373-387 (cit. on pp. $23,42,62,156)$.

[152] Theophil S Auckenthaler, Christopher H Onder, and Hans P Geering. Online estimation of the oxygen storage level of a three-way catalyst. Tech. rep. (No. 2004-01-0525). SAE Technical Paper, 2004 (cit. on pp. $23,62,106)$.

[153] JB Heywood. Internal combustion engines fundamentals. McGraw Hill, New York, 2000 (cit. on p. 24).

[154] A Pagot et al. "Combustion approach for downsizing: the IFP concept". In: Oil $\& 3$ gas science and technology 61.1 (2006), pp. 139-153 (cit. on pp. 24, 169).

[155] Alain Ranini and Gaëtan Monnier. Turbocharging a gasoline direct injection engine. Tech. rep. No. 2001-01-0736. SAE Technical Paper, 2001 (cit. on pp. 24, 169).

[156] Sebastian Martin, Christian Beidl, and Rolf Mueller. Responsiveness of a 30 bar BMEP 3-cylinder engine: Opportunities and limits of tur- 
bocharged downsizing. Tech. rep. No. 2014-01-1646. SAE Technical Paper, 2014 (cit. on pp. 24, 169).

[157] Mordecai Shelef and Robert W McCabe. "Twenty-five years after introduction of automotive catalysts: what next?" In: Catalysis today 62.1 (2000), pp. 35-50 (cit. on p. 24).

[158] Degobert Paul. Automobiles and pollution. Warrendale PA. USA: SAE: Inc, 1995 (cit. on p. 24).

[159] Regulated emissions of a Euro 5 passenger car measured over different driving cycles. European commission Joint Research Centre: Geneva, Switzerland. 2010 (cit. on p. 24).

[160] Mikiya Araki et al. "Effects of injection parameters on the amount of wall-wet fuel in a port-fuel-injected spark-ignition engine during cold start". In: International Journal of Engine Research (2019). DOI: 10 . $1177 / 1468087419837768$ (cit. on p. 24).

[161] Jian Gao and Tang-Wei Kuo. "Toward the accurate prediction of soot in engine applications". In: International Journal of Engine Research (2018). DOI: 10.1177/1468087418773937 (cit. on p. 24).

[162] Carlos Guardiola et al. "An on-board method to estimate the lightoff temperature of diesel oxidation catalysts". In: International Journal of Engine Research (2018). DOI: $10.1177 / 1468087418817965$ (cit. on p. 24).

[163] Jan H Baron and Wai K Cheng. "Back pressure effect on three-way catalyst light-off". In: International Journal of Engine Research (2018). DOI: $10.1177 / 1468087418779505$ (cit. on p. 24).

[164] Takehisa Yaegashi et al. "New technology for reducing the power consumption of electrically heated catalysts". In: SAE transactions (1994), pp. 95-102 (cit. on p. 25).

[165] Donn Glander and Saïd Zidat. Mathematical modeling of electrically heated monolith converters: meeting European emissions regulations pro- 
posed for 2000 and 2005. Tech. rep. No. 972852. SAE Technical Paper, 1997 (cit. on p. 25).

[166] Se H Oh, Edward J Bissett, and Paul A Battiston. "Mathematical modeling of electrically heated monolith converters: model formulation, numerical methods, and experimental verification". In: Industrial \& engineering chemistry research 32.8 (1993), pp. 1560-1567 (cit. on p. 25).

[167] Hideaki Katashiba et al. Development of an effective air-injection system with heated air for $L E V / U L E V$. Tech. rep. No. 950411. SAE Technical Paper, 1995 (cit. on p. 25).

[168] Karl Kollmann et al. Secondary air injection with a new developed electrical blower for reduced exhaust emissions. Tech. rep. No. 940472. SAE Technical Paper, 1994 (cit. on p. 25).

[169] Katsumi Takatsu et al. Dielectric heating catalytic converter system for reducing cold-start emissions. Tech. rep. No. 960344. SAE Technical Paper, 1996 (cit. on p. 25).

[170] B Pfalzgraf et al. "The system development of electrically heated catalyst (EHC) for the LEV and EU-III legislation". In: SAE transactions (1995), pp. 777-787 (cit. on p. 25).

[171] Martin J Heimrich, Steve Albu, and Juan Osborn. "Electrically-heated catalyst system conversions on two current-technology vehicles". In: $S A E$ transactions (1991), pp. 231-251 (cit. on p. 25).

[172] Paul F Küper et al. Ultra-low power electrically-heated catalyst system. Tech. rep. No. 940465. SAE Technical Paper, 1994 (cit. on p. 25).

[173] Louis S Socha and David F Thompson. Electrically heated extruded metal converters for low emission vehicles. Tech. rep. No. 920093. SAE Technical Paper, 1992 (cit. on p. 25).

[174] Dongkun Lee and John B Heywood. "Effects of secondary air injection during cold start of SI engines". In: SAE International Journal of Engines 3.2 (2010), pp. 182-196 (cit. on p. 25). 
[175] Ulrich Pfahl, Axel Schatz, and Roman Konieczny. Advanced exhaust gas thermal management for lowest tailpipe emissions-combining low emission engine and electrically heated catalyst. Tech. rep. No. 2012-011090. SAE Technical Paper, 2012 (cit. on p. 25).

[176] SH Chan and J Zhu. The significance of high value of ignition retard control on the catalyst lightoff. Tech. rep. No. 962077. SAE Technical Paper, 1996 (cit. on pp. 25, 122).

[177] J Felipe Rodriguez and Wai K Cheng. "Effect of operation strategy on first cycle $\mathrm{CO}, \mathrm{HC}$, and $\mathrm{PM} / \mathrm{PN}$ emissions in a GDI engine". In: SAE International Journal of Engines 8.3 (2015), pp. 1098-1106 (cit. on pp. 25, 122).

[178] Koshiro Kimura et al. "An investigation for reducing combustion instability under cold-start condition of a direct injection gasoline engine". In: International Journal of Engine Research 20.4 (2019), pp. 470-479. DOI: $10.1177 / 1468087418766924$ (cit. on pp. 25, 122).

[179] Konrad Reif. Gasoline Engine Management. Friedrichshafen: Springer Vieweg, 2015 (cit. on p. 25).

[180] Raffael Hedinger, Philipp Elbert, and Christopher Onder. "Optimal Cold-Start Control of a Gasoline Engine". In: Energies 10.10 (2017), p. 1548 (cit. on pp. 25, 123, 130).

[181] Raymond P Canale et al. General motors phase II catalyst system. Tech. rep. (No. 780205). SAE Technical Paper, 1978 (cit. on p. 25).

[182] Grunde T Engh and Stephen Wallman. Development of the Volvo lambdasond system. Tech. rep. (No. 770295). SAE Technical Paper, 1977 (cit. on p. 25).

[183] Peter Lewis Silveston. "Automotive exhaust catalysis under periodic operation". In: Catalysis Today 25.2 (1995), pp. 175-195 (cit. on pp. 25, $147,148,150)$.

[184] Sergio Tagliaferri, René A Köppel, and Alfons Baiker. "Behavior of nonpromoted and ceria-promoted $\mathrm{Pt} / \mathrm{Rh}$ and $\mathrm{Pd} / \mathrm{Rh}$ three-way catalysts 
under steady state and dynamic operation of hybrid vehicles". In: Industrial $\&$ engineering chemistry research 38.1 (1999), pp. 108-117 (cit. on p. 25).

[185] C Howitt, V Pitchon, and G Maire. "Influence of oxygen on the performance of a three-way catalyst". In: Journal of Catalysis 154.1 (1995), pp. 47-55 (cit. on p. 25).

[186] Richard K Herz. "Dynamic behavior of automotive catalysts. 1. Catalyst oxidation and reduction". In: Industrial 65 Engineering Chemistry Product Research and Development 20.3 (1981), pp. $451-457$ (cit. on p. 26).

[187] RICHARD K Herz. "The dynamic behavior of three way automotive catalysts". In: ACS Symp. Ser. Vol. 178. 1982, pp. 59-78 (cit. on p. 26).

[188] Richard K Herz, Joanna B Kiela, and Jeffrey A Sell. "Dynamic behavior of automotive catalysts. 2. Carbon monoxide conversion under transient air fuel ratio conditions". In: Industrial 68 engineering chemistry product research and development 22.3 (1983), pp. 387-396 (cit. on p. 26).

[189] Richard K Herz and Jeffrey A Sell. "Dynamic behavior of automotive catalysts: III. Transient enhancement of water-gas shift over rhodium". In: Journal of catalysis 94.1 (1985), pp. 166-174 (cit. on p. 26).

[190] Richard K Herz and Edward J Shinouskis. "Dynamic Behavior of automotive catalysts. 4. Impact of air/fuel ratio excursions during driving". In: Industrial $\&$ engineering chemistry product research and development 24.3 (1985), pp. 385-390 (cit. on p. 26).

[191] James C Schlatter and Patricia J Mitchell. "Three-way catalyst response to transients". In: Industrial \&6 Engineering Chemistry Product Research and Development 19.3 (1980), pp. 288-293 (cit. on p. 26).

[192] James C Schlatter, Robert M Sinkevitch, and Patricia J Mitchell. "Laboratory reactor system for three-way automotive catalyst evaluation". In: Industrial 8 Engineering Chemistry Product Research and Development 22.1 (1983), pp. 51-56 (cit. on p. 26). 
[193] Sergio Tagliaferri, RenéA Köppel, and Alfons Baiker. "Influence of rhodiumand ceria-promotion of automotive palladium catalyst on its catalytic behaviour under steady-state and dynamic operation". In: Applied Catalysis B: Environmental 15.3-4 (1998), pp. 159-177 (cit. on pp. 26, 146).

[194] Lukas Padeste and Alfons Baiker. "Three-way catalysts in a hybrid drive system: 1. Experimental study of dynamic behavior". In: Industrial $\& 3$ engineering chemistry research 33.5 (1994), pp. 1113-1119 (cit. on p. 26).

[195] Byong K Cho. "Performance of platinum/alumina catalysts in automobile engine exhaust with oscillatory air/fuel ratio". In: Industrial $\&$ engineering chemistry research 27.1 (1988), pp. 30-36 (cit. on p. 26).

[196] Takeshi Takiyama, Eisuke Shiomi, and Shigeyuki Morita. "Air-fuel ratio control system using pulse width and amplitude modulation at transient state". In: JSAE review 22.4 (2001), pp. 537-544 (cit. on pp. 26, 169).

[197] Lukas Padeste, Sergio Tagliaferri, and Alfons Baiker. "Behavior of threeway catalyst in a hybrid drive system". In: Chemical Engineering 8 Technology: Industrial Chemistry-Plant Equipment-Process EngineeringBiotechnology 19.1 (1996), pp. 89-95 (cit. on p. 26).

[198] Hideaki Muraki et al. "Behavior of automotive noble metal catalysts in cycled feedstreams". In: Industrial \& engineering chemistry product research and development 24.1 (1985), pp. 43-49 (cit. on p. 26).

[199] Anna Fathali et al. Thermal and Chemical Deactivation of Three-Way Catalysts: Comparison of Road-, Fuel-Cut and SAI-Aged Catalysts. Tech. rep. SAE Technical Paper, 2015 (cit. on p. 27).

[200] Roman M Kenzhin et al. "Study on Thermal Stability of Ceria-Supported Rhodium Catalysts". In: Materials Science Forum. Vol. 950. Trans Tech Publ. 2019, pp. 190-194 (cit. on p. 27).

[201] Hiroshi Yoshida et al. "Effect of Thermal Aging on Local Structure and Three-Way Catalysis of $\mathrm{Cu} / \mathrm{Al} 2 \mathrm{O} 3 "$ ". In: The Journal of Physical Chemistry C 123.16 (2019), pp. 10469-10476 (cit. on p. 27). 
[202] Hee Je Seong et al. "Deactivation of three-way catalysts coated within gasoline particulate filters by engine oil-derived chemicals". In: Industrial E Engineering Chemistry Research (2019) (cit. on p. 27).

[203] Fumio Ueda et al. "Engine oil additive effects on deactivation of monolithic three-way catalysts and oxygen sensors". In: SAE transactions (1994), pp. 332-341 (cit. on p. 27).

[204] PS Brett et al. An investigation into lubricant related poisoning of automotive three-way catalysts and lambda sensors. Tech. rep. SAE Technical Paper, 1989 (cit. on p. 27).

[205] David S Lafyatis, Rick Petrow, and Chris Bennett. The effects of oilderived poisons on three-way catalyst performance. Tech. rep. SAE Technical Paper, 2002 (cit. on p. 27).

[206] Juan R González-Velasco et al. "Thermal aging of $\mathrm{Pd} / \mathrm{Pt} / \mathrm{Rh}$ automotive catalysts under a cycled oxidizing-reducing environment". In: Catalysis today 59.3-4 (2000), pp. 395-402 (cit. on p. 27).

[207] Sung Bong Kang et al. "Effect of aging atmosphere on thermal sintering of modern commercial TWCs". In: Topics in Catalysis 56.1-8 (2013), pp. 298-305 (cit. on p. 27).

[208] Theophil S Auckenthaler, Christopher H Onder, and Hans P Geering. "Aspects of dynamic three-way catalyst behaviour including oxygen storage". In: IFAC Proceedings Volumes 37.22 (2004), pp. 331-336 (cit. on pp. 27,63$)$.

[209] Joseph R Theis. An engine test to measure the oxygen storage capacity of a catalyst. Tech. rep. (No. 961900). SAE Technical Paper, 1996 (cit. on p. 27).

[210] Kouji Miyamoto et al. Measurement of Oxygen Storage Capacity of Three-Way Catalyst and Optimization of A/F Perturbation Control to Its Characteristics. Tech. rep. (No. 2002-01-1094). SAE Technical Paper, 2002 (cit. on p. 27). 
[211] Grant A Ingram and Gopichandra Surnilla. On-line oxygen storage capacity estimation of a catalyst. Tech. rep. (No. 2003-01-1000). SAE Technical Paper, 2003 (cit. on pp. 27, 106).

[212] William M Silvis. Method and system for determining air/fuel ratio of an engine's combustion process from its exhaust emissions. US Patent 6,209,385. 2001 (cit. on pp. 34, 37, 106).

[213] P.H. Schweitzer. Scavenging of two-stroke cycle Diesel engines. Macmillan Co., 1949 (cit. on p. 34).

[214] Charles Fayette Taylor. The Internal-combustion Engine in Theory and Practice: Combustion, fuels, materials, design. Vol. 2. MIT press, 1985 (cit. on p. 34).

[215] G. Ferrari and S.E. Esculapio. Internal Combustion Engines. Società Editrice Esculapio, 2014. ISBN: 9788874888054 (cit. on p. 34).

[216] H.N. Gupta. Fundamentals of internal combustion engines. PHI Learning, 2012. ISBN: 9788120346802 (cit. on p. 34).

[217] Daniel B Olsen. "Experimental and theoretical development of a tracer gas method for measuring trapping efficiency in internal combustion engines". PhD thesis. Colorado State University, 1999 (cit. on p. 34).

[218] Daniel B Olsen et al. "Development of the tracer gas method for large bore natural gas engines. Part I: Method validation". In: Journal of engineering for gas turbines and power 124.3 (2002), pp. 678-685 (cit. on p. 34).

[219] Matthew G McGough and E Robert Fanick. Experimental investigation of the scavenging performance of a two-stroke opposed-piston diesel tank engine. Tech. rep. No. 2004-01-1591. SAE Technical Paper, 2004 (cit. on p. 36).

[220] Lino Guzzella and Christopher Onder. Introduction to modeling and control of internal combustion engine systems. Springer Science \& Business Media, 2009 (cit. on pp. 42, 43). 
[221] Karthik Ramanathan and Chander Shekhar Sharma. "Kinetic parameters estimation for three way catalyst modeling". In: Industrial E3 Engineering Chemistry Research 50.17 (2011), pp. 9960-9979 (cit. on pp. 48, $67)$.

[222] Hansjoerg Germann, Sergio Taglaiferri, and Hans P Geering. Differences in pre-and post-converter lambda sensor characteristics. Tech. rep. (No. 960335). SAE Technical Paper, 1996 (cit. on pp. 49, 106, 109, 170).

[223] Theophil S Auckenthaler, Christopher H Onder, and Hans P Geering. "Control-oriented investigation of switch-type air/fuel ratio sensors". In: IFAC Proceedings Volumes 35.1 (2002), pp. 331-336 (cit. on p. 49).

[224] Theophil S Auckenthaler, Christopher H Onder, and Hans P Geering. Modelling of a solid-electrolyte oxygen sensor. Tech. rep. (No. 2002-011293). SAE Technical Paper, 2002 (cit. on pp. 49, 62, 106, 109).

[225] GC Koltsakis, PA Konstantinidis, and AM Stamatelos. "Development and application range of mathematical models for 3-way catalytic converters". In: Applied Catalysis B: Environmental 12.2-3 (1997), pp. 161191 (cit. on p. 62).

[226] AJL Nievergeld et al. "Simulation of a catalytic converter of automotive exhaust gas under dynamic conditions". In: Studies in surface science and catalysis 109 (1997), pp. 449-458 (cit. on p. 62).

[227] Louise Olsson and Bengt Andersson. "Kinetic modelling in automotive catalysis". In: Topics in catalysis 28.1-4 (2004), pp. 89-98 (cit. on p. 67).

[228] Roman Möller et al. "Is oxygen storage in three-way catalysts an equilibrium controlled process?" In: Applied Catalysis B: Environmental 91.1 (2009), pp. 30-38 (cit. on p. 70).

[229] S Pischinger. "Current and Future Challenges for Automotive Catalysis: Engine Technology Trends and Their Impact". In: Topics in Catalysis (2016), pp. 1-11 (cit. on p. 104). 
[230] Giovanni Fiengo, JA Cook, and JW Grizzle. "Experimental results on dual uego active catalyst control". In: First IFAC Symposium on Advances in Automotive Control, Salerno Italy. 2004 (cit. on p. 106).

[231] Ralf Moos. "Catalysts as sensors?A promising novel approach in automotive exhaust gas aftertreatment". In: Sensors 10.7 (2010), pp. 67736787 (cit. on p. 106).

[232] Sebastian Schödel et al. "SI-engine control with microwave-assisted direct observation of oxygen storage level in three-way catalysts". In: IEEE Transactions on Control Systems Technology 22.6 (2014), pp. 2346-2353 (cit. on p. 106).

[233] Francis Ménil et al. "Evidence of a correlation between the non-linearity of chemical sensors and the asymmetry of their response and recovery curves". In: Sensors and Actuators B: Chemical 106.1 (2005), pp. 407423 (cit. on p. 109).

[234] Jörg Frauhammer et al. "Solving moving boundary problems with an adaptive moving grid method: Rotary heat exchangers with condensation and evaporation". In: Chemical engineering science 53.19 (1998), pp. 3393-3411 (cit. on p. 124).

[235] SJ Cornelius, N Collings, and K Glover. "The role of oxygen storage in NO conversion in automotive catalysts". In: Topics in Catalysis 16.1-4 (2001), pp. 57-62 (cit. on p. 142).

[236] Hideaki Muraki, Hirofumi Shinjoh, and Yoshiyasu Fujitani. "Reduction of nitric oxide by carbon monoxide over alumina-supported palladium catalyst". In: Industrial $\&$ engineering chemistry product research and development 25.3 (1986), pp. 419-424 (cit. on pp. 147, 148).

[237] Hideaki Muraki and Yoshiyasu Fujitani. "Nitric oxide reduction by carbon monoxide over noble-metal catalysts under cycled feedstreams". In: Industrial 83 engineering chemistry product research and development 25.3 (1986), pp. 414-419 (cit. on p. 148).

[238] Kathleen C Taylor and Robert M Sinkevitch. "Behavior of automobile exhaust catalysts with cycled feedstreams". In: Industrial \&5 Engineering 
Chemistry Product Research and Development 22.1 (1983), pp. 45-51 (cit. on p. 150).

[239] John T Betts. Practical methods for optimal control and estimation using nonlinear programming. Vol. 19. Siam, 2010 (cit. on p. 162).

[240] Pierre Leduc et al. "Downsizing of gasoline engine: an efficient way to reduce $\mathrm{CO}_{2}$ emissions". In: Oil $\mathscr{G}$ gas science and technology 58.1 (2003), pp. 115-127 (cit. on p. 169).

[241] TS Auckenthaler. "Modelling and Control of Three-way Catalytic Converters". PhD thesis. Swiss Federal Institute of Technology Zurich, Switzerland, 2005 (cit. on p. 169).

[242] Hideki Takubo, Takahiro Umeno, and Hideki Goto. New Lambda-Lambda Air-Fuel Ratio Feedback Control. Tech. rep. No. 2007-01-1340. SAE Technical Paper, 2007 (cit. on p. 169).

[243] Raymond C Turin and Hans P Geering. Model-Based Adaptive Fuel Control in an SI Engine. Tech. rep. No. 940374. SAE Technical Paper, 1994 (cit. on p. 169).

[244] J David Powell, NP Fekete, and Chen-Fang Chang. "Observer-based air fuel ratio control". In: IEEE Control Systems 18.5 (1998), pp. 72-83 (cit. on p. 169).

[245] Lino Guzzella. "Models and modelbased control of IC-engines-a nonlinear approach". In: SAE transactions (1995), pp. 1439-1447 (cit. on p. 169).

[246] Vicente Macian et al. "DFT-based controller for fuel injection unevenness correction in turbocharged diesel engines". In: IEEE transactions on control systems technology 14.5 (2006), pp. 819-827 (cit. on p. 174).

[247] V Macian et al. "Detection and correction of injection failures in diesel engines on the basis of turbocharger instantaneous speed frequency analysis". In: Proceedings of the Institution of Mechanical Engineers, Part D: Journal of Automobile Engineering 219.5 (2005), pp. 691-701 (cit. on p. 174). 
[248] Carlos Guardiola García. Detección y compensación de irregularidades de inyección a través de la medida del régimen instantáneo del turbogrupo. Reverté, 2005 (cit. on p. 174). 
